


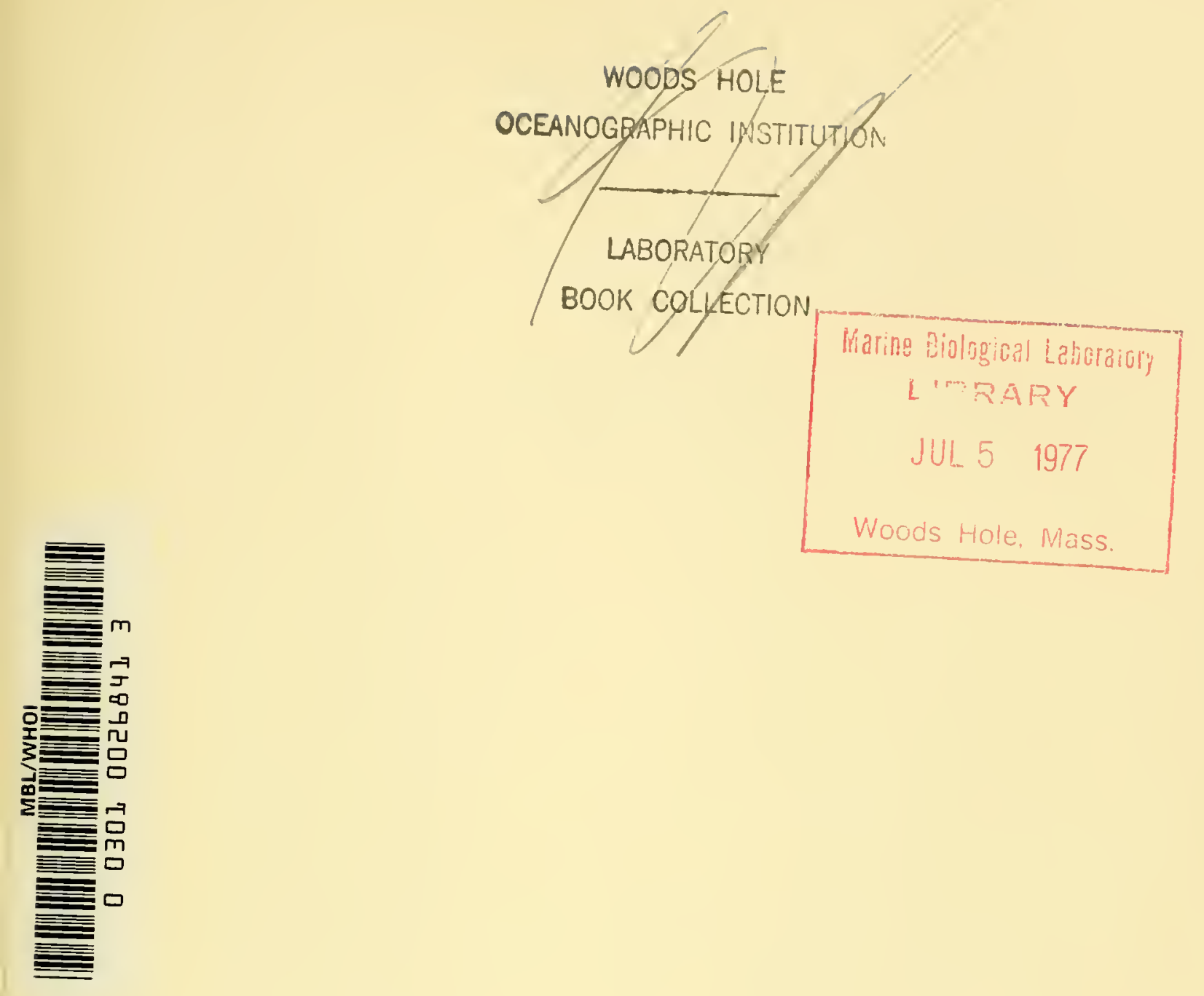

PUSEIASE ORDER NO. 15299

EOR B.H KETCHUM 1/3/6r 



\section{Biology Code of the}

CHEMICAL-BIOLOGICAL COORDINATION CENTER 



\section{Biology Code}

of the

\section{CHEMICAL-BIOLOGICAL COORDINATION CENTER}

A system for coding results, pro-

cedures, and conditions of tests for

biological responses to chemicals

Edited by

Philip G. Seitner

in cooperation with

George A. Livingston and Ann S. Williams

Publication 790

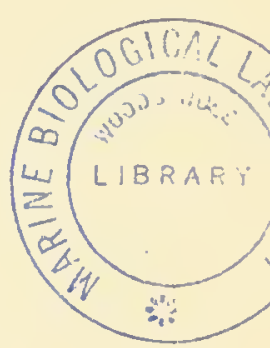

NATIONAL ACADEMY OF SCIENCES-NATIONAL RESEARCH COUNCIL

Washinglon 25, D. C. 
Library of Congress

Catalog Number 60-60056 
This book describes a system for coding biological responses to chemicals. It is published in two volumes, a Biology Code and its attendant Key. Both were developed by the Chemical-Biological Coordination Center of the National Academy of Sciences--National Research Council in the course of its work of organizing a large mass of chemical-biological data as described hereafter in the Introduction to the Code.

Established in 1946, the Chemical-Biological Coordination Center set out to develop methods for coding information on chemical structures and biological responses. Its ultimate aim was to provide both a repository for such information and means for machine searching of the stored data. Its founders were emboldened by the expectation that if information of this kind could be coded on a large scale, machine methods would provide an important research tool for discovering and exploring correlations between chemical structure and biological activity.

The concept of the Center had its roots in a widely felt need for ways to deal effectively with the growing mass of chemical-biological data, both published and unpublished.

Pertinent experience had been gained during World War II by the testing program of the Insect Control Committee of the Office of Scientific Research and Development. The late Dr. Milton C. Winternitz, in particular, recognized the potential of that program and its possible extension with machine aids to the general field of chemical-biological relationships. With his characteristic dynamic enthusiasm he developed the idea of the Center and guided its establishment as a broad experimental undertaking in the service of science.

The first essential step was the design of coding systems, one for chemical structures and one for biological responses. Newly developed accounting machines were available, and it was decided that punched card, machine sorting techniques should be used.

To devise a coding system for chemical structures was the easier of the two tasks. C. Chester Stock directed the development of the Chemical Code, which was based on an existing scheme, the Frear chemical coding system, selected as a pattern because it was designed for punched cards and was therefore adaptable to machine sorting. As developed by the Center the chemical code was ultimately used to record the structures of approximately 63,000 compounds. It was published by the Academy-Research Council in 1950 under the title, "A Method of Coding Chemicals for Correlation and Classification." Except for a few extensions it was not subsequently modified.

Construction of a coding system for biological responses proved to be more difficult. In $19+6$ the Center took over, as its Biological Codification Panel, the Biological Codification Committee which had been established under the chairmanship of McKeen Cattell by the OSRD Insect Control Committee. Given the task of devising a satisfactory biological coding system, this Panel carefully reviewed the suggestions of various CBCC subcommittees and in 1950, through the devoted efforts of Raimon Beard, who agreed to assume the immediate direction of the undertaking, a functioning code was established.

Comprehensive studies showed that workable coding procedures had been evolved, and the program of storing chemical and biological data went ahead. The Center collected and coded published data from the periodical literature and unpublished data from screening programs of various agencies, including those participating in the Center's own screening program. A total of some 220,000 punched cards were eventually put into the Center's files, each representing one "unit of information", that is, one blological response to one chemical. These cards were coded from more than 75,000 "code sheets", each containing data from one source of information on the biological responses of one chemical.

Those who used the Biology Code soon realized that the complexities of coding biological responses were such that an explanatory guide would be necessary if the coding and interpretation were to be uniform enough to insure efficient retrieval. Thus the Key to the Biology Code was progressively developed as coding experience grew. Also, the Code itself went through a number of revisions as corrections, additions, deletions, and annotations accumulated steadily.

Despite the loyalty to the Center of agencies inside and outside the Federal Government, which provided financial support through its formative stages and the beginnings of larger-scale operations, funds could not be found to permit its growth to proportions that were considered necessary for its effectiveness, and the Center was regretfully terminated by the Academy-Research Council in 1957. 
Many scientists contributed to this experiment in scientific documentation and correlation research. To all of them the gratitude of the Academy-Research Council is due. Chemists and biologists were widely consulted in the establishment of criteria for the coding systems; the names of these individuals are listed in the present book, together with the names of committee and staff members who took part. Also, besides the few to whom reference by name has already been made, special mention should be made of the devoted services to the Center of Walter R. Kirner, its first Director (19461952), Karl F. Heumann, its second Director (1952-1956), and George A. Livingston, who was Acting Director during the final year (1956-1957).

After the Center was closed, George A. Livingston, Philip G. Seitner, and Ann S. Williams, all of whom had served in its staff, undertook to prepare the Biology Code and Key for publication. They critically reviewed the accumulated additions, corrections, and suggestions in the files and reconsidered comprehensively the entire biological coding system. To Dr. Seitner fell the task of preparing drafts of the several parts of the Code and Key for the many conferences among the three editors, and of putting the manuscript in its final form.

For their ready acceptance and faithful performance of an exacting assignment, the National Academy of Sciences--National Research Council here records its appreciation to Dr. Livingston, Dr. Seitner, and Mrs. Williams. They have preserved a vital portion of the experience of the Center and have insured that it will be available to scientists and documentalists who can benefit by it.

S. D. CORNELL Executive Officer National Academy of Sciences-National Research Council 


\section{INTRODUCTION}

The Chemical-Biological Coordination Center.............................

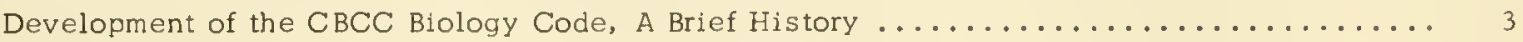

Mechanical Equipment Used by the CBCC for Information Handling ................ . . 4

The Biology Code

General Character ..............................................

Fields of the Code Considered as Independent Codes and Indexes .............. 6

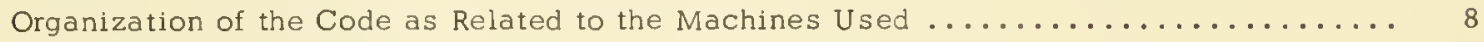

Detailed Nature of the Code; Its Limitations and Aspirations ...................

The Key: the Manual to the Use of the Biology Code

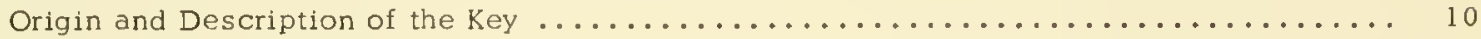

Complexity of the Key and the Complexity of Coding .....................

Considerations in Publishing the Details of the Biology Code and Key...............11

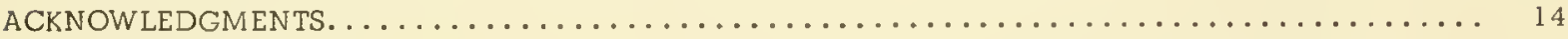

CBCC Committee Members ......................................

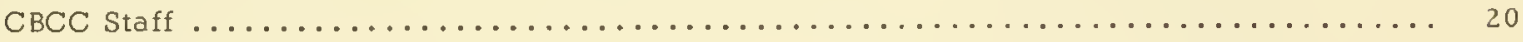

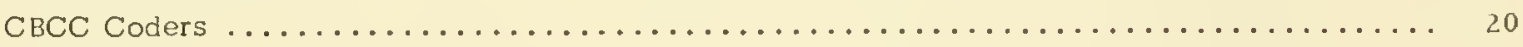

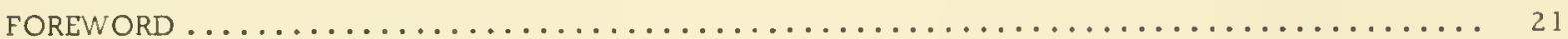

\section{FIELDS OF THE BIOLOGY CODE}

Field A: Physical State of the Test Compound; Dispersion or Nondispersion of the Test Compound; Indication that Information on Correlation of Chemical Structure and Biological Response Occurs in the Information Source

Field B: Conditioning Agent; Miscellaneous Information about the Test Compound Administration; Indication that in the Data Source there is Information on the Effect of $\mathrm{pH}$

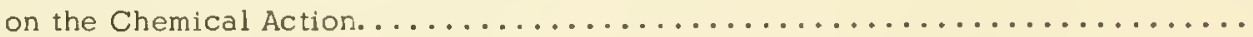

Field $\mathrm{C}$ : Solvent or Vehicle for the Test Compound ............................

Field D: Secondary Compound.................................. 
Field E: Organism or Pathological Condition Treated; Introduction. . . . . . . . . . . . 26

Taxonomy Code (Test Organism)......................... 27

Tumor Code

List of Tumors and Tumor Types with Code Symbols Assigned .......... 68

Special List of Symbols for Anatomical Structures, to be used

only for Construction of Symbols for Tumors ................... 78

Pathology Code

Representative List of Pathologies with Code Symbols Assignei ...........

Causes of Disease; Disease Etiology Code Symbols, to be used for Construction of Symbols for Non-infectious Pathologies............

Field F: Sex and Stage of Development of the Test Organism; Miscellaneous

Information Concerning Tumors $\ldots \ldots \ldots \ldots \ldots \ldots \ldots \ldots \ldots \ldots \ldots \ldots \ldots \ldots$

Fields G-1 and G-2: Pretreatment or Experimental State of the Test Organism

or of the Organ, Tissue, or Cell of the Test Organism..........

Fields $\mathrm{H}-1$ and H-2: Gross Anatomy; Primary Anatomical and Secondary

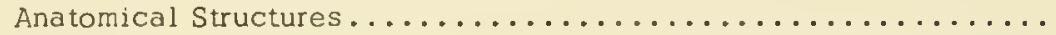

Field I: Tissues, Cells, and Fluids.............................

Field J: Host Organism; Test Environment.......................... 114

Field K: Sex and Stage of Development of the Host Organism .................

Field L: Pretreatment or Experimental State of the Host Organism or of the Organ, Tissue, or Cell (of the Host Organism) which is

the Site of the Parasite, Non-infectious Pathology, or Tumor ............ 124

Field M: Concentration of the Test Compound when Applied .................. 128

Field N: Quantity of the Test Compound Applied ..............................

Field O: Dosage Frequency; Sequence of Administration of the

Secondary Compound and the Test Compound..................... 132

Field P: Duration of Treatment; Time between Administration of

the Test Compound and a Secondary Compound..................... 133

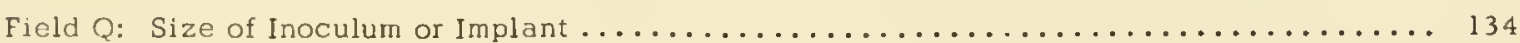

Field R: Time of Treatment Relative to Inoculation, Tumor Implantation,

Sensitization, or Incitation of Non-infectious Pathology .............. 135

Field S: Route and Manner of Administration of the Inoculum or Implant

(Field S-1), of the Secondary Compound (Field S-2), and of

the Test Compound (Field $S-3) \ldots \ldots \ldots \ldots \ldots \ldots \ldots$

Field T-1: Action of the Test Compound on the Biological State,

Quality, or Process Coded in Field T-2 ....................

Field T-2: Biological State, Quality, or Process Acted on or

Produced by the Test Compound or Secondary Compound .............. 144

Enzyme Code ..................................... 
Field T-3: Category of the Test Compound's Effect, Representing

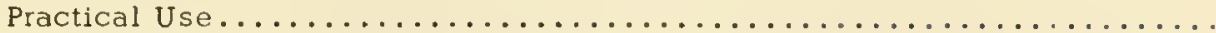

Field U: Miscellaneous Time Values: Duration of Response to the Test Compound; Alteration of the Survival Time by the Test Compound; Time to Any Response to the Test Compound other than Death; Killing Time of the Test Compound; and Persistence of Activity of a Residue of the Test Compound

Field V: Time to Evaluation of the Response to the Test Compound

Field W: Qualification of the Negative and Positive Character of Test Results; Information about Slope of the Dosage

Response Curve Present in the Data Source: Introduction ................

Qualification of a Negative Evaluation in Field $Y \ldots \ldots \ldots \ldots \ldots \ldots \ldots \ldots \ldots$

Qualification of a Positive Evaluation in Field $Y \ldots \ldots \ldots \ldots \ldots \ldots \ldots \ldots \ldots \ldots$

Fields $X$ and $Y$ : Criteria for Evaluation of Effectiveness (Field X) and Evaluation of Effectiveness (Field Y) of the Biological Response ............................ 18

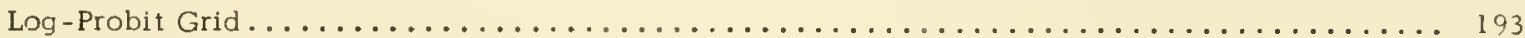

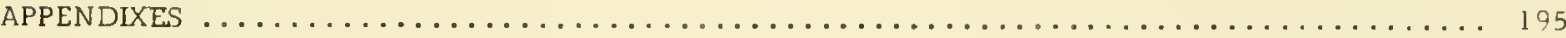

Appendix A

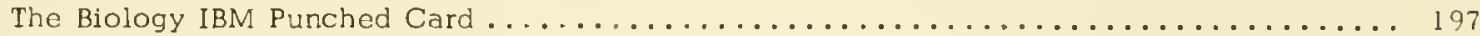

The Biology Code Sheet ..................................... 199

Coding of Chemical Structures; the CBCC Chemistry Code, the Chemistry

IBM Punched Card; the Chemistry Code Sheet; the Chemistry Index Card . . . . . . . . 200

CBCC Files

Code Sheet Files ....................................... 207

IBM Punched Card Files

Biology Punched Card Files .............................. 208

Chemistry Punched Card Files.............................. 210

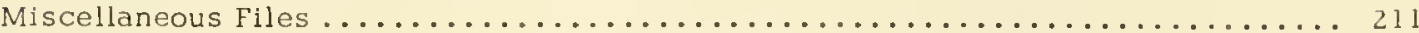

Procedures of the $\mathrm{CBCC}$ in Collecting and Organizing Information

Selection of Chemical-Biological Information....................... 21

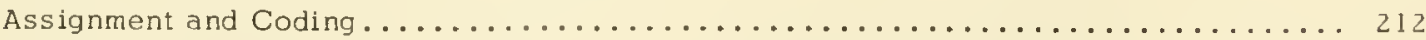

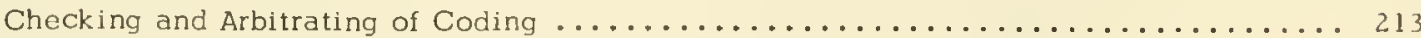

Processing of Biology Code Sheets by Chemists ................... 213

Transfer of Coded Information to IBM Punched Cards ................... 214

Filing of Biology Code Sheets ................................

Correction of the Files ......................................... 
Advantages of the CBCC System of Coding and Machine

Handling of Chemical-Biological Information ........................

Appendix B

Specificity and Adaptability of the Biology Code...................... 217

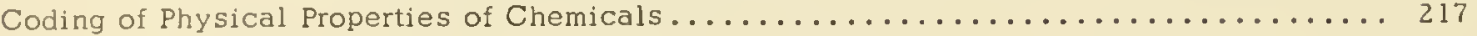

CBCC Experience in Correlation of Chemical Structures

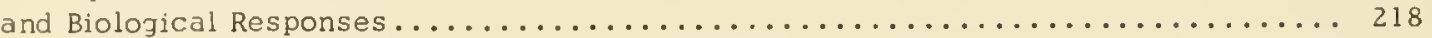

Qualifications of Coders; Residence vs. Non-residence of Coders .............. 218

Checking of Abstracting and Coding ...............................

Speed of Processing Information into the CBCC Files; Currency

and Content of the Files.................................. 220

Use of the Center's Coded Chemical-Biological Information................. 221

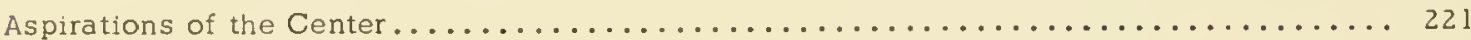




\section{INTRODUCTION}

The following descriptions of the Chemical-Biological Coordination Center, its mechanical equipment, and the Biology Code will introduce the reader to the objectives of the Center and the Code. However, reference should also be made to the Appendix. The sections of this Introduction and the Appendix form a unit which explains how the Center attempted to meet its objectives, some of the inherent problems, and its accomplishments.

\section{The Chemical-Biological Coordination Center}

The Chemical-Biological Coordination Center ( $C B C C$ ) was established on the premise that correlations exist between molecular structures of chemicals and biological responses to those chemicals and that studies of structures of chemicals causing known biological responses and of responses caused by chemicals of known structure could be of increasing orientative significance in research. Such studies should be a guide in (1) selection, synthesis, or search for chemicals to be tested for a given biological response and in (2) selecting appropriate responses for which a given chemical should be tested. The basis for such studies was conceived as a collection of data demonstrating the known biological actions of chemicals whose structures are known. The CBCC strived especially to collect the diverse but often meager existing information about biological responses to thousands of tested compounds, rather than to attempt an analysis of the detailed data on the biological responses to only the more well-known and exhaustively tested compounds. The latter information is normally available from monographs, reviews, and textbooks, while the former is frequently difficult to find in the literature or is unpublished. To make practical the study of such a large collection of data, mechanical means must be used for sorting and arranging the information, procedures which involve enormous and impractical expenditures of time when done manually. Thus, the CBCC required a means of converting chemical and biological information to a language of symbols which could be inscribed on a mechanical system. At the time the CBCC was established, no scheme was known to exist which could satisfy the specific and broad needs of the CBCC, either for chemical structures or for blological information.

It is not the purpose here to present a detailed history of the CBCC and describe all its activities; it is hoped that this may eventually be possible. However, certain observations on its evolution and activities which bear particularly on the Biology Code and the CBCC collection of biological data are appropriate. (The sponsors of the Center and the names of committee members and staff members are listed following this Introduction.)

Although the $\mathrm{CBCC}$ had collected and organized considerable information from chemical-biological tests prior to the adoption of the present Biology Code, the collecting during that earlier period had to play a subordinate and supportive role to the major objective of developing methods for coding and handling the information. That picture was altered with the adoption of the Code in essentially the form presented here. In 1951, having developed the methods to do so, the Center decided to concentrate on assembling information from every available source to create a file of data of the broadest nature which would permit any conceivable correlation in all fields of biology and with all types of chemicals. This decision was made only by resolving to abandon sponsorship of symposia and preparation of reviews, several of which had been organized prior to 1951; with the funds avallable, 1 t was not possible to meet both objectives adequately. It seemed reasonable that the path for the Center should be in original directions, not in sponsoring symposia and reviews which, for the immediate future, might be accomplished by other agencies.

Thus, the CBCC organized during 1951 procedures for collecting information and coding it by the previously developed coding scheme. This involved finding coding personnel with adequate blological training, designing a means of training personnel for coding, and establishing a pattern for handling the selection of data to be coded, assigning it to appropriate coders, checking the coding, recording, filing, and IBM punching. A description of each of these procedures is included in the Appendix.

It should again be emphasized that the Center's activities from 1951 were concentrated on building its collection of information and improving its coding (indexing) of the information. Therefore, the evaluation of the Center should be in terms of the contemporary needs for a collection of such special information and for effective methods of handling and indexing it. Correlative studies of structures 
of chemicals and biological responses to those chemicals, which has been described as an initial inspiration for this collection, might have been a valuable result of the collection, but the Center was by no means committed to limiting its objectives to complex or theoretical correlative studies.

To a degree, the collection has represented a source of information unavailable anywhere else, partly because some of its sources are not conveniently available to other agencies. This has been a natural result of the CBCC's deliberate efforts to search for more obscure sources of data from chemicalbiolcgical tests and the inclusion of test results from the CBCC's own unique and extensive Screening Program. (The Screening Program has been described in the general booklet describing the CBCC, the last edition of which was prepared in 1954.) For this reason, and because the information has been indexed in ways exceeding any other existing index of the information, the CBCC files are regarded as a valuable reference source of information. As the Center's collection became more widely known, the number of information requests coming to the Center increased; most of these requested that the Center report whatever information its files might have on a subject for which the requester gave specifications. The requests were seldom for the Center's performing actual correlation studies, partly because it has been generally understood that such interpretive projects by the Center were impossible in view of the limitation of the Center's staff size and time and partly because generally the actual correlation can only be accomplished, to the ultimate satisfaction of the requester, by the requester himself. The Center has always had the attitude, however, that the files could be made available, by special request, to any visitor for any broad project of data correlation; none of the information included in the file bears a security classification and no material has been included which is restricted for proprietary reasons.

Thus, the Center should be regarded as having been in its first years a source of both information and reference to information, supplementary to all other sources. That this has been appreciated is attested to by the use made of the $\widetilde{C B C C}$ files by an impressive number of agencies and individuals. The Center has rightly been regarded, also, as pioneering in the general field of documentation of scientific information, in developing its program for converting chemical and biological data to a form that can be handled practically by mechanical equipment. The CBCC was consulted frequently for advice for establishing other specialized programs of a similar nature and the Chemistry and Biology Codes have been studied and adapted for a number of such programs. Although it has not been possible to conduct broad correlative studies as originally intended (described in the first paragraph as a primary objective), leading to publications and chemical or biological research based on such studies, the Center's files have the important potential of correlative studies. Finally, by a program of collecting chemicals to be distributed to selected testing programs screening chemicals for specific effects, the CBCC Screening Program provided a service to this particular field of research that is probably unique and unprecedented. It made possible the testing of chemicals in many ways for which the agencies isolating or synthesizing the chemicals had no equivalent facilities, provided a rich source of chemicals for testing programs whose sources of untested chemicals were limited, and engendered thereby much information on chemicals' capacities for affecting biological systems, which is made available in the CBCC files and by the CBCC bi-monthly publication, Summary Tables of Biological Tests sponsored by the Chemical-Biological Coordination Center. A summation of the Center's aspirations related to coding of chemical-biological information will be found at the close of the final Appendix.

The announcement of the CBCC's termination was made in December 1956. Therefore, essentially all activities for collection of information and coding into the CBCC files stopped as of that date. Although the files at the date of this publication have not been discarded, they are not generally available in that no staff exists to retrieve information from them. The Screening Program was likewlse discontinued. Only one vestige of the CBCC remains active, though it is no longer identified with the Center. This is a specialized project which began as a CBCC responsibility, the Cardiovascular Literature Project of the National Research Council, sponsored by the National Heart Institute, National Institutes of Health. This, however, is not a program for extensive coding and indexing cardlovascular data by $\mathrm{CBCC}$ methods nor can it entertain requests for information about references to the literature except through sponsoring agencies. Its objective is to build and publish a comprehensive index to the literature on cardiovascular responses to chemicals, cross-indexed by author, title, and subject, to the extent possible as a publication. The original intent was for the $\mathrm{CBCC}$ to incorporate into its coded files all the cardiovascular information, as the project collected it.

The final gesture in closing the Center is this publication of the Biology Code and Key and a description of the Center's procedures for coding information from tests for biological responses to chemicals. While it is possible that no center will ever again be established with precisely the objectives of the CBCC nor would the new staff of such a center be inclined to find entirely suitable the present CBCC Biology Code and procedures for coding, the complete record of the CBCC experience in collecting 
and coding this particular information must be a useful guide. Further, individual sections of the Biology Code can be used for coding information other than that from chemical-biological tests; the details would require being reduced or expanded, according to the special needs of the project, but they are presented here as a basis for a beginning.

\section{A Brief History of the Development of the Biology Code}

While the Biology Code and coding procedures must be considered to be the products of the Center's early experiments in coding, much important assistance came initially from the several subcommittees whose members were appointed by the Chairman of the National Research Council to serve in an advisory capacity to the Center. The members and chairmen of these committees are listed in another place. One of these committees in particular, the Biological Codification Panel, the Chairman of which was Dr. Mckeen Cattell (later, Dr. Raimon L. Beard), guided the first experimental coding efforts.

A detalled comparative review of the coding schemes tried prior to 1951 can not be made here. It is hoped that this can be recorded eventually in a history of the CBCC. However, the following paragraphs record an outline of the events and preliminary codes leading to the present.

In 1949, a code was organized whose symbols were designed for use in recording biological information on IBM punched cards, subsequent to recording the Information in code written on "work sheets". This code was entitled the General Biological Code of the Biological Codification Panel, Chemical-Biological Coordination Center. As its name suggests, the items of the code represented generalizations of information from chemical-biological tests; the items of the present Code's Field T-3 illustrate the character of the items of the earlier General Biological Code. A few examples here will assist in understanding this quality of generality: "Information is available relative to viruses"; "The test compound is a plant growth stimulant"; "The test compound affects the blood and circulation"; "The test compound is an insecticide"; "The test compound is a carcinoclastic agent".

The total General Biological Code consisted of approximately 225 of these items, each of which had a different code symbol. With that Code, a single IBM punched card was used for each chemical for which the $\mathrm{CBCC}$ had chemical-biological information; on the card, Columns 1 through 54 were designated to be used for information about the chemical, leaving only 22 columns for punching symbols for biological information. (A description of the general IBM punched card will be found in the Appendix.) The symbols for the items of the Code each consisted of three numerical units; the first two indicated a specific IBM punched card column and the third indicated the specific code item. Thus, by using the three IBM zone punches, each column afforded space for 12 code symbols and, in the 22 columns, a total of 264 symbols were avallable for 264 code items of such general nature as illustrated above. On this single IBM card, all information collected about the given compound's biological effects was punched; in other words, if any additional biological information were obtained, the card was retrieved from the file and the additional information punched on it, rather than placing each piece of information on a separate IBM punched card.

This General Biological Code represented the product of the meetings of the Biological Codification Panel from early 1946 to the end of 1948. That Code was used for approximately a year, resulting in a large file of work sheets. It became apparent, however, from the experimental use of the flles built on the Code, that the pattern was inadequate and it was recommended, therefore, that a complete revision be made of the pattern.

The original procedure described above, which used only a single IBM card for each chemical, with the card containing all biological information collected relating to the chemical, was very quickly altered because of difficulties encountered in information retrieval. A new system was established whereby a separate IBM card was punched for each piece of biological information (each card having the information about the chemical used punched in Columns 1 through 54). The CBCC refers to these two systems, historically, as its "single card system" and "multiple card system". In using a separate card for each piece of biological information, it meant that on each card only one symbol would be punched for biological information in the entire 22 IBM punched card columns.

The next development was the preparation of a special experimental code resembling more the detailed character of the present Code. This intermediate code was designed specifically for 
information from insecticide tests and included features of the General Blological Code as well as symbols for details of insecticide tests, utilizing the entire space allotted to biology information on the IBM punched card (Columns 55 through 76). At this point, it was resolved to test the three systems, the single card system, the multiple card system, and the code designed especially for entomological data which was a modification of the multiple card system. This test was accomplished by coding the same data by all three systems and attempting retrieval of information from each of the three sets of IBM punched cards. The results of this test led to the decision that the CBCC Biology Code should be a detailed code using multiple cards and that the coding of biological details should be expanded.

Consequently, in the spring of 1950, Dr. Beard visited the CBCC for two weeks at the invitation of the National Research Council and, with the cooperation of the 1950 staff members, guided the revision to provide the coding detail needed. Most of the present coding "fields" were established and, within each field, lists of items were compiled to which code symbols were assigned. A further modification was the separation of the specific information about the test compound and the information about the biological test onto separate IBM punched cards so that the card on which was punched the biological information had only a serial number reference to the chemical used, the information about the chemical being on a special IBM punched card filed separately by that reference number. Thus, many more columns were made available for punching biological information on the special biology card. This code revision was duplicated and distributed internally as the second edition of the CBCC Biology Code.

The Biology Code underwent two revisions within the same year and the fifth edition appeared in 1951. The revisions consisted mostly of changing the sequence of the coding fields as they appeared on the IBM card, adding new fields and new items in each field. It was during 1951 that the intricate procedure was established for the actual selection, coding, punching on IBM cards, and filing of chemical-biological information.

By the end of 1951, a number of coders had been trained and information was being processed into the files. It had become apparent by 1952, from the innumerable problems encountered by the coders, that the Code itself, merely as a list of items and their symbols, was insufficient and that a manual for the use of the symbols under specific situations was essential.

Early in 1952, the Code was revised again and, accompanying this revision, a manual for $i$ ts use was prepared. The Code was distributed as the sixth edition and the manual, entitled The Key to the Detalled Biology Code, was distributed shortly thereafter. The same edition of the Code was used until the Center was closed in 1957, though a new edition of the Key was issued in 1953. During the years following 1952, a number of supplements to both the Code and Key were prepared notifying coders of changes and additions and by 1957 a revision was actually long overdue.

\section{Mechanical Equipment Used by the CBCC}

Before describing and commenting on the Code itself, it 1 s necessary to explain briefly the equipment used for handling the coded information, since only by understanding this background wlll the design of the Code be appreciated. It is suggested also that the reader refer to the section of the Appendix describing the special procedures used by the CBCC, including description of the special IBM punched cards, the Code Sheets, and the Center's files.

In recent years, research and development of machines for storage and retrieval of information has progressed at a remarkable rate. However, it can safely be sald that development of new equipment and methods for greater speed and capacity does not necessarily mean total obsolescence for earlier equipment of lower capacity, since documentation programs differ widely in thelr needs.

In the case of the $\mathrm{CBCC}$, it was long recognized that the mechanical equipment at its disposal was inadequate for its purposes. It must be pointed out, however, that when the Center's program began, the equipment its information collection eventually demanded did not exist and commissioning the speclal design and construction of equipment was beyond the Center's resources.

Nevertheless, whlle the equipment used bears no speclal design, it does represent an electronic mechanization for handling information which is far superior in speed to any comparable manual method. The CBCC Biology Code and coding methods have been patterned for this mechanized handling, but they are by no means dependent on the machines used and the coding done by use of the Code could be placed 
on other types of storage equipment. These observations are made to avoid any possible impression that the Blology Code is designed only for the equipment hereafter described. On the other hand, 1 t should be made clear that this equipment is not being descrlbed as obsolete nor is it being necessarily described as inadequate for use with the Biology Code, except under the situation of storing and handling an enormous quantity of data such as that of the CBCC.

Although the scope of the Center's information collection surpasses the capacity of the equipment it used, the fact that its early development has been with this equipment must be considered as a distinct advantage. It means that the procedures developed and described here are applicable to standard business machines which are widely available. It is therefore reasonable to suggest that the special designs for Code Sheets, IBM punched cards for biology coding, and the organization of the Code can be adopted directly for coding projects of more limited scope for which the machines will be fully adequate.

The electronic machines used for handling the information consisted of standard International Business Machine equipment, including IBM punches, sorters, an interpreter, a reproducing punch, and a collator. Detailed descriptions of these machines and their uses are readily available elsewhere.

Sorting has two general applications. The first and more obvious is that of arranging a file of punched cards in a given sequence (for example, in ascending Chemical Serial Number order). The second is in selecting (searching for) a card with a given symbol, or a group of cards related by having a given symbol in common, from a stack of cards or a file that is not in any order or not in such an order that would allow a rapid hand selection of the desired cards to be made. Both IBM sorters, Types 075 and 082, were available for the Center's use.

Collation refers essentially to a process of merging or matching two sets of cards, but the IBM collator is used to perform additional functions; the most important uses to the Center were: (1) checking the filing sequence in files; (2) merging two or more separate groups of cards into one combined file; (3) selection of some desired combination of information on certain cards without disturbing the original order of the remaining card file; and (4) matching two or more groups of cards for coincidence of a given characteristic. The matching operation is probably the most useful in answering questions. An answer that would justify the use of the collator in matching would be composed of at least two "components", ordinarily a chemical component vs. one or more biological components. Each of these may be selected by hand from one of the files and the matching operation then determines which of the cards, having the essential biology information punched on them, match the cards having the essential chemical punching. The matching occurs through any identical punching of the Chemical Serial Numbers between chemistry cards and biology cards.

Automatic reproduction of all or any part of the card may be accomplished on the reproducing punch. This permits establishing at will new or speclallzed files from exlsting cards. The same machine was used by the CBCC for the purpose of checking accuracy of punching as follows. The process of punching the information on either biology cards or chemistry cards was performed in duplicate. In other words, the card for the test organism file and the card for the biology serial file were each punched independently by different operators using the same coded information source. The two cards then were matched by the reproducer for identity and accuracy of punching; if a discrepancy between the supposedly identically punched cards occurred, the machine stopped and pointed out the exact discrepancy.

The interpreter is designed to read the card perforations and print the code symbols they represent; it can not interpret the code symbols into the biological information they represent.

In addition, there is an electronic statistical machine (referred to as Type 101) which supplements the sorter. The latter is limited in function by being able to sort only in a single column of the punched card. For certain large tasks, the 101 is preferred because of its capacity to sort not only in a single column, but to sort selectively in many columns simultaneously.

The Biology Code

The General Character of the Blology Code:

While the observations of this division and the next may be regarded as obvious by those readers 
accustomed to thinking in terms of coding procedures, indexing, and mechanical storage of information, they are made because it is certain that they are not always immediately or clearly appreciated by new coders.

In gaining initial understanding of the Biology Code, it might be helpful to approach it, perhaps unconventionally, by regarding it as a specially devised language. Indeed, any language is a code for transmission of thought, words belng symbols used in an organized fashion. The Biology Code is composed of special symbols which provide at least three advantages, (1) condensation of ideas and ordinary words, (2) facility, resulting from condensation, to be handled by mechanical methods, and (3) a common. medium of expression in a multilingual sclentific society.

The first of these may be appreciated by having examined the IBM punched card (illustrated and described in the Appendix) and items of the Biology Code. Any word, such as "emulsion" (a physical state of the test compound, Fleld A of the Code) could be recorded literally by perforations of the IBM card, using eight IBM punched card columns for the elght letters of the word. The purpose of the Blology Code is to reduce this idea to occupy the least possible space and it does so by substituting one symbol (the number 5 in Column 9 on the IBM punched card) for the other symbol (i. e., for the word "emulsion"). Regardless of whether information is to be placed on punched cards or merely written, the brevlty represents an advantage in recording.

The abbreviation usually accomplished by devising code symbols, described above as the first of the advantages, provides mechanical advantage. Mechanical selection of a given word or idea is far more simple and rapid when only one mechanical motion or electric contact (or the minimum possible number of mechanical motions or electric contacts) needs to be made to accomplish the selection.

The third advantage presumes that the Biology Code and the manual for its use (1. e., the Key) can be translated into any contemporary language. The Blology Code symbols for the ideas conveyed remain the same and, to the extent that coding 1 tself 1 s successful In expressing information about a test, coded biological Information on IBM punched cards (or on any other medium, such as electronic tape) can be universally exchanged.

The Biology Code, then, is first a collection of terms and ideas which represent pieces of information that are typlcal of experimental application of chemicals to biological systems; these terms and ideas of the Code are expressed In a specially devised language of symbols, each of which is defined by its equivalent in the language by which tests are described. Therefore, the Biology Code might be regarded as a forelgn language dlctionary in which the words of one language are deflned in terms of words of the other.

The original list of terms and ideas ("items") of the Biology Code were those which were recommended by the blologlsts of the several $C B C C$ subcommittees and biologists of the CBCC staff to meet the objectives of the Center. Since the second edition (refer to the description of the historIcal development of the Code), many additional items have been added by the staff of the Center, to accommodate coding of all types of biological information.

The Code's organization into fields and the influence exerted by the particular mechanical equipment used on the number and character of the fields are discussed in the following paragraphs.

Fields of the Code Considered as Independent Codes and Indexes:

The information about chemical-biologlcal tests will be seen to lend itself to being organized into categories or types, such as the identity of the organdsm used, the anatomical part affected, the dosage used, etc.

As explained in the next paragraph, organization of the Code is such that each of these categories of information about chemical-biological tests is treated independently. By virtue of this, any symbol used for an item of one category can be used for another item in another category, just as, In any language, one word symbol may have dlfferent meanings according to how it is applied (e. g., "left", "traln", "press", "bream", "crab"). Symbol A, therefore, can be used as a symbol for one state of test compounds (adsorbed gas) and can be used also as a symbol for one phylum of test organisms (Chordata), as a symbol for an anatomical organ system (skin), etc., according to the position in which it is placed on the mechanical system.

To be able to treat these categories independently, it is necessary to establish each category's identity in the mechanlcal system used. Using standard business machines as its basic mechanlcal 
equipment, the CBCC has organized the columns of the IBM punched card into significant categories. (Refer to the lllustration of the IBM punched card in the Appendix.) Thus, to cite an example, of the total 80 IBM punched card columns available, the CBCC established that one column (Column 11 ) was to be reserved for only one category of Information, the solvent of the test compound. Since nothing else might be recorded at that position on the card, any symbol being punched in that column must refer to a solvent and can not represent a taxonomy phylum or organ system, nor have any other meaning.

Each of these categories is referred to as a coding "field", being restricted to a single designated ("fixed") area or field of the IBM punched card. Each field bears a strict definition of the category of information that can be coded in it. (In a few fields, the CBCC codes two categories of information when one or both categories has so few items that no coding interference occurs. Examples are Fields A, B, F, K, O, P, and W.) The division of the total Biology Code into fields is discussed in the following section. The alphabetical designations of the fields has no significance except as a convenient reference. These designations were made after the various categories had been arranged in what seemed a convenient sequence for reading the information. Whether the sequence seems equally convenient to everyone is perhaps no more important than whether the position of keys on a typewriter suits everyone's fancy; the significant fact is that they are fixed and the coder and interpreter soon learn their positions. Throughout the Code and Key, the fields are referred to by their alphabetical designations except when it has seemed clearer to refer to them by naming the information category.

It may be understood, then, that the total Biology Code is really a composite of many independent codes. Field A represents a code for physical states of chemicals, Field $\mathrm{H}$ is a code for gross anatomical structures, Field $\mathrm{T}-2$ is a code for biological states, qualities, or processes which can be caused or affected by chemicals, etc.

Many of these codes (i. e. , independent fields of the CBCC Blology Code) could be used independently and for purposes other than indexing chemical-biological test information. The Taxonomy Code (Field E) might be used for terms of a card index of organisms or information on organisms; the Tumor Code (also Field E), the code for organs (Field H), the code for tissues (Field I), etc., each might be used independently. On the other hand, certain of the Biology Code fields would be of dubious value extracted from the Code; for example, the code for the action of the test compound (Field T- 1 ) has little meaning except when used with an item of Field T-2 indicating the biological state, quality, or process acted on.

The purpose of the CBCC Biology Code (to refer to the several codes or "fields" collectively again) is not cryptogrammic, but documentary; its objective is the indexing of information from chemicalbiological tests, using the specially adapted language of symbols. Therefore, each of the coding fields should be regarded as an indexing criterion for storage of information ("documentation"). For example, all chemical-biological tests must involve a biological system, elther an organism or a tumor or pathology of an organism; by the use of symbols of Field E, all information recorded by the CBCC is indexed according to the organism, the tumor, or the pathology.

If all information related to a specifled organism were wanted and if the arrangement of the file had no relationship to organisms, the only means of sorting out the information desired without disrupting the established order of the file (arranged according to chemicals, e. g.) would be by examining each card for the organism name. To do this manually becomes impractical, if the file is of any size and if such a search is to be made repeatedly. Two alternatives exist, (i) duplicating the cards of the initial file and establishing a second file in which the cards are arranged according to a test organism classification or (2) marking the cards in the original file so that organisms'identities are "recognized" by a mechanical apparatus such as an IBM sorter. The second of these alternatives, made practical by speed of machines, is actually equivalent to the first alternative; in other words, both represent a file of information. indexed by organisms. An advantage of the latter is that the two Indexes ([1] the index according to which the cards are arranged in the file and [2] the organism index) are contained in a single set of cards, representing conservation of storage space. In addition, information might be wanted related to specified anatomical parts, biological responses, routes of administration, dose size, etc., as well as organism and chemical identities. In the case of each of these, the information could be efficiently sorted from the information collection only by a special file indexed by that criterion (anatomical part, biological response, etc.) and, as in the case of the organism index described above, each can be establlshed within a single file of cards by marking the anatomical part, the biological response, etc. on each card so that it can be recognized and sorted by a mechanical apparatus. 
Thus, the basic advantage offered by coding chemical-biological information and placing the coded Information on a medium that can recognize and sort the coded information mechanically, such as IBM punched cards or electronic tape or wire, is that many indexes can be composited in a single file, representing an economy of space in information storage. The Appendix will disclose that, in spite of using mechanical equipment and punching all information (i.e., all the indexing criteria) in a single file, the $\mathrm{CBCC}$ established several separate punched card files for separate indexes (test organism, host, anatomical part, etc.). While this might seem to contradict the claims just made for conservation of storage space and advantage of machines, it is actually only evidence of a complication arising from the size of the information collection and the limitation of machines used. The Appendix should be consulted for an explanation of this. Under the general section describing the CBCC files, see "Biology IBM Punched Card Files".

A number of the fields of the Code are not expected to be used frequently, if ever, as indexes for retrieval of coded information. Fields T-1, V, and R are fields (i. e., indexing criteria) which should probably be regarded as essentially useless as retrieval criteria (the action of the test compound [increasing, decreasing, initiating, antagondzing, etc.], the time to evaluation of the effect, and the time of treatment with the test compound relative to the time of inoculation, respectively). Fields A, B, C, F, G, K, L, O, P, Q, S, and U (refer to the Code for their descriptions) are of more probable use as indexes, yet are of minor importance compared to the remaining fields, in terms of frequency of use.

Since a number of the coding fields can be regarded as of little importance as general retrieval criteria, they must be considered from other standpoints. First, it should be pointed out that an index which may have a low incidence of use for general retrieval of information in the CBCC coded files may be of critical importance when studying and correlating a mass of chemical-biological information of a circumscribed nature, such as all anti-malarial chemotherapy tests, all rodent repellency tests, all tumor inhiblting tests, etc., since the ability for separation of information according to this detail might be expected to become more important as the study of information becomes more specialized. Secondly, an advantage may be assumed for having available from the mechanized file of information as many details of a test as possible, in a code language, making the coded information as selfsufficient as possible; this would be especially true in the case of a system by which it was not Intended that reference would be made to the original data or to a written abstract. The CBCC has regarded coding in the light of both of these aspects and while perhaps none of the coding fields should be considered to be totally valueless as an index, some of them may be regarded as having more significance as a means of expressing in code language all aspects of chemical-biological tests.

The Organization of the Biology Code as Related to the Machines Used for Handling Coded Information:

To return to the matter of determining the number of information categories (coding "fields") to be included in the $\mathrm{CBCC}$ Blology Code and the limits of each, it must be recognized that the CBCC was committed to using standard business machines. The limitations of this equipment, as well as the equipment's advantages, were impressed on the structure of the Biology Code. This can be said of every mechanical system and when coded chemical-biological information is placed on other media, such as electronic tape, the limitations and advantages of that system will likewise be impressed on the code used, influencing such decisions as that for the number of information categories.

After studying the IBM equipment and methods, the CBCC decided that the IBM punched card handling of masses of coded information concerning individual chemical-biological tests was practical only by restricting the information about any given test to a single IBM punched card. Having made this decision, coding of information about the test was limited to less than 80 IBM punched card columns. Eight columns are needed for the eight units of the CBCC Chemical Serial Number Identlfying the chemical used in the test; nine more columns are needed for the six units of the Code Sheet Number, the two units of the Code Line Number, and the single unit of the IBM Punched Card File Number. Thus, actually only 63 columns are available for information coded by the Biology Code. The 63 available columns can not be utilized independently to permit coding of 63 types of information, since a few of the types of information require more than one IBM column. Thus, the CBCC apportioned the available IBM columns to the various categories of information it considered most essential in order to have converted into code language as completely as possible the record of the test and, by the same token, to index the information to provide the greatest posstble retrieval and correlative facility.

The Key description of each of the code flelds generally explains why a given type of information can be adequately coded using only a single IBM punched card column or why more columns must be 
used. Therefore, as the Key is studied, an understanding will be gained of the apportioning of the total avallable punched card columns to each category of information.

For example, eight IBM punched card columns have been committed to coding the biological system (a test organism or a tumor or pathology of an organism) and this group of eight columns is regarded as a single coding field, representing a major category of biology information. Considering coding of test organisms only, it will be seen that test organisms might be given simple serlal numbers, so that the Norway rat might have been assigned Symbol 1, a species of mosquito Symbol 2, a species of bacteria Symbol 3, the tobacco plant Symbol 4, etc. Had this been done, the few hundred (or perhaps, few thousand) organisms that may reasonably be expected to be used in chemical-biological tests might have been accommodated by considerably fewer than eight columns. Instead, the CBCC recognized not only the desirabillty but the necessity of indicating by code the taxonomic affinities of each organism used. Thus, the total field of eight columns was sub-divided into what might be thought of as sub-fields. As a result, only a single IBM punched card column was assigned to coding of the phyla to which organisms belong; a single column was assigned to coding of classes; a single column to coding of orders; two columns to coding of families; two columns to coding of genera; and one column to coding of species (or strains). As an illustration of the apportioning of IBM punched card columns, this particular example has been chosen with the secondary objective of preventing any initial impression that certain coding fields, such as Field E, have been assigned a number of IBM columns providing a number of code symbols far beyond the needs of the CBCC coding. This misapprehension will be avoided by recognizing that, within the fields representing major categories of information, the IBM columns may be committed to special sub-categories of information such as phyla, classes, or orders of test organisms, the coding of each of which is satisfied by one or two columns.

The question as to whether the 63 avallable IBM punched card columns are sufficient or are more than sufficient is not to be answered positively one way or the other, except in terms relative to the character of the particular coding project. This 1s discussed in the Appendix, in terms of the particular needs of the CBCC and of the Code's adaptability.

The Detailed Nature of the Code; Its Limitations and Aspirations:

While the $\mathrm{CBCC}$ functioned, there was always the reasonable assumption that any special information collection elsewhere might be advantageously indexed (coded) to be collatable with the Center's coded files. Even with the Center discontinued, it has not been unreasonable to hope that the Biology Code might be accepted as, or serve as the basis for, a standard, so that information might be freely exchanged between open collections and so that information of one collection might be collated with that of another.

Many of the specialized information collections now belng initiated are private and some are even confidential for proprietary purposes. Thus, coding of chemical-biological information in these collections may be frankly as much cryptogrammic as it is documentary. Beyond this, most projects of information collection are severely subject to justifications of time and expense in coding; the additional effort of coding to a standard and more complex scheme is, at least under the present situation, not apt to be viewed in many cases as offering foreseeable practical advantage.

When an information collection is 11 mited in scope, the varlety of indexing criterla and 1 tems is correspondingly less than that needed by the CBCC to index (code) information of all types. For example, if the information collection were never to involve more than twenty or twenty-five organisms, simple sequential code symbols of a single unit might be entirely adequate for organdsm code identification. The same would be true of categories of information other than test organisms. Because of Its broad character, the $\mathrm{CBCC}$ Biology Code has frequently been regarded critically as too detalled for practical considerations in indexing information collections of a limited nature.

If it develops that all future collections of information about chemical-blological data are to be collections of spectalized nature and that the coding of each is to be referable to none of the others or to no central and standard coding scheme, much of the effort spent on the CBCC Biology Code may prove unfortunately to have been wasted.

This Code is presented with the conviction that 1 will prove something more than a key to the information collected and coded by the CBCC during 1ts active period. It may be hoped that eventually this Code or a derivative will be found universally acceptable and will serve as the basis for better 
exchange, documentation, and correlation of information about biological responses to chemicals than is evident at the present time.

The Manual to the Use of the Biology Code: The Key to the Biology Code

The Origin and Description of the Key:

It has aiready been noted, in describing the development of the Code, that a manual for its use was discovered very quickly to be essential and that this was first prepared in 1952 . The term, "Key", applied to this manual may not have been entirely appropriate in view of the fact that a key to a code is most commonly regarded as the definitions for its symbols while the code is thought of as merely the symbols (i.e., the code language). The term has persisted, however, and the Key to the Biology Code will be understood to refer to the manual for explaining items of the Code, the Code symbols, the procedure for their use, and retrieval of coded information.

A new edition of the Key in 1953 incorporated certain changes, but no major revision was made. In preparing the Key for this published edition, every section has been re-written, attempting to clarify the organization, purpose, and use of each field (1. e., of each "subsidiary code" of the total Biology Code). In this revision, every effort was made to use the many residual notes from coders outlining problems encountered in coding certain information and suggesting additions. It is not inappropriate to point out that many details concerning early decisions about coding procedures and arrangement and use of code items and symbols had never been recorded in an organized fashion or at all, some of the staff members making the provisions have since resigned, and memory of the complex of factors considered in making decisions has been lmperfect. As a result, the task of preparing the Key has been difficult and consumed time far beyond expectations. The incentive in making it as thorough as possible has been the conviction of its value, from the standpoints of explaining each field, its future use with the Biology Code per se, and of conveying to the prospective coder or agency considering coding biology information some better idea of the nature of the task which coding represents.

For each field, the Key explains first any special organization of the items in the field and the structure of the symbols for the items. This is followed by a section describing the purpose of the field and its general relationship to the other fields of the Code in coding information about a given chemical-biological test as a "code line". The final section is devoted to details of use of the symbols for specific types of information and it attempts in most cases to explain the reasons for the particular procedure rather than to present the coder or general reader with a stark set of rules and rule exceptions.

\section{The Complexity of the Key and the Complexity of Coding:}

Each of the CBCC resident staff members and, doubtless, each of the CBCC coders has the memory of his first reaction to the Key, the manual describing coding of chemical-biological tests using the Biology Code. An introduction to the CBCC Blology Code and Key could hardiy omit, therefore, a few words preparing the new coder, or anyone reviewing the Code, for the Key.

The Key, as it is presented here, is an expansion of the 1953 edition. The expansion has been made with the view of explaining, in turn, each coding field more thoroughly than did the earlier editions of the Key.

The detalled character of the Key has met with some criticism. Paradoxically, the criticism is a wind that blows both ways. By persons who have had little experience in reducing chemicalblological test information to code, the suggestion has been made that the present Key for coding biological data is far too detalled and that its intelligibility is reduced by the sheer volume of minutiae. However, when the Key has been criticized by coders, it is to the effect that coding provisions have not always been adequately explained so that, when a special coding problem is encountered, the coder has no recourse but to correspond with the Center, when he might otherwise have been able to understand himself how to accomplish the solution.

The initial impact of such a volume of details might understandably alarm the uninitiated, making the Code seem more intricate than it actually is. This is possibly because coding is so frequently expected to be easy, mechanical, and requiring a minimum of cerebral exertion; to discover it might be otherwise can be a rude awakening. It is of course ironical that the CBCC, which had as 
one of its objectives facilitating the handling of information, may be subject to having its own Code's description (i.e., the Key) criticized as being abstruse because of its concern with detail. A more careful examination will reveal that the bulk of the Key is made of basic explanations, to which the coder need seldom return once the general coding pattern is well in mind, and explanations for special and sometimes rare coding problems, to which the coder will turn when a problem is encountered.

One observation which may prove a common one has been made, that too little has been assumed in the text of the Key and that much explanation has been made that is unnecessary and even unflattering to the chemical or biological specialist. The CBCC conviction that this assumption is a serious error is based on experience with persons who have proved talented as coders and who have considerable erudition in one or another special field of biology and chemistry. They do not all know, nor do any pretend familiarity with, all biology and chemistry met with in chemical-biological tests. Furthermore, none of them had, prior to their CBCC association, experience in transforming these facts to a coded state. It is unrealistic to make the assumptions that all biologists are necessarily trained in all fields of biology and chemistry or that they remember all aspects of the field in which they have concentrated their study. A professional taxonomist should not assume the taxonomy of insects, for example, to be well known by each pharmacologist. The pharmacologist should not expect antagonism and its measurement to be well known to the taxonomist.

Neither is it realistic to assume that these scientifically trained persons will all find easy the translation of biological data into code, even if the data are completely understood. It can not even be assumed that everyone assigned as a coder to a coding project is necessarily to be trained in the biological sclences. Thus, the persons for whom the Key is intended to be a reference are highly varied in their training.

However, the Key is not actually written nor intended for the biologically untrained person. It is intended as a coding manual for persons untrained in coding, whether they are biologists, chemists, or otherwise. There must be some middle ground in presenting the explanation for coding and the present approach is to assume that principally biologists are being addressed, but emphatically biologists of all descriptions: pathologists, plant physiologists, horticulturists, animal taxonomists, bacteriologists, anatomists, pharmacologists, biology librarians, etc.

Coding can be reduced to a simple procedure in some cases, but even the most simple coding demands establishing conventions which must be adhered to and the conventions must be logical. Furthermore, if the coder is trained as a scientist, it is probable that he has the curiosity to want to understand the reasoning behind the coding procedures. The reasons for a given procedure must be understood not only for establishing other procedures the character of which must depend on already existing procedures, but for intelligent retrieval of information coded by those procedures.

It is difficult for persons who have not contended with coding problems to appreciate what these facts mean and how invaluable are the details explaining coding conventions that must be adhered to. To entertain the opinion that the explanatory detalls are superfluous can only mean a lack of appreclation of the enormous amount of time and patience (and money) wasted under circumstances in which there exists no single reference to those detalls that are so easily forgotten or become confused.

The composition of this Key has as its objective the provision of a reference for coding procedures. If a more brief Key is more practical for ordlnary use in coding chemical-biological information, by all means 1 t should be devised by the adapter, and this can be done from the information in the present Key.

\section{Considerations in Publishing the Details of the Biology Code and Key}

Certain questions were posed by the circumstances of the Biology Code and Key belng published only after the disruption of all activities of the Center. No serious doubts have been held about the baslc matter, that the Center's experience in biology coding should be made available by publication of the Biology Code, including a record of the procedures used by the Center for handling of biological information. However, at the time the task was begun for preparing the publication, two indeterminate factors made difficult certain decisions about the form in which the Code should be published. 
First, the disposition of the CBCC collection of coded information was uncertain. Therefore, there was no assurance that the files, as statlc flles, would ever again be consulted on a regular basis, a factor that was irrespective of the undetermined intrinsic worth of the finite collection. However, the assumption was made that the files might possibly be used and that the unaltered Biology Code might be needed for its interpretation.

The second factor was the question of the extent of usefulness of a Biology Code whose design and detail had been based on the special objectives and mechanical equipment of the CBCC. The Code was recognized as being too detailed and broad in scope for use in coding and indexing information collections of very limited nature, and not sufficiently detailed in certain of its coding fields for certain other uses. It was disturbing also to recognize that the act of closing the Center had the unfortunate but unavoidable effect of creating an atmosphere of failure which the Center's Code and methods would bear with them. For these reasons, an alternative to publishing the Biology Code in its entirety had to be considered, that of publishing only an outline of the Code with examples and a very brief resume of the use of the Code.

It was finally agreed that the greatest value of the $\mathrm{CBCC}$ experience in coding biological information actually resided in those details which would be omitted in publishing only an outline.

The Code and Key, therefore, are presented here in essentially the form used by the Center.

The question as to whether to make revisions for the published form was finally settled by resolving to incorporate all the suggestions made by coders and resident staff members, since it seemed senseless to present, as a publication, a code in which there were recognized deficiencies that could be corrected. This decision was made in the face of the impossibility of altering the files to bring them to conformity with any alterations in the Code and Key. Thus, there was the prospect of defeating one purpose in publication, that of preserving the Code as an interpretive tool for the CBCC flles of information. The decision to incorporate changes had to be made, then, by accepting the philosophy that the balance of the argument was for a corrected version for publication, leaving the files to be interpreted by the last unpublished edition of the code lists, assisted by information in the published Key and Code.

It must be made clear that most of the alterations are minor. In most fields, no changes have been made except to enlarge and, it is hoped, to clarify the definition and use of symbols. In certain of the fields, some of the items have been only slightly rearranged or redefined to make a more logical pattern and this has involved making a few changes in symbols. On the other hand, the lists of the Taxonomy Code (Field E) were all reviewed and the classification and code symbols were revised where it seemed appropriate. The published symbols for test organisms must therefore no longer be depended on for retrieval from the CBCC files, even though certain of the organism groups are essentially as they were when the information in the files was coded. It might be said that, had there been promise of resumption of coding information into the CBCC files, revisions of the Taxonomy lists might have been more conservative in view of the task it might involve to retrieve all the coded information and recode it according to the new lists.

The Tumor Code and Pathology Code were both analyzed and the organization and symbols entirely replaced; neither had been used to any extent by the CBCC, because so few tumor and pathology identities had actually been needed for coding the type of information selected by the CBCC. Unfortunately, no explanation was prepared or survived for the original Pathology Code symbols and very little was recorded for the Tumor Code. The analysis of these sections of the Biology Code, in terms of time and effort, was an expensive lesson which strengthened the conviction that the detailed explanation of the Biology Code and its parts are more valuable than the bare lists of code items and symbols which conceivably might be compiled by anyone.

In preparing this edition of the Code (as a list of symbols with their definitions), there has been some deviation from the principle of restricting the definitions of symbols to the briefest possible form. The merits of brevity are not underestimated, especially when speed is important in scanning a list to select the most appropriate 1tem; to provide this quality to the Code, essentially all instructions and explanations are omitted from It and compiled separately as the Key. Nevertheless, there are limits to which abbreviation can be carried beyond which the definltions and efficiency in use are impaired. It has seemed certain that confusion of the coders and many errors in coding have been directly due to inadequacies of explanation and definition in the Code (regardless of the adequacy of explanations in the Key). This is also indicated from the experience of the resident staff members in using the Code. 
Welghing the factors involved, the definitions have been expanded in some fields, including more specific directions than was typical of the mimeographed editions used previously by the CBCC coders.

When a coder uses certain symbols constantly, he eventually becomes so familiar with their use and limitations that he needs no longer to refer to the Key nor even consult the definition in the Code. While this may lead to overconfidence which may in turn lead to coding errors, it is reasonable that the coder who has developed familiarity with the symbols would prefer having those symbols listed with definitions of one word or the fewest possible words. A given coder, however, never uses all of the Code's symbols with consistent frequency; some symbols are rarely used. Further, although coding has been generally assigned in accordance to coders' spectal biological fields of interest, this is not always possible and coders constantly must use symbols with whose definitions and use they are less familiar. It is certain that a beginning coder finds helpful having a relatively complete and distinguishing definition for each symbol, including basic specifications for its use, with the symbol in the Code; anyone examining the Code lists, in considering their appropriateness for other coding projects, should also find advantageous more complete definitions of the symbols.

Whether a proper balance has been struck between the completeness of definitions in the Code and the explanations of the Key, can not be certain. It is probable that, from the present Code, each coder or coding project might want to extract the items used most frequently and list them with definitions of the desired brevity.

Appendix B further discusses the published Code's character and adaptability, as well as CBCC problems and ambitions related to the Biology Code and its coding procedures. 


\section{ACKNOWLEDGMENTS}

The Chemical-Biological Coordination Center was sponsored by the Department of the Army, the Office of Naval Research and the Bureau of Medicine and Surgery of the Department of the Navy, the Atomic Energy Commission, the National Cancer Institute, and the American Cancer Society. After the Center's termination in December 1956, the National Science Foundation made generous grants for certain final activities, including the preparation of the Biology Code for publication. Subsequently, the National Institutes of Health gave support to the final stages of the task in preparing the Blology Code, which has taken far longer than originally estimated.

It is appropriate in this publication to express special gratitude to the two last named agencies, since without the continued interest and support of NSF and NIH, the present edition of the Code could not have been completed as the editors wanted it.

The general responsibility for all terminating activities of the CBCC was placed on the NAS-NRC Division of Chemistry and Chemical Technology of which Dr. Clem O. Miller is Executive Secretary. Completion of the review and amendment of the Blology Code, which have been made under irregular and often trying circumstances, has frequently depended on Dr. Miller's administrative efforts and his faith in the judgments of the editors. For bearing with this undertaking and its problems over the many months, the editors wish to express their gratitude to Dr. Miller.

On the following pages are listed members of those CBCC committees and subcommittees which contributed particularly to the early development of $\mathrm{CBCC}$ methods for handling biological data, Including the initial codes. The Blology Code also owes much to various members of the CBCC staff, including the coding staff. Consequently, in recognition of their varied contributions to the Code, the members of the resident staff, Including biologists, chemists, and supervisors of the Screening Program, are listed, as well as the non-resident coders of the final years. 
Adams, Roger: Advisory Committee 1947 through 1952; Chairman of the Organic Chemistry Subcommittee 1947 through 1952.

Ball, Eric G. : Member of the Biochemistry Subcommittee 1947 through 1952.

Barron, E. S. G.: Member of the Biochemistry Subcommittee 1947 to 1949.

Bauer, Walter: Member of the Medicine Subcommittee 1947 through 1949.

Beard, Raimon L.: Member of the Biological Codification Panel 1947 through 1952. Chairman of the Biological Codification Panel 1951 and 1952. Member of the Executive Committee 1949 through 1950. Member of the Entomology Subcommittee from 1949 through 1952; chairman of the Entomology Subcommittee from 1950 through 1952. Member of the 1952 Steering Committee.

Bernheim, Frederick: Member of the Physiology-Pharmacology Subcommittee 1947 to 1949.

Bishopp, Fred C.: Member of the Entomology Subcommittee 1947 through 1952.

Blanchard, Kenneth C.: Member of the Chemotherapy Subcommittee 1947 through 1952.

Bodenstein, Dietrich: Member of the Entomology Subcommittee 1947 through 1952.

Boell, E. J.: Member of the Biological Codification Panel 1947 through 1952.

Bovarnick, Max: Member of the Microbiology Subcommittee 1947 to 1949.

Boyce, A. M.: Member of the Entomology Subcommittee 1947 to 1949.

Brown, Thomas M.: Member of the Medicine Subcommittee 1950 through 1952; vice-chairman of the Medicine Subcommittee 1951 through 1952.

Cannan, R. Keith: Alternate member of the Executive Committee (alternate for Dr. Winternitz) 1952 through 1953. Member of the Executive Committee 1953 to 1957.

Cattell, McKeen: Member of the Advisory Committee 1947 through 1952; vice-chairman of the Advisory Committee 1948 to 1949; chairman of the Advisory Committee 1949 to 1952 when Advisory Committee was discontinued. Chairman of the Physiology-Pharmacology Subcommittee 1947 through 1952. Chairman of the Biological Codification Panel 1947 through 1950; member of the Biological Codification Panel through 1952. Member of the Executive Committee 1948 through 1952. Member of the 1952 Steering Committee.

Chambers, William H.: Member of the Physiology-Pharmacology Subcommittee 1947 through 1952.

Cleland, Ralph E.: Member of the Executive Committee 1950.

Comroe, Julius H., Jr.: Member of the Physiology-Pharmacology Subcommittee 1947 through 1952.

Cope, Arthur C.: Member of the Organic Chemistry Subcommittee 1947 through 1952.

Cottam, Clarence: Member of the Mammology Subcommittee 1947 through 1952.

Davis, Bernard D.: Mermber of the Microbiology Subcommittee 1949 through 1952.

De Beer, Edwin J.: Member of the Cornmittee on Industrial Liaison 1954.

Drake, Nathan L.: Member of the Organic Chemistry Subcommittee 1947 through 1952; vice-chairman of the Organic Chemistry Subcommittee late 1947 through 1952. 
Dubos, René J.: Member of the Microbiology Subcommittee 1947 to 1948.

Dunham, Lucia J.: Member of the Malignancy Subcommittee 1952.

Eagle, Harry: Member of the Advisory Committee 1947 through 1952. Chairman of the Chemotherapy Subcommittee 1947 through 1952.

Elderfield, Robert C.: Member of the Organic Chemistry Subcommittee 1947 through 1952.

Fothergill, Leroy D.: Member of the Microbiology Subcommittee 1947 through 1949.

Frlend, Roger B.: Member of the Advisory Committee 1947 through 1950. Member of the Entomology Subcommittee 1947 through 1952; chairman of the Entomology Subcommittee 1947 through 1950.

Fruton, Joseph S.: Member of the Advisory Committee 1947 through 1950. Member of the Biochemistry Subcommittee 1947 through 1952; chairman of the Biochemistry Subcommittee 1947 through 1950 .

Gellhorn, Alfred: Member of the Malignancy Subcommittee 1950 through 1952.

Gersh, Isadore: Member of the Malignancy Subcommittee 1950 through 1952.

Gilman, Alfred: Member of the Physiology-Pharmacology Subcommittee 1947 through $1952 . \quad$ Member of the Biological Codification Panel 1947 through 1952.

Goddard, David R. Member of the Advisory Committee 1947 through 1952. Chairman of the Plant Sciences Subcommittee (originally the Plant Physiology Subcommittee) 1947 through 1952. Member of the Biological Codification Panel 1948 through 1952. Member of the 1952 Steering Committee.

Griggs, Robert F. : Member of the Advisory Committee in 1947. Chairman of the Plant Ecology Subcommittee which was discontinued in 1947.

Hagan, William A.: Member of the Veterinary Mediclne Subcommittee 1947 through 1952.

Hall, Stanley A.: Member of the Committee on Coding of Chemical Reactivities 1953 to 1957.

Hanson, Harry G. : Member of the Sanitary Engineering Subcommittee 1947 through 1952.

Harris, Stanton A.: Member of the Committee on Industrial Liaison 1954.

Harvey, A. McGehee: Member of the Advisory Committee 1948 through 1952. Member of the Executive Committee 1948 through 1950. Member of the 1952 Steering Committee. Member of the Medicine Subcommittee 1947 through 1952; Chairman of the Medicine Subcommittee 1948 through 1952.

Henderson, John M.: Member of the Sanitary Engineering Subcommittee 1947 through 1952.

Herriott, Roger M.: Member of the Biochemistry Subcommittee 1947 through 1952.

Hilbert, G. E.: Chairman of the Committee on Coding of Chemical Reactivities 1953 to 1957. Alternate member of the Executive Committee 1953 (alternate to Dr. W. A. Noyes).

Hodge, Harold C.: Member of the Executive Committee 1953. Chairman of the Committee on Industrial Liaison 1954.

Horsfall, James G.: Member of the Plant Sciences Subcommittee (originally called the Plant Physiology Subcommittee) 1947 through 1952. Chairman of the Executive Committee 1953 to 1957.

Hotchkiss, Rollin D.: Member of the Microbiology Subcommittee 1949 through 1952.

Hueper, Wilhelm C.: Member of the Malignancy Subcommittee 1952.

Irish, Don D.: Member of the Commlttee on Industrial Liaison 1954. 
Jellison, William L.: Member of the Subcommittee on Mammology 1947 through 1952.

Johns, Iral B. : Member of the Committee on Industrial Liaison 1954.

Kearns, Clyde: Member of the Committee on Coding of Chemical Reactivities 1953 to 1957.

Kellog, Remington: Member of the Advisory Committee 1947 through I952. Chairman of the Mammalogy Subcommittee 1947 through 1952.

Kelser, Raymond A.: Member of the Advisory Committee 1947 through I 952 . Chairman of the Veterinary Medicine Subcommittee 1947 through 1952.

Kirner, Walter R.: Member of the Executive Committee 1951 ; Secretary of the Executive Committee and Director of the Center to 1952.

Kruse, C. W.: Member of the Sanitary Engineering Subcommittee 1947 through 1952.

Larkey, Sanford V.: Member of the Executive Committee 1954 to 1957.

Lee, Milton O.: Alternate member of the Executive Committee (alternate for Dr. P. Weiss) I953.

Longcope, Warfield T.: Member of the Advisory Committee 1947; replaced by Dr. Harvey in 1948. Chairman of the Medicine Subcommittee 1947.

MacLeod, Colin M.: Member of the Chemotherapy Subcommittee 1947 through 1950 . Vice-chairman of the Chemotherapy Subcommittee late 1947 through 1950.

Marsh, David Fielding: Member of the Physiology-Pharmacology Subcommittee 1950 through 1952.

Martin, Harry M.: Member of the Veterinary Medicine Subcommittee 1947 through 1952.

Maynard, L. A. : Member of the Executive Committee 1956.

Metcalf, Robert L. : Member of the Entomology Subcommittee 1949 through 1952.

Meyer, K. F.: Member of the Medicine Subcommittee 1947 through 1950.

Meyer, Samuel L. : Member of the Committee on Coding of Chemical Reactivities 1953 to 1957.

Mitchell, John W.: Member of the Plant Sciences Subcommittee 1949 through 1952.

Mosettig, Erich: Member of the Chemotherapy Subcommittee I 947 through 1952.

Mueller, John H.: Member of the Advisory Committee 1947; replaced by Dr. Tatum in 1948. Chairman of the Microbiology Subcommittee 1947.

Niemann, Carl: Member of the Biochemistry Subcommittee 1947 to 1949.

Noyes, W. Albert, Jr.: Member of the Advisory Committee 1947 through 1952. Member of the Executive Committee 1948 through 1953. Chairman of the Physical Chemistry Subcommittee 1947 through 1952.

Ormsbee, Richard A.: Member of the Biological Codification Panel I 947 through 1948.

Patton, Robert L.: Member of the Entomology Subcommittee 1947 through 1952.

Perry, Isabella: Member of the Malignancy Subcommittee, 1951 through 1952.

Philips, Frederick S.: Member of the Malignancy Subcommittee 1951 through 1952.

Pincus, Sol: Member of the Sanitary Engineering Subcommittee 1947 through 1949.

Renn, Charles E.: Member of the Sanitary Engineering Subcommittee 1947 through 1952. 
Rhoads, C. P.: Member of the Advisory Committee 1947 to 1949. Chairman of the Malignancy Subcommittee 1947 to 1949.

Roeder, Kenneth D.: Member of the Biological Codification Panel 1947 through 1952.

Rossini, Frederick D.: Member of the Executive Committee 1956 to 1957.

Schoening, Harry W.: Member of the Veterinary Medicine Subcommlttee 1947 through 1952.

Schwartz, Benjamin W.: Member of the Veterinary Medicine Subcommittee 1948 through 1952.

Seevers, M. H.: Member of the 1952 Steering Committee.

Shepard, Harold H.: Member of the Biological Codification Panel 1947 through 1952 . Member of the Entomology Subcommittee 1952 .

Skipper, Howard E.: Member of the Malignancy Subcommittee 1951 through 1952.

Smith, Paul K.: Member of the Physiology-Pharmacology Subcommittee 1948 through 1952.

Snyder, John C.: Member of the Microbiology Subcommittee 1949 through 1952.

Sparks, William J.: Member of the Executive Committee 1954 through 1955.

Stein, William H.: Member of the Biochemistry Subcommittee 1949 through 1952: chairman of the Biochemistry Subcommittee 1950 through 1952.

Sterner, James H.: Member of the Committee on Industrial Liaison 1954.

Stock, C. Chester: Member of the Executive Committee 1949 and 1950. Chairman of the Malignancy Subcommittee 1951 through 1952. Member of the Biological Codification Panel 1947 through 1952 .

Tatum, E. L. : Member of the Microbiology Subcommittee 1949 through 1952. Chairman of the Microbiology Subcommittee 1948 through 1950. Member of the Advisory Committee 1948 through 1950.

Taylor, John F. : Member of the Biochemistry Subcommittee 1949 through 1952.

Treffers, Henry P.: Vice chairman of the Mlcroblology Subcommittee 1948 through 1950; chairman of the Microblology Subcommittee 1950 through 1952.

Tukey, H. B. : Member of the Plant Sciences Subcommittee (originally the Plant Physiology Subcommlttee) 1947 through 1952.

Weiss, Paul A.: Member of the Executive Committee 1951 through 1955.

Welch, A. D.: Chairman of the Malignancy Subcommittee 1948.

Weston, Arthur W.: Member of the Committee on Coding Chemical Reactivities 1953 to 1957.

Whitaker, Douglas: Member of the Executive Committee 1950 and 1951.

Whitman, Bradley: Member of the Committee on Coding Chemical Reactivity 1953 to 1957.

Willaman, J. J. : Member of the Committee on Coding Chemical Reactivity 1953 to 1957.

Winternitz, M. C.: Chalrman of the Executive Committee 1948 through 1950 . Member of the Executive Committee 1948 through 1952. Chairman of the Advisory Committee 1947 through 1950. Chalrman of the Pathology Subcommittee 1947.

WIselogle, Fred Y.: Member of the Commlttee on Coding Chemical Reactivities I953 to I957.

Wolman, Abel: Member of the Advisory Committee 1947 through 1952. Chairman of the Sanitary Englneering Subcommittee 1947 through 1952. 
Woodard, Geoffrey: Member of the Mammalogy Subcommittee 1947 through 1952.

Woods, Lauren A. : Member of the Committee on Coding of Chemical Reactivities 1953 to 1957.

Yeager, J. Franklin: Member of the Entomology Subcommittee 1947 through 1952.

Zapp, John A. : Member of the Committee on Industrial Liaison. 
Ballard, Delbert L. : May 1947 to 1954

Beard, Raimon L. : July 1946 to March 1947

Blllingsley, Alice M.: Jan. 1955 to Jan. 1957

Brown, Rosamond: Sept. 1956 to Jan. 1957

Chambers, Richard: Nov. 1954 to Jan. 1957

Cicala, Lorraine: June 1951 to Jan. 1957

Dale, Estaleta: Oct. 1947 to Nov. 1956

Davison, Margaret C.: Dec. 1949 to May 1954

Defandorf, James H.: July 1956 (Contd. in CVLP*)

Filippi, Michael J.: July 1946 to May 1952

Geer, Harriett A.: July 1946 to Oct. 1954

Heumann, Karl F.: Sept. 1946 to Sept. 1947; Sept. 1952 to Sept. 1955

Huttrer, Charles P.: July 1949 to Oct. 1951

Innes, J. R. M.: Sept. 1948 to June 1949

Jeffrey, Helen L. : Aug. 1949 to July 1952

Jordan, Mary Ann: March 1949 to June 1954

Kaan, Helen W.: July 1947 to March 1952

Kirner, Walter R. : 1946 to April 1952
Kraybill, Herman F.: Feb. 1948 to March 1949

Krop, Stephen: March 1951 to July 1952

Lee, Lucy C.: July 1946 to March 1957

Livingston, George A. : June 1953 to June 1957

MacMillan, Judith T. : June 1955 (Contd. in CVLP)

Maskaleris, Chris H: July 1946 to Oct. 1954

Moser, Jean: July 1946 to Nov. 1947

Patterson, Helen: June 1955 (Contd. in CVLP)

Rich, Edgar C.: July 1955 (Contd. in CVLP)

Schuyler, Patricia: Feb. 1947 to Dec. 1947

Seitner, Philip G. : June 1953 to April 1957

Smith, Paul K.: April 1947 to March 1950

Smyrniotis, Pauline: March 1947 to March 1949

Thurlow, John F.: Nov. 1950 to Nov. 1952

Thurlow, Marian P.: July 1946 to Nov. 1952

Welt, Isaac D.: July 1953 (Contd. in CVLP)

White, Florence: Sept. 1956 to Jan. 1957

Williams, Ann S.: July 1947 to 1957

Wood, G. Congdon: Nov. 1952 to March 1957

Non-resident CBCC coders, 1954 through 1956

\begin{tabular}{|c|c|}
\hline Ackerman, Lloyd & Leonard, Clifford S. \\
\hline Beard, Frances C. & Love, Lois \\
\hline Berueffy, Robert & Parton, Jacqueline \\
\hline Chambers, Jacqueline & Simons, H. C. R. \\
\hline Gauch, Martha & Smith, Carroll \\
\hline H1ll, Charles & Smith, Charlotte \\
\hline Kaplan, Leo & Stone, Sanford H. \\
\hline Kassell, Beatrice & Weinstein, Marianne \\
\hline
\end{tabular}

* CVLP: Cardiovascular Literature Project, National Academy of Sciences - National Research Council 


\section{FOREWORD}

Each division of this volume represents one of the major categories of information which may be about, or derived from, a test for biological responses to chemicals. Examples are (i) state of the chemical, (2) organism, (3) dose size, (4) path of administration, and (5) response. Information of any one category is recorded (both as a written abstract and in written code) in only one specified location (i. e., a fixed position) on Biology Code Sheets; subsequently, it is punched (in code) in an analogous fixed position on Biology IBM Punched Cards. The fixed area of the Code Sheet or punched card used for one category may be larger or smaller, according to the nature of the category (e.g., the area for the organism is larger than the area for the state of the chemical); the area is referred to as a coding "field" on both the punched card and Code Sheet. In CBCC parlance, the categories have come to be referred to simply as "fields"--for example, the "dosage fields", "taxonomy field", and "anatomy field". For more convenient reference, however, these fixed coding fields have been assigned alphabetical designations. For example, Field A is concerned with states of the chemicals tested, Field E with the name of organisms, pathologies, or tumors treated, Field $\mathrm{H}$ with the anatomical parts affected, etc. Under each information category ("field") of this Code are classified the many specific items belonging to that category, each item being accompanied by its assigned code symbol.

In the Introduction and Appendixes, the role of the Code for indexing, machine handling, and storage of chemical-biological information is discussed.

Within each field, the organization is according to the numerical and alphabetical sequence of the items' code symbols. Since the symbols reflect the classification within a field, the items themselves are listed according to their natural relationships.

To find an item of a given field, it is necessary to scan the field. No index is furnished for any of the fields, since, in using the Code, positions of the items are quickly learned, after which an index to a field becomes more an impediment than an assistance.

Special directions and distinctions for use of code symbols are included with the items of the Code in cases where it has seemed appropriate for expediting coding. However, these are as brief as possible and are included in the Code only when needed to delineate the idea which the code symbol is to convey.

Directions for coding information about any chemical-biological test by use of the symbols, as well as explanations for the construction and arrangement of symbols, are in a separate volume designated as the Key to the CBCC Biology Code. The Code and Key have been published in separate volumes, because it has been found the most practical arrangement for use of the Code.

In the Code's symbols, the capital letter $\mathrm{O}$ and the numerical zero are distinguished by using the speclal symbol " $\varnothing$ " for the letter O. (For persons using the CBCC IBM Punched Cards, it should be observed that the IBM Interpreter distinguished these two symbols in the reverse way, the zero being typed by the Interpreter as " $\varnothing$ " and the letter $\mathrm{O}$ as "O".) 
(1) PHYSICAL STATE OF THE TEST COMPOUND

(2) INDICATION OF DIRECT, MASS APPLICATION VS. REMOTE, PARTICULATE APPLICATION (I. E. , DISPERSION VS. APPLICATION OF THE UNDISPERSED COMPOUND) $)^{1}$

\section{(3) INDICATION THAT INFORMATION ON CORRELATION OF ACTIVITY AND CHEMICAL STRUCTURES OCCURS IN THE DATA SOURCE}

Note: With only one or two exceptions, coding in Field $\mathrm{A}$ is restricted to a description of the state and method AT THE TIME OF APPLICATION to the host or the test organism. See the Key for specific directions and explanation of exceptions.

Gas; vapor (a compound applied in a normal environment such as air, water, or soil; either undiluted or a per cent composition of a mixture with air, components of air, or other innocuous gas)

A Adsorbed gas

2 Liquid (undiluted compound, not dispersed)

B Liquid (undiluted compound) applied as a spray

K Liquid (undiluted compound) applied as a mist or aerosol

3 Solid (undiluted compound, not dispersed)

C Solid (undiluted compound) applied as a dust

4 Solution (not dispersed)

D Solution applied as a spray

M Solution applied as a mist or aerosol

5 Emulsion (not dispersed)

E Emulsion applied as a spray

$\mathrm{N}$ Emulsion applied as a mist or aerosol

6 Suspension (not dispersed)

F Suspension applied as a spray

$\varnothing \quad$ Suspension applied as a mist or aerosol

7 Suspension in a solid (not dispersed)

(salve or powder)

G Suspension in a solid, applied as a dust (dust = dispersed powder)

O The article contains information on the correlation of activity and structure of chemical compounds.
(The solvent, if specified, should be expressed in Field C. )

(The vehicle, if specified, should be expressed in Field C. )

(The conditioning agent, if specified, should be expressed in Field B; the vehicle, if specified, would be in Field C.)

\footnotetext{
l"Dispersion" is used here to mean scattering the test material by use of a sprayer, atomizer, duster, aerosol; "dispersion" is NOT used in Field A definitions of the Code to describe mechanical spreading or smearing of the test material over the surface of--or diffusing through the substance of--a test organism or host. An examination of the Code terms will clarify this.
} 
(1) CONDITIONING AGENT

(2) MISCELLANEOUS INFORMATION ABOUT THE TEST COMPOUND ADMINISTRATION

(3) INDICATION THAT IN THE DATA SOURCE THERE IS INFORMATION ON THE EFFECT OF pH ON THE CHEMICAL ACTION

Presence of conditioning agents such as spreading agents, wetting agents, detergents, emulsifiers, etc. (Use this symbol when other more specific symbols cannot be used.) Examples: Tween- 80 and Tergitol.

3

Test compound is not pure; it is applied as a formulation. (A formulation is defined as a product containing a given proportion of the test compound, the remaining ingredients being disregarded and presumably inert.) Use Symbol 0 for indicating that the test compound is administered as a mixture.

Test compound is administered as a precursor (from which the test compound is biologically synthesized or degraded); the action is demonstrated to be of the test compound and not of its precursor. Include the NAME AND INFORMATION ABOUT THE PRECURSOR in the written abstract portion of Field $\mathrm{B}$ on the Code Sheet. (Consult the Key.)

0 Test compound is one ingredient of a mixture of compounds administered in a test for the action in Field T-2; the remaining compounds are written on the Code Sheet in this coding field and the evaluation, dose, etc., are based on the response to the mixture. (Consult the Key.)

Data source contains information on the effect of $\mathrm{pH}$ on the action coded in Field T-2. 


\section{SOLVENT OR VEHICLE}

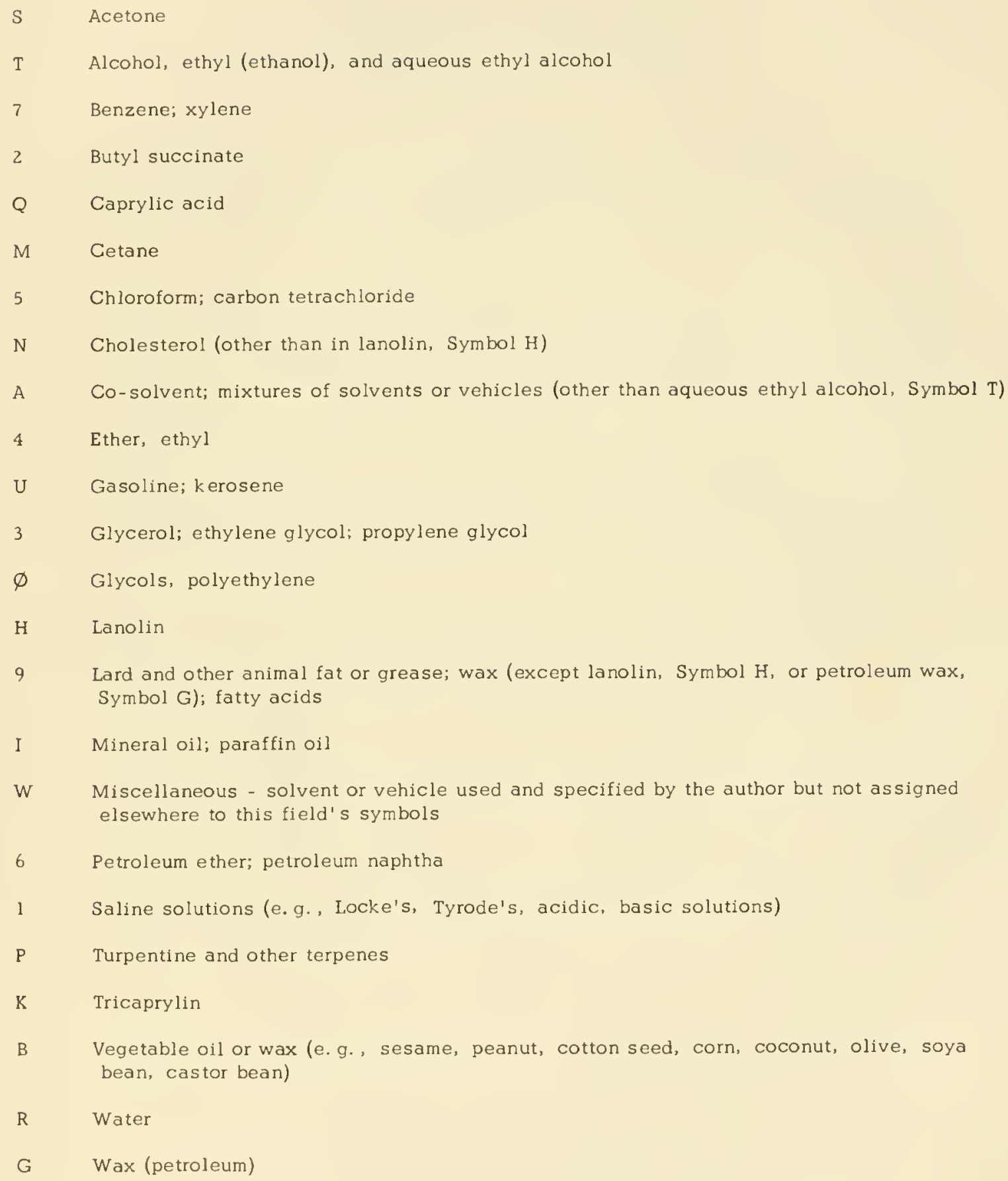


The IBM punched card columns of this field (12 through 17) are used for coding a compound other than the "test compound", i. e., a "secondary compound".

(The test compound is always expressed in Columns I through 8 on each IBM biology punched card. On the Biology Code Sheet, the test compound's name and its Serial Number are written only on the chemistry side, regardless of the number of lines of data coded on the sheet; this provision eliminates the necessity of entering the name and Serial Number of the test compound for each line of biological data when several lines are coded on a single Code Sheet.)

Examples of secondary compounds that are coded in Field D are (1) compounds whose actions are antagonized or synergized by the test compound or (2) compounds whose metabolic fate (e.g. , excretion), coded in Field T-2, is affected in some way by the test compound.

The secondary compound can be coded only by a person having access to a reference file of chemical names and Serial Numbers. In any case, the coder must always include in the written abstract for this field the full name and all other information given about the secondary compound.

A more thorough discussion of all the uses of Field D and specific directions are given in the Key, including the uses of the following special symbols.

* RADIOACTIVITY: To designate that the secondary compound is radioactive, place an asterisk in Column 16.

* STANDARD of COMPARISON: To designate that a compound is used as a stasdard of comparison for evaluation, place an asterisk in Column 17.

\# MORE THAN ONE SECONDARY COMPOUND PRESENT AND ESSENTIAL: To designate that more than one secondary compound is present and is essential to the action, place the Symbol \# in Column 16. 


\section{ORGANISM OR PATHOLOGICAL CONDITION ACTED ON BY THE TEST COMPOUND}

Field $E$ is for the entry of one of the following:

I (1) TEST ORGANISM ACTED ON BY THE TEST COMPOUND

(2) TUMOR ACTED ON BY THE TEST COMPOUND

(3) PATHOLOGICAL CONDITION OTHER THAN TUMOR ACTED ON BY THE TEST COMPOUND

\section{II (4) TUMOR PRODUCED BY THE TEST COMPOUND}

The section of the Code designated as Field $\mathrm{E}$ is divided into three major parts. The first is the Taxonomy Code, listing all the phyla, classes, orders, families, genera, and species for which the $\mathrm{CBCC}$ has already as signed code symbols.

Following the Taxonomy Code lists, the second part of Field $E$ is the Tumor Code, listing all types of tumors and specific tumors for which the $\mathrm{CBCC}$ has already assigned code symbols. Appended at the end of this Tumor Code section is a special list of anatomical items to be used only for interpreting the second and third units of the tumor symbols (Columns 19 and 20); the list is used by the Center for constructing unique symbols for tumors added to the existing list.

Finally, the third part of Field $E$ is the Pathology Code, listing the pathologies for which the $\mathrm{CBCC}$ has assigned code symbols and designated specific coding involving Fields $\mathrm{H}$ and $\mathrm{T}$ as well as Field E. Appended at the end of this list of pathologies are lists of etiologies classified and assigned code symbols to be used in interpreting the 5 th and 6 th units of the pathology symbol (Columns 22 and 23) and used by the Center in constructing unique symbols for pathologies added to the existing list.

It will be understood that the CBCC coding procedure permits Field $\mathrm{E}$ to be coded with only a single entry in any one code line, an organism, a tumor of an organism, or a pathology of an organism, whichever the chemical was tested to affect. Therefore, for any one code line, only one of the three separate Field E codes will be consulted.

The general use of the field is discussed in the Key, prior to the three special sections explaining the organization of each of the Taxonomy, Tumor, and Pathology Codes. 
FIELD E; Taxonomy Code Columns 18, 19, 20, 21 , $22,23,24$, and 25

TAXONOMY CODE

1
1
11
11
11
111
111
111
11101
11101011
11101011
11101011
11102
1110201
1110201
11102011
11102012
11102021
11102031
111

11103

111

11104

11105

112

113

114

115

1

12

12

12

121

121

12101
Protozoa

Plasmodroma, subphylum of Protozoa

Sarcodina (syn. Rhizopoda), class of subphylum

Plasmodroma

Rhizopoda (syn. Sarcodina), class of subphylum

Plasmodroma

Rhizopoda, subclass of

Sarcodina

Amoebozoa (syn. Lobosa), order of Sarcodina

Lobosa (syn. Amoebozoa)

Amoebina (syn. Amoebozoa)

Amoebidae

Amoeba proteus

Chaos diffluens (syn. Amoeba proteus)

Amiba diffluens (syn. Amoeba proteus)

Endamoebidae

Endamoeba

Entamoeba (syn. Endamoeba)

Endamoeba histolytica

Endamoeba coli

Endolimax nana

Dientamoeba fragilis

Proteomyxa, order of subclass Rhizopoda

Vampyrellidae, family of order Amoebozoa or family of order Proteomyxa

Testacea, suborder of Amoebozoa or order of subclass Rhizopoda

Thecamoebaea (syn. Testacea), suborder of Amoebozoa

Arcellidae, family of suborder Testacea

Difflugidae, family of suborder Testacea

Foraminifera

Heliozoa

Radiolaria

Mycetozoa

Ciliophora, subphylum of

Protozoa

Ciliata, class of subphylum Ciliophora

Infusoria (syn. Ciliata)

Euciliata, subclass of Ciliata

Holotricha, order of subclass Euciliata

Trichostomata, suborder of Holotricha

Parameciidae, family of suborder Trichostomata
12101011

121

121

12102

12103

12104

121

12105

121

12106

12106011

12107

121

12108

12108011

12108021

122

122

12201

12201011

123

123

12301

12302

124

12401

13

13

131

I310I

13101011

13101012

13101013

13101014

13101015

13101016
Paramecium caudatum

Gymnostomata, suborder of Holotricha

Pleurostomata, tribe of suborder Gymnostomata

Amphileptidae, family of tribe

Pleurostomata

Isotrichidae, family of suborder Trichostomata

Colpodidae, family of suborder Trichostomata

Astomata, suborder of Holotricha

Anoplophryidae, family of suborder Astomata

Hymenostomata, suborder of Holotricha

Frontoniidae, family of suborder Hymenostomata

Tetrahymena geleii

Tracheliidae, family of tribe Pleurostomata

Prosostomata, tribe of suborder Gymnostomata

Holophryidae, family of tribe Prosostomata

Parachaenia myae

Ichthyophthirius multifiliis

Spirotricha, order of subclass Euciliata

Heterotricha, suborder of Spirotricha

Bursariidae, family of suborder Heterotricha

Balantidium coli

Peritricha, order of subclass Euciliata

Mobilia, suborder of Peritricha

Urceolariidae, family of suborder Mobilia

Vorticellidae

Chonotricha, order of subclass Euciliata

Spirochonidae, family of Chonotricha

Sporozoa, class of subphylum Plasmodroma

Telosporidia, subclass of sporozoa

Haemosporidia, order of subclass Telosporidia

Plasmodiidae

Plasmodium malariae

Plasmodium vivax

Plasmodium falciparum

Plasmodium gallinaceum

Plasmodium lophurae

Plasmodium knowlesi 
13101017

13101018

13101019

$1310101 \mathrm{~A}$

$1310101 \mathrm{~B}$

$1310101 \mathrm{C}$

$1310101 \mathrm{D}$

13102

13102011

13102021

132

133

133

13301

13301011

13301012

133

13

134

134

13401

13401011

135

135

136

13

137

14

14

14

141

14101

14101

14101011

14101012

14101013

14101021

14101022

14101023

14101024

14101025

14101026

14101027
Plasmodium cathemerium

Plasmodium relictum

Plasmodium circumflexum

Plasmodium cynomolgi

Plasmodium berghei

Plasmodium praecox

Plasmodium hexamerium

Babesiidae

Babesia bigemina

Toxoplasma gondii

Gregarinida, order of subclass

Telosporidia

Coccidia, order of subclass

Telosporidia

Eimeridia, suborder of Coccidia

Eimeriidae, family of suborder

Eimeridia

Eimeria stiedae

Eimeria tenella

Adeleidea, suborder of

Coccidia

Cnidosporidia, subclass of Sporozoa

Microsporidia, order of subclass

Cnidosporidia

Monocnidea, suborder of Microsporidia

Nosematidae, family of suborder Monocnidea

Nosema apis

Myxosporidia, order of subclass Cnidosporidia

Platysporea, suborder of Myxosporidia

Actinomyxidia, order of subclass Cnidosporidia

Acnidosporidia, subclass of Sporozoa

Sarcosporidia, order of subclass Acnidosporidia

Mastigophora, class of subphylum Plasmodroma

Flagellata (syn. Mastigophora)

Zoomastigina, subclass of Mastigophora

Protomonadina, order of subclass Zoomastigina

Trypanosomatidae

Herpetomonadidae (syn. Trypanosomatidae)

Leishmania braziliensis

Leishmania donovani

Leishmania tropica

Trypanosoma brucei

Trypanosoma cruzi

Trypanosoma evansi

Trypanosoma gambiense

Trypanosoma rhodesiense

Trypanosoma equiperdum

Trypanosoma hippicum
14101028

14101029

$1410102 \mathrm{~A}$

$1410102 \mathrm{~B}$

$1410102 \mathrm{C}$

$1410102 \mathrm{D}$

$1410102 \mathrm{E}$

1410103

142

142

142

14201

1420101

14201021

14201021

14201022

14201023

14201024

14201025

14201026

14201027

14201028

14201029

$1420102 \mathrm{~A}$

$1420102 B$

14202

14202011

14

143

143

14301

14301011

14301012

144

144

144

14401

144

14402

14403

14403011

145

146
Trypanosoma lewisi

Trypanosoma theileri

Trypanosoma venezuelense

Trypanosoma congolense

Trypanosoma vivax

Trypanosoma duttoni

Trypanosoma equinum

Phytomonas sp.

Polymastigina, order of subclass Zoomastigina

Monomonadina, suborder of Polymastigina

Monozoa (syn. Monomonadina)

Trichomonadidae, family of suborder Monomonadina

Pentatrichomonas sp.

Trichomonas foetus

Tritrichomonas foetus (syn. Trichomonas foetus)

Trichomonas hominis

Trichomonas elongata

Trichomonas vaginalis

Trichomonas suis

Trichomonas canistomae

Trichomonas ruminantium

Trichomonas felistomae

Trichomonas eberthi

Trichomonas anseri

Trichomonas gallinae

Chilomastigidae, family of

suborder Monomonadina

Chilomastix mesneli

Phytomastigina, subclass of

Mastigophora

Euglenoidina, order of subclass Phytomastigina

Euglenida (syn. Euglenoidina)

Euglenidae

Euglena viridis

Euglena gracilis

Dinoflagellata, order of subclass Phytomastigina

Peridiniinae, suborder of

Dinoflagellata

Peridinoidae, tribe of suborder Peridiníinae

Peridinidae, family of tribe Peridinioidae

Gymnodinioidae, tribe of suborder Peridiniinae

Blastodinidae, family of tribe Gymnodinioidae

Noctilucidae, family of tribe Gymnodinioidae

Noctiluca scintillans

Hypermastigina, order of subclass Zoomastigina

Rhizomastigina, order of subclass Zoomastigina 
FIELD E; Taxonomy Code Columns 18, 19, 20, 21, $22,23,24$, and 25

146

147

14701

14701011

14701021

15

15

150
Pantastomatida

(syn. Rhizomastigina)

Phytomonadina, order of subclass Phytomastigina

Chlamydomonadidae, family of Phytomonadina

Chlorogonium teragamum

Chlamydomonas eugametos

Suctoria, class of subphylum Ciliophora

Acineta (syn. Suctoria)

(Familial organization into orders unknown for Suctoria)

3

3

31

311

311

311

311

31101

3110101

31101021

311

311

311

Porifera

Sponges

Calcispongiae

Calcarea (syn. Calcispongiae)

Homocoela

Asconosa (syn. Homocoela)

Leucosolenidae

Leucosolenia sp.

Heterocoela

Scyconosa (syn. Heterocoela)

Grantildae

Grantia sp.

Sciphidae

Sycon raphanus

Demospongiae

Monaxonida, subclass of

Demospongiae

Hadromerina, order of subclass

Monaxonida

Clionidae

Cliona celata

Haplosclerina, order of subclass

Monaxonida

Spongillidae

Spongilla sp.

Keratosa, subclass of

Demospongiae

312

313

314

315

315

32

32

321

322

33

33

33

33

331

331

33

33

332

332
Cnidaria

Coelenterata (syn. Cnidaria)

Hydrozoa

Hydroida

Gymnoblastea, suborder of Hydroida

Anthomedusae (syn. Gymnoblastea), suborder of Hydroida

Athecata (syn. Gymnoblastea), suborder of Hydroida

Hydridae, family of suborder Gymnoblastea

Hydra sp.

Pelmatohydra oligactis

Calyptoblastea, suborder of Hydroida

Leptomedusae (syn. Calyptoblastea), suborder of Hydroida

Thecaphora (syn. Calyptoblastea), suborder of Hydroida

312 Trachylina

313 and 314 Hydrocorallina (order, includes

Trachymedusae, suborder of Trachylina

Milleporina

Mllleporina plus Stylasterina)
Stylasterina

Siphonophora

Physophorida, suborder of Siphonophora

Scyphozoa

Jellyfishes

Semaeostomeae

Rhizostomeae

Anthozoa

Alcyonaria, subclass of Anthozoa

Octocorallia (syn. Alcyonaria)

Soft corals (Alcyonaria)

Pennatulacea

Sea pens (Pennatulacea)

Zoantheria, subclass of Anthozoa

Hexacorallia (Syn. Zoantheria), subclass of Anthozoa

Actiniaria

Sea anemones 
4

4

41

41

41

41

41

41

411

411

41101

41101

41101011

41101011

41102

412

41201

413

413

413

41301

41301011

41301011

41302

41302011

41303

41304

41305

414

414

415

41501
Platyhelminthes

Flat worms

Cestoda, class of Platyhelminthes

Cestoidea, class of Platyhelminthes (equiv. of Cestoda)

Cestodaria, subclass of Cestoda or of Cestoidea

Eucestoda, subclass of class Cestoda

Cestoda (equiv. of Eucestoda), subclass of Cestoidea

Tapeworms

Pseudophyllidea, order of subclass Eucestoda of class Cestoda

Bothriocephaloidea, superfamily of order Pseudophyllidea

Diphyllobothriidae, family of order Pseudophyllidea (or of superfamily

Bothriocephaloidea)

Dibothriocephalidae (syn. Diphyllobothriidae)

Diphyllobothrium latum

Dibothriocephalus latus (syn. Diphyllobothrium latum)

Ptychobothriidae, family of order Pseudophyllidea (or of superfamily Bothriocephaloidea)

Tetraphyllidea, order of subclass Eucestoda of class Cestoda (or order of subclass

Cestoda)

Phyllobothriidae

Cyclophyllidea, order of subclass Eucestoda of class Cestoda (or order of subclass Cestoda)

Taenioidea (syn. of order Cyclophyllidea)

Taenioidea, superfamily of order Cyclophyllidea (equiv. of Taenioidea, order of Euces toda)

Taeniidae, family of order Cyclophyllidea (or of superfamily Taenioidea)

Taenia saginata

Cysticercus bovis (larva of Taenia saginata)

Davaineidae, family of order Cyclophyllidea (or of superfamily Taenioidea)

Raillietina cesticillus

Dilepididae, family of order Cyclophyllidea (or of superfamily Taenioidea)

Hymenolepididae, family of order Cyclophyllidea (or of superfamily Taenioidea)

Anoplocephalidae, family of order Cyclophyllidea (or of superfamily Taenioidea)

Trypanorhyncha, order of subclass Eucestoda of class Cestoda (or order of subclass Cestoda)

Tetrarhynchoidea (syn. Trypanorhyncha)

Diphyllidea, order of subclass Eucestoda of class Cestoda (or order of subclass

Cestoda)

Echinobothriidae

The following code symbols for Trematoda are based on a single scheme, marked by (1). Included, however, are certain other commonly encountered names of groups in which the Trematoda have been classified by other schemes, marked by $(0)$ and $(\mathrm{X})$.

42

42

42

42

42

Trematoda, class of Platyhelminthes

(1) (0) Digenea, subclass of class Trematoda

(X) Digenea, order of class Trematoda. (When Digenea is treated by the author as an order, it is equivalent to the combination of the five orders as listed here, Symbols $421,422,423,424$, and 425 and equivalent to Digenea as a subclass, Symbol 42.)

(1) Anepitheliocystidia, superorder of subclass Digenea

(X) Prosostomata, a suborder of order Digenea. (The suborder was conceived to include all digenetic families except Bucephalidae. Since in this list, the Bucephalidae are not separated into a distinct suborder, but are included with the order Strigeatoidea, Prosostomata here is essentially equivalent to Digenea, Symbol 42.)

(0) Prosostomata, an order of subclass Digenea. (Equivalent to Prosostomata as a suborder of order Digenea and equivalent to Digenea minus Bucephalidae.) 
(0) Distomata*, a suborder of order Prosostomata. Not recognized in the scheme used here in which "distome" Digenea are in each of the five orders recognized by Symbols 421,422,423,424, and 425, except that the Strigeata, Symbol 422, have ordinarily been considered separate from "Distomata". A reference to a "distome trematode" can be coded only as Symbol 42 .

421 (0) Monostomata*, a suborder of order Prosostomata. Not recognized in the scheme used for code symbols here. Examples of "monostome" Digenea are in the superfamily Notocotyloidea, Symbol 421.

421 (0) Amphistomata*, a suborder of order Prosostomata. Not recognized in this scheme in which "amphistome" families are included under superfamily Paramphistomatoidea, Symbol 421.

(0) Fascioloidea, superfamily of suborder Distomata. The superfamily Fascioloidea is not recognized in this scheme in which its families are included in the superfamily Echinostcmatoidea, Symbol 421.

421 (1) Echinostomida, order of superorder Anepitheliocystidia

421 (1) Echinostomata, suborder of superorder Echinostomida

421 (1) Echinostomatoidea, superfamily of suborder Echinostomata

42101 (1) Echinostomatidae, family of superfamily Echinostomatoidea

42102 (1) (0) Fasciolidae, family of superfamily Echinostomatoidea (or of superfamily Fascioloidea)

$42102011 \quad$ Fasciola hepatica

$42102011 \quad$ Liver fluke

421 (1) Paramphistomata, suborder of order Echinostomida

421 (1) Paramphistomatoidea, superfamily of suborder Paramphistomata

421 (1) Notocotyloidea, superfamily of suborder Paramphistomata

422 (1) Strigeatoidea, order of superorder Anepitheliocystidia

422 (1) Strigeata, a suborder of order Strigeatoidea

422 (0) Strigeata, a suborder of order Prosostomata. (Equivalent to Strigeata as a suborder of order Strigeatoidea, Symbol 422.)

422

(1) Schistosomatoidea, superfamily of suborder Strigeata

42201

42201011

(1) Schistosomatidae, family of superfamily Schistosomatoidea

Schistosoma mansoni

42201012 Schistosoma japonicum

42201013 Schistosoma haematobium

$42201021 \quad$ Schistosomatium douthitti

422 (1) Brachylaimata, suborder of order Strigeatoidea

422 (1) Bucephaloidea, superfamily of suborder Brachylaimata

422 (X) Gasterostomata, suborder of order Digenea. The suborder accommodated the single family Bucephalidae which is considered in this scheme as a member of order Strigeatoidea, Symbol 422.

422

(0) Gasterostomata, order of subclass Digenea. (Equivalent to Gasterostomata as a suborder of order Digenea. )

423 (1) Renicolida, order of superorder Anepitheliocystidia

42

(1) Epitheliocystidia, superorder of subclass Digenea

424

424

424

424

(1) Opisthorchiida, order of superorder Epitheliocystidia

(1) Opisthorchiata, suborder of order Opisthorchiida

(1) Opisthorchioidea, superfamily of suborder Opisthorchiata

(0) Opisthorchioidea, superfamily of suborder Distomata. (Distomata is not recognized in this scheme.) (Equivalent to Opisthorchioidea, Symbol 424, superfamily of suborder Opis thorchiata.)

42401 (1) Opisthorchildae, family of superfamily Opisthorchioidea

42401011

42401021

425

Clonorchis sinensis

Heterophyes heterophyes

(1) Plagiorchidda, order of superorder Epitheliocystidia

* The terms, monostome, amphistome, distome, holostome, echinostome, etc. , are commonly used as convenient designations of the distinctive forms of adult digenetic trematodes. However, this characteristic of the adult has long been abandoned as a major or strict taxonomic criterion and the groups designated as Monostomata, Amphistomata, and Distomata are therefore no longer generally accepted as valid. Any of these designations must be coded by the symbol for its nearest equivalent, as indicated in the list above. 
FIELD E; Taxonomy Code

Columns 18, 19, 20, 21, $22,23,24$, and 25

425 (1) Plagiorchiata, suborder of order Plagiorchiida

425 (1) Troglotrematoidea, superfamily of suborder Plagiorchiata

$425(0)$ Troglotrematoidea, superfamily of suborder Distomata. (Distomata is not recognized in this scheme.) (Equivalent to Troglotrematoidea, Symbol 425, superfamily of suborder Plagiorchiata.)

42561 (1) Troglotrematidae, family of superfamily Troglotrematoidea. (In the present scheme, provisionally placed in superfamily Allocreadioidea. )

$42501011 \quad$ Paragonimus westermanii

$42501012 \quad$ Paragonimus kellicotti

425 (1) Plagiorchioidea, superfamily of suborder Plagiorchiata

425 (1) Plagiorchioidea, superfamily of suborder Distomata. (Distomata is not recognized in this scheme.) (Equivalent to Plagiorchioidea, Symbol 425, superfamily of suborder Plagiorchiata.)

42502

42502011

(1) Dicrocoeliidae, family of superfamily Plagiorchioidea

42502011

42

Dicrocoelium dendriticum

Lancet fluke

42

(1) Monogenea, subclass of class Trematoda

(X) Monogenea, order of class Trematoda (equivalent to Monogenea as a subclass of Trematoda, Symbol 42)

(1) Monopisthocotylea, order of subclass Monogenea

426

(X) Monopisthocotylea, suborder of order Monogenea (equivalent to Monopisthocotylea, order of subclass Monogenea)

(1) Capsaloidea, superfamily of order Monopisthocotylea

(X) Capsaloidea, superfamily of suborder Monopisthocotylea (equivalent to Capsaloidea, superfamily of order Monopisthocotylea)

42601 Capsalidae, family of superfamily Capsaloidea

426

426

(1) Gyrodactyloidea, superfamily of order Monopisthocotylea

(X) Gyrodactyloidea, superfamily of suborder Monopisthocotylea (equivalent to Gyrodactyloidea, superfamily of order Monopis thocotylea)

42602 Gyrodactylidae, family of superfamily Gyrodactyloidea

427

(1) Polyopisthocotylea, order of subclass Monogenea

(X) Polyopisthocotylea, suborder of order Monogenea (equivalent to Polyopisthocotylea, order of subclass Monogenea)

427

(1) Polystomatoidea, superfamily of order Polyopisthocotylea

(X) Polystomatoidea, superfamily of suborder Polyopisthocotylea (equivalent to Polystomatoidea, superfamily of order Polyopisthocotylea)

42701

42701

42701

Polystomatidae, family of superfamily Polystomatoidea

Polystomatinae, subfamily of Polystomatidae

Sphyranurinae, subfamily of Polystomatidae

$428 *$

428

(1) Aspidobothria*, subclass of class Trematoda (equivalent of Aspidobothria, order of class Trematoda)

(X) Aspidobothria, order of class Trematoda (equivalent to Aspidobothria, subclass of class Trematoda)

428

42801

4280101

42802

43

43

431

431

431

43101

Aspidogastrea, subclass (or order) of class Trematoda (synonym for Aspidobothria)

Aspidogastridae, family of subclass (or order) Aspidobothria

Aspidogaster sp.

Stichocotylidae, family of subclass (or order) Aspidobothria

Turbellaria, class of Platyhelminthes

Flatworms, free living

Tricladida, order of Turbellaria

Paludicola, suborder of Tricladida

Probursalia (syn. Paludicola)

Planariidae

* Although code symbols follow the scheme marked by (1), the scheme would omit the division of this subclass into orders, but would divide it into families. By adhering strictly to rules for forming $\mathrm{CBCC}$ taxonomy symbols, the third digit would need to be 0 , indicating that there were no orders, merely because the division of the class was into subclasses rather than orders. Under these circumstances, the code symbol reflects the category between the class and the family, regardless of whether it is designated as subclass or order. 


\section{1 \\ 4310102 \\ 4310102 \\ 43101021 \\ 43101021}

432

432

432

43201

5

5

5

5

51

51

511

511

511

511

511

51101

51102

51103

51103011

51103021

51103031

51103031

51103031

51104

51104011

51104012

51104013

511

51105

51105011

51105011

51105012
Planaria sp.

Dugesia sp.

Euplanaria sp. (syn. Dugesia)

Dugesia dorotocephala

Planaria dorotocephala

(syn. Dugesia dorotocephala)

Polycladida

Acotylea, suborder of Polycladida

Schematommata, section of

Acotylea

Leptoplanidae, family of section Schematommata

Nematoda (excludes Rotifera, Gastrotricha, Kinorhyncha, and Nematomorpha)

Nemathelminthes (to include

Rotifera, Gastrotricha,

Kinorhyncha, Nematoda, and Nematomorpha)

Aschelminthes

(syn. Nemathelminthes)

Round worms

Secernentea, class of phylum Nematoda

Phasmidia (syn. Secernentea)

Rhabditida, order of class Secernentea

Rhabditina, suborder of order Rhabditida

Anguillulata (syn. Rhabditina)

Rhabditoidea, superfamily of suborder Rhabditina

Anguillulinoidea (equiv. of Rhabditida)

Diplogasteridae, family of superfamily Rhabditoidea

Rhabditidae, family of superfamily Rhabditoidea

Cephalobidae, family of superfamily Rhabditoidea

Panagrolaimus subelongatus

Panagrellus redivivus

Turbatrix aceti

Anguillula aceti

(syn. Turbatrix aceti)

Vinegar eel

Strongyloididae, family of superfamily Rhabditoidea

Strongyloides stercoralis

Strongyloides papillosus

Strongyloides ratti

Tylenchoidea, superfamily of suborder Rhabditina

Tylenchidae, family of superfamily Tylenchoidea

Meloidogyne marioni

Heterodera radicicola

(syn. Meloidogyne marioni)

Meloidogyne incognita
51105021

51105022

51105031

51105031

51105041

5110505

51105061

51106

51106011

511

511

51107

51107011

51107011

51107021

51107021

51107031

51107041

51108

51108011

51108011

51108021

51108021

51108022

51108022

51108021

51109

51109011

511

51110

51110011

511

51111

51111011

511

511

51112

51112011

51112021

51112021

51112031

51112041
Heterodera schachtii

Heterodera rostochiensis

Pathoaphelenchoides ritzemabosi

Aphelenchoides ritzemabosi

(syn. Pathoaphelenchoides

ritzemabosi)

Pratylenchus pratensis

Ditylenchus sp.

Paraphelenchus pseudoparietinus

Steinernematidae, family of superfamily Rhabditoidea

Neoaplectana glaseri

Strongylina, suborder of order

Rhabditida

Strongyloidea, superfamily of suborder Strongylina

Strongylidae, family of superfamily Strongyloidea

Ternidens deminutus

Tridontophorus déminutus

(syn. Ternidens deminutus)

Oesophagostomum radiatum

Bosicola radiatum (syn.

Oesophagostomum radiatum)

Chabertia ovina

Strongylus equinus

Ancylostomatidae, family of superfamily Strongyloidea

Necator americanus

Hookworm, human

Ancylostoma duodenale

Hookworm, human

Ancylostoma caninum

Hookworm, dog

Bunostomum phlebotomum

Syngamidae, family of

superfamily Strongyloidea

Syngamus laryngeus

Trichostrongyloidea, superfamily of suborder Strongylina

Trichostrongylidae, family of superfamily Trichostrongyloidea

Haemonchus contortus

Metastrongyloidea, superfamily of suborder Strongylina

Metastrongylidae, family of superfamily Metastrongyloidea

Metastrongylus elongatus

Oxyurina, suborder of order

Rhabditıda

Oxyuroidea, superfamily of suborder Oxyurina

Oxyuridae, family of superfamily Oxyuroidea

Oxyuris equi

Enterobius vermicularis

Oxyuris vermicularis

(syn. Enterobius vermicularis)

Syphacia obvelata

Aspiculuris tetraptera 
5111204

511

511

51113

51114

51114011

51114011

51115

51115011

51115021

51115021

512

512

512

51201

51202

51202011

51202011

51202021

51202022

51202031

51202041

51202041

51202051

512

51203

51204

512

512

51205

51205011

51205011

52

52

521

521

521
Pinworm, mouse

521

Ascaridina, suborder of order Rhabditida

52101

Ascaridoidea, superfamily of suborder Ascaridina

Kathlaniidae, family of superfamily Ascaridoidea

Heterakidae, family of superfamily Ascaridoidea

Heterakis gallinarum

Heterakis gallinae (syn. Heterakis gallinarum)

Ascarididae, family of superfamily Ascaridoidea

Ascaris lumbricoides

Parascaris equorum

Ascaris megalocephala

(syn. Parascaris equorum)

Spirurida

Spirurina, suborder of order Spirurida

Filarioidea, superfamily of suborder Spirurina

Filaridae, family of superfamily Filarioidea

Acanthocheilonematidae, family of superfamily Filarioidea

Wuchereria bancrofti

Filaria bancrofti (syn.

Wuchereria bancrofti)

Dirofilaria immitis

Dirofilaria repens

Litomosoides carini

Loa loa

Eye worm

Onchocerca volvulus

Spiruroidea, superfamily of suborder Spirurina

Spiruridae, family of superfamily Spiruroidea

Gnathostomatidae, family of superfamily Spiruroidea

Camallanina, suborder of order Spirurida

Dracunculoidea, superfamily of suborder Camallanina

Dracunculidae, family of superfamily Dracunculoidea

Dracunculus medinensis

Guinea worm

Adenophorea, class of phylum Nematoda

Aphasmidia (syn. Adenophorea)

Enoplida, order of class

Adenophorea

Dorylaimina, suborder of order Enoplida

Trichinelloidea, superfamily of suborder Dorylaimina
52101011

52101011

52102

52102

52102011

52102011

52102011

52102021

52102021

521

521

52103

52103011

B

$\mathrm{Bl}$

Bl1

B1 100011

C

C

Cl

Cl1

C1101

C 1102

C1 102011

$\mathrm{C} 2$

C3

D

E

E

$D$ and $E$

6

6

61

61

611

611

61101
Trichuroidea

(syn. Trichinelloidea)

Trichinellidae, family of superfamily Trichinelloidea

Trichinella spiralis

Trichina spiralis

(syn. Trichinella spiralis)

Trichuridae, family of superfamily Trichuroidea

Trichocephalidae

(syn. Trichuridae)

Trichuris trichiura

Trichocephalus trichiurus (syn. Trichuris trichiura)

Whipworm

Trichuris suis

Trichocephalus suis (syn. Trichuris suis)

Dioctophymatina, suborder of order Enoplida

Dioctophymatoidea, superfamily of suborder Dioctophymatina

Dioctophymatidae, family of superfamily Dioctophymatoidea

Dioctophyma renale

Acanthocephala

Metacanthocephala

Archiacanthocephala

Echinorhynchus trutta

Rotatoria

Rotifera (syn. Rotatoria)

Monogononta

Ploima

Notommatidae

Brachionidae

Brachionus calyciflorus

Bdelloidea

Seisonidea

Entoprocta

Bryozoa, phylum excluding

Entoprocta

Ectoprocta (equiv. to Bryozoa, phylum excluding Entoprocta)

Bryozoa, phylum including Entoprocta (obs.)

Echinodermata

Eleutherozoa, subphylum of Echinodermata

Asteroidea, class of subphylum Eleutherozoa

Starfishes

Phanerozonia

Cribellosa, suborder of order Phanerozonia

Porcellanasteridae, family of suborder Cribellosa 
612

61201

61202

61202011

613

61301

61301

61301011

62

621

62101

62101011

63

631

63101

63101011

63101011

63101012

63102

63102011

63103

63103

63103011

63103012

63104

632

63201

63201011

633

63301

63301011

634

64

641

64101

64101

642

6

65

7

71

71

711

711

712

712

71

713
Spinulosa

Asterinidae

Echinasteridae

Henricia sanguinolenta

Forcipulata

Asteriidae

Asteriinae

Asterias forbesi

Ophiuroidea

Ophiurae

Ophiolepididae

Ophiura robusta

Echinoidea

Camarodonta

Toxopneustidae

Lytechinus variegatus

Toxopneustes variegatus

(syn. Lytechinus variegatus)

Lytechinus pictus

Echinometridae

Echinometra lacunter

Strongylocentrotidae

Sea urchins

Strongylocentrotus pulcherrimus

Strongylocentrotus drobachiensis

Echinidae

Clypeastroida

Scutellidae

Echinarachnius parma

Stirodonta

Arbacilidae

Arbacia punctulata

Spatangoida

Holothuroidea

Dendrochirota

Cucumaridae

Sea cucumber

Apoda

Pelmatozoa, subphylum of

Echinodermata

Crinoidea

Mollusca

Amphineura

Aplacophora, subclass of class

Amphineura

Caudofoveata, order of subclass Aplacophora

Chaetodermatina (syn.

Caudofoveata, order of

subclass Aplacophora)

Ventroplicida, order of subclass Aplacophora

Neomeniina (syn. Ventroplicida, order of subclass Aplacophora)

Polyplacophora, subclass of

class Amphineura

Lepidopleurina, order of

subclass Polyplacophora
714

71401

71401011

71402

71402011

72

72

721

722

72201

72201011

72202

72202011

72203

72203011

723

723

72301

72301011

72301011

72

724

725

726

727

728

72

729

72901

7290101

72901021

72901031

72901041

72902

72902011

72902021

72902021

72902022

72902022

7290203

72902041

72902051
Chitonina, order of subclass Polyplacophora

Ischnochitonidae

Chaetopleura opiculata

Chitonidae

Chiton tuberculatus

Gastropoda

Prosobranchia, subclass of class Gastropoda

Archaeogastropoda, order of subclass Prosobranchia

Mesogastropoda, order of subclass Prosobranchia

Calyptraeidae

Crepidula plana

Littorinidae

Littorina litorea

Hydrobiidae

Oncomelania quadrasi

Neogastropoda, order of subclass Prosobranchia

Stenoglossa (syn. Neogastropoda, order of subclass Prosobranchia)

Buccinidae

Busycon canaliculatum

Fulgar canaliculatum

(syn. Busycon canaliculatum)

Opisthobranchia, subclass of Gastropoda

Tectibranchia, order of subclass Opisthobranchia

Pteropoda, order of subclass Opisthobranchia

Sacoglossa, order of subclass Opisthobranchia

Acoela, order of subclass

Opisthobranchia

Ditremata, order of subclass

Opisthobranchia

Pulmonata, subclass of class Gastropoda

Basommatophora, order of subclass Pulmonata

Planorbidae

Planorbis sp.

Australorbis glabratus

Bulinus sp.

Biomphalaria boissyi

Lymnaeidae

Lymnaea stagnalis

Stagnicola bulimoides

Lymnaea bulimoides

(syn. Stagnicola bulimoides)

Stagnicola cubensis

Fossaria cubensis

(syn. Stagnicola cubensis)

Galba sp.

Fossaria ollula

Pseudosuccinea columella 
FIELD E; Taxonomy Code

Columns 18, 19, 20, 21,

$22,23,24$, and 25

72903

7290301

$72 \mathrm{~A}$

$72 \mathrm{AO} 1$

$72 \mathrm{~A} 01011$

$72 \mathrm{~A} 01012$

$72 \mathrm{~A} 01021$

$72 \mathrm{~A} 01021$

$72 \mathrm{A0} 2$

$72 \mathrm{~A} 02011$

$72 \mathrm{~A} 02021$

$72 \mathrm{~A} 02031$

$72 \mathrm{A0} 3$

$72 \mathrm{~A} 03011$

73

731

732

732

732

73201

73201011

73201011

73201021

73202

73202011

73203

7320301

733

733

733

733

733

73301

73301011

73301011

73302

73302011

73303

7330301

7330302
Physidae

Physa sp.

Stylommatophora, order of subclass Pulmonata

Helicidae

Helix aspersa

Helix pomatia

Cepea nemoralis

Helix nemoralis (syn. Cepea nemoralis)

Limacidae

Limax maximus

Deroceras reticulatum

Milax gagates

Testacellidae

Testacella haliotidea

Pelecypoda

Protobranchia, order of class Pelecypoda

Filibranchia, order of class Pelecypoda

Taxodonta, suborder of order

Filibranchia

Anisomyaria, suborder of orcer

Filibranchia

Ostreidae, family of suborder

Anisomyaria

Crassostrea virginica

Ostrea virginica

(syn. Crassostrea virginica)

Ostrea lurida

Mytilidae, family of suborder

Anisomyaria

Mytilus edulis

Pectinidae, family of suborder

Anisomyaria

Pecten sp.

Eulamellibranchia, order of class Pelecypoda

Schizodonta, suborder of order Eulamellibranchia

Heterodonta, suborder of order Eulamellibranchia

Adapedonta, suborder of order Eulamellibranchia

Anomalodesmacea, suborder of order Eulamellibranchia

Veneridae, family of suborder Heterodonta

Mercenaria mercenaria

Venus mercenaria

(syn. Mercenaria mercenaria)

Myidae, family of suborder

Adapedonta

Mya arenaria

Teredinidae, family of suborder Adapedonta

Teredo sp.

Bankia sp.
73304

73304011

73304021

73304022

73305

73305011

74

74

741

741

74101

74101011

74

743

743

743

74301

74301011

74301012

74301013

744

744

744

74401

7440101

742

74201

74201011

74201012

8

8

81,83 , and 84

81 and 82

81

81
Unionidae, family of suborder Schizodonta

Lamellidens marginalis

Anodonta cataracta

Anodonta fluvialis

Solenidae, family of suborder Adapedonta

Ensis directus

Cephalopoda

Tetrabranchiata, subclass of Cephalopoda

Nautiloidea, order of subclass Tetrabranchiata

Nautilida, suborder of order Nautiloidea

Nautilidae, family of suborder Nautilida

Nautilus pompilius

Dibranchiata, subclass of Cephalopoda

Teuthoidea, order of subclass Dibranchiata

Myopsida, suborder of order Teuthoidea

Oegopsida, suborder of order Teuthoidea

Loliginidae, family of suborder Myopsida

Loligo pealii

Loligo opalescens

Loligo vulgaris

Octopoda, order of subclass Dibranchiata

Cirromorpha, suborder of order Octopoda

Incirrata, suborder of order Octopoda

Octopodidae, family of suborder Incirrata

Octopus sp.

Sepioidea, order of subclass Dibranchiata

\section{Sepiidae}

Sepia officinalis

Sepia cultrata

Annelicia

Annulata (syn. Annelida)

Chaetopoda, class of Annelida (equals Archiannelida plus Oligochaeta and Polychaeta, classes of Annelida)

Clitellata, class of Annelida (equals classes Oligochaeta and Hirudinea)

Oligochaeta, class of Annelida

Oligochaeta, subclass of class Clitellata 
811,812 and 813

811

811

81101

81101

81101011

812

81201

81201011

813

82

82

821

821

82101

82101

82101011

822

83

83

831 to 836

831

83101

832

832

832

83201

83

833

833

833

83301
Oligochaeta, order of Chaetopoda (equals orders Opisthopora,

Plesiopara, and Prosopora)

Opisthopora, order of class Oligochaeta

Opisthopora, suborder of order Oligochaeta

Lumbricidae, family of order Opisthopora

Earthworms

Lumbricus terrestris

Plesiopora, order of class Oligochaeta or suborder of order Oligochaeta

Tubificidae

Tubifex tubifex

Prosopora, order of class

Oligochaeta or suborder of order Oligochaeta

Hirudinea, class of phylum Annelida or subclass of class Chaetopoda

Leeches

Arhynchobdellida (syn. Gnathobdellida)

Gnathobdellida (syn. Arhynchobdellida)

Hirudidae

Gnathobdellidae

(syn. Hirudidae)

Hirudo medicinalis

Rhynchobdellida, order of class

Hirudinea

Polychaeta, class of Annelida

Errantia, subclass of class

Polychaeta

Polychaeta, order of Chaetopoda (equals all other orders listed of class Polychaeta)

Amphinomorpha, order of subclass Errantia

Amphinomidae

Nereimorpha (syn. Nereidiformia), order of subclass Errantia

Nereidiformia (syn. Nereimorpha), order of subclass Errantia

Nereidiformia, suborder of order Polychaeta

Aphroditidae, family of order

Nereimorpha

Sedentaria, subclass of class Polychaeta

Spiomorpha (syn. Spioniformia), order of subclass Sedentaria

Spioniformia (syn. Spiomorpha), order of subclass Sedentaria

Spioniformia, suborder of order Polychaeta

Ariciidae, family of order Spioniformia
836

\section{F}

Fl

F11

F1101

F1101011

F1101021

F1102

G

$\mathrm{H}$

9

91

91

91

91

912

91201

91201011
Drilomorpha

(syn. Capitelliformia), order of subclass Sedentaria

Capitelliformia

(syn. Drilomorpha), order of subclass Sedentaria

Capitelliformia, suborder of order Polychaeta

Cirratulidae, family of order Drilomorpha

Terebellomorpha (syn. Terebelliformia), order of subclass Sedentaria

Terebelliformia

(syn. Terebellomorpha), order of subclass Sedentaria

Terebelliformia, suborder of order Polychaeta

Serpulimorpha (syn. Sabelliformia), order of subclass Sedentaria

Sabelliformia (syn. Serpulimorpha), order of Sedentaria

Sabelliformia, suborder of order Polychaeta

Sabellariidae, family of order Serpulimorpha

Archiannelida, class of Annelida

Archiannelida (no acceptable organization into orders in 1957)

Polygordiidae

Echiuroidea

Echiurida

Echiuroinea

Echiuridae

Echiurus pallasii

Urechis caupo

Bonelliidae

Sipunculidoidea

Priapulidoidea

Arthropoda

Crustacea

Branchiopoda, subclass of class Crustacea

Eubranchiopoda, superorder of subclass Branchiopoda

Anostraca, order of subclass Branchiopoda (or order of Eubranchiopoda)

Oligobranchiopoda, superorder of subclass Branchiopoda

Cladocera, order of subclass Branchiopoda (or order of Oligobranchiopoda)

Daphnidae

Daphnia pulex 
91

91

913

91301

91301011

91

91

91

914

91401

91402

91403

91404

91405

91406

91407

91408

91409

9140901

91

915

915

91501

916

916

91601

9160101

92

92

921

922

922

92201

92201011

923
Phyllopoda (syn. Branchiopoda or syn. Eubranchiopoda)

Cirripedia, subclass of class Crustacea

Thoracica, order of subclass Cirripedia

Balanidae

Balanus tintinnabulum

Malacostraca, subclass of class Crustacea

Eumalacostraca, series of subclass Malacostraca

Eucarida, superorder of subclass Malacostraca (and superorder of series Eumalacostraca)

Decapoda, order of subclass Malacostraca (and order of superorder Eucarida)

Homaridae

Hippidae

Cancridae

Portunidae

Ocypodidae

Majidae

Palaemonidae

Palinuridae

Astacidae

Cambarus sp.

Peracarida, superorder of subclass Malacostraca (and superorder of series Eumalacostraca)

Isopoda, order of subclass Malacostraca (and order of superorder Peracarida of series Eumalacostraca)

Asellota, suborder of order Isopoda

Asellidae, family of suborder Asellota of order Isopoda

Amphipoda, order of subclass Malacostraca (and order of superorder Peracarida of series Eumalacostraca)

Gammaridea, suborder of order Amphipoda

Gammaridae, family of suborder Gammaridea of order Amphipoda

Gammarus sp.

Arachnida

Arachnoidea (syn. Arachnida)

Xiphosura, order of class Arachnida

Araneida, order of class Arachnida

Araneae (syn. Araneida)

Theridiidae

Latrodectus mactans

Acarina, order of class Arachnida
923

92301

92301011

92301021

92301031

92301041

92301042

92301043

92302

92302011

92302011

92302012

92302013

(92302014)

(92302015)

92302016

92302016

92302017

92302021

92302021

92302022

92302022

92302031

923

92303

92303011

9230302

92303031

92303041

92304

92304011

923

92305

9230501

923

92306

92306011

92306021

923

92307

923

92308
Ixodoidea, superfamily of order Acarina

Ixodidae, family of superfamily Ixodoidea

Dermacentor variabilis

Rhipicephalus sanguineus

Amblyomma americanum

Boöphilus annalatus

Boöphilus australis

Boöphilus decoloratus

Tetranychidae

Tetranychus telarius

Tetranychus althaeae

(syn. of T. telarius)

Tetranychus pacificus

Tetranychus bimaculatus

(Available for Tetranychus sp.)

(Available for Tetranychus sp.)

Tetranychus cinnabarinus

Tetranychus multisetis

(syn. Tetranychus cinnabarinus)

Tetranychus atlanticus

Metatetranychus pilosus

Paratetranychus pilosus

(syn. Metatetranychus pilosus)

Metatetranychus citri

Paratetranychus citri

(syn. Metatetranychus citri)

Eotetranychus sexmaculatus

Trombidioidea, superfamily of order Acarina

Trombidiidae, family of superfamily Trombidioidea

Eutrombicula alfreddugesi

Hannemania sp.

Trombicula acuscutellaris

Acariscus masoni

Argasidae, family of superfamily Ixodoidea

Argas persicus

Sarcoptoidea, superfamily of order Acarina

Sarcoptidae, family of superfamily Sarcoptoidea

Knemidokoptes sp.

Parasitoidea, superfamily of order Acarina

Dermanyssidae, family of superfamily Parasitoidea

Dermanyssus gallinae

Ornithonyssus bacoti

Acaroidea, superfamily of order Acarina

Acaridae, family of superfamily Acaroidea

Tarsonemoidea, superfamily of order Acarina

Tarsonemidae, family of superfamily Tarsonemoidea 
FIELD E; Taxonomy Code Columns 18, 19, 20, 21. $22,23,24$, and 25

92309

92309011

923

92310

923

92311

92312

9231201

9231202

92312031

93

931

932

933

934

93401

93401011

93401021

93402

93402

93402

9340201

93402011

93402012

93402013

93402014

9340202

93402021

93402

9340203

93402031

935

936

93601

93602

93603

93603011

93604

9360402

937

938

939

$93 \mathrm{~A}$

$93 \mathrm{~B}$
Laelaptoidea, superfamily of order Acarina

Laelaptidae, family of superfamily Laelaptoidea

Echinolaelaps echidninus

Analgesoidea, superfamily of order Acarina

Analgesidae, family of superfamily Analgesoidea

Hydrachnae, superfamily of order Acarina

Hydrachnidae, family of superfamily Hydrachnae

Eriophyoidea, superfamily of order Acarina

Eriophyidae, family of superfamily Eriophyoidea

Eriophyes sp.

Phyllocoptes sp.

Aceria sheldoni

Insecta

Protura

Thysanura

Collembola

Orthoptera

Blattidae

Periplaneta americana

Blattella germanica

Locustidae (not in current valid use)

Acrididae (syn. Locustidae)

Cyrtacanthacridinae, subfamily of Acrididae

Melanoplus, genus of subfamily Gyrtacanthacridinae

Melanoplus femur-rubrum

Melanoplus bivittatus

Melanoplus mexicanus

Melanoplus differentialis

Locusta, genus of subfamily Oedipodinae

Locusta migratoria

Oedipodinae, subfamily of Locustidae

Camnula, genus of subfamily Oedipodinae

Camnula pellucida

Zoraptera

Isoptera

Mastotermitidae

Kalotermitidae

Hodotermitidae

Zootermopsis nevadensis

Rhinotermitidae

Reticulitermes sp.

Neuroptera

Ephemeroptera

Odonata

Plecoptera

Psocoptera
$93 \mathrm{C}$

$93 \mathrm{D}$

$93 \mathrm{E}$

$93 \mathrm{E}$

$93 \mathrm{E} 01$

$93 \mathrm{E} 01011$

$93 \mathrm{E} 01021$

$93 \mathrm{E} 01031$

$93 \mathrm{E} 01041$

$93 \mathrm{~F}$

$93 \mathrm{~F} 01$

$93 \mathrm{~F} 01011$

$93 \mathrm{G}$

$93 \mathrm{GOl}$

$93 \mathrm{GO} 1$

93G01011

$93 \mathrm{G} 01011$

$93 \mathrm{G} 01012$

$93 \mathrm{G} 01021$

93G01031

$93 \mathrm{GOl} 041$

$93 \mathrm{G} 01051$

$93 \mathrm{G} 02$

$93 \mathrm{G} 02011$

$93 \mathrm{G} 02012$

93G02021

$93 \mathrm{G} 02022$

$93 \mathrm{G} 02023$

93G02024

$93 \mathrm{G} 02025$

$93 \mathrm{G} 02026$

$93 \mathrm{G} 02031$

$93 \mathrm{G} 03$

93G03011

$93 \mathrm{G} 03012$

93G03013

93G03014

93G0302

93G03031

93G03041

93G04

93G04011

93G0402 I

93G0403 I

$93 \mathrm{G} 05$

93G06

$93 \mathrm{G} 07$

$93 \mathrm{G} 08$

$93 \mathrm{G} 08011$

93G0802 1

$93 \mathrm{H}$

$93 \mathrm{Hol}$

$93 \mathrm{H} 02$

$93 \mathrm{H} 0201 \mathrm{l}$

$93 \mathrm{H} 03$

$93 \mathrm{HO} 4$

$93 \mathrm{H} 04011$
Mallophaga

Embioptera

Thysanoptera

Terebrantia, suborder of order Thysanoptera

Thripidae, family of suborder Terebrantia

Heliothrips haemorrhoidalis

Thrips tabaci

Anaphothrips obscurus

Frankliniella fusca

Anoplura

Pediculidae

Pediculus humanus humanus

Homoptera

Cicadellidae

Jassidae (syn. Cicadellidae)

Empoasca fabae

Potato leaf hopper, Apple leaf hopper

Empoasca abrupta

Erythroneura elegantula

Circulifer tenellus

Macrosteles divisus

Idiocerus pistacioe

Aphidae

Aphis gossypii

Aphis spiraecola

Macrosiphum solanifolii

Macrosiphum pisi

Macrosiphum gei

Macrosiphum onobrychidis

Macrosiphum rosae

Macrosiphum ambrosiae

Brevicoryne brassicae

Coccidae

Pseudococcus citri

Pseudococcus maritimus

Pseudococcus comstocki

Pseudococcus njalensis

Myzodes sp.

Lecanium corni

Aonidiella aurantii

Cercopidae

Aphrophora saratogensis

Philaenus leucophthalmus

Clastoptera achatina

Membracidae

Aleyrodidae

Cicadidae

Psyllidae

Psylla pyricola

Paratrioza cockerelli

Hemiptera

Miridae

Gimicidae

Cimex lectularius

Reduviidae

Coreidae

Anasa tristis 
FIELD E; Taxonomy Code

Columns 18, 19, 20, 21,

$22,23,24$, and 25

\section{H05 \\ $93 \mathrm{H} 06$ \\ $93 \mathrm{H} 0601 \mathrm{I}$ \\ $93 \mathrm{H} 06021$ \\ $93 \mathrm{H} 06031$ \\ $93 \mathrm{HO} 07$ \\ $93 \mathrm{H} 070 \mathrm{II}$ \\ $93 \mathrm{H} 07012$ \\ $93 \mathrm{H} 0702$ \\ $93 \mathrm{H} 0703$ \\ $93 \mathrm{H} 07041$ \\ $93 \mathrm{H} 08$ \\ $93 \mathrm{H} 09$ \\ $93 \mathrm{H} 10$ \\ $93 \mathrm{H} 100 \mathrm{Il}$ \\ $93 \mathrm{~J}$ \\ $93 \mathrm{J01}$ \\ $93 \mathrm{J01011}$ \\ 93501021 \\ 93501031 \\ $93 \mathrm{~J} 01041$ \\ 93J01051 \\ $93 \mathrm{~J} 01052$ \\ $93 \mathrm{~J} 01061$ \\ $93 J 01071$ \\ $93 \mathrm{J01081}$ \\ $93 J 01091$ \\ $93 J 01092$ \\ $93 \mathrm{~J} 01093$ \\ $93 \mathrm{J01094}$ \\ 93J01095 \\ $93 J 01096$ \\ 93501101 \\ 93501111 \\ 93501121 \\ $93 \mathrm{J02}$ \\ 93502011 \\ 93502012}

93J02013

$93 \mathrm{~J} 02021$

$93 \mathrm{J03}$

$93 \mathrm{J03011}$

$93 \mathrm{~J} 03021$

$93 J 03031$

93J03041

93J0305

93J04

93J04011

93J04021

93504031

93J04041

93J04051

93J0406 I

93J04071

$93 J 04071$

93504072

$93 \mathrm{~J} 04081$

93504091
Tingidae

Lygaeidae

Blissus leucopterus

Nysius ericae

Oncopeltus fasciatus

Nabidae

Nabis alternatus

Nabis ferus

Pagasa

Prostemma

Geocoris punctipes

Pentatomidae

Pyrrhocoridae

Anthocoridae

Orius insidiosus

Coleoptera

Chrysomelidae

Chrysomela lapponica

Diabrotica vittata

Leptinotarsa decemlineata

Galerucella xanthomelaena

Altica chalybea

Altica ambiens

Crioceris asparagi

Lema melanopa

Phyllotreta vittata

Epitrix cucumeris

Epitrix fuscula

Epitrix hirtipennis

Epitrix parvula

Epitrix subcrinita

Epitrix tuberis

Paria canella

Phaedon cochleariae

Gastrophysa cyanea

Tenebrionidae

Tribolium madens

Tribolium castaneum

(syn. Tribolium ferrugineum)

Tribolium confusum

Tenebrio molitor

Coccinellidae

Epilachna varivestis

Adalia bipunctata

Hippodamia convergens

Ceratomegilla fuscilabris

Scymnus sp.

Curculionidae

Anthonomus grandis

Rhynchites bicolor

Cylas formicarius elegantulus

Hypera postica

Conotrachelus nenuphar

Sitona cylindricollis

Sitophilus granarius

Calandra granaria

(syn. Sitophilus granarius)

Sitophilus oryza

Brachyrhinus ovatus

Plssodes strobi
$93 \mathrm{~J} 0410$

$93 \mathrm{~J} 04111$

$93 \mathrm{~J} 04121$

93504131

93J04141

$93 J 04141$

$93 J 05$

93505011

$93 J 05021$

93J05031

$93 J 06$

93J06011

93J0602 I

93J0603 I

$93 J 07$

93507011

9350702

93J07031

93J07041

$93 \mathrm{J0} 8$

93J09

93510

$93 \mathrm{J11}$

$93 \mathrm{J1} 1011$

$93 J 12$

$93 J 13$

$93 J 14$

$93 \sqrt{15011}$

$93 \mathrm{~J} 15021$

$93 \mathrm{~K}$

93L

$93 \mathrm{M}$

$93 \mathrm{~N}$

$93 \mathrm{NO} 1$

$93 \mathrm{NO} 01011^{\circ}$

$93 \mathrm{NO} 1021$

$93 \mathrm{~N} 0103 \mathrm{I}$

$93 \mathrm{~N} 0103 \mathrm{I}$

93 N01041

$93 \mathrm{~N} 0105 \mathrm{I}$

93N0105I

93 N0I06I

$93 \mathrm{~N} 01061$

$93 \mathrm{~N} 01062$

$93 \mathrm{~N} 02$

$93 \mathrm{NO} 3$

$93 \mathrm{~N} 03011$

$93 \mathrm{~N} 03021$

$93 \mathrm{No} 4$

93 N05

93 N05

$93 \mathrm{~N} 05011$

93 N05011

$93 \mathrm{~N} 05021$

$93 \mathrm{~N} 05022$
Calendra sp.

Ceutorhynchus assimilis

Sciobius granosus

Listroderes costirostris obliquus

Graphognathus leucoloma

Pantomorus leucoloma

(syn. Graphognathus leucoloma)

Bruchidae

Acanthoscelides obtectus

Bruchus brachialis

Callosobruchus maculatus

Anobiidae

Anobium punctatum

Stegobium peniceum

Lasioderma serricorne

Scarabaeidae

Anomala orientalis

Phyllophaga sp.

Macrodactylus subspinosus

Popillia japonica

Dermestidae

Byturidae

Scolytidae

Meloidae

Epicauta lemniscata

Cucujidae

Elateridae

Lyctidae

Rhizopertha dominica

Dinoderus minutus

Strepsipera

Mecoptera

Trichoptera

Lepidoptera

Olethreutidae

Carpocapsa pomonella

Evetria comstockiana

Lobesia viteana

Polychrosis viteana

(syn. Lobesia viteana)

Spilonota ocellana

Cydia pomonella

Carpocapsa pomonella

(syn. Cydia pomonella)

Grapholitha molesta

Laspeyresia molesta

(syn. Grapholitha molesta)

Grapholitha packardi

Pieridae

Arctiidae

Hyphantria cunea

Estigmene acrea

Pyralidae

Noctuidae

Phalaenidae (syn. Noctuidae)

Psecidaletia unipuncta

Cirphis unipuncta

(syn. Pseudaletia unipuncta)

Heliothis armigera

Heliothis zea 
93N05031

93N05041

$93 \mathrm{~N} 05051$

$93 \mathrm{~N} 05052$

93 N05053

$93 N 05061$

$93 \mathrm{~N} 0507$

93N05081

$93 \mathrm{~N} 05082$

93 N05091

$93 \mathrm{~N} 05101$

$93 \mathrm{~N} 05111$

93 N05121

$93 \mathrm{~N} 05131$

93 N05141

$93 \mathrm{~N} 05$ I 5

93N05161

$93 \mathrm{~N} 05171$

$93 \mathrm{~N} 05181$

93 N05181

93 N06

93 N07

$93 \mathrm{~N} 08$

$93 \mathrm{~N} 08011$

93 N09

$93 \mathrm{~N} 10$

$93 \mathrm{~N} 11$

$93 \mathrm{~N} 12$

$93 \mathrm{~N} 13$

$93 \mathrm{~N} 14$

$93 N 14$

$93 N 15$

$93 \mathrm{~N} 16$

$93 \mathrm{~N} 17$

$93 \mathrm{~N} 18$

$93 N 19$

$93 \mathrm{~N} 20$

$93 \mathrm{~N} 21$

$93 N 21011$

$93 \mathrm{~N} 22$

$93 \mathrm{~N} 23$

$93 \mathrm{~N} 23011$

$93 \mathrm{~N} 24$

$93 \mathrm{~N} 24011$

$93 N 24021$

$93 \mathrm{~N} 24031$

$93 \mathrm{~N} 24041$

$93 \mathrm{~N} 24041$

$93 \mathrm{~N} 24051$

$93 \mathrm{~N} 24061$

$93 \mathrm{~N} 2407 \mathrm{I}$

93 N24072

93 N24081

$93 \varnothing$

$93 \varnothing 01$

$93 \varnothing 01011$

93001021

$93 \varnothing 01031$
Alabama argillacea

Feltia subterranea

Prodenia litura

Prodenia eridania

Prodenia ornithogalli

Ceramica picta

Caenurgina erechtea

Laphygma exigua

Laphygma frugiperda

Mamestra brassicae

Peridroma margaritosa

Trichoplusia ni

Agrotis orthogonia

Anticarsia gemmatalis

Crymodes devastator

Aramisa sp.

Euxoa messoria

Hypena humuli

Pseudoplusia rogationis

Pseudoplusia includens

(syn. Pseudoplusia rogationis)

Bombycidae

Tineidae

Plutellidae

Plutella maculipennis

Gelechiidae

Tortricidae

Citheroniidae

Notodontidae

Gracilariidae

Lymantriidae

Liparidae (syn. Lymantriidae)

Hyponemeutidae

Lasiocampidae

Aegeriidae

Sphingidae

Psychidae

Geometridae

Hesperiidae

Urbenus proteus

Saturniidae

Dioptidae

Phryganidia californica

Pyraustidae

Pyrausta nubilalis

Hymenia recurvalis

Pachyzancla bipunctalis

Udea rubigalis

Phlyctaenia rubigalis

(syn. Udea rubigalis)

Hellula undalis

Loxostege similalis

Diaphania hyalinata

Diaphania nitidalis

Evergestis rimosalis

Diptera

Calliphoridae

Phormia regina

Calliphora augur

Chrysomyia macellaria
$93 \varnothing 0104$

$93 \varnothing 01051$

$93 \varnothing 01061$

$93 \varnothing 02$

$93 \varnothing 02011$

$93 \varnothing 02012$

$93 \varnothing 02013$

$93 \varnothing 02014$

$93 \varnothing 02015$

93002016

$93 \varnothing 02017$

$93 \varnothing 02021$

$93 \varnothing 02031$

$93 \varnothing 02032$

$93 \varnothing 02033$

$93 \varnothing 02034$

$93 \varnothing 02035$

$93 \varnothing 02036$

$93 \varnothing 02037$

$93 \varnothing 02041$

$93 \varnothing 02042$

$93 \varnothing 02042$

$93 \varnothing 02043$

$93 \varnothing 02044$

$93 \varnothing 02045$

$93 \not 003$

$93 \varnothing 03011$

$93 \varnothing 03021$

$93 \varnothing 0303$

$93 \varnothing 03041$

$93 \varnothing 0305$

$93 \varnothing 0305$

$93 \varnothing 0306$

$93 \varnothing 03071$

$93 \varnothing 03072$

$93 \varnothing 04$

$93 \varnothing 04$

$93 \varnothing 04011$

$93 \varnothing 04021$

$93 \varnothing 04022$

$93 \varnothing 04023$

$93 \varnothing 05$

$93 \varnothing 05011$

$93 \varnothing 06$

$93 \varnothing 07$

$93 \varnothing 08$

$93 \varnothing 09$

$93 \varnothing 10$

$93 \varnothing 11$

$93 \varnothing 11$

$93 \varnothing 12$

$93 \varnothing 12$

$93 \varnothing 1201$

$93 \varnothing 1201$

93012021

$93 \varnothing 12021$
Rhinia sp.

Lucilia caesar

Callitroga americana

Culicidae

Aedes aegypti

Aedes sollicitans

Aedes taeniorhynchus

Aedes communis

Aedes excrucians

Aedes pionips

Aedes trivittatus

Mansonia fasciolata

Anopheles quadrimaculatus

Anopheles gambiae

Anopheles pseudopunctipennis

Anopheles albimanus

Anopheles aztecus

Anopheles claviger

Anopheles farauti

Culex pipiens

Culex quinquefasciatus

Culex fatigans

(syn. Culex quinquefasciatus)

Culex apicalis

Culex bitaeniorhynchus

Culex erraticus

Muscidae

Stomoxys calcitrans

Musca domestica

Anthomya sp.

Chrysomyia megacephala

Haematobia irritans

Siphona irritans

(syn. Haematobia irritans)

Muscina stabulans

Glossina morsitans

Glossina palpalis

Tephritidae

Trypetidae (syn. Tephritidae)

Rhagoletis pomonella

Dacus oleae

Dacus ferrugineus

Dacus dorsalis

Drosophilidae

Drosophila melanogaster

Tabanidae

Agromyzidae

Acroceridae

Asilidae

Hippoboscidae

Itonididae

Cecidomyiidae (syn. Itonididae)

Tendipedidae

Chironomidae (syn. Tendipedidae)

Tendipes sp.

Chironomus (syn. Tendipes)

Hydrobaenus stercorarius

Smittia stercorarius

(syn. Hydrobaenus stercorarius) 
FIELD E; Taxonomy Code

Columns 18, 19, 20, 21,

$22,23,24$, and 25

$93 \emptyset 12021$

$93 \varnothing 1203$

$93 \varnothing 12041$

$93 \varnothing 12042$

93012042

$93 \varnothing 12051$

$93 \varnothing 12051$

$93 \not 12061$

93013

$93 \varnothing 14$

$93 \varnothing 14$

$93 \varnothing 14$

$93 \varnothing 1401$

$93 \varnothing 14021$

$93 \varnothing 14022$

$93 \emptyset 14022$

$93 \varnothing 1403$

$93 \emptyset 1404$

$93 \varnothing 14051$

$93 \varnothing 14061$

$93 \varnothing 14061$

$93 \varnothing 14071$

$93 \varnothing 14071$

$93 \varnothing 1408$

$93 \varnothing 1409$

$93 \varnothing 1410$

$93 \varnothing 1411$

$93 \varnothing 1412$

$93 \varnothing 14131$

$93 \varnothing 14132$

$93 \varnothing 15$

$93 \varnothing 16$

$93 \varnothing 17$

$93 \varnothing 17$

$93 \emptyset 18$

$93 \varnothing 19$

$93 \varnothing 20$

$93 \varnothing 21$

$93 \varnothing 22$

$93 \not 23$

$93 \not 23011$

$93 \varnothing 23021$

$93 \varnothing 23021$

$93 \varnothing 2303$

$93 \emptyset 23041$

$93 \varnothing 23042$

93023043

$93 \emptyset 23044$

$93 \varnothing 23045$

$93 \varnothing 23046$

$93 \not 23047$
Camptocladius byssinus $93 \mathrm{P}$

(syn. Hydrobaenus stercorarius) 93P0l

Cricotopus trifasciatus

Procladius pusillus

Procladius culiciformis

Protenthes culiciformis

(syn. Procladius culiciformis)

Pentaneura carnea

Tanypus carneus

(syn. Pentaneura carnea)

Tanytarsus obediens

Chaoboridae

$93 \mathrm{P} 0101$

$93 \mathrm{P} 01012$

$93 \mathrm{P} 01021$

$93 Q$

93Q0 1

93Q01011

$93 \mathrm{Q} 02$

$93 \mathrm{Q} 03$

$93 \mathrm{Q} 0303$

$93 \mathrm{Q} 04$

$93 \mathrm{Q} 05$

93Q06

Ceratogonidae (syn. Heleidae)

Ceratopogonidae (syn. Heleidae)

93Q07

93Q08

93Q08011

94

95

96

(syn. Bezzia glabra)
Siphonaptera

Pulicidae

Ctenocephalides canis

Ctenocephalides felis

Xenopsylla cheopis

Hymenoptera

Apidae

Apis mellifera

Tenthredinidae

Braconidae

Habrobracon sp.

Formicidae

Vespidae

Ichneumonidae

Cephidae

Chalcididae

Eurytoma pistaciae

Symphyla

Chilopoda

Diplopoda
Atrichopogon

Palpomyia

Forcipomyia cilipes

Dicrohelea argentata

Johannesenomyia argentata

(syn. Dicrohelea argentata)

Sphaeromias longipennis

Palpomyia longipennis

(syn. Sphaeromias longipennis)

Leptoconops sp.

Lasiohelea sp.

Stilobezzia

Macropeza

Monohelea

Culicoides nubeculosus

Culicoides tristriatulus

Chloropidae

Gasterophilidae

Fungivoridae

Mycetophilidae

(syn. Fungivoridae)

Oestridae

Piophilidae

Psilidae

Psychodidae

Sarcophagidae

Simuliidae

Austrosimulium bancrofti

Cnephia dacotensis

Eusimulium lascivum

(syn. Cnephia dacotensis)

Prosimulium hirtipes

Simulium damnosum

Simulium metallicum

Simulium ochraceum

Simulium ornatum

Simulium venustum

Simulium vittatum

Simulium downsi 


\section{PROTOCHORDATA AND VERTEBRATA}

THROUGH PISCES

The list of lower Chordata has presented a particular difficulty. It has been decided finally to arrange a selected number of group and intergroup names, each accompanied with a note of its taxonomic status relative to the superior group of which it is a member. The thread of more than one taxonomic scheme can be traced through the list, therefore, by examination of the definitions of the items. Regardless of the multiplicity of schemes that are represented by the many taxonomic names, the basic scheme that has been followed in assigning code symbols (for fishes) is that of Berg. 1 The others are more or less "obsolete" schemes, yet they include names and organizations encountered frequently enough to justify their inclusion.

A supplemental guide to the taxonomic relationships is provided by the parenthetical numbers and letters immediately preceding the name: all those items designated by the same parenthetical figure represent a single classification scheme. (In general, the scheme according to Berg is marked $\overline{\text { by [2]. ) }}$

In the following list, any group name which does not represent a category assigned it in the taxonomic scheme of Berg has been assigned a symbol--as far as possible--on the basis of that group's equivalent in Berg's scheme; for example, Hyperoartia, which has been described as an order of a class, Marsipobranchii, (in a scheme now probably considered "obsolete", designated as the "X" series), has been assigned Code Symbol Al on the basis of the fact that its equivalent (as recognized in this list) is a class, Petromyzones.

A

A

A

A

A

A

A

A

A

A

A

A

A.

A

A

A

A

A

A

A

A

A

(1, 0, T, X) Chordata, phylum (equals phylum Vertebrata plus Hemichordata and Tunicata)

(1) Protochordata (syn. Prochordata), division of phylum Chordata (equals Tunicata plus Leptocardii and Hemichordata)

(1) Prochordata (syn. Protochordata), division of phylum Chordata (equals Tunicata plus Leptocardii and Hemichordata)

(1) Tunicata, sub-division of division Protochordata

(1) Leptocardii, sub-division of division Protochordata

(1) Hemichordata, sub-division of division Protochordata

(1) Enteropneusta (syn. Hemichordata)

(1) Adelochorda (syn. Hemichordata)

(0) Tunicata, subphylum of phylum Chordata

( 1 or 0$)$ Urochordata (syn. Tunicata, subdivision or subphylum)

(0) Leptocardii, subphylum of phylum Chordata (equals division Acrania)

(T) Acrania (syn. Cephalochordata), (excluding Hemichordata and Tunicata) division of phylum Chordata

(T) Cephalochordata (syn. division Acrania excluding Hemichordata and Tunicata), division of phylum Chordata

( 1 and T) Vertebrata (syn. division Craniata), division of phylum Chordata

(l and T) Craniata (syn. division Vertebrata), division of phylum Chordata

(0) Vertebrata (syn. subphylum Craniata), subphylum of phylum Chordata

(0) Craniata (syn. subphylum Vertebrata), subphylum of phylum Chordata

(2) Vertebrata, phylum

(2) Acrania, subphylum of phylum Vertebrata

(2) Cephalochordata (syn. Acrania, subphylum of phylum Vertebrata)

(2) Leptocardii (syn. Acrania, subphylum of phylum Vertebrata)

(X) Leptocardii, class of phylum Chordata (equals Leptocardii, subphylum of phylum Vertebrata)

${ }^{1}$ Classification of Fishes Both Recent and Fossil; Leo S. Berg; 1940: English and Russian Edition, 1947, J. W. Edwards, Ann Arbor, Michigan. 
A

A

A

A

A

A

A

$A 1$ and $A 2$

$A 1$ and $A 2$

$A 1$ and $A 2$ $A 1$ and $A 2$

$A 1$ and $A 2$

$A 1$ and $A 2$

A1

Al

Al

A 12

Al 2

A 1201

A1201

A1201011

A2

A2

A2 1

A2

A2 1

A2 1

A

A

A

A.

AA

AA

AA

AA

AA

AA

$A A$

AA

AA (x) Myelozoa (syn. Leptocardii, class of phylum Chordata) (equals Leptocardii, subphylum of phylum Vertebrata)

(2) Craniata, subphylum of phylum Vertebrata

(2) Anamnia, sub-subphylum of subphylum Craniata

(1) Anamnia, subdivision of division Craniata (equals Anamnia, sub-subphylum of subphylum Craniata)

(1) Pisces, superclass of subdivision Anamnia

(2) Agnatha, superclass of sub-subphylum Anamnia

(1) Agnatha, class of superclass Pisces (equals Agnatha, superclass of sub-subphylum Anamnia)

(1) Cephalaspidomorphi, subclass of superclass Pisces

(1) Cyclostomata, order of subclass Cephalaspidomorphi (equals Cyclostomata, class of superclass Agnatha)

(2) Cyclostomata (syn. Marsipobranchii), class of superclass Agnatha

(2) Marsipobranchii (syn. Cyclostomata, class of superclass Agnatha)

(X) Marsipobranchii, class of phylum Chordata (equals Marsipobranchii, class of superclass Agnatha) (equals Petromyzones plus Myxini, classes of superclass Agnatha)

(X) Cyclostomi (syn. Marsipobranchii, class of Chordata) (equals Marsipobranchii, class of superclass Agnatha) (equals Petromyzones plus Myxini, classes of superclass Agnatha)

(2) Petromyzones, class of superclass Agnatha

(2) Hyperoartii (syn. Petromyzones, class of superclass Agnatha)

(X) Hyperoartia, order of Marsipobranchii, class of Chordata (equals Petromyzones, class of superclass Agnatha)

(2) Petromyzoniformes, order of class Petromyzones

(1) Petromyzontia, suborder of order Cyclostomata (equals Petromyzoniformes, order of class Petromyzones)

(2) Petromyzonidae, family of Petromyzoniformes, order of Petromyzones

(X) Petromyzonidae, family of Hyperoartia, order of Marsipobranchii (equals family Petromyzonidae, family of Petromyzoniformes) Petromyzon marinus

(2) Myxini, class of superclass Agnatha

(2) Hyperotreti (syn. Myxini, class of superclass Agnatha)

(2) Myxiniformes, order of class Myxini

(x) Hyperotreta, order of Marsipobranchii, class of Chordata (equals Myxini, class of superclass Agnatha)

(1) Myxinoidea, suborder of order Cyclostomata (equals Myxiniformes, order of class Myxini)

(1) Hyperotreti (syn. Myxinoidea, suborder of order Cyclostomata) (equals Myxiniformes, order of class Myxini)

(2) Gnathostomata, superclass of sub-subphylum Anamnia

(1) Chondrichthyes, class of superclass Pisces (is included in Gnathostomata, superclass of sub-subphylum Anamnia)

(1) Gnathostomata, class of superclass Pisces (equals class Chondrichthyes plus class Osteichthyes of superclass Pisces) (equals Gnathostomata, superclass of sub- subphylum Anamnia)

(2) Pisces, series of Gnathostomata

(2) Elasmobranchii, class of series Pisces

(1) Elasmobranchii, subclass of class Chondrichthyes (equals Elasmobranchil, class of series Pisces)

(X) Elasmobranchii, class of phylum Chordata (equals Elasmobranchii, class of series Pisces)

( 2 or $\mathrm{X}$ ) Selachii, subclass of class Elasmobranchii

(1) Selachii, order of subclass Elasmobranchii (equals Selachii, subclass of class Elasmobranchii)

(2) Euselachii (syn. Selachii, subclass of class Elasmobranchii)

(2) Plagiostomi (syn. Selachi, subclass of class Elasmobranchii)

(2) Selachoidei, superorder of subclass Selachii

(2) Pleurotremata (syn. Selachoidei, superorder of subclass Selachii) 
(2) Heterodontiformes, order of superorder Selachoidei

(X) Cestraciontes, order of subclass Selachii

(1) Heterodontoidea, suborder of order Selachii (equals Heterodontiformes, order of superorder Selachoidei)

(2) Heterodontoidei, suborder of order Heterodontiformes

(X) Prosarthri, suborder of order Cestraciontes

(2 or 1) Heterodontidae, family of suborder Heterodontoidei or of suborder Heterodontoidea

(X) Heterodontidae, family of suborder Prosarthri (equals Heterodontidae, family of suborder Heterodontoidei)

(2) Hexanchiformes, order of superorder Selachoidei

(2) Hexanchidae, family of order Hexanchiformes

(2) Notidanoidei (syn. Hexanchiformes, order of superorder Selachoidei)

(1) Notidantoidea, suborder of order Selachij (equals Hexanchiformes, order of superorder Selachoidei)

(X) Notidani, order of subclass Selachii

(X) Opistharthri, suborder of order Notidani

(X) Hexanchidae, family of suborder Opistharthri (equals Hexanchidae, family of order Hexanchiformes)

(2) Lamniformes, order of superorder Selachoidei

(2) Galeoidei (syn. Lamniformes, order of superorder Selacnoidei)

(2) Lamnoidei, suborder of order Lamniformes

(2) Lamnidae, family of suborder Lamnoidei

(1) Galeoidea, suborder of order Selachii (equals Lamniformes, order of superorder Selachoidei)

(X) Euselachii, order of subclass Selachii

(X) Galei, suborder of order Euselachii

(X) Lamnoidei, series of suborder Galei

(X) Lamnidae, family of series Lamnoidei (equals family Lamnidae of suborder Lamnoidei)

(2) Squaliformes, order of superorder Selachoidei

(1) Squaloidea, suborder of order Selachii (equals Squaliformes, order of superorder Selachoidei)

(x) Tectospondyli, order of subclass Selachii (syn. Squaliformes, order of superorder Selachoidei)

(2) Squaloidei, suborder of order Squaliformes

(X) Squaloidei, suborder of order Tectospondyli (equals Squaloidei, suborder of order Squaliformes)

(2) Squatinoidei, suborder of order Squaliformes

(X) Squatinoidei, suborder of order Tectospondyli (equals Squatinoidei, suborder of order Squaliformes)

(2) Batoidei, superorder of subclass Selachii

(2) Hypotremata (syn. Batoidei, superorder of subclass Selachii)

(X) Batoidei, order of subclass Selachii (equals Batoidei, superorder of subclass Selachii)

(X) Hypotremata (syn. Batoidea, order of subclass Selachii) (equals Batoidei, superorder of subclass Selachii)

(1) Batoidea, order of subclass Elasmobranchii (equals superorder of subclass Selachii)

(2) Rajiformes, order of superorder Batoidei

(2) Pristidae, family of order Rajiformes

(X) Sarcura, suborder of order Batoidea (plus suborder Masticura equals order Rajiformes)

(X) Pristidae, family of suborder Sarcura (equals Pristidae, family of order Rajiformes)

(X) Masticura, suborder of order Batoidea (plus suborder Sarcura equals order Rajiformes)

(X) Dasyatidae, family of suborder Masticura (equals Trygonidae, family of order Rajiformes)

(2) Torpediniformes, order of superorder Batoidei

(2) Torpedinidae, family of order Torpediniformes

(1) Narcaciontes, suborder of order Batoidea (equals order Torpediniformes) 
FIELD E; Taxonomy Code

Columns 18, 19, 20, 21 ,

$22,23,24$, and 25

AA601 (1) Torpedinidae, family of suborder Narcaciontes (equals Torpedinidae, family of order Torpediniformes)

AB (2) Holocephali, class of series Pisces

AB (1) Holocephali, subclass of class Chondrichthyes (equals Holocephali, class of series Pisces)

$\mathrm{AB}$

(X) Holocephali, subclass of class Elasmobranchii (equals Holocephali, class of series Pisces)

$A B$

(2) Chimaerae, subclass of class Holocephali

$\mathrm{ABl}$

(2) Chimaeriformes, order of subclass Chimaerae

$\mathrm{AB}$

$\mathrm{ABl}$

(1) Chimaerae, order of subclass Holocephali (equals Chimaerae, subclass of class Holocephali)

A

(X) Chimaeroidei, order of subclass Holocephali (equals Chimaeriformes, order of subclass Chimaerae)

(X) Pisces, class of phylum Chordata (equals Pisces, series of superclass Gnathostomata)

$\mathrm{AC}$

$\mathrm{AC}$

A

(2) Dipnoni, class of series Pisces

(2) Dipneusta (syn. Dipnoi, class of series Pisces)

(1) Osteichthyes, class of superclass Pisces (is included in superclass Gnathostomata, of sub-subphylum Anamnia)

A

$\mathrm{AC}$

$A C$

$\mathrm{AC}$

$\mathrm{ACl}$

$\mathrm{AC} 1$

(1) Amphibioidei, subclass of class Osteichthyes (see Osteichthyes)

(1) Dipnoi, order of subclass Amphibioidei (equals Dipnoi, class of series Pisces)

(2) Dipneusta, subclass of class Pisces (equals Dipnoi, class of series Pisces)

(2) Ceratodi, superorder of class Dipnoi

(2) Ceratodiformes, order of superorder Ceratodi

(X) Crossopterygii, subclass of class Pisces (Symbol A3)

(X) Sirenoidei, order of subclass Crossopterygii (equals Ceratodiformes, order of superorder Ceratodi)

A3

A3

A3

A3

A3

A3 1

A3 1

A3 1

(2) Teleostomi, class of series Pisces

(2) Crossopterygii, subclass of class Teleostomi

(X) Crossopterygii, subclass of class Pisces (equals Crossopterygii, subclass of class Teleostomi)

(1) Crossopterygii, order of subclass Amphibioidei (equals Crossopterygii, subclass of class Teleostomi)

(2) Coelancanthi, superorder of subclass Crossopterygii

(2) Coelacanthiformes, order of superorder Coelacanthi

(2) Actinistia (syn. Coelacanthiformes, order of superorder Coelacanthi)

(X) Actinistia, order of subclass Crossopterygii (equals Coelacanthiformes, order of superorder Coelacanthi)

(X) Coelacanthini (syn. Actinistia, order of subclass Crossopterygii) (equals Coelacanthiformes, order of superorder Coelacanthi)

(2) Coelacanthoidei, suborder of order Coelacanthiformes

(1) Coelacanthini, suborder of order Crossopterygii (equals Coelacanthi, superorder of subclass Crossopterygii)

(2) Actinopterygii, subclass of class Teleostomi

(1) Actinopterygii, subclass of class Osteichthyes (equals Actinoperygii, subclass of class Teleostomi)

(1) Chondrostei, superorder of subclass Actinopterygii

(X) Actinopteri, subclass of class Pisces (plus Cladistia equals Teleostomi, class of series Pisces)

(2) Polypteriformes, order of subclass Actinopterygii

(2) Cladistia (syn. Polypteriformes, order of subclass Actinopterygii)

(2) Brachiopterygii (syn. Polypteriformes, order of subclass Actinopterygii)

(X) Cladistia, order of subclass Crossopterygii (equals Polypteriformes, order of subclass Actinopterygii)

(X) Polypteridae, family of order Cladistia (equals Polypteridae, family of order Polypteriformes)

A32 (1) Polypterini, order of superorder Chondrostei (equals Polypteriformes order of subclass Actinopterygii)

(2) Acipenseriformes, order of subclass Actinopterygii (equals order Glaniostomi plus order Selachostomi) 
(1) Acipenseroidei, order of superorder Chondrostei (equals Acipenseriformes, order of subclass Actinopterygii)

A33, A34,

and $\mathrm{A} 35$

A3301

A33

A3301

A3302

A.33

A3302

A3

A3 B

A3 B

A3 B

A3 B

A3 B0 1

$\mathrm{A} 3 \mathrm{C}$

$\mathrm{A} 3 \mathrm{C} 01$

A3

A34

A3 4

A3 4

A3 4

A34

A34

A3 4

A34

A3401

A340 I

A34

A3 4

A34

A3402

A3402011

A3402011

A3402012

A3402012

A3402013

A3 402013

A340202

A3402021

A35

A35

A36

A36

A36

A37

(X) Ganoidei, superorder of subclass Actinopteri

(2) Acipenseridae, family of order Acipenseriformes

(X) Glaniostomi, order of superorder Ganoidei (plus order Selachostomi equals order Acipenseriformes)

(X) Acipenseridae, family of order Glaniostomi (equals Acipenseridae, family of order Acipenseriformes)

(2) Polyodontidae, family of order Acipenseriformes

(X) Selachostomi, order of superorder Ganoidei (plus order Glaniostomi equals order Acipenseriformes)

(X) Polyodontidae, family of order Selachostomi (equals Polyodontidae, family or order Acipenseriformes)

(1) Holostei, superorder of subclass Actinopterygii

(2) Amilformes, order of subclass Actinopterygii

(1) Amioidea, order of superorder Holostei (equals Amiformes, order of subclass Actinopterygii)

(X) Halecomorphi, order of superorder Ganoidei (equals Amilformes, order of subclass Actinopterygii)

(X) Amioidei (syn. Halecomorphi, order of superorder Ganoidei) (equals Amilformes, order of subclass Actinopterygii)

(X) Amiidae, family of order Halecomorphi (equals Amidae, family of order Amiiformes)

(2) Lepidosteiformes, order of subclass Actinopterygii

(2) Lepidosteidae, family of order Lepidosteiformes

( 1 and $X$ ) Teleostei, superorder of subclass Actinopterygii

(2) Clupeiformes, order of subclass Actinopterygii

(2) Isospondyli (syn. Clupeiformes, order of subclass Actinopterygii)

(2) Thrissomorphi (syn. Clupeiformes, order of subclass Actinopterygii)

( 1 and X) Isospondyli, order of superorder Teleostei (equals Clupeiformes, order of subclass Actinopterygii)

(2) Clupeoidei, suborder of order Clupeiformes

(X) Clupeoidei, suborder of order Isospondyli

(1) Clupeoidea, suborder of order Isospondyli (equals Clupeoidei, suborder of order Clupeiformes)

(2) Clupeoidae, superfamily of suborder Clupeoidei

(2) Clupeidae, family of superfamily Clupeoidae

(X) Clupeidae, family of suborder Clupeoidei (equals Clupeidae, family of superfamily Clupeoidae)

(2) Salmonoidei, suborder of order Clupeiformes

(X) Salmonoidei, suborder of order Isospondyli (equals Salmonoidei, suborder of order Clupeiformes)

(1) Salmonoidea, suborder of order Isospondyli (equals Salmonoidei, suborder of order Clupeiformes)

(2) Salmonidae, family of suborder Salmonoidei

Salmo salar

Atlantic salmon

Salmo irideus

Rainbow trout

Salmo trutta

Brown trout

Oncorhynchus nerka

Blue-back salmon

(2) Anguilliformes, order of subclass Actinopterygii

(X) Apodes, order of superorder Teleostei (equals Anguilliformes, order of subclass Actinopterygii)

(2) Mormyriformes, order of subclass Actinopterygii

(2) Scyphophori (syn. Mormyriformes, order of subclass Actinopterygii)

(X) Scyphophori, suborder of order Isospondyli

(2) Cyprinodontiformes, order of subclass Actinopterygii 
FIELD E; Taxonomy Code

Columns 18, 19, 20, 21, $22,23,24$, and 25

A37

A 37

A 3701

A 3701

A 3702

A 3702

A370201I

A38

A39

A3A.

A3A

A3A

A3

A3A

A3A

A3A

$\mathrm{A} 3 \mathrm{~A} 01$

$\mathrm{A} 3 \mathrm{~A} 01$

A $3 \mathrm{~A} 01011$

A3A01021

A $3 A 01021$

A $3 A 01021$

A3A01022

$\mathrm{A} 3 \mathrm{~A} 02$

$\mathrm{A} 3 \mathrm{~A} 02$

A3A02011

A3A02011

$\mathrm{A} 3 \mathrm{~A} 03$

A3A

$\mathrm{A} 3 \mathrm{~A} 03$

A3A03011

A3D

A3E

$\mathrm{A} 3 \mathrm{~F}$

A3G

$\mathrm{A} 3 \mathrm{H}$

$\mathrm{A} 3 \mathrm{H}$

$\mathrm{A} 3 \mathrm{H}$

$\mathrm{A} 3 \mathrm{H}$

$\mathrm{A} 3 \mathrm{H}$

A3HO !

A3HOl

A3 $\mathrm{HOl}_{01}$

A3H0101]

A3 H0l01

A3 $\mathrm{H}$

$\mathrm{A} 3 \mathrm{H}$

$\mathrm{A} 3 \mathrm{H}$

$\mathrm{A} 3 \mathrm{H}$

A3 H

(2) Cyprinodontes (syn. Cyprinodontiformes, order of subclass Actinopterygii)

(X) Cyprinodontes, order of superorder Teleostei

(2) Cyprinodontidae, family of order Cyprinodontiformes

(X) Cyprinodontidae, family of order Cyprinodontes

(2) Poeciliidae, family of order Cyprinodontiformes

(X) Poeciliidae, family of order Cyprinodontes Gambusia affinis

(2) Gasterosteiformes, order of subclass Actinopterygii

(2) Syngnathiformes, order of subclass Actinopterygii

(2) Perciformes, order of subclass Actinopterygii

(2) Acanthopterygii (syn. Perciformes, order of subclass Actinopterygii)

(2) Percomorphi (syn. Perciformes, order of subclass Actinopterygii)

(X) Acanthopterygii, superorder of subclass Actinopterygii

(X) Percomorphi, order of superorder Acanthopterygii

(2) Percoidei, suborder of order Perciformes

(1) Percoidea, suborder of order Acanthopterygii

( 2 or 1 ) Centrarchidae, family of suborder Percoidei or of suborder Percoidea

(X) Centrarchidae, family of order Percomorphi

Chaenobryttus gulosus

Lepomis macrochirus

Helioperca incisor (syn. Lepomis macrochirus)

Bluegill sunfish Lepomis cyanellus

(2 or 1) Percidae, family of suborder Percoidei or of suborder Percoidea

Percidae, family of order Percoidei

Perca flavescens

Yellow perch

(2 or 1) Cichlidae, family of suborder Percoidei or of suborder Percoidea

(X) Chromides, order of superorder Teleostei (included in the suborder Percoidei of the order Perciformes)

(X) Cichlidae, family of order Chromides (equals Cichlidae, family of suborder Percoidei)

Tilapia kafuensis

(2) Ophiocephaliformes, order of subclass Actinopterygii

(2) Symbranchiformes, order of subclass Actinopterygii

(2) Pleuronectiformes, order of subclass Actinopterygii

(2) Mastacembeliformes, order of subclass Actinopterygii

(2) Cypriniformes, order of subclass Actinopterygii

(2) Cyprinoidei, suborder of order Cypriniformes

(2) Eventognathi, suborder of order Cypriniformes (syn. Cyprinoidei, suborder of order Cypriniformes)

(X) Eventognathi, order of superorder Teleostei (equals Eventognathi, suborder of order Cypriniformes)

(1) Ostariophysi, order of superorder Teleostei (included in order Cypriniformes) (Symbol A3H)

(1) Cyprinoidea, suborder of order Ostariophysi (equals Cyprinoidei, suborder of order Cypriniformes)

(2) Cyprinidae, family of suborder Cyprinoidei

(X) Cyprinidae, family of order Eventognathi (equals Cyprinidae, family of suborder Cyprinoidei)

Cyprinidae, family of suborder Cyprinoidea

Carasslus auratus

Goldfish

(1) Ostariophysi, order of superorder Teleostei (included in order Cypriniformes)

(1) Siluroidea, suborder of order Ostariophysi

(2) Siluroidei, suborder of order Cypriniformes

(2) Nematognathi, suborder of order Cypriniformes (syn. Siluroidei, suborder of order Cypriniformes)

(x) Nematognathi, order of superorder Teleostei (equals Nematognathi, suborder of order Cypriniformes) 
FIELD E; Taxonomy Code Columns 18, 19, 20, 21, $22,23,24$, and 25

A3H02 (2) Ameiuridae, family of suborder Siluroidei

A3H02 (X) Ameiuridae, family of order Nematognathii

A3H02 (1) Ameiuridae, family of suborder Siluroidea

A3H02011

A3 302021

$\mathrm{A} 3 \mathrm{H}$

$\mathrm{A} 3 \mathrm{H}$

A3 $\mathrm{HO} 3$

A3H03

A3H03011

A3H03011

A4

A4

A41

A41

A41

A4 101

A4101011

A4101021

A4 I

A4102

A41020 I

A4 1

A4103

A4103011

A41

A41 04

A4104011

A41 104021

A41 04022

A4104022

A4104022

A 42

$\mathrm{A} 42$

A42
Ameiurus nebulosus

Ictalurus punctatus

(2) Gymnotoidei, suborder of order Cypriniformes

(X) Gymnonoti, order of superorder Teleostei (equals Gynotoidei, suborder of order Cypriniformes)

(2) Electrophoridae, family of suborder Gymnotoidei

(X) Electrophoridae, family of order Gymnonoti (equals Electrophoridae, family of suborder Gymnotoidei)

Electrophorus electricus

Electric eel

Amphibia, class of division Craniata

Amphibia, class of phylum Chordata

Caudata, order of class Amphibia

Urodela (syn. Caudata)

Proteidea, suborder of order Caudata

Proteidae, family of suborder Proteidea

Necturus maculosus

Proteus anguinus

Cryptobranchoidea, suborder of order Caudata

Cryptobranchidae, family of suborder Cryptobranchoidea

Cryptobranchus sp.

Ambystomoidea, suborder of order Caudata

Ambystomidae, family of suborder Ambystomoidea

Ambystoma tigrinum

Salamandroidea, suborder of order Caudata

Salamandridae, family of suborder Salamandroidea

Salamandra salamandra

Triton cristatus

Triton taeniatus (syn. Triturus taeniatus)

Triturus taeniatus (syn. Triton taeniatus)

European salamander

Salientia

Anura (syn. Salientia) Anura
Amphicoela, suborder of order
A4201

$\mathrm{A} 42$

$\mathrm{A} 4202$

A4202011

A 4203

A4203011

A42

A4204

A 42

A4205

A4205011

A4205012

A4205013

A4205014

A420501 5

A4206

A4206011

A4206011

A4206012

A4206013

A42

A4207

A4207011

A4207012

A4207013

A4207014

A4207015

A4207016

A4207017

A4208

A4209

A4209011

A 5

A5

A5

A5 1

A 51

A51

A5101

A5101011

A5101021

A5
Liopelmidae, family of order Anura or of suborder Amphicoela

Opisthocoela, suborder of order Anura

Discoglossidae, family of order Anura or of suborder Opis thocoela Alytes obstetricans

Pipidae, family of order Anura or of suborder Opis thocoela

Xenopus laevis

Anomocoela, suborder of order Anura

Pelobatidae, family of order Anura or of suborder Anomocoela

Procoela, suborder of order Anura Bufonidae, family of order Anura or of suborder Procoela

Bufo americanus

Bufo fowleri

Bufo cognatus

Bufo marinus

Bufo bufo

Hylidae, family of order Anura or of suborder Procoela

Hyla crucifer

Hyla pickeringii (syn. Hyla crucifer)

Hyla versicolor

Hyla aborea

Diplasiocoela, suborder of order Anura

Ranidae, family of order Anura or of suborder Diplasiocoela

Rana pipiens

Rana esculenta

Rana aurora

Rana catesbeiana

Rana clamitans

Rana temporaria

Rana sylvatica

Brevicipitidae, family of order Anura or of suborder

Diplasiocoela

Leptodactylidae, family of order Anura or of suborder Procoela

Leptodactylus ocellatus

Reptilia, class of division Craniata

Reptilia, class of phylum Chordata

Archosauria, subclass

Crocodilia, order of subclass Archosauria

Loricata (syn. Crocodilla)

Eusuchia, suborder of order Crocodilia

Crocodilidae, family of suborder Eusuchia

Crocodylus acutus

Alligator mississipiensis

Subclass Lepidosauria 
FIELD E; Taxonomy Code

Columns 18, 19, 20, 21 , $22,23,24$, and 25

A52

A52

A52

A5201

A5201011

A5201011

A5202

A520201

A5203

A.5203011

A 5203021

A520303

A520304

A5204

A5204011

A520402

A520403

A5204041

A5205

A5206

A5207

A.5207011

A5208

A5209

A52 10

A5211

A5212

A.52

A5213

A521301

A521302

A521303

A5214

A.5214011

A.52 \4021

A52 14022

A52 14023

A52 14024

A5214031

A52 15
Squamata, order of subclass Lepidosauria

Lacertilia, suborder of order Squamata

Sauria (syn. Lacertilia), suborder of order Squamata

Helodermatidae, family of suborder Lacertilia

Heloderma suspectum

Gila monster

Chamaeleontidae, family of suborder Lacertilia

Chamaeleon sp.

Iguanidae, family of suborder Lacertilia

Anolis carolinensis

Sceloporus undulatus

Phrynosoma sp.

Iguana sp.

Gekkonidae, family of suborder Lacertilia

Tarentola mauritanica

Phyllodactylus sp.

Hemidactylus sp.

Coleonyx variegatus

Scincidae, family of suborder Lacertilia

Lacertidae, famlly of suborder Lacertilia

Teiidae, famlly of suborder Lacertilia

Cnemidophorus tessellatus

Varanddae, family of suborder Lacertilla

Agamidae, family of suborder Lacertilla

Xantusidae, family of suborder Lacertilia

Amphlsbaenidae, family of suborder Lacertilla

Anguldae, family of suborder Lacertilia

Serpentes, suborder of order Squamata

Viperidae, family of suborder Serpentes (no division into subfamilies)

VIpera sp.

Cerastes sp.

Bitis sp.

Crotalldae, famlly of suborder Serpentes

Bothrops jararaca

Crotalus horrldus

Crotalus viridls

Crotalus atrox

Crotalus cerastes

Agklstrodon mokeson

Elapldae, famlly of suborder Serpentes
A5215011

A5215011

A5216

A5216

A5216011

A521602I

A5217

A5217011

A521702

A5217031

A5217041

A52 17051

A53

A53

A53

A5 3

A5301

A530101

A530102

A530103

A530104

A 5302

A5302011

A5303

A530301

A5303021

A5303022

A5303023

A5303023

A530303 I

A5304

A53040 I

A5305

A 5305011

A5306

A530601

A530602

A5 4

A540 I

A5401011

A6

A6
Naja tripudians

Cobra

Boidae, family of suborder Serpentes

Pythoninae, subfamily of family Boidae

Python reticulatus

Eunectes murinus

Colubridae, family of suborder Serpentes

Natrix sipedon

Thamnophis sp.

Coluber constrictor

Pituophis catenifer

Lampropeltis zonata

Chelonia, order of class Reptilia

Testudinata (syn. Chelonia) (obsolete)

Turtles

Thecophora, suborder of order Chelonia

Testudinidae, family of order Chelonia (or of suborder Thecophora)

Testudo sp.

Terrapene sp.

Graptemys sp.

Gopherus sp.

Chelydridae, family of order

Chelonia (or of suborder Thecophora)

Chelydra serpentina

Emydidae, family of order Chelonia (or of suborder Thecophora)

Emys sp.

Chrysemys picta

Chrysemys picta marginata

Chrysemys picta picta

Eastern painted turtle

Pseudemys elegans

Chelonidae, family of order Chelonia (or of suborder Thecophora)

Chelonia sp.

Trionychidae, family of order Chelonia (or of suborder Thecophora)

Trionyx ferox

Kinosternidae, family of order Chelonia (or of suborder Thecophora)

Kinosternon sp.

Sternotherus $\mathrm{sp}$.

Rhynchocephalia, order of class Reptilia

Sphenodontidae

Sphenodon punctatum

Aves, class of Phylum Chordata

Aves, class of division Crandata 
A6

A6

A6 1

A6101

A6101011

A6 101011

A6102

A6102011

A6102021

A6 103

A610301

A6 104

A6104011

A6

A62

A6201

A6201

A6201011

A63

A6301

A6301

A6301011

A6301011

A6301011

A6301011

A64

A6401

A6401011

A6401011

A6401012

A6401012

A6401021

A6401021

A65

A65

A6501

A6501011

A6501011

A6502

A6502011

A6502011

A6502011

A6 503

A6 504

A6505
Neornithes, subclass of class

Aves

Neognathae, superorder of subclass Neornithes

Galliformes, order of superorder Neognathae

Meleagrididae

Meleagris gallopavo

Wild turkey

Phasianidae

Gallus domesticus

Phasianus torquatus

Tetraonidae

Tympanuchus sp.

Perdicidae

Lophortyx gambelii

Palaeognathae, superorder of subclass Neornithes

Struthioniformes, order of superorder Palaeognathae

Struthionidae

Ostriches

Struthio camelus

Ansertformes, order of

superorder Neognathae

Anatidae

Ducks

Anas platyrhynchos

Anas boschas

Domestic duck

Mallard duck

Columbiformes, order of

superorder Neognathae

Columbidae

Columba llvia

Pigeon

Columba fasciata

Plgeon

Zenaldura macroura

Mourning dove

Passeriformes, order of

superorder Neognathae

Oscines, suborder of order

Passerlformes

Fringillidae, family of

suborder Oscines

Serinus canarius

Canary

Ploceidae, family of suborder Oscines

Passer domesticus

House sparrow

English sparrow

Corvidae, family of suborder

Oscines

Sturnidae, famlly of suborder

Oscines

Icteridae, family of suborder

Oscines
A66

A6601

A6601011

A6601011

A6601012

A6601012

A6602

A6602011

A67

A6701

A6701011

A68

A6801

A6801011

A7

A7

A7

A7

A7

A7

A7 1

A7 I

A7 1

A7 1

A7 101

A7 101

A7 101

A7 101011

A7101011

A7 101012

A7 101013

A7101

A7 101

A7 101021

A7 101022

A7 101031

A7 1

A7 1
Falconiformes, order of superorder Neognathae

Cathartidae

Cathartes aura

Turkey vulture

Cathartes urubu

Vulture

Accipitridae

Buteo regalis

Strigiformes, order of superorder Neognathae

Strigidae

Bubo virginianus pallescens

Charadriformes, order of superorder Neognathae

Laridae

Larus argentatus

Mammalia, class of phylum Chordata

Mammalia, class of division Craniata

Theria, subclass of class Mammalia

Eutheria, infraclass of subclass Theria

Ferungulata, cohort of infraclass Eutheria

Paraxonia, superorder of cohort Ferungulata

Artiodactyla, order of superorder Paraxonia

Ruminantia, suborder of order Artiodactyla

Pecora, infraorder of suborder Ruminantia

Bovoldea, superfamily of infraorder Pecora

Bovidae, family of superfamily Bovoldea

Bovinae, subfamily of family Bovidae

Bovini, tribe of subfamily Bovinae

Bos taurus (subfamily Bovinae)

Domestic cow

Bos sondaicus (subfamily Bovinae)

Bos indicus (subfamily Bovinae)

Caprinae, subfamlly of family Bovidae

Caprind, tribe of subfamlly Caprinae

Ovis musimon (tribe Caprint)

Ovis aries (tribe Caprint)

Capra hircus (tribe Caprini)

Sulformes, suborder of order Artiodactyla

Suina, infraorder of suborder Suiformes 
A71

A7 102

A7 102

A7 102011

A7 102011

A7

A72

A72

A72

A.7201

A7201

A7201011

A7201011

A7201012

A7201013

A7201021

A7201021

A7201021

A720103

A7201041

A7202

A7202

A7202011

A7202021

A7202022

A7203

A7203

A7203011

A7203011

A7203

A720302

A7203

A7203031

A7204

A7204
Suoidea, superfamily of infraorder Suina

Suidae, family of superfamily Suoidea

Sulnae, subfamily of family Suidae

Sus scrofa (subfamily Suinae)

Pigs

Ferae, superorder of cohort

Ferungulata

Carnivora, order of superorder Ferae

Fissipedia, suborder of order Carnivora

Canoidea, superfamily of suborder Fissipedia

Canidae, family of superfamily Canoidea

Caninae, subfamily of family Canidae

Canis familiaris (subfamily Caninae)

Domestic dog

Canis latrans (subfamily Caninae)

Canis nubilis (subfamily Caninae)

Urocyon cinereoargenteus (subfamily Caninae)

Urocyon cinereoargenteus scotti (subfamily Caninae)

Gray fox

Alopex sp.

Vulpes fulva (subfamily Canlnae)

Felidae, family of superfamily Canoidea

Felinae, subfamily of family Felidae

Felis catus (subfamily Felinae)

Lynx rufus baileyi (subfamily Fellnae)

Lynx canadensis (subfamily Felinae)

Mustelidae, famlly of superfamily Canoidea

Mustelinae, subfamily of family Mustelidae

Mustela vison (subfamily Mustelinae)

Mink

Mephitinae, subfamily of family Mustelidae

Mephdtis sp.

Melinae, subfamily of family Mustelidae

Taxidea taxus berlandieri (subfamily Melinae)

Ursldae, family of superfamily Canoidea

Bears
A7204011

A7204011

A72

A7201

A7201

A7201011

A7

A73

A73 plus A77

A73

A73

A73

A7301

A7301

A7301011

A7301

A7301021

A7301022

A73

A73

A7302

A7302

A7302011

A7302012

A7302021

A7302022

A7302022

A73

A7303

A7303

A7303

A730301
Ursus horribills

Grizzly bear

Pinnipedia, suborder of order Carnivora

Phocidae, family of suborder Pinnipedia

Phocinae, subfamily of family Phocidae

Phoca vitulina (subfamily Phocinae)

Glires, cohort of infraclass Eutheria

Rodentia, order of cohort Glires

Rodentia, order of cohort Glires

(inc. suborder Duplicidentata) (obs.)

Sciuromorpha, suborder of order Rodentia A73

Simplicidentata, suborder of Rodentia A73 plus A77 (obs.)

(equals Rodentia A73)

Geomyoidea, superfamlly of suborder Sciuromorpha

Heteromyidae, family of superfamily Geomyoldea

Perognathinae, subfamily of family Heteromyidae

Perognathus inornatus (subfamily Perognathinae)

Dipodomyinae, subfamily of family Heteromyidae

Dipodomys spectabilis (subfamily Dipodomyinae)

Dipodomys merriami (subfamily Dipodominae)

Myomorpha, suborder of order Rodentia A73

Muroidea, superfamily of suborder Myomorpha

Muridae, family of superfamily Muroidea

Murinae, subfamily of family Muridae

Mus musculus (subfamily Murlnae)

Micromys minutus (subfamlly Murinae)

Rattus rattus (subfamily Murinae)

Rattus norvegicus (subfamily Murinae)

Norway rat

Sciuroidea, superfamily of suborder Sciuromorpha

Sciuridae, family of superfamily Sciuroidea

Sciurinae, subfamily of family Sciuridae

Marmotini, trlbe of subfamily Sclurinae

Citellus richardsoni (tribe Marmotini) 
A73

A73

A7304

A.7304

A7304011

A7304011

A73

A7305

A7306

A7306

A7306

A7306011

A7306011

A7306

A.7306021

A7306

A7306

A7306031

A630604

A7306051

A730605

A7306061

A7306061

A73

A7307

A73

A7308

A730801

A7

A74

A74

A74

A7401
Hystricomorpha, suborder of order Rodentia A73

Cavioidea, superfamily of suborder Histricomorpha

Caviidae, family of superfamily

Cavioidea

Caviinae, subfamily of family

Caviidae

Cavia porcellus (subfamily Cavinae)

Guinea pig

Geomyoidea, superfamily of suborder Sciuromorpha

Geomyidae, family of superfamily Geomyoidea

Cricetidae, family of superfamily Muroidea

Cricetinae, subfamily of family Cricetidae

Cricetini, tribe of subfamily Cricetinae

Cricetus cricetus (tribe Cricetini)

Hamster (large European)

Hesperomyini, tribe of subfamily Cricetinae

Neotoma lepida intermedia (trlbe Hesperomyini)

Microtinae, subfamily of famlly Cricetidae

Microtinl, tribe of subfamily Microtinae

Microtus ochrogaster haydeni (tribe Mlcrotini)

Peromyscus sp. (tribe Hesperomyini)

Sigmodon hispidus (tribe Hesperomyini)

Cotton rat

Mesocricetus auratus (tribe Cricetini)

Golden hamster

Erethizontoidea, superfamily of suborder Hystricomorpha

Erethizontidae, family of superfamlly Erethizontoldea

Chinchilloidea, superfamlly of suborder Hystricomorpha

Chinchlllidae, famlly of superfamily Chinchllloldea

Chinchilla sp.

Unguiculata, cohort of infraclass Eutheria

Primates, order of cohort Unguiculata

Anthropoidea, suborder of order Primates

Hominoidea, superfamily of suborder Anthropoidea

Hominidae, family of superfamily Homlnoidea
A7401011

A7 401011

A74

A7 402

A7 402

A740201

A740201

A7 403

A7403

A740301

A7 403

A7 403021

A7 4

A7 4

A7 404

A7 404

A7404012

A7 404013

A7 405

A7 405

A7405011

A7405011

A7

A75

A75

A7 5

A75

A.7501

A7501011

A7501011

A7

A76
Homo sapiens

Man

Ceboidea (syn. Platyrhini), superfamily of suborder

Anthropoidea

Callithricidae, family of superfamily Ceboidea

Hapalidae (syn. Callithricidae)

Calluthrix sp

Hapale sp. (syn. Callithrix sp.)

Cebidae, family of superfamily Ceboidea

Cebinae, subfamily of family Cebidae

Cebus sp. (subfamily Cebinae)

Atelinae, subfamily of family Cebidae

Ateles ater (subfamily Atelinae)

Cercopithecoidea (6yn. Catarrhini), superfamily of suborder Anthropoidea

Catarrhini (equ. Cercopithecoidea plus Hominoidea), superfamily of suborder Anthropoidea

Cercopithecidae, family of superfamily Cercopithecoidea

Cercopithecinae, subfamily of family Cercopithecidae

Macaca mulatta (syn. Macaca rhesus) (subfamily Cercopithecinae)

Macaca philippinensis (subfamily Cercopithecinae)

Pongidae, family of superfamily Hominoidea

Ponginae, subfamily of family Pongidae

Pan troglodytes (subfamily Ponginae)

Anthropopithecus troglodytes (syn. Pan troglodytes)

Mesaxonia, superorder of cohort Ferungulata

Perissodactyla, order of superorder Mesaxonia

Hippomorpha, suborder of order Perlssodactyla

Ceratomorpha, suborder of order Perissodactyla

Equoidea, superfamily of suborder Hippomorpha

Equidae, family of superfamily Equidae

Equus caballus

Horse

Metatheria, infraclass of subclass Theria

Marsupialia, order of infraclass Metatheria 
FIELD E; Taxonomy Code

Columns 18, 19, 20, 21,

$22,23,24$, and 25

\begin{tabular}{|c|c|c|c|}
\hline A76 & $\begin{array}{l}\text { Didelphoidea, superfamily of } \\
\text { order Marsupialia }\end{array}$ & $\mathrm{E}$ & $\begin{array}{l}\text { Ectoprocta (equiv. to Bryozoa, } \\
\text { phylum excluding Entoprocta) }\end{array}$ \\
\hline A7601 & $\begin{array}{l}\text { Didelphidae, family of } \\
\text { superfamily Didelphoidea }\end{array}$ & $\mathrm{D}$ and $\mathrm{E}$ & $\begin{array}{l}\text { Bryozoa, phylum including } \\
\text { Entoprocta (obsolete) }\end{array}$ \\
\hline A7601 & $\begin{array}{l}\text { Didelphinae, subfamily of } \\
\text { family Didelphidae }\end{array}$ & $\mathrm{F}$ & Echiuroidea \\
\hline A7601011 & Didelphis virginianus & F 1 & Echiurida \\
\hline & (subfamily Didelphinae) & F 11 & Echiuroinea \\
\hline $\begin{array}{l}\text { A7601011 } \\
\text { A77 }\end{array}$ & Opossum & F 1101 & Echiuridae \\
\hline A77 & $\begin{array}{l}\text { Lagomorpha, order of cohort } \\
\text { Glires }\end{array}$ & $\begin{array}{l}F 1101011 \\
F 1101021\end{array}$ & $\begin{array}{l}\text { Echiurus pallasii } \\
\text { Urechis caupo }\end{array}$ \\
\hline A77 & $\begin{array}{l}\text { Duplicidentata, suborder of } \\
\text { order Rodentia A73 plus A77 } \\
\text { (obs. ) (equals order } \\
\text { Lagomorpha A77) }\end{array}$ & $\begin{array}{l}\text { F1102 } \\
\text { G }\end{array}$ & $\begin{array}{l}\text { Bonelliidae } \\
\text { Sipunculidoidea }\end{array}$ \\
\hline A7701 & $\begin{array}{l}\text { Leporidae, family of order } \\
\text { Lagomorpha }\end{array}$ & $\mathrm{H}$ & Priapulidoidea \\
\hline A7701 & $\begin{array}{l}\text { Leporinae, subfamily of family } \\
\text { Leporidae }\end{array}$ & J & $\begin{array}{l}\text { Thallophyta (Fungi, Algae and } \\
\text { Bacteria) }\end{array}$ \\
\hline A7701011 & Lepus americanus (subfamily & J9 & Fungi (otherwise unspecified) \\
\hline A7701011 & $\begin{array}{l}\text { Leporinae) } \\
\text { Snowshoe hare }\end{array}$ & $\begin{array}{l}\mathrm{Jl} \\
\mathrm{J} 11\end{array}$ & $\begin{array}{l}\text { Myxothallophyta } \\
\text { Acrasiales }\end{array}$ \\
\hline A7701012 & Lepus campestris (subfamily & J1101 & Dictyosteliaceae \\
\hline & Leporinae) & $\mathrm{J} 110101$ & Dictyostelium \\
\hline A7701012 & Jack rabbit, white-tailed & $\mathrm{J1101011}$ & Dictyostelium discoideum \\
\hline A7701021 & $\begin{array}{l}\text { Oryctolagus cuniculus } \\
\text { (subfamily Leporinae) }\end{array}$ & $\begin{array}{l}\mathrm{J} 12 \\
\mathrm{~J} 13\end{array}$ & $\begin{array}{l}\text { Labyrinthulales } \\
\text { Hydromyxales }\end{array}$ \\
\hline A7701021 & Domestic rabbit & $\mathrm{J} 14$ & Myxomycetes \\
\hline A7701031 & $\begin{array}{l}\text { Sylvilagus auduboni } \\
\text { (subfamily Leporinae) }\end{array}$ & $\mathrm{J} 3$ & $\begin{array}{l}\text { Phycomycetes } \\
\text { Hyphochytriales }\end{array}$ \\
\hline A78 & $\begin{array}{l}\text { Insectivora, order of cohort } \\
\text { Unguiculata }\end{array}$ & $\begin{array}{l}\mathrm{J} 32 \\
\mathrm{~J} 33\end{array}$ & $\begin{array}{l}\text { Chytridiales } \\
\text { Blastocladiales }\end{array}$ \\
\hline A7 8 & $\begin{array}{l}\text { Soricoidea, superfamily of } \\
\text { order Insectivora }\end{array}$ & $\begin{array}{l}\mathrm{J} 34 \\
\mathrm{~J} 35\end{array}$ & $\begin{array}{l}\text { Monoblepharidales } \\
\text { Saprolegniales }\end{array}$ \\
\hline A7 801 & $\begin{array}{l}\text { Talpidae, family of superfamily } \\
\text { Soricoidea }\end{array}$ & $\begin{array}{l}\mathrm{J} 3501 \\
\mathrm{~J} 350101\end{array}$ & $\begin{array}{l}\text { Saprolegniaceae } \\
\text { Aphanomyces }\end{array}$ \\
\hline A7801 & $\begin{array}{l}\text { Talpinae, subfamily of family } \\
\text { Talpidae }\end{array}$ & $\begin{array}{l}\text { J3 } 501011 \\
\text { J36 }\end{array}$ & $\begin{array}{l}\text { Aphanomyces cochlioides } \\
\text { Leptomitales }\end{array}$ \\
\hline A7801011 & $\begin{array}{l}\text { Talpa europaea (subfamily } \\
\text { Talpinae) }\end{array}$ & $\begin{array}{l}\mathrm{J} 37 \\
\mathrm{~J} 38\end{array}$ & $\begin{array}{l}\text { Lagenidiales } \\
\text { Peronosporales }\end{array}$ \\
\hline A7801011 & Mole, European & $\begin{array}{l}\text { J3801 } \\
\text { J380101 }\end{array}$ & $\begin{array}{l}\text { Peronosporaceae } \\
\text { Pythium }\end{array}$ \\
\hline B & Acanthocephala & J3801011 & Pythium ultimum \\
\hline Bl & Metacanthocephala & $\mathrm{J} 3801012$ & Pythium debaryanum \\
\hline B1 1 & Archiacanthocephala & $\mathrm{J} 3801013$ & Pythium aphanidermatum \\
\hline B1100011 & Echlnorhynchus trutta & $\begin{array}{l}\mathrm{J} 380102 \\
\mathrm{~J} 3801021\end{array}$ & $\begin{array}{l}\text { Phytophthora } \\
\text { Phytophthora infestans }\end{array}$ \\
\hline C & Rotatoria & $\mathrm{J} 3801022$ & Phytophthora cinnamomi \\
\hline $\mathrm{C}$ & Rotifera (syn. Rotatorla) & J39 & Mucorales \\
\hline $\mathrm{Cl}$ & Monogononta & $\mathrm{J} 3901$ & Endogonaceae \\
\hline Cl1 & Ploima & $\mathrm{J} 3902$ & Mucoraceae \\
\hline C1101 & Notommatidae & $\mathrm{J} 390201$ & Rhizopus \\
\hline Cl 102 & Brachionidae & $\mathrm{J} 3902011$ & Rhizopus nigricans \\
\hline Cl1 102011 & Brachionus calyciflorus & $\mathrm{J} 390202$ & Phycomyces \\
\hline $\mathrm{C} 2$ & Bdelloidea & J3902021 & Phycomyces blakesleeanus \\
\hline $\mathrm{C} 3$ & Seisonidea & $\begin{array}{l}\text { J390203 } \\
\text { J3902031 }\end{array}$ & $\begin{array}{l}\text { Mucor } \\
\text { Mucor mucedo }\end{array}$ \\
\hline $\mathrm{D}$ & Entoprocta & $\begin{array}{l}\text { J3902032 } \\
\text { J390204 }\end{array}$ & $\begin{array}{l}\text { Mucor piriformis } \\
\text { Absidia }\end{array}$ \\
\hline $\mathbf{E}$ & $\begin{array}{l}\text { Bryozoa, phylum excluding } \\
\text { Entoprocta }\end{array}$ & $\begin{array}{l}\text { J3902041 } \\
\text { J3903 }\end{array}$ & $\begin{array}{l}\text { Absidia glauca } \\
\text { Choanephoraceae }\end{array}$ \\
\hline
\end{tabular}




\begin{tabular}{|c|c|c|c|}
\hline $\mathrm{J} 390301$ & Cunninghamella & $\mathrm{J} 48$ & Erysiphales \\
\hline J3903011 & Cunninghamella elegans & $\mathrm{J} 480 \mathrm{l}$ & Erysiphaceae \\
\hline J3904 & Thamnidiaceae & $\mathrm{J} 480101$ & Erysiphe \\
\hline J390401 & Thamnidium & J4801011 & Erysiphe polygoni \\
\hline J3904011 & Thamnidium elegans & J49 & Hypocreales \\
\hline $\mathrm{J} 3 \mathrm{~A}$ & Entomophthorales & $\mathrm{J} 4901$ & Nectriaceae \\
\hline J3B & Phycomycetes Incertae Sedis & $\mathrm{J} 490101$ & Nectria \\
\hline J4 & Ascomycetes & $\mathrm{J} 4901011$ & Nectria galligena \\
\hline J41 & Endomycetales & J4902 & Hypocreaceae \\
\hline $\mathrm{J} 4101$ & Endomycetaceae & $\mathrm{J} 49020 \mathrm{l}$ & Claviceps \\
\hline $\mathrm{J} 410101$ & Piedraia & J4902011 & Claviceps purpurea \\
\hline $\mathrm{J} 4101011$ & Piedraia sarmontoi & $\mathrm{J} 4 \mathrm{~A}$ & Laboulbeniales \\
\hline $\mathrm{J} 410102$ & Endomyces & $\mathrm{J} 4 \mathrm{~B}$ & Sphaeriales \\
\hline $\mathrm{J} 4101021$ & Endomyces magnusii & $\mathrm{J} 4 \mathrm{BO} 1$ & Chaetomiaceae \\
\hline $\mathrm{J} 410103$ & Eremothecium & $\mathrm{J} 4 \mathrm{~B} 0101$ & Chaetomium \\
\hline $\mathrm{J} 4101031$ & Eremothecium ashbyii & $\mathrm{J} 4 \mathrm{~B} 01011$ & Chaetomium globosum \\
\hline $\mathrm{J} 4102$ & Coccidioideaceae & $\mathrm{J} 4 \mathrm{BO} 1012$ & Chaetomium convolutum \\
\hline $\mathrm{J} 410201$ & Coccidioides & $\mathrm{J} 4 \mathrm{BO} 2$ & Xylariaceae \\
\hline $\mathrm{J} 4102011$ & Coccidioides immitis & J4B0201 & Xylaria \\
\hline $\mathrm{J} 4103$ & Saccharomycetaceae & $\mathrm{J} 4 \mathrm{~B} 02011$ & Xylaria hypoxylon \\
\hline $\mathrm{J} 410301$ & Debaryomyces & $\mathrm{J} 4 \mathrm{~B} 03$ & Sphaeriaceae \\
\hline $\mathrm{J} 4103011$ & Debaryomyces matruchoti & $\mathrm{J} 4 \mathrm{~B} 0301$ & Neurospora \\
\hline $\mathrm{J} 4103012$ & Debaryomyces neoformans & $\mathrm{J} 4 \mathrm{~B} 03011$ & Neurospora crassa \\
\hline $\mathrm{J} 410302$ & Hansenula & $\mathrm{J} 4 \mathrm{~B} 03012$ & Neurospora sitophila \\
\hline $\mathrm{J} 4103021$ & Hansenula anomala & $\mathrm{J} 4 \mathrm{~B} 03013$ & Neurospora tetrasperma \\
\hline $\mathrm{J} 4103022$ & Hansenula saturnus & $\mathrm{J} 4 \mathrm{~B} 04$ & Ceratostomataceae \\
\hline $\mathrm{J} 410303$ & Nematospora & $\mathrm{J} 4 \mathrm{~B} 040 \mathrm{I}$ & Ceratocystis \\
\hline $\mathrm{J} 4103031$ & Nematospora phaseoli & & (syn. Ceratostomella) \\
\hline $\mathrm{J} 410304$ & Pichia & $\mathrm{J} 4 \mathrm{~B} 04011$ & Ceratocystis ulmi \\
\hline J41 03041 & Pichia membranaefaciens & & (syn. Ceratostomella ulmi) \\
\hline $\mathrm{J} 410305$ & Saccharomyces & $\mathrm{J} 4 \mathrm{~B} 04012$ & Ceratocystis fimbriata \\
\hline $\mathrm{J} 4103051$ & Saccharomyces chodati & & (syn. Ceratostomella fimbriata) \\
\hline $\mathrm{J} 4103052$ & Saccharomyces carlsbergensis & $\mathrm{J} 4 \mathrm{~B} 04013$ & Ceratocystis multiannulata \\
\hline $\mathrm{J} 4103053$ & Saccharomyces cerevisiae & & (syn. Ophiostoma multiannulatum) \\
\hline $\mathrm{J} 4103054$ & Saccharomyces ellipsoideus & $\mathrm{J} 4 \mathrm{~B} 05$ & Mycosphaerellaceae \\
\hline $\mathrm{J} 4103055$ & Saccharomyces fragilis & $\mathrm{J} 4 \mathrm{~B} 0501$ & Venturia \\
\hline J4103056 & Saccharomyces lactis & J4B05011 & Venturia inaequalis \\
\hline $\mathrm{J} 4103057$ & Saccharomyces pastorianus & $\mathrm{J} 4 \mathrm{BO} 502$ & Mycosphaerella \\
\hline J410306 & Schizosaccharomyces & J4B05021 & Mycosphaerella tulasni \\
\hline $\mathrm{J} 4103061$ & Schizosaccharomyces pombe & $\mathrm{J} 4 \mathrm{C}$ & Hysteriales \\
\hline $\mathrm{J} 410307$ & Torulaspora & $\mathrm{J} 4 \mathrm{D}$ & Phacidiales \\
\hline $\mathrm{J} 4103071$ & Torulaspora rosei & $\mathrm{J} 4 \mathrm{E}$ & Helotiales \\
\hline $\mathrm{J} 410308$ & Zygosaccharomyces & $\mathrm{J} 4 \mathrm{EO} 1$ & Sclerotiniaceae \\
\hline $\mathrm{J} 4103081$ & Zygosaccharomyces marxianus & $\mathrm{J} 4 \mathrm{E} 0101$ & Monilinia \\
\hline $\mathrm{J} 4103082$ & Zygosaccharomyces mandshuricus & $\mathrm{J} 4 \mathrm{E} 01011$ & Monilinia fructicola \\
\hline $\mathrm{J} 4103083$ & Zygosaccharomyces lactis & & (syn. Sclerotinia fructicola) \\
\hline J41 03084 & Zygosaccharomyces barkeri & $\mathrm{J} 4 \mathrm{E} 01012$ & Monilinia fructigena \\
\hline $\mathrm{J} 410309$ & Saccharomycodes & & (syn. Sclerotinia fructigena) \\
\hline $\mathrm{J} 4103091$ & Saccharomycodes ludwigii & $\mathrm{J} 4 \mathrm{E} 01013$ & Monilinia laxa \\
\hline $\mathrm{J} 410310$ & Endomycopsis & & (syn. Sclerotinia laxa) \\
\hline $\mathrm{J} 4103101$ & Endomycopsis javanensis & $\mathrm{J} 4 \mathrm{E} 0102$ & Sclerotinia \\
\hline $\mathrm{J} 42$ & Taphrinales & $\mathrm{J} 4 \mathrm{E} 01021$ & Sclerotinia sclerotiorum \\
\hline $\mathrm{J} 43$ & Eurotiales & $\mathrm{J} 4 \mathrm{E} 01022$ & Sclerotinia homeocarpa \\
\hline J4301 & Eurotiaceae & $\mathrm{J} 4 \mathrm{~F}$ & Pezizales \\
\hline $\mathrm{J} 430101$ & Thielavia & $\mathrm{J} 4 \mathrm{G}$ & Tuberales \\
\hline $\mathrm{J} 44$ & Myriangiales & $\mathrm{J} 4 \mathrm{H}$ & Ascomycetes Incertae Sedis \\
\hline $\mathrm{J} 45$ & Dothideales & J5 & Basidiomycetes \\
\hline $\mathrm{J} 46$ & Microthyriales & J51 & Tremellales \\
\hline & (syn. Hemisphaeriales) & $\mathrm{J} 52$ & Uredinales \\
\hline $\mathrm{J} 47$ & Meliolales & J5201 & Pucciniaceae \\
\hline
\end{tabular}


FIELD E; Taxonomy Code

Columns 18, 19, 20, 21,

$22,23,24$, and 25

\section{J520101 \\ J5201011 \\ $\mathrm{J} 520102$ \\ J5201021 \\ J5201022 \\ J53 \\ J54 \\ J55 \\ J5501 \\ J550101 \\ J5501011 \\ J5501012 \\ J550102 \\ J5501021 \\ J5501022 \\ J550103 \\ J5501031 \\ J5501032 \\ J5501033 \\ J5501034 \\ J5501035 \\ J5501036 \\ J5501037 \\ J5502 \\ J550201 \\ J5502011 \\ $\mathrm{J} 550202$ \\ J5502021 \\ J550203 \\ J5502031 \\ $\mathrm{J} 5503$ \\ J550301 \\ J5503011 \\ J550302 \\ J5503021}

J56

J57

J58

J59

J5A

J6

J61

J6101

$\mathrm{J} 610101$

J6101011

$\mathrm{J} 610102$

J6101021

J610103

J6101031

$\mathrm{J} 62$

$\mathrm{J} 63$

J6301

J630101

$\mathrm{J} 6301011$

$\mathrm{J} 6301012$

$\mathrm{J} 6301013$
Gymnosporangium

Gymnosporangium clavipes

Puccinia

Puccinia coronata

Puccinia graminis

Ustilaginales

Exobasidiales

Agaricales

Polyporaceae

Poria

Poria monticola

Poria microspora

Fomes

Fomes pini

Fomes pomaceus

Polyporus

Polyporus squamosus

Polyporus circinatus

Polyporus croceus

Polyporus obtusus

Polyporus schweinitzii

Polyporus alboluteus

Polyporus tulipiferus

Agaricaceae

Agaricus

Agaricus campestris

Coprinus

Coprinus fimetarius

Schizophyllum

Schizophyllum commune

Thelephoraceae

Stereum

Stereum murrayi

Pellicularis

Pellicularis filamentosa

(imperfect stage known as:

Rhizoctonia solani or obs.

Corticium solani)

Hymenogastrales

Phallales

Lycoperdales

Sclerodermatales

Nidulariales

Fungi Imperfecti

Sphaeropsidales

Sphaerioidaceae

Ascochyta

Ascochyta chrysanthem1

Diplodia

Diplodia natalensis

Phomopsis

Phomopsis citri

Melanconiales

Moniliales

Cryptococcaceae (syn.

Pseudosaccharomycetaceae)

Candida

Candida albicans

Candida crusei

Candida pulcherrima
J6301014

$\mathrm{J} 6301015$

J6301016

$\mathrm{J} 6301017$

J6301018

J6301019

$\mathrm{J} 630102$

$\mathrm{J} 6301021$

$\mathrm{J} 630103$

J6301031

$\mathrm{J} 6301032$

J6301033

J630104

$\mathrm{J} 6301041$

$\mathrm{J} 6301042$

$\mathrm{J} 6301043$

J630105

J6301051

J630106

J6301061

J6301062

J630107

J6301071

$\mathrm{J} 6302$

J630201

J6302011

$\mathrm{J} 6303$

J630301

J6303011

J6303012

J6303013

J6303014

J6303015

$\mathrm{J} 630302$

J6303021

$\mathrm{J} 630303$

J6303031

$\mathrm{J} 6303032$

J630304

J6303041

J6303042

J630305

$\mathrm{J} 630306$

$\mathrm{J} 630307$

J630308

J6303081

$\mathrm{J} 6303082$

$\mathrm{J} 6303083$

J630309

J630310

J6303101

J630311

J6303111

J630312

J6303121

J6303122

$\mathrm{J} 6303123$

J6303124

J6303125

J6303126
Candida lipolytica

Candida tropicalis

Candida guilliermondii

Candida flareri

Candida monosa

Candida pseudotropicalis

Kloeckeria

Kloeckeria brevis

Rhodotorula

Rhodotorula aurantiaca

Rhodotorula mucilaginosa

Rhodotorula sanniei

Torulopsis

Torulopsis neoformans

Torulopsis hominis

Torulopsis utilis

Pullularia

Pullularia pullulans

Mycoderma

Mycoderma cerevisiae

Mycoderma vini

Brettanomyces

Brettanomyces anomolus

Sporobolomycetaceae

Sporobolomyces

Sporobolomyces salmonicolor

Moniliaceae

Aspergillus

Aspergillus candidus

Aspergillus niger

Aspergillus tamarii

Aspergillus terreus

Aspergillus wenti

Monosporium

Monosporium apiospermum

Sporotrichum

Sporotrichum schenckii

Sporotrichum floccosum

Botrytis

Botrytis cinerea

Botrytis allii

Paecilomyces

Scopulariopsis

Gliocladium

Trichoderma

Trichoderma lignorum

Trichoderma viride

Trichoderma koeningi

Trichothecium

Oidium

Oidium lactis

Monilia

Monilia albicans

Penicillium

Peniclllium digitatum

Penicillium chrysogenum

Penicillium citrinum

Penicillium patulum

Penicillium brevicompactum

Penicillium expansum 
J6303127

J6303128

J6303129

J630312A

$\mathrm{J} 6304$

J630401

J6304011

$\mathrm{J} 6304012$

$\mathrm{J} 6304013$

$\mathrm{J} 630402$

$\mathrm{J} 6304021$

$\mathrm{J} 6304022$

J630403

J630404

J6304041

J6304042

J6304043

J6304044

J630405

J6304051

J630406

J6304061

J630407

J6304071

J630408

J6304081

J6304082

J630409

J6304091

J6304092

J6304093

J630410

J630410]

J630411

J6305

J630501

$\mathrm{J} 6305011$

J6305012

J6305013

J6305014

$\mathrm{J} 6305015$

J6305016

J6305017

J6305018

J6305019

J630502

J6305021

J6306

J630601

J6306011

J6306012

J630602

J6306021

J6306022

J6306023

J6306024

$\mathrm{J} 630603$

J6306031
Penicillium notatum

Penicillium gladioli

Penicillium cyclopium

Penicillium italicum

Dematiaceae

Hormodendron

Hormodendron compactum

Hormodendron pedrosoi

Hormodendron cladosporoides

Phialophora

Phialophora verrucosa

Phialophora braziliensis

Memnoniella

Alternaria

Alternaria oleracea

Alternaria solani

Alternaria tenuis

Alternaria brassicae

Cercospora

Cercospora nicotianae

Cladosporium

Cladosporium herbarum

Margarinomyces

Margarinomyces atrovirens

Helminthosporium

Helminthosporium sativum

Helminthosporium avenae

Torula

Torula utilis

Torula lactosa

Torula cremoris

Stemphylium

Stemphylium sarcinaeforme

Curvularia

Tuberculariaceae

Fusarium

Fusarium coeruleum

Fusarium oxysporum

Fusarium nivale

Fusarium culmorum

Fusarium lycopersici

Fusarium graminearum

Fusarium avenaceum

Fusarium dianthi

Fusarium lini

Myrothecium

Myrothecium verrucaria

Dermatophytes (not a true family designation but is term listed

in Ainsworth and Bisby.)

Blastomyces

Blastomyces dermatitidis

Blastomyces brasiliensis

Microsporum

Microsporum audouinl

Microsporum canis

Microsporum lanosum

Microsporum gypseum

Trichophyton

Trichophyton floccosum
J6306032

J6306033

J6306034

J6306035

J6306036

J6306037

J6306038

J6306039

J630604

J6306041

J64

J9

JF

JA

JA!

JA101

JA10101

JA101011

JA10102

JA1 01021

$\mathrm{JA2}$

JA3

JA4

JA5

JA6

JA7

JA8

JA9

JAA

$J A B$

JAC

JB

JB1

JB2

JC

$\mathrm{JCl}$

$\mathrm{JC} 2$

JC3

JC4

JC 5

JC6

JC7

JD

JDI

JD2

JD3

JD4

JD5

JD6

JD7

JE

JE I

JE101

JE10101

JE101011

JE 102

JE10201

JE 102011

JE2
Trichophyton gypseum

Trichophyton interdigitale

Trichophyton mentagrophytes

Trichophyton purpureum

Trichophyton rubrum

Trichophyton schoenleine

Trichophyton rosaceum

Trichophyton crateriforme

Histoplasma

Histoplasma capsulatum

Mycelia Sterilia

Fungi otherwise unspecified

Algae (otherwise unspecified)

Phaeophyceae (Brown Algae)

Fucales

Fucaceae

Fucus

Fucus evanescens

Ascophyllum

Ascophyllum nodosum

Chordariales

Sporochnales

Desmaristiales

Punctariales

Dictyosiphonales

Laminariales

Dictyotales

Tilopteridales

Cutleriales

Sphacelariales

Ectocarpales

Cyanophyceae (Blue-Green Algae)

Coccogonales

Hormogonales

Rhodophyceae (Red Algae)

Ceramiales

Rhodymeniales

Gigartinales

Cryptonemiales

Gelidiales

Nemalionales

Bangiales

Chrysophyceae (Yellow - Green

Algae)

Tribonemeae (subclass)

Diatomeae (subclass)

Chrysomonadineae (subclass)

Peridineae (subclass)

Cryptomonadineae (subclass)

Chloromonadineae (subclass)

Euglenineae (subclass)

Chlorophyceae (Green Algae)

Chlorococcales

Scenedesmaceae

Scenedesmus

Scenedesmus quadricauda

Oocystaceae

Chlorella

Chlorella pyrenoldosa

Ulotrichales 


JE201
JE20101
JE201011
JE3
JE4
JE5
JE6
JE7
JE8
JF
JS

JS

JS

JS 1

JS 1

JS 1

JS101

JS 102

JS 103

JS 104

JS 10401

JS 10402

JS 10403

JS 105

JS 106

JS 107

JS 10701

JS 107011

JS 107011

JS 107012

JS 107013

JS 10702

JS 10702 I

JS 107022

JS 10703

JS 107031

JS 10704

JS 107041

JS1 0705

JS 108

JS 10801

JS 10802

JS 10803
Ulotrichaceae

JS 109

tichococcus

Stichococcus subtilis

JS 110

Ulvales

Conjugales

Chaetophorales

Siphonales

Charales

Siphonocladales

Algae, not otherwise specified

Schizophyceae, class of division Protophyta

(Thallophyta)

Schizomycetes, class of

division Protophyta

(Thallophyta)

Microtatobiotes,

(addendum to class

Schizomycetes)

Pseudomonadales, order of class Schizomycetes

Rhodobacteriineae, suborder of order Pseudomonadales

Pseudomonadineae, suborder of order Pseudomonadales

Thiorhodaceae, family of suborder Rhodobacteriineae

Athiorhodaceae, family of suborder Rhodobacteriineae

Chlorobacteriaceae, family of suborder Rhodobacteriineae

Nitrobacteraceae, family of suborder Pseudomonadineae

Nitrosomonas

Nitrosococcus

Nitrobacter

Methanomonadaceae, family of suborder Pseudomonadineae

Thiobacteriaceae, family of suborder Pseudomonadineae

Pseudomonadaceae, family of suborder Pseudomonadineae

Pseudomonas

Pseudomonas aeruginosa

Pseudomonas pyocyaneus

Pseudomonas fluorescens

Pseudomonas putida

Xanthomonas

Xanthomonas vitians

Xanthomonas phaseoli

Acetobacter

Acetobacter suboxydans

Photobacterium

Photobacterium fischeri

Azotomonas

Caulobacteraceae, family of suborder Pseudomonadineae

Caulobacter

Gallionella

Nevskia
JS 11001

JS 110011

JS 110012

JS 11002

JS 11003

JS2

JS201

JS202

JS203

JS3

JS301

JS 302

JS4

JS401

JS 40101

JS401011

JS 402

JS 40201

JS402011

JS 402012

JS 40202

JS402021

JS40203

JS402031

JS403

JS40301

JS403011

JS 403012

JS 40302

JS 404

JS404

JS40 4

JS 404

JS 404

JS404

JS4040I

JS4040 I 1

JS 40402

JS 404021
Siderocapsaceae, family of suborder Pseudomonadineae

Spirillaceae, family of suborder Pseudomonadineae

Vibrio

Vibrio comma

Vibrio metschnikovii

Methanobacterium

Spirillum

Chlamydobacteriales, order of class Schizomycetes

Chlamydobacteriaceae, family of order Chlamydobacteriales

Peloplocaceae, family of order Chlamydobacteriales

Crenotrichaceae, family of order Chlamydobacteriales

Hyphomicrobiales, order of class Schizomycetes

Hyphomicroblaceae, family of order Hyphomicrobiales

Pasteuriaceae, family of order Hyphomicrobiales

Eubacteriales, order of class Schizomycetes

Azotobacteraceae, family of order Eubacteriales

Azotobacter

Azotobacter chroococcum

Rhizobiaceae, family of order Eubacteriales

Rhizobium

Rhizobium leguminosarum

Rhizobium meliloti

Agrobacterium

Agrobacterium tumefaciens

Chromobacterium

Chromobacterium amethystinum

Achromobacteraceae, family of

order Eubacteriales

Alcaligenes

Alcaligenes faecalis

Alcaligenes metalcaligenes

Achromobacter

Enterobacteriaceae, family of order Eubacteriales

Escherichieae, tribe of family Enterobacteriaceae

Erwinieae, tribe of family

Enterobacteriaceae

Serratieae, tribe of family Enterobacteriaceae

Proteae, tribe of family

Enterobacteriaceae

Salmonelleae, tribe of family

Enterobacteriaceae

Escherichia

Escherichía coli

Aerobacter

Aerobacter aerogenes 


$\begin{array}{ll}\text { JS40403 } & \text { Klebsiella } \\ \text { JS404031 } & \text { Klebsiella pneumoniae } \\ \text { JS40404 } & \text { Paracolobactrum } \\ \text { JS404041 } & \text { Paracolobactrum coliforme } \\ \text { JS40405 } & \text { Erwinia } \\ \text { JS40406 } & \text { Serratia } \\ \text { JS404061 } & \text { Serratia marcescens } \\ \text { JS40407 } & \text { Proteus } \\ \text { JS404071 } & \text { Proteus vulgaris } \\ \text { JS404072 } & \text { Proteus morganii } \\ \text { JS404073 } & \text { Proteus mirabilis }\end{array}$

The distinct species of Salmonella have not been given separate code numbers as decided by the NRC-CBCC Microbiology Subcommittee, since the serological types do not always refer to separate species and the rules of binomial nomenclature have not always been followed. The code numbers refer to the various serological groups themselves but may be altered without difficulty to provide a uniform pattern throughout the code.

$\begin{array}{ll}\text { JS40408 } & \text { Salmonella } \\ \text { JS404081 } & \text { Salmonella: A group } \\ \text { JS404082 } & \text { S. paratyphi } \\ & \text { Salmonella: B group } \\ & \text { S. schottmuelleri } \\ & \text { S. typhimurium } \\ & \text { S. abortivoequina } \\ & \text { S. abortusovis }\end{array}$

JS404083

JS404084

JS404085

JS 404086

JS 40409

JS404091

JS404092

JS404092

JS 404093

JS404094

JS 405

JS40501

S. pullorum
S. choleraesuis

S. typhisuis

S. tennessee

S. bovismorbificans

Salmonella: D group

S. typhosa

S. enteritidis

S. gallinarum

Salmonella: E group

Salmonella: F group

Shigella

Shigella dysenteriae

Shigella flexneri

Shigella paradysenterlae

Shigella boydii

Shigella sonnei

Brucellaceae, family of order

Eubacteriales

Pasteurella
JS405011

JS 405012

JS405013

JS405014

JS 40502

JS 405021

JS 405022

JS40503

JS405031

JS405032

JS 405033

JS40504

JS405041

JS 405042

JS 40505

JS40506

JS405061

JS40507

JS406

JS 40601

JS40602

JS407

JS 40701

JS407011

JS 40702

JS 407021

JS 407022

JS4 07023

JS 407024

JS40703

JS 407031

JS40704

JS 40704

Pasteurella pestis

Pasteurella multocida

Pasteurella pseudotuberculosis

Pasteurella tularensis

Bordetella

Bordetella pertussis

Bordetella bronchiseptica

Brucella

Brucella abortus

Brucella melitensis

Brucella suis

Haemophilus

Haemophilus influenzae

Haemophilus ducreyi

Actinobacillus

Calymmatobacterium

Calymmatobacterium granulomatis

Moraxella

Bacteroidaceae, family of order

Eubacteriales

Bacteroides

Fusobacterium

Micrococcaceae, family of order

Eubacteriales

Micrococcus

Micrococcus flavus

Staphylococcus

Staphylococcus aureus

Staphylococcus aureus var. aureus

Staphylococcus aureus var. albus

Staphylococcus aureus var. citreus

Gaffkya

Gaffkya tetragena

Sarcina

Zymosarcina, subgenus of genus Sarcina

JS40704 Methanosarcina, subgenus of genus Sarcina

JS 40704

JS40704

JS40704 1

JS 408

JS 40801

JS408011

JS 408012

JS408013

JS409

JS410
Sarcinococcus, subgenus of genus Sarcina

Urosarcina, subgenus of genus Sarcina

Sarcina lutea

Neisseriaceae, family of order Eubacteriales

Neisseria

Neisseria catarrhalis

Neisseria gonorrhoeae

Nelsseria meningitidis

Brevibacteriaceae, family of order Eubacteriales

Lactobacillaceae, family of order Eubacteriales 
JS4 10

Streptococceae, tribe of family Lactobacillaceae

JS 410 Lactobacilleae, tribe of family Lactobacillaceae

JS41001 Diplococcus

JS410011 Diplococcus pneumoniae

The distinct species of Streptococcus have not been assigned individual code numbers but rather separated into the groups listed in Bergey's Manual of Determinative Bacteriology, 7 th edition. This decision was made by the NRC-CBCC Microbiology Subcommittee on the basic assumption that any questioner interested in a specific Streptococcus would also want the data on other species in a given group. Since the numbering system may be expanded there is no hindrance to disregarding this grouping and giving each species an individual code designation.

JS4 1002

JS4 10021

JS 410022

JS4 10023

JS410024

JS4 1003

JS4 10031

JS4 10032

JS 410033

JS 41004

JS41004

JS41004

JS4 10041

JS4 10042

JS 410043

JS 410044

JS 410044

JS 410045

JS 410046

JS 410047
Streptococcus

Streptococcus: pyogenic group

S. pyogenes

S. zooepidemicus

S. equi

S. equisimilis

S. agalactiae

Streptococcus: viridans group
S. salivarius
S. mitis
S. bovis
S. thermophilus
S. equinus

Streptococcus: lactic group

S. lactis

S. cremoris

Streptococcus: enterococcus group

S. faecalis

S. durans

Leuconos toc

Leuconostoc mesenteroides

Leuconostoc dextranicum

Leuconostoc citrovorum

Lactobacillus

Lactobacillus, subgenus of genus Lactobacillus

Saccharobac1llus, subgenus of genus Lactobacillus

Lactobacillus acidophtlus

Lactobacillus casei

Lactobacillus fermenti

Lactobacillus plantarum

Lactobacillus pentosus

Lactobacillus lactis

Lactobacillus delbrueckii

Lactobacillus brevis
JS41 10048

JS4 10049

JS41004A

JS41004B

JS411

JS41101

JS 41102

JS4 12

JS41201

JS 412011

JS 412012

JS412013

JS412014

JS41202

JS412021

JS4 1203

JS412031

JS41204

JS4 13

JS 41301

JS413011

JS413012

JS 413013

JS413014

JS 413015

JS 413016

JS 413017

JS 413018

JS413019

JS41301A

JS41301 B

JS4 1302

JS4 13021

JS 413022

JS413023

JS 413024

JS4 13025

JS4 13026

JS4 13027

JS4 13028

JS 5

JS50 I

JS50101

JS501011

JS501012

JS501013

JS501014

JS501015

JS501015

JS502
Lactobacillus leichmannii

Lactobacillus helveticus

Lactobacillus bulgaricus

Lactobacillus bifidus

Propionibacteriaceae, family of order Eubacteriales

Propionibacterium

Butyribacterium

Corynebacteriaceae, family of order Eubacteriales

Corynebacterium

Corynebacterium diphtheriae

Corynebacterium michiganense

Corynebacterium pyogenes

Corynebacterium xerose

Listeria

Listeria monocytogenes

Erysipelothrix

Erysipelothrix insidiosa

Microbacterium

Bacillaceae, family of order

Eubacteriales

Bacillus

Bacillus anthracis

Bacillus brevis

Bacillus cereus

Bacillus pumilus

Bacillus polymyxa

Bacillus subtilis

Bacillus subtilis var. niger

Bacillus coagulans

Bacillus megaterium

Bacillus alvei

Bacillus circulans

Clostridium

Clostridium botulinum

Clostridium butyricum

Clostridium perfringens

Clostridium tetani

Clostridium novyi

Clostridium histolyticum

Clostridium septicum

Clostridium acetobutylicum

Actinomycetales, order of class Schizomycetes

Mycobacteriaceae, family of order Actinomycetales

Mycobacterium

Mycobacterium avium

Mycobacterium leprae

Mycobacterium phlei

Mycobacterium tuberculosis

Mycobacterium smegmatis

Mycobacterium lacticola

Actinomycetaceae, family of order Actinomycetales 
JS 50201

IS502011

JS502012

JS 502013

JS 50202

JS502021

JS 503

JS50301

JS503011

JS503012

JS503013

JS 50302

JS 504

JS6

JS60 I

JS602

JS603

JS7

JS7 01

JS702

JS703

JS704

JS8

JS8 01

JS802

JS 803

JS804

JS8 05

JS8050 I

JS80502

JS80 05021

JS9

JS 901

JS 902

JS90201

JS 902011

JS 90202

JS 902021

JS 90203
Nocardia

Nocardia farcinica

Nocardia globerula

Nocardia asteroides

Actinomyces

Actinomyces bovis

Streptomycetaceae, family of

order Actinomycetales

Streptomyces

Streptomyces griseus

Streptomyces fradiae

Streptomyces aureofaciens

Micromonospora

Actinoplanaceae, family of

order Actinomycetales

Caryophanales, order of class

Schizomycetes

Caryophanaceae, family of

order Caryophanales

Oscillospiraceae, family of

order Caryophanales

Arthromitaceae, family of order

Oscillospiraceae

Beggiatoales, order of class

Schizomycetes

Beggiatoaceae, family of order Beggiatoales

Vitreoscillaceae, family of order Beggiatoales

Leucotrichaceae, family of order Beggiatoales

Achromatiaceae, family of order Beggiaioales

Myxobacterales, order of class Schizomycetes

Cytophagaceae, family of order Myxobacterales

Archangiaceae, family of order Myxobacterales

Sorangiaceae, family of order Myxobacterales

Polyangiaceae, family of order Myxobacterales

Myxococcaceae, family of order Myxobacterales

Myxococcus

Chondrococcus

Chondrococcus columnaris

Spirochaetales, order of class

Schlzomycetes

Spirochaetaceae, family of order Spirochaetales

Treponemataceae, family of order Spirochaetales

Borrelia

Borrelia novyi

Treponema

Treponema pallidum

Leptospira
JSA

JSAO 1

JSB

JSBO 1

JSBO I

JSBO 1

JSBOIOI

JSBO 101

JSBOIOI

JSBO 01

JSBOl0l

JSBO1011

JSBO 1012

JSBO 1012

JSBO 1013

JSBO 1014

JSBO 102

JSBO 1021

JSBO 103

JSBO 2

JSB0201

JSB0202

JSB0202 1

JSB02022

JSB02023

JSB02024

JSB02025

JSB02026

JSB0 3

JSB0 301

JSB03011

JSB0 4

JSC

JSC

JSC

JSC

JSC0 1
Mycoplasmatales, order of class Schizomycetes

Mycoplasmataceae, family of order Mycoplasmatales

Rickettsiales, order of class Microtatabiotes

Rickettsiaceae, family of order Rickettsiales

Rickettsieae, tribe of family Rickettsiaceae

Ehrlichieae, tribe of family Rickettsiaceae

Rickettsia

Rickettsia, subgenus of genus Rickettsia

Zinssera, subgenus of genus Rickettsia

Dermacentroxenus, subgenus of genus Rickettsia

Rochalimaea, subgenus of genus Rickettsia

Rickettsia prowazekii

Rickettsia typhi

Rickettsia mooseri

Rickettsia akari

Rickettsia rickettsii

Coxiella

Coxiella burnetii

Cowdria

Chlamydiaceae, family of order Rickettsiales

Chlamydia

Miyagawanella

Miyagawanella

lymphogranulomatosis

Miyagawanella ornithosis

Miyagawanella psittaci

Miyagawanella felis

Miyagawanella

bronchopneumoniae

Miyagawanella pneumoniae

Bartonellaceae, family of order Rickettsiales

Haemobartonella

Haemobartonella muris

Anaplasmataceae, family of order Rickettsiales

Virales, order of class Microtatabiotes

Phagineae, suborder of order Virales

Phytophagineae, suborder of order Virales

Zoophagineae, suborder of order Virales

Phagaceae, family of suborder Phagineae

Note: All phages of the genus Phagus, Holmes, Bergey's 


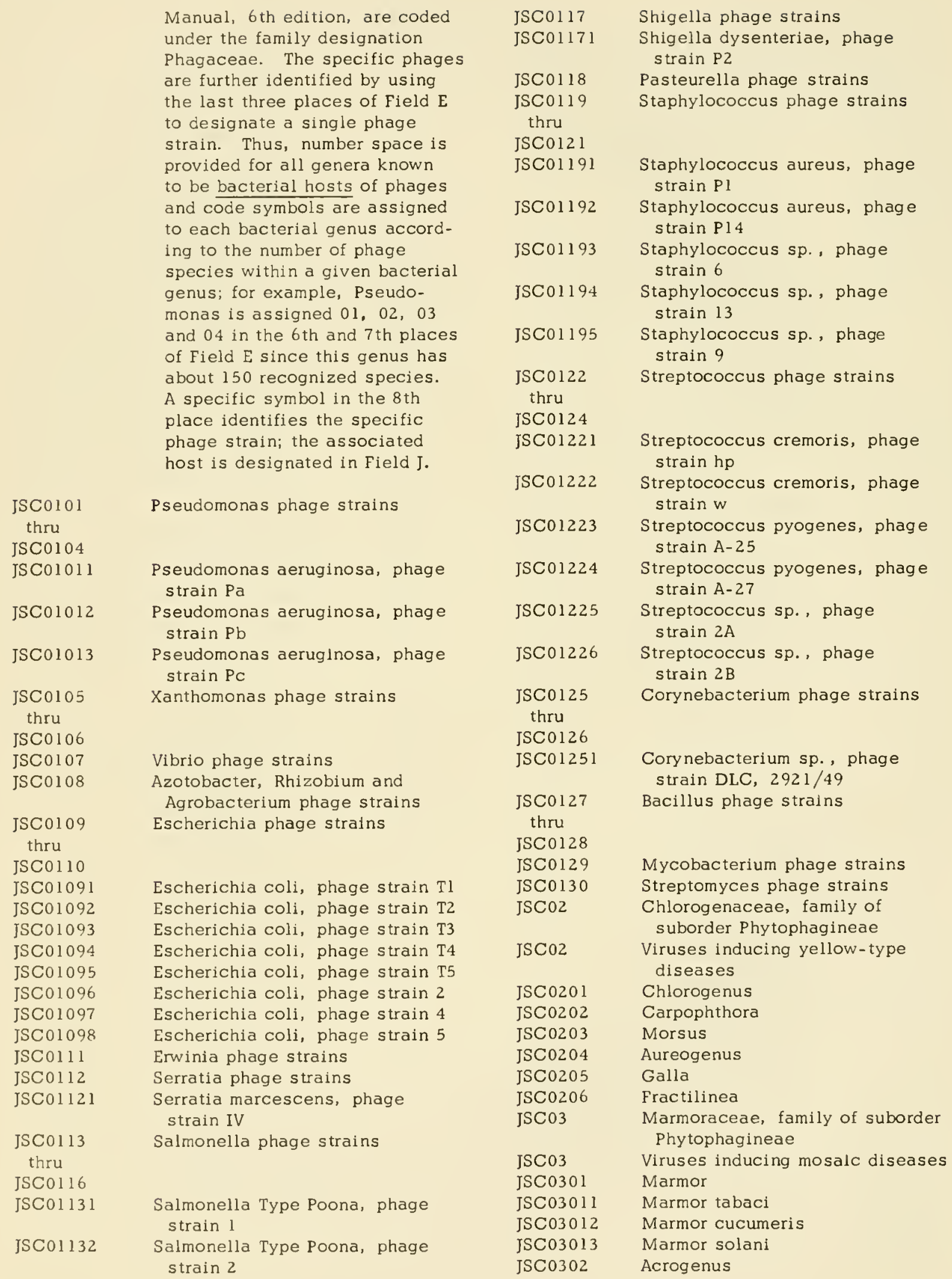


FIELD E; Taxonomy Code Columns 18, 19, 20, 21, $22,23,24$, and 25

\section{JSC 0303 \\ JSC 0304 \\ JSC0304I \\ JSC 0305 \\ JSC 0306 \\ JSC0 4}

JSC 04

JSC 0401

JSC05

JSC 05

JSC 0501

JSC06

JSC06

JSC0601

JSC 07

JSC07

JSC 0701

JSC08

JSC 08

JSC080 I

JSC0802

JSC09

JSC09

JSC 0901

JSC09011

JSC09012

JSC 0902

JSC0903

JSC09031

JSC 0904

JSC0905

JSC 10

JSC 10

JSC 1001

JSC 10011

JSC 10012

JSC 1002

JSC 10021

JSC 1003

JSC 10031

JSC 11

JSC 11

JSC 1101

JSC11011
Corium

Nanus

Nanus mirabilis

Rimocortius

Adelonosus

Annulaceae, family of suborder

Phytophagineae

Viruses inducing ringspot diseases

Annulus

Rugaceae, family of suborder

Phytophagineae

Viruses inducing leaf curl diseases

Ruga

Savoiaceae, family of suborder Phytophagineae

Viruses inducing leaf-savoying diseases

Savoia

Lethaceae, family of suborder Phy tophagineae

Viruses inducing spotted wilt disease

Lethum

Borellinaceae, family of suborder Zoophagineae

Viruses inducing diseases of insects as exclusive hosts

Borrelina

Morator

Borreliotaceae, family of suborder Zoophagineae

Viruses inducing diseases of the pox group

Borreliota

Borreliota avium

Borreliota variolae var. bovis

Briareus

Scelus

Scelus recurrens

Hostis

Molitor

Erronaceae, family of suborder Zoophagineae

Viruses inducing diseases of the encephalitis group

Erro

Erro nill

Erro equinus

Legio

Legio debilitans

Formido

Formido inexorabilis

Charonaceae, family of suborder Zoophagineae

Viruses inducing diseases of the yellow-fever group

Charon

Charon vallis

\begin{tabular}{|c|c|}
\hline JSC 1102 & Tarpeia \\
\hline JSC 11021 & Tarpeia alpha \\
\hline JSC 11022 & Tarpeia premens \\
\hline JSC 1103 & Tortor \\
\hline JSC 12 & $\begin{array}{l}\text { Trifuraceae, family of suborder } \\
\text { Zoophagineae }\end{array}$ \\
\hline JSC I 2 & $\begin{array}{l}\text { Viruses inducing diseases of the } \\
\text { infectious anemia group }\end{array}$ \\
\hline JSC1201 & Trifur \\
\hline C12011 & Trifur gallinarum \\
\hline $\mathrm{Cl} 3$ & $\begin{array}{l}\text { Rabulaceae, family of suborder } \\
\text { Zoophagineae }\end{array}$ \\
\hline $\mathrm{ISC} 13$ & $\begin{array}{l}\text { Viruses inducing diseases of } \\
\text { the mumps group }\end{array}$ \\
\hline TSCI 301 & Rabula \\
\hline JSC 13011 & Rabula inflans \\
\hline $\mathrm{SC} 14$ & Borrelomycetaceae \\
\hline $\mathrm{Cl} 4$ & $\begin{array}{l}\text { Pleuropneumonia and } \\
\text { Pleuropneumonia-like organisms }\end{array}$ \\
\hline C1401 & Asterococcus \\
\hline
\end{tabular}

$\mathrm{K}$

$\mathrm{K} 1$

K11

$\mathrm{K} 12$

$\mathrm{K} 13$

$\mathrm{K} I 4$

$\mathrm{K} 2$

K21

K3

$\mathrm{K} 3 \mathrm{l}$

K3 2

$\mathrm{K} 33$

K34

K35

K36

$\mathrm{K} 37$

K38

K39

$\mathrm{K} 3 \mathrm{~A}$

$\mathrm{K} 3 \mathrm{~B}$

$\mathrm{K} 3 \mathrm{C}$

$\mathrm{K} 3 \mathrm{D}$

$\mathrm{K} 3 \mathrm{E}$

K3F

L

L1

LII

L2

L2 1

L22

L23

L3

L3 1

L4

L41

I 42

L43
Bryophyta

Hepaticae

Marchantiales

Sphaerocarpales

Jungermanniales

Calobryales

Anthocerotae

Anthocerotales

Musci

Sphagnales

Andreaeales

Fissidentales

Dicranales

Pottiales

Grimmiales

Funariales

Schizostegiales

Tetraphidales

Eubryales

Isobryales

Hookeriales

Buxbaumiales

Polytrichinales

Dawsoniales

Pteridophyta

Psilophytinae

Psilotales

Lycopodinae

Lycopodiales

Selaginellales

Isoetales

Equisetinae

Equisetales

Filicinae

Ophioglossales

Marattiales

Filicales 
FIELD E; Taxonomy Code

Columns 18, 19, 20, 21 ,

$22,23,24$, and 25

M

MA

MAI

MA2

MA20 1

MA202

MA203

MA20 4

MA205

MA206

MA207

MA20701

MA20701 1

MA3

MA4

MA401

MA4010I

MA40102

MA401021

MA40103

MA40104

MA401041

MA40105

MA40106

MA40107

MA40108

MA401081

MA40109

MA40110

MA40111

MA40112

MA40!121

MA40113

MA40114

MA401141

MA40115

MA401151

MA40116

MA401161

MA40117

MA40118

MA40119

MA40120

MA40121

MA401211

MA40122

MA40123

MA401231

MA40124

MA40125

MA40126

MA401261

MA401262

MA40127

MA401271

MA40128

MA40128 I

MA40129

MA402

MA40201
Spermatophyta

Monocotyledoneae

Pandanales

Helobiae

Potamogetonaceae

Najadaceae

Aponogetonaceae

Juncaginaceae

Alismaceae

Butomaceae

Hydrocharitaceae

Elodea

Elodea canadensis

Triuridales

Glumiflorae

Gramineae

Agropyron

Agrostis

Agrostis tenuis

Andropogon

Avena

Avena sativa

Bouteloua

Bromus

Buchloe

Cynodon

Cynodon dactylon

Dactylis

Digitaria

Echinochloa

Festuca

Festuca rubra var. commutata

Holcus

Hordeum

Hordeum vulgare

Lolium

Lolium multiflorum

Oryza

Oryza sativa

Panicum

Pennisetum

Phalaris

Phleum

Poa

Poa pratensis

Saccharum

Secale

Secale cereale

Setaria

Sorghum

Triticum

Triticum aestivum

Triticum dicoccum

Zea

Zea mays

Bambusa

Bambusa vulgaris

Agropyron-Triticum hybrid

Cyperaceae

Cyperus

\begin{tabular}{|c|c|}
\hline MA402011 & Cyperus rotundus \\
\hline MA5 & Principes \\
\hline MA6 & Synanthae \\
\hline MA7 & Spathiflorae \\
\hline MA701 & Araceae \\
\hline MA702 & Lemnaceae \\
\hline MA8 & Farinosae \\
\hline MA801 & Flagellariaceae \\
\hline MA802 & Restionaceae \\
\hline MA803 & Centrolepidaceae \\
\hline MA804 & Mayacaceae \\
\hline MA805 & Xyridaceae \\
\hline MA806 & Eriocaulaceae \\
\hline MA807 & Rapateaceae \\
\hline MA808 & Bromeliaceae \\
\hline MA8080 I & Ananas \\
\hline MA809 & Commelinaceae \\
\hline MA80901 & Rhoeo \\
\hline MA809011 & Rhoeo discolor \\
\hline MA810 & Pontederiaceae \\
\hline MA9 & Liliflorae \\
\hline MA901 & Juncaceae \\
\hline MA902 & Stemonaceae \\
\hline MA903 & Liliaceae \\
\hline MA90301 & Allium \\
\hline MA903011 & Allium cepa \\
\hline MA90302 & Asparagus \\
\hline MA90303 & Lilium \\
\hline MA903031 & Lilium regale \\
\hline MA903032 & Lilium longiflorum \\
\hline MA90304 & Sansevieria \\
\hline MA90305 & Smilax \\
\hline MA90306 & Tulipa \\
\hline MA90307 & Yucca \\
\hline MA90308 & Scilla \\
\hline MA903081 & Scilla sibirica \\
\hline MA90309 & Aloe \\
\hline MA903091 & Aloe vulgaris \\
\hline MA904 & Haemodoraceae \\
\hline MA905 & Amaryllidaceae \\
\hline MA90501 & Agave \\
\hline MA905011 & Agave toumeyana \\
\hline $\mathrm{MAA}$ & Scitamineae \\
\hline MAB & Microspermae \\
\hline $\mathrm{MB}$ & Dicotyledoneae \\
\hline $\mathrm{MBl}$ & Verticillatae \\
\hline MB2 & Piperales \\
\hline $\mathrm{MB} 201$ & Saururaceae \\
\hline $\mathrm{MB} 202$ & Piperaceae \\
\hline MB3 & Salicales \\
\hline $\mathrm{MB} 301$ & Salicaceae \\
\hline MB30101 & Salix \\
\hline MB4 & Myricales \\
\hline MB5 & Balanopsidales \\
\hline MB6 & Leitneriales \\
\hline MB7 & Juglandales \\
\hline MB8 & Fagales \\
\hline MB801 & Betulaceae \\
\hline $\mathrm{MB802}$ & Fagaceae \\
\hline MB80201 & Castanea \\
\hline
\end{tabular}

MA402011 Cyperus rotundus

MA701

MA702

MA8

MA802

MA803

MA805

MA806

MA807

MA8080

MA809

MA810

MA9

MA903

MA9030

MA90303

MA903031

MA903032

MA9030

MA90306

MA90307

MA90308

MA90309

MA903091

MA904

MAA

MAB

$M B$

$\mathrm{MB} 20$

$\mathrm{MB} 202$

$\mathrm{MB} 3$

MB30101

MB4

MB5

MB7

MB8

MB8020I 


\begin{tabular}{|c|c|c|c|}
\hline MB80202 & Fagus & $\mathrm{MBG} 02031$ & Raphanus sativus \\
\hline MB80203 & Quercus & MBG0204 & Lepidium \\
\hline MB9 & Urticales & MBG02041 & Lepidium sativum \\
\hline MB901 & Ulmaceae & MBG03 & Tovariaceae \\
\hline $\mathrm{MB} 902$ & Moraceae & MBG04 & Capparidaceae \\
\hline MB9020I & Artocarpus & $\mathrm{MBH}$ & Sarraceniales \\
\hline MB90202 & Cannabis & MBI & Rosales \\
\hline MB90203 & Ficus & MBI01 & Podostemonaceāe \\
\hline MB903 & Urticaceae & $\mathrm{MBIO} 2$ & Hydrostachyaceae \\
\hline $\mathrm{MBA}$ & Proteales & $\mathrm{MBI03}$ & Crassulaceae \\
\hline $\mathrm{MBB}$ & Santalales & $\mathrm{MBI04}$ & Cephalotaceae \\
\hline $\mathrm{MBC}$ & Aristolochiales & MBI05 & Saxifragaceae \\
\hline $\mathrm{MBD}$ & Polygonales & MBI0501 & Ribes \\
\hline MBD0 1 & Polygonaceae & MBI06 & Pittosporaceae \\
\hline MBDOIOI & Fagopyrum & MBI07 & Brunelliaceae \\
\hline MBD0I0I1 & Fagopyrum esculentum & MBI08 & Cunoniaceae \\
\hline MBD0102 & Polygonum & MBI09 & Myrothamnaceae \\
\hline MBD0103 & Rheum & MBI 10 & Bruniaceae \\
\hline MBD0 104 & Rumex & MBI I 1 & Hamamelidaceae \\
\hline MBD0 041 & Rumex acetosa & MBI 12 & Platanaceae \\
\hline $\mathrm{MBE}$ & Centrospermae & $\mathrm{MBI} 13$ & Crossosomataceae \\
\hline MBEOI & Chenopodiaceae & MBI 14 & Rosaceae \\
\hline MBE0101 & Beta & MBI I 40 I & Amelanchier \\
\hline MBE01011 & Beta vulgaris & MBI 1402 & Crataegus \\
\hline MBE02 & Amarantaceae & MBI 1403 & Cydonia \\
\hline MBE0201 & Amarantus & MBI 1404 & Eriobotrya \\
\hline MBE02011 & Amarantus retroflexus & MBI 405 & Fragaria \\
\hline MBE03 & Nyctaginaceae & MBII 406 & Potentilla \\
\hline MBE04 & Batidaceae & MBI 1407 & Prunus \\
\hline MBE0 5 & Cynocrambaceae & MBI I 407 I & Prunus amygdalus \\
\hline MBE06 & Phytolaccaceae & MBI 14072 & Prunus armeniaca \\
\hline MBE07 & Aizoaceae & MBI 14073 & Prunus avium \\
\hline MBE08 & Portulacaceae & MBI 14074 & Prunus cerasus \\
\hline MBE09 & Basellaceae & MBII 4075 & Prunus domestica \\
\hline $\mathrm{MBE} 10$ & Carophyllaceae & MBI I 4076 & Prunus salicina \\
\hline MBE 1001 & Dianthus & MBI 14077 & Prunus persica \\
\hline MBEl0011 & Dianthus caryophyllus & MBI 1408 & Pyrus \\
\hline MBE 1002 & Saponaria & MBI 1409 & Rosa \\
\hline MBE 1003 & Stellaria & $\mathrm{MBI} 14 \mathrm{IO}$ & Rubus \\
\hline MBE 10031 & Stellaria media & MBII 411 & Sorbus \\
\hline $\mathrm{MBF}$ & Ranales & MBI 1412 & Spiraea \\
\hline MBF01 & Nymphaeaceae & MBI1413 & Malus \\
\hline MBF0101 & Cabomba & MBI14131 & Malus sylvestris \\
\hline $\mathrm{MBG}$ & Rhoeadales & MBI 15 & Connaraceae \\
\hline MBGOI & Papaveraceae & MBII 6 & Leguminosae \\
\hline MBG02 & Cruciferae & MBI 1601 & Acacia \\
\hline MBG0201 & Brassica & MBI 1602 & Arachis \\
\hline MBG02011 & Brassica kaber & MBI1603 & Astragalus \\
\hline MBG02012 & Brassica nigra & MBI 1604 & Ceratonia \\
\hline MBG02013 & Brassica rapa & MBI 1605 & Crotalaria \\
\hline MBG02014 & Brassica campestris & MBI 1606 & Gleditschia \\
\hline MBG020I 5 & Brassica napus & MBI 1607 & Glycine \\
\hline MBG02016 & $\begin{array}{l}\text { Brassica oleracea var. } \\
\text { gemmifera }\end{array}$ & $\begin{array}{l}\text { MBI } 16071 \\
\text { MBI } 1608\end{array}$ & $\begin{array}{l}\text { Glycine max } \\
\text { Lathyrus }\end{array}$ \\
\hline MBG02017 & Brassica oleracea var. capitata & MBI 1609 & Lens \\
\hline MBG02018 & Brasslca oleracea var. botrytis & MBI1610 & Lespedeza \\
\hline MBG02019 & Brassica oleracea var. italica & MBI 1611 & Lupinus \\
\hline MBG0201A & Brassica napobrassica & MBI16111 & Lupinus albus \\
\hline MBG0202 & Armoracia & MBII6I2 & Medicago \\
\hline MBG0203 & Raphanus & MBI1613 & Melilotus \\
\hline
\end{tabular}


FIELD E; Taxonomy Code

Columns 18, 19, 20, 21,

$22,23,24$, and 25

\begin{tabular}{|c|c|}
\hline MBI 1614 & Phaseolus \\
\hline MBI 16141 & Phaseolus vulgaris \\
\hline MBII6142 & Phaseolus limensis \\
\hline MBII6143 & Phaseolus coccineus \\
\hline MBI 1615 & Pisum \\
\hline MBIl6151 & Pisum sativum \\
\hline MBI1616 & Trifolium \\
\hline MBI16161 & Trifolium incarnatum \\
\hline MBI 16162 & Trifolium repens \\
\hline MBI 16163 & Trifolium pratense \\
\hline MBI1617 & Vicia \\
\hline MBII6171 & Vicia faba \\
\hline MBI1618 & Vigna \\
\hline MBI16181 & Vigna sinensis \\
\hline MBI1619 & Canavalia \\
\hline MBIl6191 & Canavalia ensiformis \\
\hline MBJ & Geraniales \\
\hline MBJ0 1 & Geraniaceae \\
\hline MBJ02 & Oxalidaceae \\
\hline MBJ03 & Tropaeolaceae \\
\hline MBJ04 & Linaceae \\
\hline MBJ0401 & Linum \\
\hline MBJ04011 & Linum usitatissimum \\
\hline MBJ05 & Humiriaceae \\
\hline MBJ06 & Erythroxylaceae \\
\hline MBJ07 & Zygophyllaceae \\
\hline MBJ0B & Cneoraceae \\
\hline MBJ09 & Rutaceae \\
\hline MBJ0901 & Citrus \\
\hline MBJ09011 & Citrus aurantifolia \\
\hline MBJ09012 & Citrus aurantium \\
\hline MBJ09013 & Citrus paradisl \\
\hline MBJ09014 & Citrus limon \\
\hline MBJ09015 & Citrus medica \\
\hline MBJ09016 & Citrus sinensis \\
\hline MBJ 10 & Simarubaceae \\
\hline MBJ11 & Burseraceae \\
\hline MBJ 12 & Meliaceae \\
\hline MBJ 13 & Malpighiaceae \\
\hline $\mathrm{MBJ} 14$ & Trigoniaceae \\
\hline MBJ 15 & Vochysiaceae \\
\hline MBJ 16 & Tremandraceae \\
\hline MBJ 17 & Polygalaceae \\
\hline MBJ 18 & Dichapetalaceae \\
\hline MBJ 19 & Euphorbiaceae \\
\hline MBJ1901 & Aleurites \\
\hline MBJ 1902 & Croton \\
\hline MBJ 1903 & Euphorbia \\
\hline MBJ 19031 & Euphorbia pulcherrima \\
\hline MBJl 904 & Hevea \\
\hline MBJ 1905 & Codiaeum \\
\hline MBJ 1906 & Ricinus \\
\hline MBK & Sapindales \\
\hline $\mathrm{MBKO} 1$ & Buxaceae \\
\hline $\mathrm{MBKO2}$ & Coriariaceae \\
\hline $\mathrm{MBK} 03$ & Empetraceae \\
\hline $\mathrm{MBK} 04$ & Limnanthaceae \\
\hline MBK05 & Anacardiaceae \\
\hline MBK06 & Cyrillaceae \\
\hline MBK07 & Pentaphylacaceae \\
\hline
\end{tabular}

\begin{tabular}{|c|c|}
\hline MBK0B & Corynocarpaceae \\
\hline MBK09 & Aquifoliaceae \\
\hline MBK 10 & Celastraceae \\
\hline MBKII & Hippocrateaceae \\
\hline $\mathrm{MBK} 12$ & Stackhouslaceae \\
\hline MBK13 & Staphyleaceae \\
\hline MBK 14 & Icacinaceae \\
\hline MBK15 & Aceraceae \\
\hline MBK1501 & Acer \\
\hline$M B K 15011$ & Acer saccharum \\
\hline MBL & Rhamnales \\
\hline MBLO 1 & Rhamnaceae \\
\hline MBL02 & Vitaceae \\
\hline MBL0201 & Vitis \\
\hline MBL02011 & Vitis vinifera \\
\hline $\mathrm{MBM}$ & Malvales \\
\hline MBMOI & Elaeocarpaceae \\
\hline $\mathrm{MBM02}$ & Chlaenaceae \\
\hline $\mathrm{MBM03}$ & Gonystylaceae \\
\hline $\mathrm{MBM04}$ & Tiliaceae \\
\hline MBMO5 & Malvaceae \\
\hline MBM0501 & Abutilon \\
\hline MBM0502 & Althae \\
\hline MBM0503 & Gossypium \\
\hline MBM06 & Triplochitonaceae \\
\hline MBMO7 & Bombacaceae \\
\hline MBMOB & Sterculiaceae \\
\hline MBMOBO 1 & Theobroma \\
\hline MBM08011 & Theobroma cacao \\
\hline $\mathrm{MBN}$ & Parietales \\
\hline$M B \emptyset$ & Opuntiales \\
\hline MBP & Myrtiflorae \\
\hline MBPOI & Geissolomaceae \\
\hline $\mathrm{MBP} 02$ & Penaeaceae \\
\hline $\mathrm{MBP} 03$ & Oliniaceae \\
\hline MBP04 & Thymelaeaceae \\
\hline MBP05 & Elaeagnaceae \\
\hline MBP06 & Lythraceae \\
\hline MBP07 & Sonneratiaceae \\
\hline MBPOB & Crypteroniaceae \\
\hline MBP09 & Punicaceae \\
\hline MBPIO & Lecythidaceae \\
\hline MBPll & Rhizophoraceae \\
\hline MBP12 & Combretaceae \\
\hline MBP 13 & Myrtaceae \\
\hline MBP 14 & Melastomataceae \\
\hline MBP 15 & Onagraceae \\
\hline$M B Q$ & Umbelliflorae \\
\hline MBQ01 & Araliaceae \\
\hline MBQ02 & Umbelliferae \\
\hline MBQ0201 & Apium \\
\hline MBQ0202 & Conium \\
\hline MBQ0203 & Daucus \\
\hline MBQ02031 & Daucus carota var. sativa \\
\hline MBQ03 & Cornaceae \\
\hline MBQ0301 & Cornus \\
\hline MBR & Ericales \\
\hline MBR0 1 & Clethraceae \\
\hline $\mathrm{MBR02}$ & Pirolaceae \\
\hline MBR03 & Lennoaceae \\
\hline
\end{tabular}


FIELD E; Taxonomy Code Columss 18, 19, 20, 21, $22,23,24$, and 25

\begin{tabular}{|c|c|}
\hline MBR04 & Ericaceae \\
\hline MBR0401 & Calluna \\
\hline MBR0402 & Erica \\
\hline MBR0 403 & Kalmia \\
\hline MBR0404 & Rhododendron \\
\hline MBR0405 & Vaccinium \\
\hline MBS & Primulales \\
\hline $\mathrm{MBT}$ & Ebenales \\
\hline MBU & Contortae \\
\hline MBUOl & Oleaceae \\
\hline MBUOl 01 & Fraxinus \\
\hline MBU0102 & Jasminum \\
\hline MBU0103 & Ligustrum \\
\hline MBU01031 & Ligustrum ovalifolium \\
\hline MBU02 & Salvadoraceae \\
\hline MBU03 & Loganiaceae \\
\hline MBU04 & Gentianaceae \\
\hline MBU0 5 & Apocynaceae \\
\hline MBU050! & Apocynum \\
\hline MBU0502 & Carissa \\
\hline MBU0503 & Nerium \\
\hline MBU0504 & Vinca \\
\hline MBV & Tubiflorae \\
\hline MBV0 1 & Convolvulaceae \\
\hline MBV0101 & Convolvulus \\
\hline MBV0102 & Cuscuta \\
\hline MBVOI03 & Ipomoea \\
\hline MBV01031 & Ipomoea tricolor \\
\hline MBVO 1032 & Ipomoea batatas \\
\hline MBV02 & Polemoniaceae \\
\hline MBV03 & Hydrophyllaceae \\
\hline MBVO 4 & Borraginaceae \\
\hline MBV0 5 & Verbenaceae \\
\hline MBV06 & Labiatae \\
\hline MBV0601 & Mentha \\
\hline MBV0602 & Nepeta \\
\hline MBV0603 & Salvia \\
\hline MBV0604 & Thymus \\
\hline MBV0605 & Coleus \\
\hline MBV06051 & Coleus blumei \\
\hline MBV07 & Nolanaceae \\
\hline MBV08 & Solanaceae \\
\hline MBV080 l & Atropa \\
\hline MBV0802 & Capsicum \\
\hline MBV0803 & Datura \\
\hline MBV08031 & Datura stramonium \\
\hline MBV0804 & Hyoscyamus \\
\hline MBV0805 & Lycopersicon \\
\hline MBV08051 & Lycopersicon esculentum \\
\hline MBV0806 & Nicotiana \\
\hline MBV08061 & Nicotiana tabacum \\
\hline MBV08062 & Nicotiana glutinosa \\
\hline MBV0807 & Petunia \\
\hline MBV0808 & Solanum \\
\hline MBV08081 & Solanum tuberosum \\
\hline MBV09 & Scrophulariaceae \\
\hline MBVIO & Bignoniaceae \\
\hline MBVI 1 & Pedaliaceae \\
\hline MBW & Plantaginales \\
\hline MBWOl & Plantaginaceae \\
\hline
\end{tabular}

\begin{tabular}{|c|c|}
\hline MBW0 101 & Plantago \\
\hline MBX & Rubiales \\
\hline MBY & Campanulatae \\
\hline MBYOl & Cucurbitaceae \\
\hline MBY0101 & Citrullus \\
\hline MBY01011 & Citrullus vulgaris \\
\hline MBY0102 & Cucumis \\
\hline MBY01021 & Cucumis sativus \\
\hline MBY01022 & Cucumis melo \\
\hline MBY0103 & Cucurbita \\
\hline MBY01031 & Cucurbita maxima \\
\hline MBY01032 & Cucurbita pepo var. torticollis \\
\hline $\mathrm{MBY} 02$ & Campanulaceae \\
\hline MBY03 & Goodeniaceae \\
\hline MBY04 & Stylidiaceae \\
\hline MBY05 & Calyceraceae \\
\hline MBY06 & Compositae \\
\hline MBY0601 & Achillea \\
\hline MBY0602 & Ambrosia \\
\hline MBY0603 & Artemisia \\
\hline MBY0604 & Aster \\
\hline MBY0605 & Carduus \\
\hline MBY0606 & Chrysanthemum \\
\hline MBY0607 & Cichorium \\
\hline MBY0608 & Cirsium \\
\hline MBY0609 & Cosmos \\
\hline MBY06 10 & Dahlia \\
\hline MBY0611 & Helianthus \\
\hline MBY06111 & Helianthus annuus \\
\hline MBY0612 & Lactuca \\
\hline MBY06121 & Lactuca sativa \\
\hline MBY0613 & Parthenium \\
\hline MBY0614 & Solidago \\
\hline MBY0615 & Sonchus \\
\hline MBY0616 & Taraxacum \\
\hline MBY0617 & Tragopogon \\
\hline MBY0618 & Xanthium \\
\hline MBY06181 & Xanthium canadense \\
\hline MBY06182 & Xanthium echinatum \\
\hline MBY0619 & Crepis \\
\hline MBY0620 & Piqueria \\
\hline MBY06201 & Piqueria trinervia \\
\hline MBY0621 & Carthamus \\
\hline MBY06211 & Carthamus tinctarius \\
\hline $\mathrm{MN}$ & Gymnospermae \\
\hline $\mathrm{MN} l$ & Coniferales \\
\hline MN101 & Pinaceae \\
\hline MN10101 & Pinus \\
\hline MN101011 & Pinus taeda \\
\hline MN2 & Gnetales \\
\hline MN201 & Gnetaceae \\
\hline MN20101 & Ephedra \\
\hline MN3 & Cycadales \\
\hline MN4 & Ginkgoales \\
\hline $\mathrm{Z}$ & Organism, general \\
\hline $\mathrm{Zl}$ & $\begin{array}{l}\text { Plant (including bacteria, virus, } \\
\text { rickettsia), not otherwise } \\
\text { specified }\end{array}$ \\
\hline $\mathrm{Z2}$ & Animal, not otherwise specified \\
\hline
\end{tabular}




\section{TUMOR CODE}

This catalogue of tumors and tumor types is arranged in an order corresponding to tumor classification based on the tissues from which they originated. Therefore, to recognize the continuity and to follow the sequence of this particular list of tissue types of tumors, the eye must learn to inspect the 4 th, 5th, and 6 th units of the symbols (Columns 21,22 , and 23), ignoring the other units. The spaces left between units 3 and 4 and between units 6 and 7 have no other significance than to make the part of the symbol designating tissue origins more easily distinguishable. The meaning of the 2 nd and 3 rd units (Columns 19 and 20) will be found by reference to the special list of anatomical items immediately following this list of tumors. The 7 th and 8 th units (Columns 24 and 25 ) are explained in the Key.

\section{$S$}

So0 1

SBI

SB 11

SBI 10001

SBI 10002

SBI 10003

SOO 1001

S00 1002

50011

SoO 1101

59211

S92 II 001

SOO 11011

SOO 1102

SOO 1103

SOO 111

S51

S51 111

S51 111101

S5I 11102

S51 11103

S51 11104

S5A

S5A 111

S5A 11101

S5A 1111

S5A 11111

S5A 11112

S5A 11113

S5A 11114

S5A 11115

S5A 11116

S5A 11117

S5A 11118

S5A 1112

S5A 11121

S5A 1113
Tumor, unspecified

Tumor of epithelial tissue, unspecified

Tumor of skin, unspecified

Carcinoma (tumor of epithelium) of skin, unspecified as to whether the origin is of glandular or non-glandular epithelium

Carcinoma DC5

Carcinoma Krebs 2

Carcinoma 1025 Furth (of cutaneous or subcutaneous tissue)

Carcinoma, otherwise unspecified (no organ origin known and epithelial type unknown)

Papilloma, unspecified as to squamous (non-glandular) or mucous (glandular) epithelium

Tumors of glandular epithelium, unspecified

Adenocarcinoma of unspecified glandular origin, unspecified

Pancreatic tumor, glandular, unspecified

Pancreatic tumor SB4

Adenocarcinoma JS2

Adenoma, otherwise unspecified (no organ origin known)

Papilloma of mucous epithelium, unspecified

Endocrine tumor, unspecified

Testicular tumor, unspecified

Tumor of testicular interstitial (endocrine) cells, unspecified

Testicular interstitial cell tumor $3 \mathrm{AC}_{1} \mathrm{SS}$

Testicular interstitial cell tumor $2 \mathrm{OAB}_{2} \mathrm{~T}$

Testicular interstitial cell tumor Bonser

Leydig cell tumor Furth

Ovarian tumor, unspecified

Ovarian glandular epithelium tumor, unspecified

Ovarian carcinoma XXX

Granulosa cell tumor, unspecified

Granulosa cell tumor, 18C57

Granulosa cell tumor, OL

Granulosa cell tumor E4478

Granulosa cell tumor Eschenbrenner

Granulosa cell tumor V

Granulosa cell tumor XIV

Granulosa cell tumor C57bI 10

Granulosa cell tumor NIH

Luteoma, unspecified

Luteoma IX

Theca cell tumor, unspecifled 
S5A 1114

S5A 11141

SA5 111101

SA5 11102

SA5 11103

SA4 11101

SA7 11101

SAI 11101

SAl 11102

S92 111

SOO 112

SIA

S1A 11201

S1A 11202

S 1 A 11203

S21 112

S21 1121

S21 11211

$\mathrm{S} 211122$

S21 11221

S2I 1123

S21 11231

S21 1124

S2l 11241

S31 112

S31 11201

S41 112

S41 11201

S4I 11202

S41 11203

S4I 11204

S41 11205

S41 11206

S41 11207

S41 11208

$\mathrm{S} 4111209$

S43

S43

S43 112

$\mathrm{S} 4311201$

S91 1121

S91 11211

S91 11212

59111213

S91 $112 \quad 14$

S91 11215

S9I 11216

S91 11217

S91 11218

S91 11219

S91 $1121 \mathrm{~A}$

S91 $1121 \mathrm{~B}$
Ovarian pseudomucinous cystadenoma; mucinous adenocarcinoma; mucinous papillary cystadenoma; etc. , unspecified

Ovarian tumor Symeonidis

Adrenal cortical tumor Illinois

Adrenal cortical carcinoma W35

Adrenal cortical carcinoma W92

Adrenal tumor Lorenz

Thyroid tumor \#180 (colloid adenoma)

Chromophobe pituitary tumor Furth dependent on absence of thyroid

Chromophobe pituitary tumor Furth independent of absence of thyroid

Pancreatic endocrine tumor (Islets of Langerhans tumor), unspecified

Exocrine gland tumor, unspecified

Tumor of fundic stomach, unspecified; rodent glandular stomach tumor, unspecified

Carcinoma 303

Carcinoma 328

Carcinoma 342

Glandular epithelial tumors of the lung, unspecified ${ }^{1}$

Pulmonary adenomatosis, unspecified l

Jaag siek te ${ }^{l}$

Pulmonary adenocarcinoma ${ }^{1}$

Pulmonary adenocarcinoma C4461

Pulmonary carcinomal

Pulmonary carcinoma MT8 ${ }^{1}$

Pulmonary adenoma, unspecified ${ }^{1}$

Pulmonary adenoma, Cohen ${ }^{1}$

Kidney carcinoma, unspecified

Kidney carcinoma Lucke

Liver tumor, unspecified (assuming glandular origin), hepatoma

Hepatoma \# 10 Andervont

Hepatoma $112 / \mathrm{B}$

Hepatoma $98 / 15$

Hepatoma C954

Hepatoma 3683

Hepatoma $3924 \mathrm{~A}$

Hepatoma 3930

Hepatoma N (Hepatoma NK Novikoff)

Hepatoma LCl 8

Carcinoma of the bile duct (= cholangioma)

Tumors of the bile duct, unspecified

Cholangioma, unspecified (typically adenocarcinoma)

Hepatoma 3924C (cholangioma)

Adenocarcinoma of the mammary gland, unspecified

Adenocarcinoma C3HBA ( $=\mathrm{C} 3 \mathrm{Hba})$

Adenocarcinoma $\mathrm{C} 3 \mathrm{H}-\mathrm{HC}$

Adenocarcinoma $\mathrm{C} 3 \mathrm{HB}$

Adenocarcinoma $\mathrm{H} 2712$

Adenocarcinoma, Indiana Untversity Tumor I

Adenocarcinoma Ll22 l

Adenocarcinoma MT-8

Adenocarcinoma S (L.E.O.)

Adenocarcinoma 5663

Adenocarcinoma $\mathrm{Ca}-\mathrm{Z}$

Adenocarcinoma Cal 49

\footnotetext{
These pulmonary epithelial tumors have been placed with glandular epithelial tissue tumors only because it seemed reasonable. The tissue-designating part of the pulmonary section can be altered, If the glandular association does not prove congenial to the concepts of any coding project adopting the coding scheme.
} 
FIELD E; Tumor Code

Columns 18, 19, 20, 21 , $22,23,24$, and 25

$\mathrm{S} 911121 \mathrm{C}$

S91 $1121 \mathrm{D}$

S9l II 2 IE

S91 $1121 \mathrm{~F}$

S9I 112 IG

S9l $1121 \mathrm{H}$

S9l112 II

S91 I12 IJ

S9l II 2 IK

S91 $1121 \mathrm{~L}$

S91 $1121 \mathrm{M}$

S9I II IN

S91 11210

S91 I1 IP

S9I II2 IQ

S9I II IR

S91 112 IS

S9l I12 1T

S91 I12 1U

S91 II IV

S91 I 12 1W

S9I 112 IX

S91 $1121 Y$

S9l 112 IZ

S9l $112 \mathrm{Al}$

S91 112 A2

S91 $112 \mathrm{~A} 3$

S9I 112 A4

S9I 112 A5

S9I 1122

S91 II 21

S91 11222

S91 11223

S91 11224

S91 11225

S91 11226

S91 11227

S9I 11228

59I 11229

592112

S93 112

59311201

S94 112

S94 11201

S97 112

S9A 112

S9A 11201

S98 1123

SOO 12

S00 121

S00 122

SOO 123

S34

S34 12301

S34 12302

SOO 124

SOO 1241

SOO 125

SI8 12501
Adenocarcinoma $\mathrm{Ca}-15$

Adenocarcinoma SPC $3 \mathrm{H}$

Adenocarcinoma DC4

Adenocarcinoma E0771 (=E0771)

Adenocarcinoma 755 Bagg, Jacksen

Adenocarcinoma Bl

Adenocarcinoma BW 1898

Adenocarcinoma 7-SBT

Adenocarcinoma 41 -SBT

Adenocarcinoma 21 -SBT

Adenocarcinoma 49-SBT

Adenocarcinoma 71 -SBT

Adenocarcinoma C57X

Adenocarcinoma dbaH

Adenocarcinoma Cal69

Adenocarcinoma Mijono

Adenocarcinoma $\mathrm{Cal}$

Adenocarcinoma $\mathrm{IT}_{\mathrm{I}}$

Adenocarcinoma $\mathrm{dbr} B(=\mathrm{dBr} B)$

Adenocarcinoma RC

Adenocarcinoma DC2

Adenocarcinoma DC3

Adenocarcinoma SPAH

Adenocarcinoma TA3

Adenocarcinoma R2426

Adenocarcinoma R2857

Adenocarcinoma IRC741

Adenocarcinoma Webster

Adenocarcinoma Shay ("Duct cell type")

Mammary carcinoma, unspecified

Carcinoma $\mathrm{TC} 3 \mathrm{H}$ (mixed cell)

Carcinoma, Tumor \# I Youngner

Carcinoma, Tumor \#2 Youngner

Carcinoma D1905 Heston

Carcinoma 63 Bashford (English)

Carcinoma I509la

Carcinoma 10 Lewis

Carcinoma, Ehrlich tumor (ascitic form)

Carcinoma S674

Pancreatic tumor, exocrine, unspecified

Tumors of sebaceous glands, unspecified

Hamartoma-malignum BS $_{I}$ (sebaceous gland origin?), gluteal region of rat

Tumors of harderian glands, unspecified

Harderian gland carcinoma 2226

Tumor of glandular tissue of submaxillary gland, unspecified

Tumor of glandular epithelium of seminal vesicles, unspecified

Carcinoma Flexner-Jobling

Pleomorphic cell parotid gland tumor, unspecified

Tumors of non-glandular epithellum, unspecified

Tumors of columnar, non-glandular epithelium, unspecified

Tumors of stratified, non-glandular epithelium, unspecified

Tumors of transitional, non-glandular epithelium, unspecified

Tumors of urinary bladder, unspecifled

Bladder tumor $\mathrm{C} 3 \mathrm{H}$

Bladder tumor A

Tumors of squamous, non-glandular epithelium, unspecified

Papllloma of squamous, non-glandular epithellum, unspecified

Tumors of squamous stratified, non-glandular epithelium, unspecifled

Gastric carcinoma line A (squamous-cell type) 


\author{
S $18 \quad 12502$ \\ S1A 12501 \\ S52 12501 \\ S5D 12501 \\ S81 12501 \\ SBI 12502 \\ SB 11251 \\ S77 12511 \\ SO0 1252 \\ SB1 12521 \\ S00 126 \\ $596 \quad 126 \quad 11$ \\ $\$ 96 \quad 126 \quad 12$ \\ S96 $126 \quad 13$ \\ $\$ 99 \quad 126 \quad 11$ \\ SO0 1201 \\ SO0 13 \\ SO0 131 \\ SO0 I3A \\ SO0 13B \\ $59 \mathrm{C} 13 \mathrm{~B} 1$ \\ $\mathrm{S} 002$ \\ $\mathrm{S} 002 \mathrm{I}$
}

SO0 211

SO0 2111

S8B 2111

$S 8821111$

S8B 21112

S8B 21113

S8B 21114

S8B 21115

S8B 21116

$S 8 B 21117$

S8B 21118

S8D 2111

S8D 21111

S8D 21112

S8D 21113

S8D 21114

S8D 21115

S8D 21116

S8D 21117

SA8 2111

SA8 211111

SA8 21112

SA8 21113

SA8 21114

SOO 2112

500212
Carcinoma G8755 (squamous-cell type)

Carcinoma \#338 (squamous-cell type)

Carcinoma Brown-Pearce (Epithelioma Brown-Pearce)

Cervical carcinoma T145

Tumor 1 Cowdry (Tumor I)

Tumor D Cowdry

Tumor of basal cells of squamous stratified epithelium (basal-cell carcinoma

[variety of squamous-cell carcinoma]), unspecified

Carcinoma HCl (basal-cell type)

Papilloma tumor of squamous stratified non-glandular eplthelium, unspecified

Papilloma Shope (squamous-cell type)

Tumors of myoepithelial (non-glandular) epithelium, unspecified

Myoepithelial salivary gland tumors of dogs and mice, general

Myoepithelioma $243 \mathrm{C}$

Pleomorphic carcinoma BW 1081

Submaxillary tumor C-CBA

Cystadenoma (assumed to be of non-glandular epithelial origin), unspecified

Tumors of mixed glandular and non-glandular epithella, unspecified

Tumors of mixed endocrine and unspecified non-glandular epithelia, unspecified

Tumors of mixed exocrine and unspecified non-glandular epithelia, unspecified

Tumors of mixed exocrine glandular tissue and myoepithelial tissue, unspecified

Myoepithelial sweat gland tumor, unspecified

Tumors of blood and lymph and blood-and lymph-forming tissues

Tumors of the specific leukoblastic tissues of the lymphatic organ system;

leukemla. (This symbol is not used to code tumors of the lymph organs, lymphomas [S0022].)

Lymphocytic leukemia (leukemia in which the involved leukocytes are lymphocytes and lymphoblasts). (Synonyms: lymphoid leukemia, lymphatic leukemia, lymphoblastic leukemia, lymphogenous leukemia, lymphocythemic leukemia, leukocytic leukemia)

Lymphocytic leukemia, leukemic, unspecified

Leukemic lymphocytic leukemia with origin in the spleen, unspecified

Lymphoid leukemia AK4

Lymphoid leukemia 100

Lymphoid leukemia 868

Lymphoid leukemia 876

Lymphoid leukemia 926R

Lymphatic leukemia $926 \mathrm{~F}$

Lymphatic leukemla Shay

Leukemia Line I MacDowell (lymphocytic)

Leukemic lymphatic leukemia with origin in the spleen and lymph nodes, unspecified

Lymphoid leukemia HE8186

Lymphoid leukemia L1210

Lymphatic leukemia L4616

Lymphatic leukemia L3054

Leukemia L3660 (lymphocytic)

Lymphatic leukemia Ak

Lymphoid leukemia Furth

Leukemic lymphatic leukemia with origin in the thymus, unspecified

Lymphatic leukemia $1016 \mathrm{~F}$

Lymphatic leukemia P 1534

Lymphatic leukemia Leu 3

Lymphoid leukemia VII

Lymphatic leukemia, aleukemic, unspecified

Granulocytic leukemia (leukemia in which the involved leukocytes are myelocytic and polymorphonuclear; i. e., granulocytes). (This symbol's definition includes chloroma [= chlorosarcoma], since it is a type of myelogenous leukemia.) 
SO0 2121

S8B 2121

S8B 21211

S8B 21212

S8B 21213

S8B 21214

S8B 21215

S8B 21216

S8B 21217

S8A 2121

S8A 21211

SOO 2122

SOO 213

S00 2131

SOO 2132

S00 22

SO0 2201

S21 2201

S21 22011

S41 2201

S4l 22011

S41 22012

54122013

S41 22014

S5A 220 !

S5A 22011

S8B 2201

S8B 22011

S8B 22012

S00 221

S8B 221

S8B 22101

$\mathrm{S} 8 \mathrm{C} 221$

$\mathrm{S} 8 \mathrm{C} 22101$

$58 \mathrm{C} 22102$

S8C 22103
Myelogenous leukemia, leukemic, unspecified

Leukemic myelogenous leukemia with origin in the spleen, unspecified

Myeloid leukemia 15F

Myeloid leukemia A

Myeloid leukemia 274

Myeloid leukemia 686

Myeloid leukemia 765

Myeloid leukemia 15A

Myeloid leukemia Cl 498

Leukemic myelogenous leukemia with origin described as being "blood", unspecified

Myelogenous leukemia Shay (chloroma type)

Myelogenous leukemia, aleukemic, unspecified

Monocytic leukemia (leukemias in which the involved leukocytes are mostly monocytes). (Synonym: aleukemic reticulosis.) (This is possibly an atypical myelogenous leukemia.)

Monocytic leukemia, leukemic, unspecified

Monocytic leukemia, aleukemic, unspecified

Tumor of lymphoid tissue, as distinct from tissues of the strictly leukoblastic tissues of the lymphatic organ system. Tumors of the lymph nodes, spleen, thymus, tonsils, lymphoid tissue elements of bone marrow, and diffuse lymphatic tissue of the respiratory organs, the gastro-intestinal tract, liver, etc. ; lymphoma, unspecified. Includes the common experimental lymphoid tumors of chickens, distinguished by Symbol 1 as the seventh digit in a symbol for a specified chicken lymphoid tumor. Note: In constructing symbols for tumors of lymphoid tissue (S0022---), when these tumors arise in lymph nodes or diffuse lymphatic tissues associated with only a body area or cavity, the structural (anatomical) origin will be indicated merely as lymph node or lymph tissue (Symbol 8I) rather than to attempt to code the body region or organ in or near which was the lymph node or tissue in which the tumor originated. (It is recognized that this makes the anatomical and tissue units of the tumor symbol somewhat redundant, but this occurs because of the sltuation of the organs involved being of almost a single tissue type so that having identified the organs, the tissue is also identified.) If the lymphatic tissue tumor arises in the spleen, thymus, tonsil, liver, intestine, lungs, or in any other definite organ (rather than in a lymph node or "near" or "in the region" of an organ or at a general body area), that organ is specified in the anatomical unit of the symbol.

Lymphoid tumor of fowls (a group of experimental transplantable tumors), unspeclfied

Lymphold tumor of fowls with origin in the lung, unspecified

Lymphold tumor RPL 14

Lymphoid tumor of fowls with origin in the liver, unspecified

Lymphold tumor RPL12 (Olson lymphoid tumor)

Lymphoid tumor RPL16

Lymphoid tumor RPL17

Lymphoid tumor RPL21

Lymphoid tumor of fowls with origin In the ovary, unspecified

Lymphoid tumor RPL 18

Lymphold tumor of fowls with origin in the spleen, unspecified

Lymphoid tumor RPL 15

Lymphold tumor RPL20

Lymphosarcoma, unspectfied

Lymphosarcoma with origin in the spleen, unspecified

Lymphosarcoma 1527

Lymphosarcoma with orlgin in a lymph node (any body region), unspecified

Lymphosarcoma Patterson

Lymphosarcoma Mecca

Lymphosarcoma DS9 
S8C 22104

S8C 22105

S8C 22106

S8C 22107

S8C 22108

S8C 22109

S8C $2210 \mathrm{~A}$

SA8 221

SA8 22101

SA8 22102

SA8 22103

SA8 22104

S00 222

S8C 222

S8C 22201

S8C 22202

S00 223

S41 223

S41 22301

S5A 223

S5A 22301

S8C 223

S8C 22301

S8C 22302

S8C 22303

S8C 22304

S8C 22305

S8C 22306

S91 223

S91 22301

SA8 223

SA8 22301

SO0 224

S41 224

S41 22401

S8C 224

S8C 22401

SOO 23

SOO 24

SO0 2401

S5A 24011

S8A 24011

S8A 24012

SOO 3

S00 3001

SO0 3002

SO0 31

S00 3101

SO0 3102
Lymphosarcoma TT 15

Lymphosarcoma TT8

Lymphosarcoma TTIO

Lymphosarcoma Krebs, Rask-Nielsen, Wagner

Lymphosarcoma Murphy-Sturm

Lymphoid Sarcoma 15BL

Lymphoma \# 1 (L-I) (L\# I)

Lymphosarcoma with origin in the thymus

Lymphosarcoma 6C3HED Gardner, solid form

Lymphosarcoma 6C3HED Gardner, ascitic form

Thymoma Dalton (Lymphosarcoma)(Thymoma dba)

Lymphosarcoma C43 Kaplan

Lymphocytic lymphoma, unspecified

Lymphocytic lymphoma with origin in a lymph node (any body region), unspecified Lymphoma \#2 (L\#2) (lymphocytic)

Lymphoma A40 (lymphocytic)

Reticulum cell sarcoma; reticulum-cell-like tumor

Reticulum cell sarcoma with origin in the liver, unspecified

Reticulum cell sarcoma 48814

Reticulum cell sarcoma with origin in the ovary, unspecified

Reticulum cell sarcoma F8469

Reticulum cell type sarcoma with origin in lymph node

Sarcoma R39, reticulum-cell type

Lymphosarcoma R2788, reticulum-cell type

Lymphosarcoma Bagg, reticulum-cell type

Reticuloendothelioma \#9

Reticuloendothelioma \#19

Reticulum-cell-like sarcoma, Yoshida

Reticulum cell sarcoma or reticulum-cell-like tumor with origin in the mammary gland, unspecified

Reticulum-cell-like tumor Copeland

Reticulum cell sarcoma or reticulum-cell-like tumor with origin in the

thymus gland, unspecified

B-leukemia Bichel; reticulum-cell type

Plasma cell tumor, unspecified

Plasma cell tumor with origin in the liver, unspecified

Plasmoma IRS 6820

Plasma cell tumor with origin in a lymph node, unspecified

Plasma cell leukemia Bichel

Erythremia and related erythrocytic tumors

Tumors of combined erythroblastic and leukoblastic elements. Also, tumors described as "hemocytoblastic" and not otherwise defined.

Tumors as defined by S0024 (--of fowls, unspecified)

Lymphoid tumor RPL1 9

Erythrogranuloblastosis RPL3

Erythrogranuloblastosis RPL4

Tumors of connective tissue, unspecified. (Excluded from the definition of this symbol are tumors of the connective tissues making up sheaths and membranes enclosing peripheral and central parts of the nervous system: endoneurium [sheath of Henle], perineurium, epineurium, and meninges. Also excluded are tumors of the interstitial tissues of the nervous system: neurilemma [sheath of Schwann], satellite cells, astroglia, oligodendroglia, mesoglia, and ependyma. Tumors of these tissues are coded with tumors of nerve tissue, regardless of differences in embryonic origin and function, by Symbol S007.-...) Benign or innocent connective tlssue tumor, unspecified

Sarcoma, unspecified

Tumors of fibroblastic origin, unspecified; fibroma or fibrosarcoma

Fibroma, unspecified

Fibrosarcoma, unspecified 
S91310

S91 31011

SBO 3101

SBO 310 Il

SOO 3102

S91 3102

59131021

59131022

S91 31023

$\mathrm{SC} 33102$

SC3 31021

SC3 31022

SC3 31023

SC3 31024

SC3 31025

SC3 31026

SC3 31027

SC3 31028

SC3 31029

SC3 $3102 \mathrm{~A}$

SC3 $3102 \mathrm{~B}$

SC3 $3102 \mathrm{C}$

SC3 $3102 \mathrm{D}$

SC3 $3102 \mathrm{E}$

SC3 $3102 \mathrm{~F}$

SC3 $3102 \mathrm{G}$

SC3 $3102 \mathrm{H}$

SD3 3102

SD3 31021

SD5 3102

SD5 31021

$S C 13002$

SCI 30021

SCA 3002

SCA 30021

SOO 3003

SOO 30031

SOO 3004

S00 30041

S00 3005

S00 3006

SO0 3106

SC3 3106

SC3 31061

SO0 3007

SO0 3008

SO0 3108

SC3 3108

SC3 31081

S00 3009

S00 32

SD6 32

SD6 32001

S00 3201

S00 3202

5183202

S18 32021
Fibroma with origin in the mammary gland, unspecified

Fibroma Emge

Fibroma with origin in skin, unspecified

Infectious fibroma Shope

Fibrosarcoma, unspecified

Fibrosarcoma with origin in the mammary gland, unspecified

Sarcoma dba G (fibrosarcoma)

Fibrosarcoma R 2572

Fibrosarcoma Noble

Fibrosarcoma with origin in subcutaneous tissue, unspecified

Fibrosarcoma S 620

Fibrosarcoma S 621

Fibrosarcoma S 629

Fibrosarcoma Sa 89

Fibrosarcoma S 636

Fibrosarcoma HE 8971

Sarcoma Earle L (L Sarcoma), fibrosarcoma

Fibrosarcoma Sa 87

Fibrosarcoma DS7

Sarcoma DS 8 (fibrosarcoma)

Fibrosarcoma BP 839

Fibrosarcoma ACMCA 2

Fibrosarcoma King A \#231

Fibrosarcoma \#7

Fibrosarcoma \#8

Fibrosarcoma JS 1

Fibrosarcoma Friedewald

Fibrosarcoma of the thoracic region, unspecified

Tumor C, fibrosarcoma of chicken

Fibrosarcoma of the forelimb, unspecified

Fibrosarcoma Sa 27

Sarcoma with origin in bone region, but not of osteoblastic origin, unspecified Sarcoma R 92

Sarcoma with origin in muscle region, but not of muscle tissue origin, unspecified

Sarcoma MCIM

Myxoma, unspecified

Infectious myxoma

Myxosarcoma, unspecified

Sarcoma HS 5 (No. 5), myxosarcoma

Myxoma mixed with a benign connective tissue tumor, unspecified

Myxoma mixed with a malignant connective tissue tumor, unspecified

Fibrosarcoma mixed with a myxoma

Fibrosarcoma mixed with a myxoma with origin in subcutaneous tissue, unspecified

Chicken tumor I (Rous Sarcoma), fibrosarcoma and myxoma

Myxosarcoma mixed with a benign connective tissue tumor, unspecified

Myxosarcoma mixed with a malignant connective tissue tumor, unspecified

Fibrosarcoma mixed with a myxosarcoma

Fibrosarcoma mixed with a my xosarcoma with origin in subcutaneous tissue, unspecified

Myxosarcoma 14(d) 7, fibrosarcoma

Rhabdosarcoma (a sarcoma mixed with striated muscle fibers), unspecified

Tumors of osteoblastic origin; osteoma or osteosarcoma, unspecified

Osteoblastic tumor (unspecified as to being osteoma or osteosarcoma) with

origin in a bone of the hind limb, non-specific

Bone tumor \#4 NCI

Osteoma, unspecified

Osteosarcoma, unspecified

Osteosarcoma with origin in the stomach, unspecified

Osteogenlc Sarcoma \#344 
$\mathrm{SCl} 3202$

SCl 32021

SD3 3202

SD3 32021

SD3 32022

SD8 3202

SD8 32021

S00 33

S00 3301

SO0 3302

S00 34

SOO 340

S00 3402

SC 33402

SC3 34021

SOO 4

S00 40001

SC3 4

SC3 40001

SC3 40002

SD 44

SD4 40001

S00 41

S9l 41

59141001

SOO 42

$\$ 4142$

54142001

S91 42

59142001

S91 42002

$\mathrm{SC} 342$

SC3 42001

SC 342002

SC 342003

SC3 42004

SC3 42005

SD4 42

SD4 42001

S00 43

SOO 44

S2 144

S21 44001

SD4 44

SD4 44001

SO0 45

S91 45

S91 45001

S91 45002

SC 345

SC3 45001

SC3 45002

SC3 $450 \quad 03$
Osteosarcoma with origin in an unspecified bone, non-specific

Sarcoma \#4 Argonne

Osteosarcoma with origin in (an unspecified bone of) the thoracic region, non-specific

Osteogenic Sarcoma Wagner (WA Sarcoma)

Osteogenic Sarcoma T 491

Osteosarcoma with origin in (an unspecified bone of) the inguinal region, unspecified

Osteogenic Sarcoma Ridgway

Tumors of cartilaginous origin; chondroblastoma, unspecified

Chondroma, unspecified

Chondrosarcoma, unspecified

Tumors of lipoid origin; lipoblastoma, unspecified

Lipoma, unspecified

Liposarcoma, unspecified

Liposarcoma with origin in subcutaneous tissue, unspecified

Liposarcoma D4888

Tumors designated only as "round cell sarcoma", "spindle cell sarcoma", "mixed cell sarcoma", "pleomorphic cell sarcoma", "anaplastic cell sarcoma", or "sarcoma undifferentiated"

Sarcoma M 4

Sarcoma presumably of connective tissue origin, but the cell types not designated; with origin in subcutaneous tissue

Sarcoma E 2730

Sarcoma \#3 Lewis

Sarcoma presumably of connective tissue origin, but the cell types not designated; with origin in the perineal region

Sarcoma 319 Walker

"Round cell sarcoma", unspecified

Round cell sarcoma with origin in the mammary gland, unspecified

Sarcoma C $3 \mathrm{H}(\# 2)$, round cell

"Spindle cell sarcoma", unspecified

Spindle cell sarcoma with origin in the liver, unspecified

Sarcoma IRS 4337, spindle cell

Spindle cell sarcoma with origin in the mammary gland, unspecified

Sarcoma RIII (\#4), spindle cell

Sarcoma Emge, spindle cell

Spindle cell sarcoma with origin in subcutaneous tissue, unspecified

Sarcoma B 12 (L. E. O.), spindle cell

Sarcoma I (SI), spindle cell

Sarcoma DS 2, spindle cell

Sarcoma DS 3, spindle cell

Sarcoma DS 5, spindle cell

Spindle cell sarcoma with origin in the abdominal region, unspecified

Sarcoma Jensen, spindle cell

"Mixed cell sarcoma", unspecified

"Fusiform cell sarcoma", unspecified

Fusiform cell sarcoma with origin in the lung, unspecified

Sarcoma Ma 387, fusiform cell

Fusiform sarcoma with origin in the abdominal region, unspecified

Sarcoma 1643, fusiform

"Pleomorphic cell sarcoma", unspecified

Pleomorphic cell sarcoma with origin in the mammary gland, unspecified

Sarcoma Al9E, pleomorphic cell

Sarcoma 37, pleomorphic cell

Pleomorphic cell sarcoma with origin in subcutaneous tissue, unspecified

Sarcoma T 241 Lewis, pleomorphic cell

Sarcoma DS 4, pleomorphic cell

Sarcoma IRS 1548, pleomorphic cell 


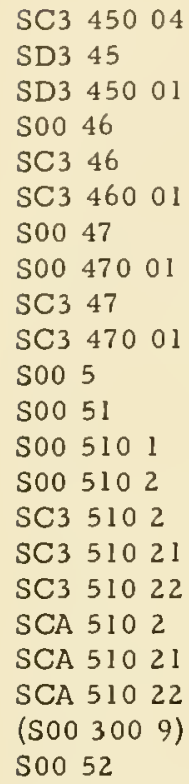

Sarcoma HS 6, pleomorphic cell

Pleomorphic cell sarcoma with origin in the thoracic region, unspecified Sarcoma 180 Crocker, pleomorphic cell

"Anaplastic cell sarcoma", unspecified

Anaplastic cell sarcoma with origin in subcutaneous tissue, unspecified Sarcoma S 637, anaplastic cell

"Undifferentiated cell sarcoma", unspecified

Sarcoma A 274, undifferentiated

Undifferentiated cell sarcoma with origin in subcutaneous tissue, unspecified

Sarcoma MCI, undifferentiated

Tumors of muscle tissue, unspecified

Tumors of striated muscle, unspecified

Rhabdomyoma; benign tumor of striated muscle; unspecified

Rhabdomyosarcoma; a sarcoma mixed with a rhabdomyoma; unspecified

Rhabdomyosarcoma with origin in subcutaneous tissue, unspecified

Rhabdomyosarcoma S 653

Rhabdomyosarcoma HS 4

Rhabdomyosarcoma with origin in an unspecified muscle, non-specific

Rhabdomyosarcoma H 6668

Rhabdomyosarcoma MCIA

Rhabdosarcoma (a sarcoma mixed with striated muscle fibers), unspecified

Tumors of smooth muscle, unspecified

Leiomyoma, innocent or benign tumor of smooth muscle, unspecified

Leiomyosarcoma; malignant tumor of smooth muscle, unspecified

Tumors of vascular tissue; endothelial tumors; angiomas; unspecified

Capillary angioma

Hemangioendothelioma, unspecified

Hemangioendothelioma with origin in the epididymis, unspecified

Hemangioendothelioma $\mathrm{H} 622 \mathrm{I}$

Cavernous angioma, unspecified

Tumor of nervous tissue or of tissues of the nerve sheath, the meninges, and the mesoglia; unspecified

Tumors of nerve cells and fibers or derivatives, unspecified

Tumors of the adrenal medulla and sympathetic nerves (including neuroblastoma), unspecified

Neuroblastoma, unspecified

Neuroblastoma with orlgin in the region of the spinal cord, unspecified

Neuroblastoma C 1300

Tumors of nerve cells of the ganglia, unspecified

Ganglioneuroma, unspecified

Tumors of sensory receptor nerve cells or their modifications and derivatives, unspecified

Retinoblastoma, unspecified

Tumors of neuroglia, nerve sheaths, or other nerve interstitial tissue, unspecified

Tumors of tissues of the nerve sheath and the meninges, unspecified

Neurofibroma, unspecified. This tumor type has an obscure or controversial

tissue origin; it is from either the perineurium or neurilemma. (Synonyms:

neurinoma, perineurial fibroma, fibroblastoma, Schwannoma)

Neurofibromatosis (Recklinghausen's disease, neuromatosis, multiple neuroma), unspecified

Neurogenic sarcoma; neurosarcoma (origin in the nerve sheath and usually located in the subcutaneous tissue or in a muscle of the arm or leg); unspecified as to organ

Meningioma, unspecified

Tumors of the interstitial tissues of the brain; glioma; unspecified

Tumors of spongioblasts; glioblastoma; glioblastoma multiforme; spongioblastoma multiforme; gliosarcoma; unspecified

Glloblastoma 8100 Moore 
S00 7222

S6l 72221

S00 7223

S67 7223

S00 7224

S00 7224

S67 7224

S61 7224

S6l 72241

S00 8

S00 8001

S00 8002

S7A 8002

S7A 80021

SD7 8002

SD7 80021

SD7 80022

SB2 8002

SB2 800 21

SO0 9

S00 91

S9191

S91 91001

So0 92

S91 92

S91 92001

S91 92002

S00 93

S91 93001

S00 94

S5A 94001

S5A 94002

SO0 A
Tumors of astrocytes; astrocytoma; unspecified

Astrocytoma $\mathrm{C} 3 \mathrm{H}$ (18)

Tumor of undifferentiated preneurogliar cells, unspecified

Medulloblastoma of the cerebellum

Tumor of ependymal cells, unspecified

Ependymoma, unspecified

Ependymoma of the cerebellum, unspecified

Ependymoma of the brain, unspecified

Ependymoma $\mathrm{A}(22)$

Tumors of melanin-forming tissues, unspecified

Benign or innocent melanoma; naevus; mole; unspecified

Malignant melanoma; melanotic sarcoma; unspecified

Malignant melanoma with origin in the ear, unspecified

Melanoma Harding Passey

Malignant melanoma with origin in the tail, unspecified

Melanoma S91 Cloudman (dba melanoma)

Amelanotic melanoma S91A (C91AA)

Malignant melanoma with origin in the corium, unspecified

Melanotic tumor Brunst (Chromatophoroma malignum)

Tumors of mixed tissues (epithelial and connective tissues)

Tumors of connective tissue containing glandular structures (adenofibroma), unspecified

Mammary adenofibroma, unspecified

Adenofibroma Emge

Tumors of glandular epithelial tissue with fibrous connective tissue; fibroadenoma

Mammary gland fibroadenoma, unspecified

Fibroadenoma R2737

Fibroadenoma Tumor \#6

Tumors of epithelial and connective tissue origin; carcinosarcoma; unspecified Carcinosarcoma 256 Walker (Walker rat tumor)

Teratomas

Embryoma Brues-Jackson

Teratoma E6496

Tumors of embryonal tissues, unspecified 


\section{SYMBOLS FOR ANATOMICAL ITEMS, INCORPORATED AS THE SECOND AND THIRD UNITS OF TUMOR SYMBOLS}

These items (for the second and third units of the tumor symbols, Columns 19 and 20) represent gross structures only. (Tissue types are indicated by the fourth, fifth, and sixth units and are not a part of this list.) For example, smooth muscle, striated muscle, bone marrow, etc., are not included here, since they are types of tissue; however, organs containing smooth muscle, organs and body areas containing striated muscle (or specific skeletal muscles [organs], such as the gastrocnemius, trapezius, etc.), and specific bones (organs) are in the list. The list may be expanded as necessary for specific organs.

1 Alimentary tract

11 Lip and inner cheek

12 Mandible

13 Palate

14 Gums

15 Tongue

16 Throat

17 Esophagus

18 Stomach; fetal stomach

19 Cardiac region of stomach; rodent forestomach or cardiac sac

IA Fundic region of stomach; rodent glandular stomach

I B

IC

ID

$1 \mathrm{E}$

IF

$1 \mathrm{G}$

$1 \mathrm{H}$

$1 \mathrm{I}$

2

2.1

Pyloric region of stomach

Duodenum

Small intestine

Large intestine

Rectum

Appendix and caecum

Anus

Mesentery

Respiratory system

Lung

Excretory system.

Kidney

Kidney pelvic region

Urethra

Urinary bladder

Ureter

Liver and associated structures

Liver

Gall bladder

Bile duct

Reproductive system

Testicle

Scrotum

Seminiferous tubule

Epididymls

Vas deferens

Penis

Ovary

Oviduct

Uterus, in toto, or not otherwise

specified

Cervix
$5 E$

$5 \mathrm{~F}$

6

61

62

63

64

65

66

67

68

69

$6 \mathrm{~A}$

7

71

72

73

74

75

76

77

78

$7 \mathrm{~A}$

8

81

$8 \mathrm{~A}$

$8 \mathrm{~B}$

$8 \mathrm{C}$

8D

9

91

92

93

94

95

96

97

98

99

$9 \mathrm{~A}$

$9 B$

$9 \mathrm{C}$

A
Body of uterus

Vagina

Nervous system, exclusive of sensory organs

Brain

Cerebrum

Mid-brain

Thalamus

Hypothalamus

Pons

Cerebellum

Medulla

Meninges

Spinal cord

Sensory organs

Eye

Retina

Iris, choroid coat, intrinsic muscles

Lens

Cornea

Sclera

Eyelid, conjunctiva

Nictitating membrane

Ear

Circulatory system; heart, vessels, and fluids

Heart

Blood and lymph

Spleen

Lymph node

Spleen and lymph nodes (combination)

Exocrine glands (exclusive of the liver)

Mammary gland

Pancreas

Sebaceous gland

Harderian gland

Gastric gland

Salivary gland, unspecified

Sub-maxillary gland

Parotid gland

Sub-lingual gland

Seminal vesicle

Prostate

Sudoriparous (sudoriferous) gland

Endocrine glands 


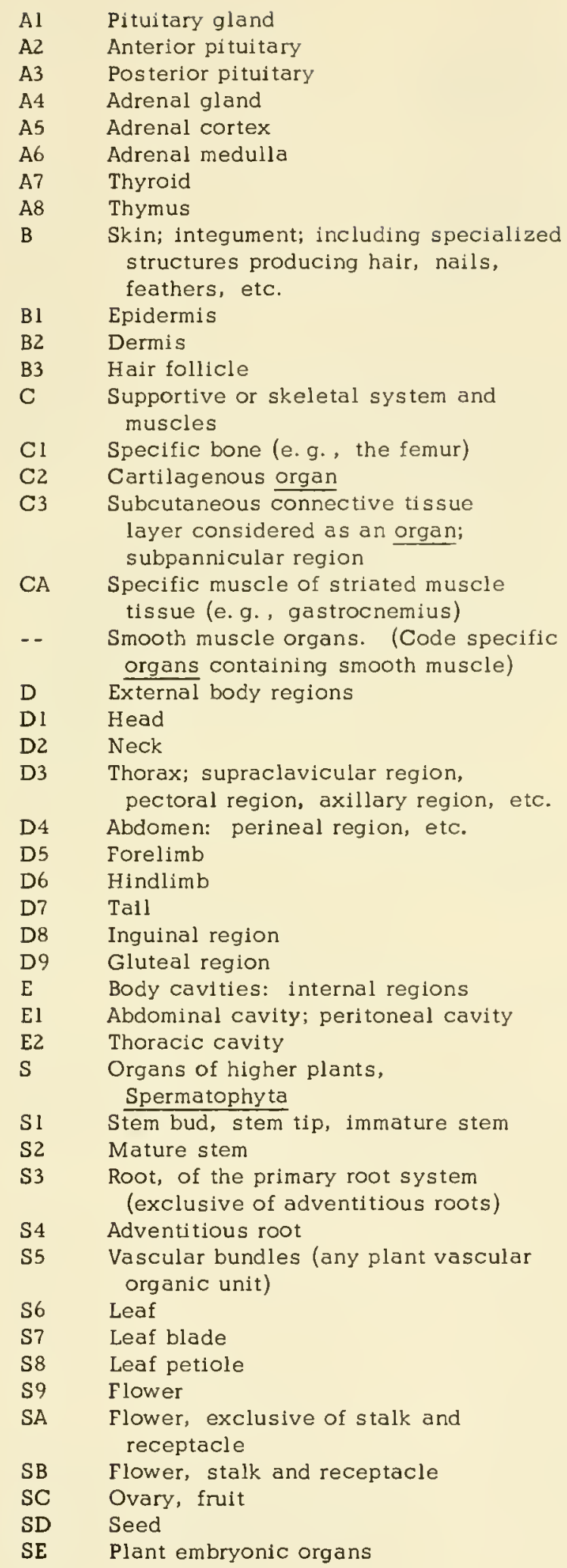




\title{
PATHOLOGY CODE
}

\author{
REPRESENTATIVE LIST OF DISEASES \\ AND IDENTIFYING CODE SYMBOLS
}

Other pathologies may be added to this list and symbols constructed according to the procedures and policies outlined in the Key discussion of the Pathology Code.

The spaces between the fourth and fifth and between the sixth and seventh units of the symbols have no significance in the list except to facilitate analysis of the second and third (anatomical and etiological) parts of the symbol.

The information coded into these symbols assigned to pathologies is, or can be, supplemented by coding in Fields $\mathrm{H}$ and $\mathrm{T}-2$, as described in the Key. In a few instances, to describe a pathology adequately, it is necessary to use Field $\mathrm{H}$ and, for these pathologies, the definition of each includes specification of that Field $\mathrm{H}$ code entry. This is generally the case with infectious diseases entered in the list and with certain others such as dermatomyositis, sprue, arthritis due to rheumatic fever, jaundice, etc.

The anatomy list of Field $\mathrm{H}$ should be consulted for the definitions of the second part of the symbol (Columns 19, 20, and 21); the etiology list (following this list of pathologies) should be consulted for the definitions of the third part (Columns 22 and 23). A supplementary list of general pathological manifestations, indicated by letter symbols in Column 25, follows the etiology list.

T1 108100

T1108200

T1108300 JSC 10021

JSC 10031

T2130001

T2 IE 00 OA T3100001

T3110001

T3110002

T3120001

T3 1700 OF

T31C 8100

T32000 01

T320 G1 02

T3250001

T325 4300

T325 P2 00

T325 $\times 200$

$\mathrm{T} 325 \times 300$

T325 8100

T32900 01

T32D P2 00

T3330001

T3330002

T33300 03

T3330004

T333 F9 02

T333 FE 02

T333 7403

T339 WS 00
Epilepsy, Grand mal

Petit mal

Psychomotor seizure

Poliomyelitis (Legio debilitans); Field $\mathrm{H}$ : nervous system (1)

Rabies (Formida inexorabilis); Field $\mathrm{H}$ : nervous system (1)

Glaucoma (aqueous humour), cause unspecified

Conjunctivitis, cause unspecified

Anginal syndrome

Auricular flutter, cause unspecified

Auricular fibrillation, cause unspecified

Ventricular paroxysmal tachycardia

Myocardial infarction

Sinus arrhythmia

Thrombosis, unspecified as to whether arterial or venous, cause unspecified

Thromboangiitis obliterans

Arterial thrombosis, cause unspecified

Hypertensive vascular disease

Arteriosclerosis

Periarteritis nodosa

Atherosclerosis

Hypertension, essential

Purpura, non-thrombopenic; capillary purpura, cause not specified

Coronary sclerosis

Anemia, unspecified as to cause or type

Anemia, macrocytic, unspecified as to cause

Anemia, hemolytic, unspecified as to cause

Jaundice, cause unspeclfied; hyperbilirubinemia. (For all hepatogenous jaundices, code liver. Symbol $\mathrm{E}$, in Field $\mathrm{H}$.)

Anemia due to Vitamin $B_{12}$ deficiency

Anemia due to deficiency of folic acid and intrinsic factor; perniclous anemia

Anemia, slckle cell

Purpura, idiopathic thrombocytopenic 
T339 XJ 00 $\mathrm{T} 34200 \mathrm{OH}$

T342 $43 \mathrm{OH}$

T346 6300 JS410021

T50000 $0 \mathbf{1}$ $\mathrm{T} 500 \mathrm{Ll} 101$ T500 0002 T5 $14000 A$ T51900 $1 \mathrm{~B}$ T519 S2 00 JS50IOI 4 T6IA OO OA T6600001 T660 0002 T66000 03 $\mathrm{T} 660 \times 100$ T6700001 J6301011 42101011 T70000 01 T71 100002 T715 00 0A T7 $15000 \mathrm{G}$ T818 00 0A T930 00 0A

T930 61 0A T930710A T930 $900 \mathrm{~A}$ T970 G1 00

T970 GI 01 T970 Ni OE T9J0 00 OA TAI0 00 OA TAIO LI OA TBO0 0001

TB00 GI 02

TB00 0003

TBOO OO OA

TBOO OO OB TBOO 00 OF TBOO $00 \quad 0 \mathrm{G}$ TBO0 2100 TBO0 2500

TB00 2600
Hemophilia

Splenomegaly, cause unspecified. Splenomegaly due to Gaucher's Disease:

Code Gaucher's Disease in Field E and splenomegaly in Fields T-2 and H

(T-2: 281; H-1:342) and the chemical effect by one of Symbols J-R in Field T-1.

Splenic anemia. Note: Code the actual anemia of this condition, if specifically

treated or affected by treatment, in Field T-2 (853).

Gaucher's Disease

Tonsilitis due to Streptococcus pyogenes; Field H: tonsil (345); Fleld T-2:

Inflammation (1132)

Cough, cause unspecified

Cough due to tobacco smoke or other foreign irritant (smoker's cough)

Dyspnea, cause unspecified

Sinusitis (paranasal)

Bronchiectasis, cause unspecified

Asthma, allergic

Tuberculosis; Field H: lungs (52)

Gingivitis, cause unspecified

Achlorhydia, cause unspecified

Hypochlorhydria, cause unspecified

Hyperchlorhydria, cause unspecified

Ulcer, gastric

Diarrhea, cause unspecified

Thrush (Candida albicans): Fleld $\mathrm{H}$ : mouth (61)

Fasciolopsiasis (Fasciolopsis busk1); Field H: intestine (67) or gall bladder (E2)

Hematuria, cause not specified

Hemaglobinuria, cause not specified

Nephritis, cause unspecified

Nephrosis, cause unspecifled

Cervicitis, cause not specified

Inflammation of joints; arthritis, cause unspecified. For arthritis due to rheumatic fever, code rheumatic fever in Field $\mathrm{E}$, inflammation (1132) in Field T-2, joint (930) in Field $\mathrm{H}-1$, and the response in Field $\mathrm{T}-1$.

Arthritis due to gout

Osteoarthritis

Rheumatoid arthritis

Dermatomyositis; Fleld $\mathrm{H}$ : skin (A1). If an identifiable infective agent is named, this should be coded in lieu of T970Gi00.

Fibrositis

Myasthenia gravis

Bursitis, cause unspecifled

Dermatitis, cause unspecified

Dermatitis, contact

Fever (pyrexla), cause unspecifled. Note: It is usually a greater advantage to code fever in Field T-2 (Symbol FD) as a symptom of a pathology coded in Field $E$ or as an abnormal state of the test organism in Fleld $E$.

Rheumatic fever. Code the organ affected by the disease and the organ specifically affected by chemical treatment in Field $\mathrm{H}$.

Burn. Specify the site of the burn in Field $H$ and any effect of the burn specifically treated by the test compound in Field $\mathrm{T}-2$.

Inflammation, cause unspecified. Code the site of Inflammation in Fleld H, or, If the inflammation is a specific recognized disease entity, construct a new symbol, substltuting the symbol for the organ inflamed for the non-speciflc anatomical part B00.

Shock, not otherwise distingulshed

Infarction, not otherwise distingulshed

Gangrene, cause and site not specifled

Lead poisoning

Snake venom polsoning. Note: If the specific snake venom is known, the taxonomic symbol for the snake species should be coded in Field E, the victim animal in Field J, and the organ system affected (blood or nervous, e. g.) in Fleld $\mathrm{H}$.

Chloroform poisoning 
TBOO S 100 TBOO C 100 TBOO 32 OB TBOO C2 OB TBOO C4 OD TBO0 44 OF TBO0 6100 TBO0 Fi 00 TB00 F2 00 TB00 F3 00 TB00 F7 00 TB00 F8 00 TBO0 F 900 TBOO FA 00 TBOO FC 00 TBOO FE 00

TBOO FK 00 TBOO FL 00 TB00 W1 00 TBOO W4 00 TB00 W5 00 TB00 8100 TB7 100 IC TE10 0001 TE1O 0002 TE 1000 OA TE10 4202 TEIO 62 OG 42103011 JS 902021
Anaphylaxis, cause unspecified

Frost bite, site unspecified. If the site is specified, code it in Field $\mathrm{H}$.

Shock, surgical

Shock due to burn

Radiation sickness

Infarction due to thrombosis. Code the site of infarction in Field $\mathrm{H}$.

Gout

Avitaminosis, not otherwise distinguished

Vitamin A deficiency, not otherwise distinguished

Vitamin B deficiency, not otherwise distinguished

Vitamin B6 pyridoxine deficiency, not otherwise distinguished

Pantothenic acid deficiency

Vitamin BI2 deficiency

Vitamin C deficiency, not otherwise distinguished

Vitamin E deficiency, not otherwise distinguished

Sprue. Note: Identify in Field $\mathrm{H}$ the structures affected by sprue and the structure responding to chemical treatment.

Boron deficiency, not otherwise distinguished

Calcium deficiency, not otherwise distinguished

Addison's Disease, adrenal insufficiency, adrenal cortical hypofunction

Diabetes mellitus

Hyperthyroidism

Alcoholism

Ascites, cause unspecified

Fatty liver, cause unspecified

Cirrhosis, cause unspecified

Hepatitis, cause unspecified

Cirrhosis, due to congestion

Yellow atrophy of the liver

Cionorchiasis (Clonorchis sinensis); Field H: liver (E)

Cirrhosis, syphilitic (Treponema pallidum); Field H: liver (E); Field T-2: Cirrhosis (4189) 


\section{CAUSES OF DISEASE}

Disease etiologies, classified under several categories and assigned code symbols, to be used in constructing Field E code symbols for specific pathologies.

The following catalog of etiologies is divided into eight basic groups to which Symbols 2, 3, 4, $5,6,7,8$, and 9 have been assigned, to be coded in Column 22 as part of the total eight-unit symbol identifying pathologies. To provide an adequate number of symbols for specific etiologies within each category, the numerical symbols are combined with IBM zone punches, giving three letter symbols, in addition to the numerical symbol, in each category. Therefore, the first category is represented by any of Symbols 2, B, K, or S, the second category by any of Symbols 3, C, L, or T, the third by Symbols 4, $D, M$, or $U$, etc. A general sub-classification has been made within some of the categories. For example, within the first category, Symbols 2, B, and $\mathrm{K}$ have been reserved for specific extraneous poisons and intoxicants, while Symbol $S$ has been reserved for those materials to which individuals are peculiarly sensitive (hypersensitive responses).

Within each sub-category, however, each specific etiology is distinguished simply by assigning it a sequential number for Column 23. Thus, lead was the first of the specific poisonous materials as a cause of pathology listed in the category of poisons and was assigned Symbol 21 ; subsequently, the next poisonous material added, carbon monoxide, was assigned Symbol 22, etc.

The seventh major category (Symbols 8, H, Q, and $Y$ in Column 22) differs somewhat from the pattern of other categories for designating specific etiologies. This is a category for those diseases for which causes have not been discovered or are highly conjectural (resembling in this respect the sixth category, Symbols 7, G, P, and X) and which result less in morphological change than in physiological disorders. The criterion for distinguishing diseases of this category lies, therefore, in the physiological process affected by the disease and is not actually an etiological classification at all. Here, It has seemed most practical to assign no specific meanings to symbols in Column 23 , but rather to allow the symbol in Column 22 to refer generally to functions of the anatomical part coded in Columns 19, 20, and 21 . The normal physiological process of the anatomical part which is disrupted by the pathology is merely assigned a sequential number in Column 23. Thus, for each anatomical part coded distinctly in Columns 19,20 , and 21 , a very large number of diseases (whose causes are unknown) can be distinguished on the basis of the functional disturbance brought about by the disease. The alternative to this would have been the assignment of specific functional disturbances to the 140 available symbols within this category, only one or a few of which would be applicable to any one anatomical part coded in Columns 19, 20, and 21 .

Symbols 2, B, K, and S

Extraneous poisons, intoxicants, and materials to which individuals are sensitive, as causes of pathology.

$\left.\begin{array}{l}2 \\ B \\ K\end{array}\right\}$

Poisons and intoxicants

S

Substances producing hypersensitive reactions

2 i Lead

22 Carbon monoxide

23 Arsenic

24 Mercury

25 Snake venom, unspecified

26 Chloroform
Si Anaphylactic response, substances producing, unspecified

S2 Allergic, hypersensitive reaction, substances producing, unspecifled 
Symbols $3, \mathrm{C}, \mathrm{L}$, and $\mathrm{T}$

Trauma and physical agents as causes of disease.

3 Traumas

C Heat, cold, radiation, etc.

L Substances which cause physical injury rather than damage by chemical interaction

\begin{tabular}{|c|c|c|c|c|c|}
\hline 31 & Trauma, unspecified & $\mathrm{Cl}$ & Cold, freezing, frostbite & LI & $\begin{array}{l}\text { Foreign substances, } \\
\text { irritants, etc. }\end{array}$ \\
\hline \multirow[t]{3}{*}{32} & Operative wound & $\mathrm{C} 2$ & Contact burn & & \\
\hline & & $\mathrm{C} 3$ & Sunburn, ultraviolet ray burn & & \\
\hline & & $\mathrm{C} 4$ & $\begin{array}{l}\text { X-rays, radium, other radio- } \\
\text { active substances, unspecified }\end{array}$ & & \\
\hline
\end{tabular}

Symbols 4, D, M, and $U$

Disturbances of circulation as causes of pathology, regardless of the primary cause of the circulatory disturbance.

$4 \quad$ Blood supply and blood pressure

D Abrormality of blood components, character

41 Increased blood supply, due to dilation of vascular bed

42 Stasis

43 Increased blood pressure

44 Thrombosis, disruption of circulation to the part

Symbols 5, E, N, and V

Disturbances of the nervous system as causes of disease, regardless of the primary cause of the nervous disorder.

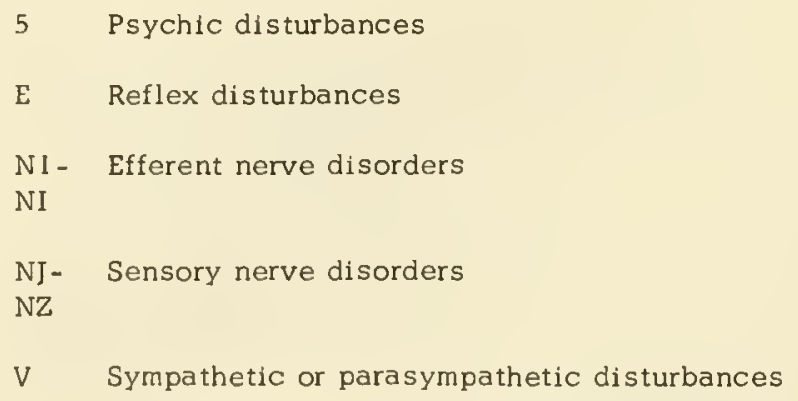


Symbols 6, F, $\varnothing$, and $W$

Disturbances of metabolism, growth, and nutrition as causes of disease, regardless of the primary cause of the metabolic disorder.

6 Metabolic disorders; toxins of metabolic origin

\begin{tabular}{l|l}
$\varnothing$ & Deficiencies
\end{tabular}

Wl - Endocrine functional abnormalities

WR

WS- Growth and development disorders WZ

61 Disturbances of purine metabolism

62 Toxic products of aberrant metabolism, unspecified

63 Lipoid metabolism

\section{Fl General vitamin deficiency}

F2 Vitamin A deficiency

$F$

F3 Vitamin B deficiency, n. o. s.

F4 Vitamin $B_{1}$ deficiency

F5 Vitamin $B_{2}$, riboflavin, deficiency

F6 Nicotinic acid deficiency

F7 Vitamin $B_{6}$ deficiency

F8 Pantothenic acid deficiency

F9 Vitamin $\mathrm{B}_{12}$ deficiency

FA Vitamin C deficiency

FB Vitamin D deficiency

FC Vitamin E deficiency

FD Vitamin $\mathrm{K}$ deficiency

FE Folic Acid deficiency

FF - (Reserved for

FI other vitamin deficiencies)
Wl Adrenal cortex hyperfunction

WS Arrested or retarded development
W4 Islets of Langerhans, hypofunction

W5 Thyroid gland, hyperfunction

W6 Thyroid gland, hypofunction 
FJ Iodine deficiency

FK Boron deficiency

FL Calcium deficiency

FM Copper deficiency

FN - (Reserved for

FZ other mineral and elemental deficiencies)

Symbols 7, G, $P$, and $X$

Diseases due to unknown causes, with the structural change manifest in the affected part (which may result in a functional disorder).

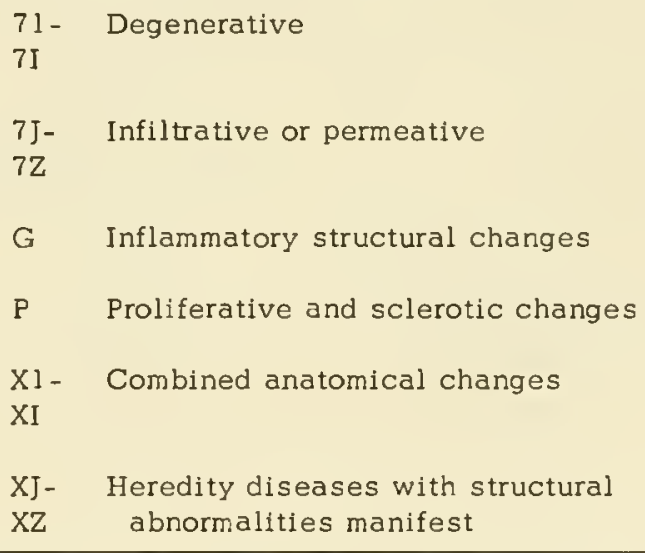

71 Degenerative, unspecified

\section{Atrophy}

73 Necrosis

74 Abnormal form, abnormal development

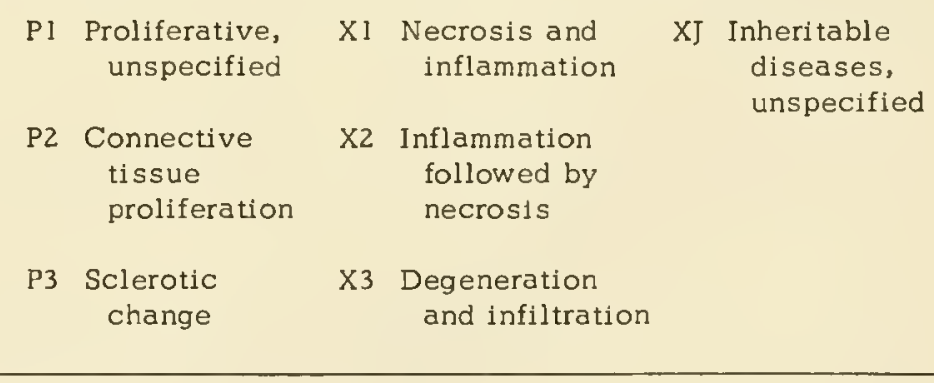

Symbols $8, \mathrm{H}, \mathrm{Q}$, and $\mathrm{Y}$

Diseases of unknown cause with a physiological disorder being the principal manifestation. (See the explanation in the introduction to this etiology list.)

Symbols 9, I, R, and Z

Chronic conditions or permanent impairment due to prevlous infection. 
FIELD E; Pathology Code

Columns 18, 19, 20, 21, $22,23,24$, and 25

List of General Pathological States

which may be Associated with any

Anatomical Structure Affected Pathologically

(Columns 24 and 25)

These conditions are general states, each of which may be associated with many specifically recognized and named pathologies. They can be used as the final part of pathology symbols in Field $\mathrm{E}$ (Columns 24 and 25), serving to distinguish certaln pathologies not otherwise adequately described or distinguished by the anatomical and etiological coding in Columns 19-23.

It is planned to use only a single IBM zone punch in Column 25 to distinguish this category of entries having fixed definitions from the other category coded in Columns 24 and 25, with numerical entries in Column 25 and without fixed definitions. (Refer to Division 6 of the discussion of the Pathology Code in the Key.) Thus, only the letter symbols A through I are used in Column 25 combined with numerical symbols in Column 24 (OA-0I, 1A-1I, 2A-2I, etc.). This will permit 90 such general states which is predicted to be adequate for distinguishing all pathological states for which the $\mathrm{CBCC}$ will need symbols.

\begin{tabular}{|c|c|c|c|}
\hline $\mathrm{OA}$ & Inflammation & $1 \mathrm{~A}$ & Constriction \\
\hline $\mathrm{OB}$ & Shock & $1 \mathrm{~B}$ & Dilatation \\
\hline $0 \mathrm{C}$ & $\begin{array}{l}\text { Congestion (blood); for congestion of } \\
\text { other fluids (dropsy), use Symbol lC }\end{array}$ & $1 \mathrm{C}$ & $\begin{array}{l}\text { Accumulation of body fluids; } \\
\text { dropsy; ascites }\end{array}$ \\
\hline$O D$ & $\begin{array}{l}\text { General malaise or acute general } \\
\text { symptoms due to the specific etiology } \\
\text { coded }\end{array}$ & & \\
\hline $0 E$ & $\begin{array}{l}\text { Reduction of normal physiological } \\
\text { function; disturbance of action }\end{array}$ & & \\
\hline OF & Infarction & & \\
\hline $0 G$ & Necrosis, degeneration & & \\
\hline $\mathrm{OH}$ & Hypertrophy & & \\
\hline OI & Atrophy & & \\
\hline
\end{tabular}




\section{MISCELLANEOUS INFORMATION CONCERNING TUMORS} (See final page of Field F)

\begin{tabular}{|l||l|l|}
\hline$*$ & Male & $\begin{array}{l}\text { Use both symbols }(* \text { and \#) when use of a mixture of sexes is specified. Use } \\
\text { neither if it is not known whether the organism is male or female or whether a } \\
\text { group of organisms is of all male, all female, or a mixture of individuals. } \\
\text { Consult the Key. }\end{array}$ \\
\hline
\end{tabular}

\begin{tabular}{|c|c|c|}
\hline \multicolumn{2}{|r|}{ (Symbol A in Column 18 of Field E) } & $\begin{array}{l}\text { Invertebrata (cont'd on next page) } \\
\text { (Any of Symbols I through } 9 \text { and } E \\
\text { through Gin Column } 18 \text { of Field E) }\end{array}$ \\
\hline Symbol & & $\begin{array}{c}\text { Sporozoa (Symbol } 13 \text { in Columns } 18 \\
\text { and } 19 \text { of Field E) }\end{array}$ \\
\hline 1 & Spermatocyte and ovum; gametes; haploid stages ${ }^{1}$ & Sporont, gametocyte \\
\hline 2 & Zygote; fertilized egg & Zygote \\
\hline 3 & $\begin{array}{l}\text { Early embryo: first cleavages; morula, blastula, and } \\
\text { gastrula. (For subsequent stages of differentiation, } \\
\text { beginning with the neurula, use Symbol 4.) }\end{array}$ & Oökinete \\
\hline 4 & $\begin{array}{l}\text { Stages of differentiation after gastrulation: neurula; } \\
\text { fetus; all stages from gastrula to hatching or birth, } \\
\text { regardless of the state of maturity at release from } \\
\text { the egg membranes or uterus }\end{array}$ & Oöcyst \\
\hline 5 & $\begin{array}{l}\text { Infant: early stages beginning with hatching or } \\
\text { birth; stages in which the animal is often relatively } \\
\text { helpless or to some degree dependent; first period } \\
\text { of growth. (Symbol } 5 \text { includes all developmental } \\
\text { stages of tadpoles of Amphibia.) }\end{array}$ & Sporozoite \\
\hline 6 & $\begin{array}{l}\text { Young animal: the stages between infancy and sexual } \\
\text { maturity. (Includes young Amphibians from the stage } \\
\text { of emergence from a tadpole--in general, from the } \\
\text { time all four legs have appeared and assumed } \\
\text { functions.) }\end{array}$ & Trophozoite \\
\hline 7 & $\begin{array}{l}\text { Young sexually mature animal: any stages between } \\
\text { sexual maturity and assumption of characteristic } \\
\text { adult size, appearance, and behavior; adolescence } \\
\text { of humans }\end{array}$ & Schizont \\
\hline 8 & Adult animal & Merozoite \\
\hline 9 & $\begin{array}{l}\text { Senile animal: stages of somatic degeneration to } \\
\text { death }\end{array}$ & \\
\hline
\end{tabular}

IIf necessary to code a distinction between sperm and egg, it can be accomplished by the IBM zone punches, if the test compound is administered to that particular stage, and/or by Field $\mathrm{H}-1$, when that is the stage (structure) responding to the test compound. 
* Male

\# Female

\begin{tabular}{|c|c|c|}
\hline \multirow[b]{2}{*}{ Symbol } & \multicolumn{2}{|c|}{$\begin{array}{l}\text { Invertebrata (continued from the previous page) } \\
\text { (Any of Symbols l through } 9 \text { and } E \text { through } G \text { in Column } 18 \text { of Field } E \text { ) }\end{array}$} \\
\hline & $\begin{array}{l}\text { Nematoda (Symbol } 51 \text { in Columns } 18 \\
\text { and } 19 \text { of Field E) }\end{array}$ & $\begin{array}{l}\text { Insecta (Symbol } 93 \text { in Columns } 18 \\
\text { and } 19 \text { of Field E) }\end{array}$ \\
\hline 1 & Sperm and egg ${ }^{1}$ & Gametes \\
\hline 2 & Zygote; fertilized egg & Zygote \\
\hline 3 & Embryo (including microfilaria) & Embryo \\
\hline 4 & $\begin{array}{l}\text { First stage postembryonic juvenile; rhabditoid } \\
\text { larva }\end{array}$ & $\begin{array}{l}\text { Larva or nymph at the first or second } \\
\text { instar stage } 2\end{array}$ \\
\hline 5 & $\begin{array}{l}\text { Second stage juvenile; filariform larva; juvenile } \\
\text { after first molt }\end{array}$ & $\begin{array}{l}\text { Larva or nymph at the third instar } \\
\text { stage }^{2}\end{array}$ \\
\hline 6 & Third stage juvenile (after second molt) & $\begin{array}{l}\text { Larva or nymph at the fourth or later } \\
\text { instar stage }\end{array}$ \\
\hline 7 & Fourth stage juvenile (after third molt) & Prepupal stage \\
\hline 8 & Immature adult (after fourth molt) & Pupa $^{3}$ \\
\hline 9 & Mature adult producing eggs/spermatozoa & Adult \\
\hline $\begin{array}{l}\text { (See th } \\
2 \text { If the } \\
\text { Symbol } \\
\text { it is ar } \\
\text { accord }\end{array}$ & $\begin{array}{l}\text { footnote with the vertebrate list.) } \\
\text { tage of the larva is in no way specified, use } \\
6 \text {, but if there is adequate reason for believing } \\
\text { "early" or "late" larva, use Symbol 4, } 5 \text {, or } 6 \text {, } \\
\text { ng to best judgment. }\end{array}$ & $\begin{array}{l}3 \text { If a distinction is desired between } \\
\text { the early and late pupa, it can only } \\
\text { be made in the written abstract. }\end{array}$ \\
\hline
\end{tabular}

\section{SPECIAL EMBRYONIC AND LARVAL STAGES OF INVERTEBRATE ANIMALS; BACTERIA SPORE}
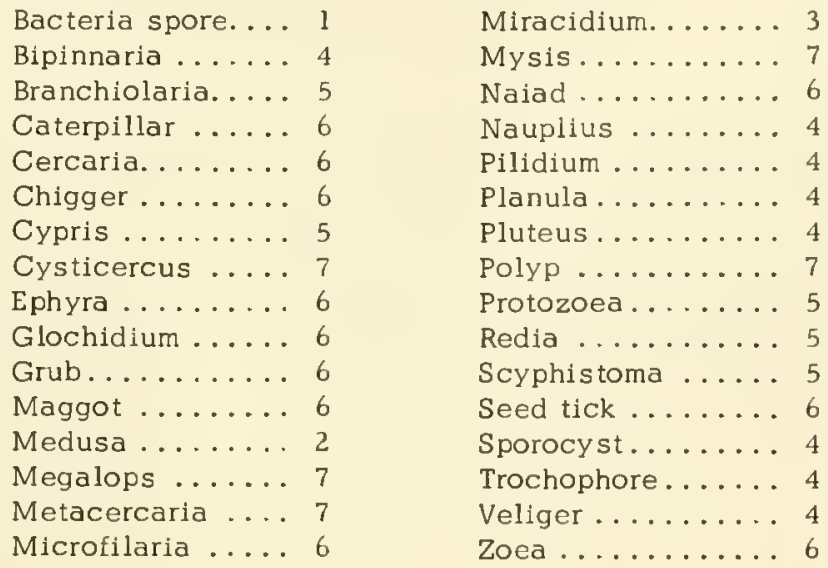
Female

\begin{tabular}{|c|c|c|}
\hline Symbol & $\begin{array}{l}\text { Spermatophytes } \\
\text { (Symbol } M \text { in Columns } \\
18 \text { and } 19 \text { of Field } E \text { ) }\end{array}$ & Basidiomycetes (Symbol J5 in Columns 18 and 19 of Field E) \\
\hline 1 & Spore & $\begin{array}{l}\text { Basidiospore (a haploid, uninucleate spore, formed by meiotic } \\
\text { division of the diploid basidium) }\end{array}$ \\
\hline 2 & Zygote & $\begin{array}{l}\text { Young mycelium (haploid, uninucleate ["haplophasic"]), not yet } \\
\text { producing haploid, uninucleate spores (oïdia; conidia; spermatia } \\
\text { of wheat rust, e.g.)! (For a binucleate mycelium producing } \\
\text { binucleate spores [diplophasic], use Symbols } 5 \text { and } 6 . \text { ) }\end{array}$ \\
\hline 3 & Embryo & $\begin{array}{l}\text { Mycelium as in Symbol 2, but producing haploid spores (spermatia, } \\
\text { e.g.); a haplophasic mycelium reproducing a sexually. }\end{array}$ \\
\hline 4 & Seed & $\begin{array}{l}\text { Spore, haploid, uninucleate and not formed by meiotic division; } \\
\text { spore of haplophasic mycelium; spore that will produce a mycelium } \\
\text { as in Symbol } 2 \text {; oidia; conidia; spermatia. } 1 \text { (For haploid, } \\
\text { binucleate spores, use Symbol } 7 \text {.) }\end{array}$ \\
\hline 5 & Seedling & $\begin{array}{l}\text { Young mycelium (haploid, binucleate ["diplophasic"])(from the } \\
\text { union of two sexes of uninucleate mycelia, or from a union of } \\
\text { spermatia [or of spermatium with a hypha] of opposite sexes, or } \\
\text { from binucleate haploid spores--e.g., aecidiospore or uredospore) } \\
\text {--which is not yet producing basidia (or teleutospores). (If at a } \\
\text { reproductive stage, use Symbol 6.) }\end{array}$ \\
\hline 6 & $\begin{array}{l}\text { Non-flowering } \\
\text { vegetative plant }\end{array}$ & $\begin{array}{l}\text { Mycelium as in Symbol 5, but mature and producing binucleate, } \\
\text { haploid spores (aecidiospores or uredospores or teleutospores) or } \\
\text { producing basidia. (Use Symbol } 6 \text { also for young basidia still in } \\
\text { the haploid binucleate stage before nuclear fusion. Use Symbol } 8 \\
\text { for the diploid uninucleate stage.) }\end{array}$ \\
\hline 7 & Flowering plant & $\begin{array}{l}\text { Spore, haploid, binucleate; aecidiospore or uredospore. Includes } \\
\text { young teleutospore (but not basidium) prior to nuclear fusion. (Use } \\
\text { Symbol } 6 \text { for a basidium prior to nuclear fusion. Use Symbol } 8 \text { for } \\
\text { any diploid uninucleate stage of a basidium or germinating } \\
\text { teleutospore.) }\end{array}$ \\
\hline 8 & Fruiting plant & Basidium or teleutospore, at diploid, uninucleate stage \\
\hline 9 & Senescent plant & $\begin{array}{l}\text { Basidium at the haploid ( } 2 \text { or } 4 \text { nuclei) stage--or germinating } \\
\text { teleutospore at the haploid stage (or epibasidium [haploid] stage } \\
\text { of germinating teleutospore). Forms basidiospores (Symbol 1). }\end{array}$ \\
\hline
\end{tabular}

${ }^{1}$ If necessary to code a distinction between sexes of haploid spores and mycelia, it can be accomplished by the IBM zone punches, if the test compound is administered to that particular stage and/or by Field $\mathrm{H}-1$, when that is the stage responding to the test compound.

(When an author does not specify the stage of the life cycle other than "mycelium", use the symbol for "mature vegetative mycelium producing asexual spores". If spores are not specified beyond "spores", use the symbol for "haploid spores" [i.e., ascospores, basidiospores, or conidia]. ) 
* Male

\# Female

\begin{tabular}{|c|c|}
\hline Symbol & (Symbols $\mathrm{J} 4$ or $\frac{\text { Ascomycetes and Fungi imperfecti }}{\mathrm{J} \text {, respectively, in Columns } 18 \text { and } 19 \text { in Field E) }}$ \\
\hline ] & $\begin{array}{l}\text { Ascospore (a haploid, uninucleate spore, formed by a meiotic division } \\
\text { of the diploid ascus) }\end{array}$ \\
\hline 2 & $\begin{array}{l}\text { Young mycelium (haploid, uninucleate) not yet producing conidia nor } \\
\text { reproducing sexuallyl }\end{array}$ \\
\hline 3 & $\begin{array}{l}\text { Nycelium as in Symbol 2, but producing conidiospores and conidia } \\
\text { and/or sex organs } 1\end{array}$ \\
\hline 4 & $\begin{array}{l}\text { Conidium (haploid, uninucleate spore, formed from a haploid, uninucleate } \\
\text { mycelium. Will form a mycelium as in Symbol 2. })^{1}\end{array}$ \\
\hline 5 & $\begin{array}{l}\text { "Zygote": a binucleate haploid cell resulting from the fusion of protoplasts } \\
\text { of two uninucleate sex cells, the ascogonium and the antheridium. Symbol } \\
5 \text { represents the stage prior to nuclear fusion. Included is any mycelium } \\
\text { (binucleate, haploid ascogenous hyphae) resulting from this gamete union } \\
\text { prior to ascus formation. }\end{array}$ \\
\hline 6 & $\begin{array}{l}\text { Ascus-forming stage of a post-zygotic mycelium or of the "zygote". (Use } \\
\text { Symbol } 7 \text { for ascus.) }\end{array}$ \\
\hline 7 & Ascus at the binucleate, haploid stage, prior to nuclear fusion \\
\hline 8 & Ascus after nuclear fusion (uninucleate diploid) \\
\hline 9 & Ascus after reduction division (haploid and with 2 or 4 nuclei) \\
\hline
\end{tabular}

${ }^{\text {l }}$ (See the footnote under the Basidiomycetes) 
* Male

\# Female

\begin{tabular}{|c|c|}
\hline Symbol & (Symbol J3 in Columns 18 and 19 of Field E) \\
\hline 1 & $\begin{array}{l}\text { Gametes, uninucleate or multinucleate, haploid, either isogametes or } \\
\text { heterogametes; antherozoid and egg }{ }^{2}\end{array}$ \\
\hline 2 & $\begin{array}{l}\text { Zygote, diploid, uninucleate or multinucleate (if multinucleate, the } \\
\text { diploid condition may be uninucleate or multinucleate according to the } \\
\text { number of nuclei contributed by the antherozoid) }\end{array}$ \\
\hline 3 & $\begin{array}{l}\text { Germinating zygote, haploid (i.e., after meiosis), multinucleate, } \\
\text { forming either spores (Symbol 4) immediately from its protoplast } \\
\text { (ordinarily zoospores) or a mycelium (Symbol 5) }\end{array}$ \\
\hline 4 & $\begin{array}{l}\text { Spore formed directly from a germinating zygote, haploid. }{ }^{2} \\
\text { Includes spores which are formed from a special, limited mycelium (not } \\
\text { comparable to vegetative mycelium) produced by the germinating zygote. } \\
\text { (Use Symbol } 7 \text { for a spore from a vegetative mycelium.) }\end{array}$ \\
\hline 5 & $\begin{array}{l}\text { Young vegetative (haploid) mycelium (either nonseptate or, if septate, } \\
\text { usually having multinucleate cells), not yet producing asexual spores } \\
\text { nor gametes. }{ }^{2} \text { Formed from a zygote or a spore or a mycelial fragment. } \\
\text { (If the mycelium is producing spores or gametes, use Symbol } 6 \text { or } 8 \text {, } \\
\text { respectively.) }\end{array}$ \\
\hline 6 & $\begin{array}{l}\text { Vegetative mycelium as in Symbol } 5 \text {, but mature and producing haploid } \\
\text { spores. } 2 \text { (If the mycelium is producing gametes, use Symbol 8.) }\end{array}$ \\
\hline 7 & $\begin{array}{l}\text { Spore, haploid, uninucleate (either a motile zoospore or a nonmotile, } \\
\text { resting aplanospore), formed from a vegetative mycelium. Includes } \\
\text { conidiosporangia (= Phycomycete "conidia") and chlamydospores. } 2 \\
\text { (Use Symbol } 4 \text { for a spore from a germinating zygote.) }\end{array}$ \\
\hline 8 & $\begin{array}{l}\text { Vegetative mycelium as in Symbol } 5 \text {, but in a stage of producing sex } \\
\text { organs, antheridia and/or oogonia, instead of, or in addition to, } \\
\text { asexual spores }\end{array}$ \\
\hline 9 & Stages of maturation of gametes within the oogonium or antheridium ${ }^{2}$ \\
\hline
\end{tabular}

${ }^{1}$ Except those Phycomycetes which apparently include an alternation of generations in which the diploid condition is retained from the zygote through a vegetative mycelial stage which reproduces only asexually-- to return to the haploid stage by producing haploid spores. In the scheme above, this diploid generation could be represented only by Symbol 2; if finer distinctions are needed, it will be necessary to devise a special list of life cycle stages for Phycomycete members like Allomyces sp.

${ }^{2}$ (See the footnote under the Basidiomycetes.) 


\begin{tabular}{|c|c|}
\hline Symbol & (Symbols JA through JE in $\frac{\text { Algae }}{\text { Columns } 18 \text { and } 19 \text { of Field E) }}$ \\
\hline 1 & Gametes (haploid); antherozoid and egg ${ }^{1}$ \\
\hline 2 & Zygote \\
\hline 3 & $\begin{array}{l}\text { Germinating zygote (haploid after reduction) to produce haploid thallus } \\
\text { (Symbol 8) or to produce immediately zoospores (or carpospores of } \\
\text { Rhodophyta)(Symbol 7). If the germinating zygote remains diploid (as } \\
\text { in Phaeophyta and certain Rhodophyta), use Symbol } 4 \text {. }\end{array}$ \\
\hline 4 & Germinating zygote (diploid) to produce diploid thallus (sporophyte) \\
\hline 5 & $\begin{array}{l}\text { Mature diploid sporophyte producing sporangia (diploid) which are } \\
\text { either "neutral" sporangia (producing "neutral" diploid spores, } \\
\text { Symbol 6) or "unilocular" sporangia (producing haploid zoospores, } \\
\text { Symbol 7). Includes diploid sporophytes producing diploid "unilocular } \\
\text { sporangia" that functionally are "macrosporangia" or "microsporangia" } \\
\text { which produce eggs and antherozoids, respectively, by reduction } \\
\text { division (Symbol l). }\end{array}$ \\
\hline 6 & "Neutral" spore, diploid; will form a diploid thallus as in Symbol 5 \\
\hline 7 & $\begin{array}{l}\text { Spore (haploid), from a haploid thallus (Symbol 8); spore (haploid), } \\
\text { from a diploid thallus (Symbol 5); spore (haploid), from a zygote } \\
\text { (Symbol 3). The distinction of this spore according to its origin can } \\
\text { only be made, if necessary, by the written abstract. }\end{array}$ \\
\hline 8 & $\begin{array}{l}\text { Haploid thallus, from a haploid spore, producing only haploid spores } \\
\text { (Symbol 7), or producing haploid spores and sex organs, or producing } \\
\text { only haploid sex organs (oogonia and antheridia, Symbol 9) }\end{array}$ \\
\hline 9 & Maturation of egg and antherozoid in the oogonia and antheridia \\
\hline
\end{tabular}

\section{SYMBOLS FOR DESCRIPTION OF TUMORS BEING TREATED}

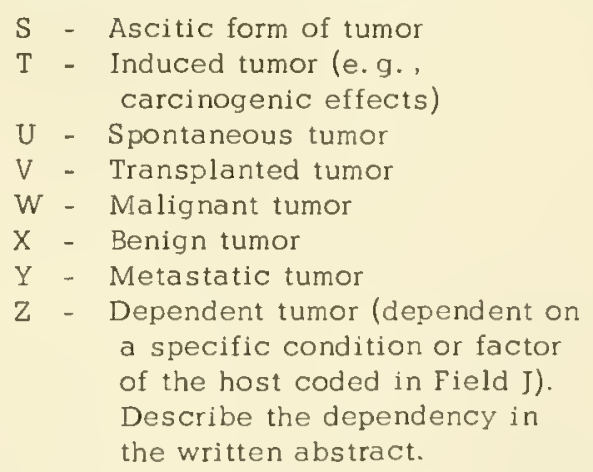

${ }^{1}$ (See the footnote under the Basidiomycetes.) 


\section{PRETREATMENT OR \\ EXPERIMENTAL STATE OF THE \\ TEST ORGANISM OR OF THE ORGAN, TISSUE, OR CELL OF THE TEST ORGANISM}

\author{
Symbol Z only: \\ EXPERIMENTAL TREATMENT OF THE TEST \\ ORGANISM OTHER THAN TREATMENT \\ WITH THE TEST COMPOUND AND \\ COMPOUND CODED IN FIELD D
}

1 ORGANISM, ORGAN, TISSUE, OR CELL IS EXPERIMENTALLY ADAPTED OR CONDITIONED to a particular environment or situation (Pavlov dog, light-adapted cockroach, etc.). Any exposures to particular environments which do not result in specific adaptations are coded by Symbol 3 or 4 .

ORGANISM, ORGAN, TISSUE, OR CELL IS PRETREATED SURGICALLY (as in the states of Symbols $P, Q$, and R), OR CHEMICALLY, OR BY ELECTRIC SHOCK, but (in contrast to Symbols $P$, $Q$, and R) FOR ANY PURPOSE OTHER THAN ISOIATION OF THE ORGANISM AND AN ANATOMICAL COMPONENT. Includes staining with dyes, surgical exposure of an organ for observation, treatment for rendering an animal or muscular organ quiet or otherwise receptive to treatment by the test compound, etc. (See the Key for a description of Symbols 2, P, Q, R, and B.)

ORGANISM, ORGAN, TISSUE, OR CELL IS EXPOSED TO AN ABNORMAL PHYSICAL OR CHEMICAL, ENVIRONMENT to which adaptation is not intended, preparatory for or during the test (high atmospheric pressures, changes in $\mathrm{O}_{2}: \overline{\mathrm{CO}}_{2}$ ratio, temperature changes, changes in gravitational pull, anaerobic culture conditions, etc.). For radiation exposure, use Symbol 4 . When the test organism has become adapted to such an environment (prior to the test), Symbol 1 must be used rather than Symbol 3 .

ORGANISM, ORGAN, TISSUE, OR CELL IS EXPOSED TO RADIATION which is not responsible for the action coded in Field $\mathrm{T}-2$. If radiation is administered as part of the treatment instead of a pretreatment (i.e., administered with the test compound so that both the chemical and radiation factors are expected to be responsible for the response coded in Field $\mathrm{T}$ ), Symbol $\mathrm{Z}$ must be used.

ORGANISM IS EXPERIMENTALLY OR NATURALLY INFECTED. (For non-infectious pathological states of the test organism, use Symbol 7, B, C, D, or E.) If the organism responding as a whole to the test compound has an infection that is restricted to a single organ, use Symbol $\varnothing$ and code the organ in Field $\mathrm{H}-2$; however, if the infection is restricted to a single tissue and Symbol $\varnothing$ is used, the tissue can not be coded (neither in Field H-2 or I). (If the organism does not respond as a unit to the test compound, but an organ [in Field H-I] or a tissue [in Field I] is the unit responding to the test compound and having an infection, use Symbol $\mathrm{N}$ rather than Symbol 5 or $\varnothing$.) If the organism has an organ or tissue implant, either normal or pathological, use Symbol $\mathrm{S}$.

ORGANISM, ORGAN, TISSUE, OR CELL HAS BEEN MADE SENSITIVE OR HYPERSENSITIVE to the test compound. (For a sensitive strain, use Symbol $H$. Use Symbol $\mathrm{J}$ for the state of induced resistance to the test compound.)

ORGANISM IS IN AN EXPERIMENTAL PATHOLOGICAL STATE not otherwise specified by special symbols - -5 (infectious disease), B (hormone deficiency), C (hormone excess), D and E (dietary deficiencies), $\mathrm{P}$ (loss of an anatomical part), and S (bearing an implant). Symbol 7 includes all other non-infectious pathologies, including spontaneous tumors (but not implanted tumors). Also, it includes general experimental stress either brought about by administration of excesses of a specific material (e. g. , $\mathrm{H}_{2} \mathrm{O}$, salt, $\mathrm{CO}_{2}$, etc.), removal of an organ (to be described in the written abstract and not coded in Field $\mathrm{H}-2$ ), or a natural or unspecified 
physiological stress. (If the test organism has had removed from it an organ for any purpose other than to produce stress, the condition is coded by Symbol P.) If the organism has an organ or tissue, other than an organ or tissue responding specifically to the test compound (therefore not coded in Field $\mathrm{H}-\mathrm{l}$ or $\mathrm{I}$ ), which is in a pathological state different from the state of the test organism as a whole, use Symbol $\varnothing$ and, if it is an organ in this pathological state, code it in Field H-2 (if it is a tissue, it can not be coded in Field I). If, instead of the organism as a whole, an organ or tissue is the structure responding specifically to the test compound and is therefore coded in Field $\mathrm{H}-\mathrm{l}$ or $\mathrm{I}$, and it is in a pathological state, use Symbol $\mathrm{N}$ or $\mathrm{S}$.

ORGANISM, ORGAN, TISSUE, OR CELL IS IN AN INACTIVE STATE; e. g., hypnosis, estivation, diapause, dormancy, bacterial resting stage, hibernation.

PARABIOTIC

\section{PARTHENOGENETIC}

ORGANISM, ORGAN, TISSUE, OR CELL IS HORMONE DEFICIENT (the deficiency not being the condition treated). Symbol B has priority over Symbol P in Field G and is used for any experimental hormone deficiency. When an endocrine gland is extirpated to produce the experimental hormone deficiency, code the gland removed or modified in Field $\mathrm{H}-2$. This includes situations in which the hormone deficiency is relative only to the developmental stage of the test organism being treated with the test compound; e.g., the removal of the endocrine gland and juvenile hormone of larval insect stages.

ORGANISN, ORGAN, TISSUE, OR CELI HAS A HORNIONE EXCESS (this excess not being the condition treated). This includes situations in which the excess is relative only to the developmental stage of the test organism being treated with the test compound; e. g., the application of the juvenile hormone to insect stages in which the hormone is normally virtually absent.

ORGANISM, ORGAN, TISSUE, OR CELI IS DEFICIENT IN ONE OR MORE VITAMINS, ONE OR MORE MINERALS, ONE OR NORE SPECIFIC NUTRIENTS (E.G. , A SPECIFIC AMINO ACID), OR WATER. Symbol D is not used for general deficiency in nourishment--see Symbol E. Symbol D is used to code incidental dietary deficiencies of normal organisms; it is not a device for indicating that the organism is a special strain or breed which can not synthesize the nutrient or vitamin. Any special strain, such as one dependent on exogenous nutrient or vitamin sources, is indicated by Symbol F.

ORGANISM, ORGAN, TISSUE, OR CELL IS UNDERNOURISHED; generally deficient in nutrients; fasted; deficient in caloric intake. For the deficiency of a specific essential dietary component, use Symbol D.

ORGANISM IS OF A SPECIAL STRAIN: selected, adapted, derived, mutant. (This excludes those special strains for which are provided the specific symbols, G, H, and I, below. Neither is Symbol $\mathrm{F}$ used to distinguish a taxonomic strain which is either given special designation in the Taxonomy Code of Field $\mathrm{E}$ or is not indicated at all by code.) (See the Key section on Specific Directions and Explanations, Division 9, for the CBCC's exceptional use of Symbol F. ) strain, made resistant by a prior exposure to the test compound. ) sensitized to the test compound by prior exposure.)

Use Symbol $\mathrm{F}$ for strains resistant to, sensitive to, or dependent on compounds other than the test compound

ORGANISM IS OF A NON-RESISTANT STRAIN, OR ORGAN, TISSUE, OR CELL IS OF SUCH AN ORGANISM, AND IS MADE RESISTANT TO (I. E. , TOLERANT OF) THE TEST COMPOUND. (USE Symbol 6 for the state of sensitization to the test compound. For a resistant strain, use Symbol G.) 

implanted tumors; if a tumor is implanted, use Symbol S). Use of this symbol includes indication of physiological stress on the organ; e.g. , the removal of one of a pair of organs, or part of an organ, or an entire organ, or any other special pretreatment to produce the exaggerated condition of in situ experimental stress on the organ specified in Field $\mathrm{H}-\mathrm{l}$ or the tissue specified in Field I. The description of the specific pretreatment employed to produce stress is not coded (e.g., the organ removed to produce stress is not coded), but it is included in the written abstract. (Any stress other than in situ is also eligible for being indicated by Symbol N.) The symbol is used when the organ in Field $\mathrm{H}-1$ or the tissue in Field I is infected, but only if that infection is restricted to that organ or tissue or if the organ or tissue is excised (indicated by Symbol $R$ in Field G-1, placing Symbol $N$ in Field G-2); if the infection is more general and the organ or tissue is in situ, use Symbol 5. Similarly, Symbol $\mathrm{N}$ is used if the organ in Field $\mathrm{H}-\mathrm{l}$ or the tissue in Field I has a non-infectious disease that is restricted to that organ or tissue, but if the disease is more general and the organ or tissue is in situ, use Symbol 7.

ORGAN (TO BE SPECIFIED IN FIELD H -2) IS IN A PATHOLOGICAL STATE DIFFERENT FROM THE STATE (NORNIAL OR OTHERWISE) OF THE ORGAN CODED IN FIELD H- l. This organ may be an organ to which the test compound is administered and which is not the specific organ responding (a frequent usc of Field $\mathrm{H}-2$ ), but if Symbol $\varnothing$ is coded in Field $G_{2}$ it may be ANY pathological organ, treated or not, which is not the organ coded in Field $\mathrm{H}-1$. Use of Symbol $\varnothing$ includes indicating any pretreatment to produce stress in an organ other than the organ in Field $\mathrm{H}-1$. Symbol $\varnothing$ is used whon an organ other than the organ in Field $\mathrm{H}-1$ is infected or has a noninfectious disease or a spontaneous or implanted tumor.

ORGANISM (RESPONDING AS A WHOLE TO THE TEST CONPOUND) PREPARED FOR EXPERIMENTAL STUDY BY EXTIRPATING, CUTTING, AMPUTATING, OR DESTROYING AN ORGAN, TISSUE, OR FLUID (or by blocking or anesthetizing in situ a specific organ or tissue). The organ removed or blocked in the organism is coded in Field $\mathrm{H}-2$, though if the structure is a tissue, it can not be coded either in Field H-2 or I. Use Symbol B when an endocrine gland is removed or treated to produce a hormone deficiency. Use of Symbol $\mathrm{P}$ does not include removal of one of a pair of organs or part of an organ to produce the exaggerated experimental condition of stress in the organism, for which Symbol 7 is used. Consult the Key for a discussion of Symbols 2 , $P, Q, R$, and $B$.

ORGAN OR TISSUE, IN SITU, (SPECIFIED IN FIELD H- 1 AS THE ORGAN, OR IN FIELD I AS THE TISSUE RESPONDING TO THE TEST COMPOUND) IS ISOLATED in some specific way from the organism (denervation, circulatory obstruction, etc.), isolated from a material it normally processes (gastric or intestinal pouch), surgically isolated from one of its tissue components, etc. This includes any in situ nerve-organ preparations. To code the fact that this organ coded by Symbol $Q$ is isolated from a nother organ or tissue by excision or destruction of that second organ or tissue, code Field G-2 with Symbol P (assuming Symbol Q is in Field G-1) and, if the structure is an organ, code it in Field H-2. Consult the Key for a discussion of Symbols 2, $P, Q, R$, and $B$.

ORGAN, TISSUE, CELI, OR FLUID IS EXCISED (specified in Field H-l or Field I as the organ or tissue responding to the test compound) for the purpose of isolating it from influences of all other factors of the organism. Includes excised nerve-organ preparations.

ORGANISM, ORGAN, OR TISSUE RESPONDING TO THE TEST COMPOUND HAS AN ORGAN OR TISSUE (EITHER NORNAL OR PATHOLOGICAL) IMPLANTED IN IT. (E. g. , an organism with a tumor implant is treated with a test compound for its analgesic action or its toxicity.) Excluded are situations when the implant is an endocrine gland implanted to create a hormone excess (Symbol C) or an organ implanted to produce a special stress (Symbol $7, N$, or $\varnothing$ ). If an implanted organ is identified, it can be coded in Field $\mathrm{H}-2$, but if the implant is a tissue, 
it can not be coded. In other words, Field $\mathrm{H}-2$ is used for coding the implanted structure (which differs from the structure in Field $\mathrm{H}-1$ ) rather than for coding an organ, other than the organ in Field $\mathrm{H}-1$, which is a site of such a transplant. The latter should always be recorded in the written abstract when the situation exists. If an organ or tissue is implanted as a part of the treatment of the test organism and shares with the test compound responsibility for the action coded in Field T-2, Symbol S can not be used; only Symbol $\mathrm{Z}$ indicates this situation.

NORMAL ORGAN, TISSUE, OR CELL IS IMPIANTED IN ANOTHER INDIVIDUAL ORGANISM, ORGAN, OR TISSUE. The implanted structure is specified in Field $\mathrm{H}-\mathrm{l}$ or $\mathrm{I}$ as the structure responding to the test compound. (The organism, into which these normal organs, tissues, or cells are transplanted, is not coded in Field J as a host, since it is not a host-parasite or host-pathology relationship that is given treatment.) If the structure into which the implant is made is an organ, it can be coded in Field $\mathrm{H}-2$, but if it is a tissue, it can not be coded in Field $\mathrm{H}-2$ or $\mathrm{I}$.

U

HOMOGENATE, BREI, OR CELL SUSPENSION OF AN ORGAN ) OR TISSUE OF THE TEST ORGANISM

$V$ EXTRACT OF A TISSUE OR ORGAN OF THE TEST ORGANISM

W CULTURE OF A TISSUE OR ORGAN OF THE TEST ORGANISM

$\mathrm{X}$
The organ or tissue of the definitions of these symbols is the organ or tissue specifically responding to the test compound and therefore coded in Field $\mathrm{H}-\mathrm{l}$ or Field I.

Second use of Field $G$ (one symbol only):

EXPERIMENTAL TREATMENT OTHER THAN WITH

THE TEST COMPOUND OR SECONDARY COMPOUND

ANY TREATMENT (NOT PRETREATMENT) OF THE TEST ORGANISM, ORGAN, TISSUE, OR CELL, OTHER THAN TREATMENT WITH THE TEST COMPOUND (OR OTHER THAN TREATMENT WITH THE TEST COMPOUND AND SECONDARY COMPOUND) AND ACCOMPANYING THE TREATMENT WITH THE TEST CONPOUND (OR ACCOMPANYING THE TREATMENT WITH THE TEST COMPOUND AND SECONDARY COMPOUND). Examples are radiation, thermal, and mechanical treatments. To qualify for being coded by Symbol Z, such treatment must be considered as being in part responsible for the action coded in Field $\mathrm{T}$ to the degree indicated in Field $Y$. Symbol $\mathrm{Z}$ is coded in Field G-2 only. 
FIELD $\mathrm{H}-1$

Columns 29, 30, and 31

FIELD $\mathrm{H}-2$

Columns 32,33 , and 34

\section{GROSS ANATOMICAL STRUCTURE: \\ ORGAN, SYSTEM, BODY AREA}

Field H-1: Primary anatomical structure

Field H-2: Secondary anatomical structure

(Consult the Key for distinctions

and uses for Fields $\mathrm{H}-1$ and $\mathrm{H}-2$ )

Animal Structures: Symbols 1-- through 9-- and A- - through G--. Plant Structures: Symbols $\mathrm{H}$ through $\mathrm{Q}$.

(Column 30 only)--The organ coded in Field H-1 is the organ whose specific response to the test compound is being coded and is an organ affected by the pathology coded in Field E, but THE ORGAN which is actually IN THE PATHOLOGICAL STATE INDICATED BY FIELD E (i. e., the organ infected by a pathogen, the organ in atrophy, the organ that is the focus of the Field E pathology, etc.) IS CODED IN FIELD H-2. Consult the Key about Symbol *

Nervous system, in toto; neuromotor system (fibrillar system) of Ciliata; nerve net of Coelenterata

Central nervous system, in toto

Brain, in toto; suprapharyngeal ganglion of Annelida; supraesophageal ganglion of Arthropoda

Cerebral cortex

Corpus striatum

Rhinencephalon; olfactory lobe

Corpus callosum

Epithalamus

Thalamus

Hypothalamus

Midbrain, in toto

Cerebral peduncles (crura cerebri)

Corpora quadrigemina

Hindbrain, in to to

Cerebellum

Pons

Medulla oblongata

Brain stem, in toto (includes the tubular portions of the hindbrain and midbrain, as well as the median portion of the forebrain)

$11 \mathrm{H} \quad$ Ventricles of the brain

12 Nerve cord (spinal cord); ventral nerve cord of Annelida and Arthropoda; longitudinal nerve cord of helminths

121 Spinal canal (vertebral canal)

122 Spinal fluid (For cerebrospinal fluid in toto, use Symbol 155.)

Connective (e. э. , circumesophageal connective) of invertebrate systems

124 Segmental ganglion; annelid and arthropod subesophageal ganglion and other ventral ganglia

13 Peripheral nervous system (somatic nervous system), in toto (excludes autonomic nervous system, Symbol 14)

131 Cranial nerves, in toto

132 Olfactory nerve

133 Optic nerve

Microanatomical structures (tissues, cells, fluids) constitute Field I. 


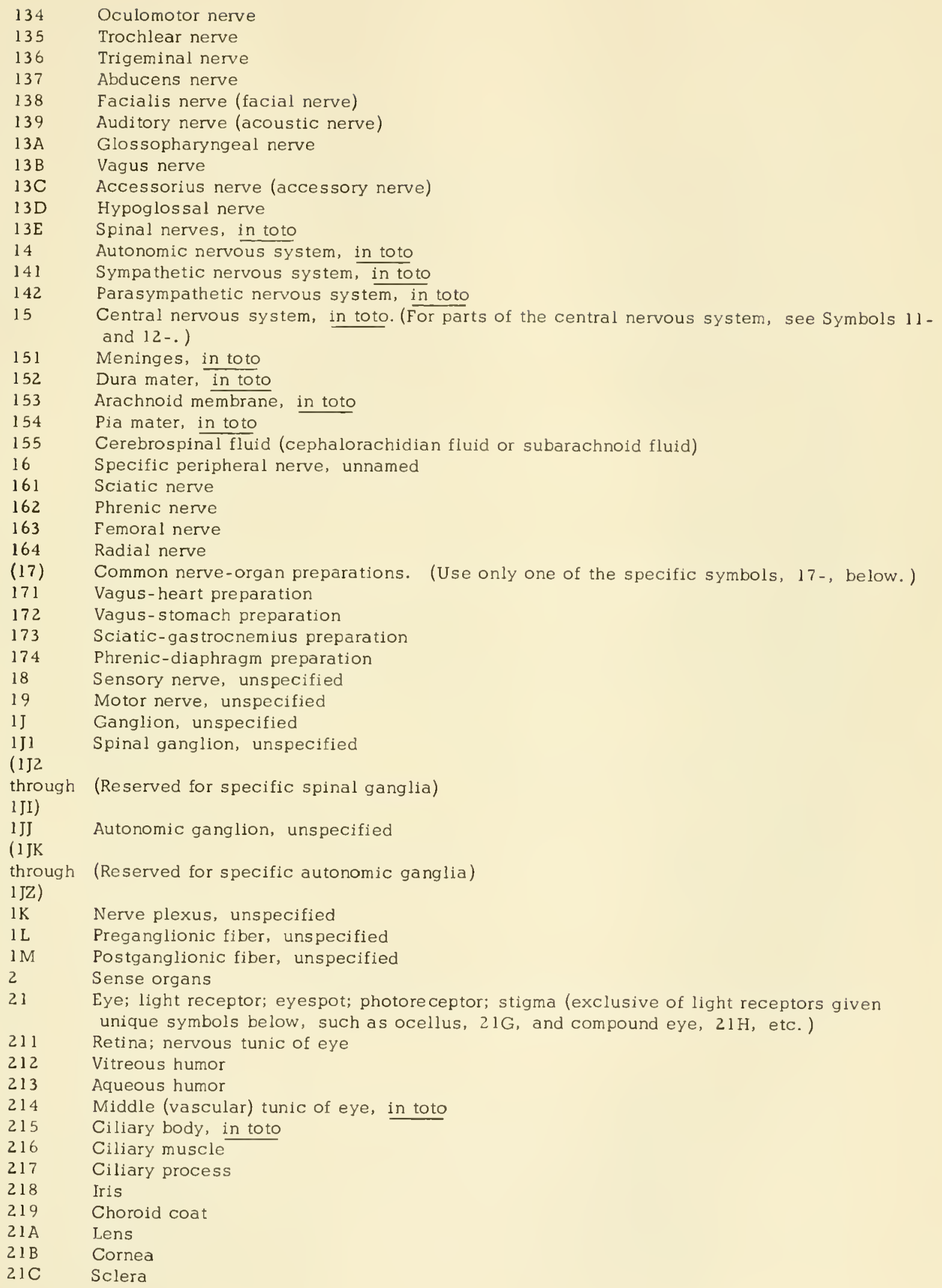


Columns 29, 30, 31,

32,33 , and 34

$21 \mathrm{D}$ Eyelid

21E Conjunctiva

2 IF Nictitating membrane

133 Optic nerve

971 Extrinsic muscles of the eye, in toto

$21 \mathrm{G}$ Ocellus

$21 \mathrm{H}$ Compound eye

Ear; tympanal organ

External ear, in toto; pinna (auricle) and external auditory canal

Tympanic membrane (ear drum)

Middle ear, in toto

Eustachian tube

Auditory ossicles, in toto

Inner ear (internal ear or labyrinth)

Cochlea

Semicircular canals

Posterior semicircular canal

Superior semicircular canal

Lateral semicircular canal

Ampulla

Utricle

Saccule

Cochlear duct

Auditory nerve

Organ of equilibrium (balancing organ). (Use one of the specific symbols, 23-, below.)

\section{Statocyst (Crustacea)}

Semicircular canals

Proprioceptor sensory nerve end organs; kinesthetic nerve end organs

Chemoreceptor organs. (Use one of the specific symbols, 24-, below.)

Gustatory receptor; tastebuds

Olfactory receptors (nasal receptors of vertebrates; invertebrate receptors such as antennal olfactory receptors)

Mechanoreceptors (specific touch receptors, temperature receptors, pain receptors, and proprioceptors)

Specific touch receptor (Meissner's corpuscle)

Specific cold receptor (Krause's end bulb)

Specific heat receptor (Ruffini's end organ)

Specific pressure receptor (Pacinian corpuscle)

Pain receptor

Proprioceptors, in to to

Specific tactile organs (particularly of invertebrate animals)

Specific tactile tentacles

Antennae, antennule

Cardiovascular system

Heart; pulsating vessel (both vertebrate and invertebrate vascular circulatory pumps)

Atrium, auricle

Right auricle

Left auricle

Ventricle

Right ventricle

Left ventricle

Sinus venosus (more primitive vertebrates)

System of tissues conducting impulses across the heart; Bundle of His

Pace maker. (For a single specifically named pace maker, use Symbols 3 IB or 3 lC. Note also the structures $32 \mathrm{M}$ and $32 \mathrm{~N}$ which affect cardiac pace.)

Cardiac valve, including the cardiac ostial valves (pulmonary and aortic). (For a speciflc valve, use Symbols $31 \mathrm{H}, 31 \mathrm{I}, 31 \mathrm{~J}$, or $31 \mathrm{~K}$.

Left auriculoventricular valve (mitral valve or bicuspid valve)

Right auriculoventricular valve (tricuspid valve)

Aortic valve (semilunar aortic valve) 
Pulmonary valve

Septum

Endocardium

Myocardium

Pericardium

Associated structures of the heart: alary muscles, suspensory ligaments; lateral vessels; diverticula of insect hearts, etc.

Pace maker. (For a single specifically named pace maker, use Symbols $31 \mathrm{~B}$ or $31 \mathrm{C}$. Note also the structures $32 \mathrm{M}$ and $32 \mathrm{~N}$ which affect cardiac pace.)

Atrioventricular node (= auriculoventricular node; AV node)

Sinus node (= sinal node; sino-atrial node; sino-auricular node)

Right auricle

Left auricle

Right ventricle

Left ventricle

Left auriculoventricular valve (= bicuspid valve or mitral valve)

Right auriculoventricular valve (= tricuspid valve)

Aortic valve (semilunar aortic valve)

Pulmonary valve

Sinus venosus (more primitive vertebrates)

Circulatory vessel, not otherwise specified. (For specific vessels or specific vessel types, use one of the symbols below.)

\section{Aorta}

Pulmonary vessel, not otherwise specified. (For pulmonary artery or pulmonary vein, use Symbols $32 \mathrm{~F}$ or $32 \mathrm{G}$.)

Pulmonary artery

Pulmonary vein

Hepatic portal vein; hepatic portal system

Renal portal vein; renal portal system

Systemic vessel (= circulatory vessels other than the heart). (For specific vessels or specific vessel types, use one of the symbols below.)

Artery; efferent blood vessel. (For specific arteries, use one of the arterial symbols below.)

Pulmonary artery

Coronary artery

Aorta

Arteriole

Vein; afferent blood vessel. (For specific veins, use one of the symbols below.)

Coronary vein

Pulmonary vein

Vena cava

Hepatic portal vein

Renal portal vein

Arteriole

Venule

Capillary

Lymphatic system. (For specific parts of the lymphatic system, use the symbols below.)

Lymphatic vessel

Lymph node

Coronary vessel

Coronary artery

Coronary vein

Pulmonary artery

Pulmonary vein

Vena cava

Renal portal vein

Peripheral blood vessels (as opposed to visceral vascular bed)

Visceral blood vessels (as opposed to peripheral vascular bed)

Vessels of the extremities

Carotid sinus

Carotid body (= Carotid gland, intercarotid body, glomus caroticum) 
FIELDS $\mathrm{H}-1$ and $\mathrm{H}-2$

Columns 29, 30, 31,

32,33 , and 34

33 Blood

331 Plasma

332 Serum

333 Erythrocyte

334 Reticulocyte

335 Leukocyte, not otherwise specified. (For specific leukocytes, use Symbols 336, 337,338, $33 \mathrm{~B}, 33 \mathrm{C}$, or $33 \mathrm{D}$.

336 Lymphocyte (of blood). (For lymphocyte of the lymph, use Symbol 351.)

337 Monocyte

Granular leukocyte (= granulocyte). (See Symbols 33B - 33D for specific granulocytes.)

Eosinophilic granulocyte

Basophilic granulocyte

Neutrophilic granulocyte

Platelet

$33 \mathrm{~A}$

$33 \mathrm{~B}$

$33 \mathrm{C}$

Formed elements other than those given unique symbols

Eosinophilic granulocyte

Basophilic granulocyte

Neutrophilic granulocyte

34

341

342

343

344

Hematopoietic system

Bone marrow

Spleen

Adenoid tissue of nasopharynx (adenoids)

Lymph node

Tonsil

Reticulo-endothelial system

Lymph

Lymphocyte of the lymph

(Available for any special organ systems not already in this list)

Respiratory system

Air passage of vertebrates. (For specific parts of the respiratory tract, use the appropriate symbol below.)

Nose

512 Anterior nares, nostril, respiratory pore, spiracle

513 Nasal fossa (nasal cavity); nasal air passage. (For the anterior olfactory region of the nasal fossa, use Symbol 242.)

Paranasal sinus, not otherwise specified

$515 \quad$ Nasopharynx

62 Pharynx 
Buccal cavity (oral cavity; ostium; mouth [cavity]; osculum; cytostome; stomodeum). (This symbol is not used for oral orifices, but describes oral cavities and the walls and structures thereof.)

Lips

Palate

Tongue

Membranelle; manubrium; velum; oral lobe; hypostome; labium

Proboscis; prostomium

Mandible; jaw (describing a mount or head area). (Do not use this symbol for the vertebrate mandibular bone, Symbol 924.)

Labrum; chelicera

Maxilla; maxilliped; pedipalp. (Do not use this symbol for vertebrate maxillary bone, Symbol 925.)

Teeth

Cheek (lateral wall of buccal cavity)

Gums

Salivary pump

Pharynx

Mastax (rotifers)

Endostyle (tunicates)

Esophagus (= gullet)

Crop; honey stomach

Gizzard; proventriculus

Stomach; ventriculus; enteron of coelenterates

Cardiac sphincter

Cardia (including cardiac sac of the rat)

Fundus

Pylorus

Pyloric sphincter

Gastric mill

Intestine

Small intestine

Duodenum

Jejunum

Ileum

Anterior intestine

Posterior intestine

Large intestine; colon

Cecum

Appendix

Rectum; proctodeum

Anus

Anal sphincter

Cloaca

Peritoneum. (Use Symbol B7 I for peritoneal cavity.)

Mesentery (visceral peritoneum)

Parietal peritoneum

Excretory system

Kidney. (For invertebrate excretory structures, use other symbols of the 7 -- series.)

Cortex of kidney

Medulla of kidney

Pelvis of kidney

Malpighian corpuscle (Bowman's capsule and glomerulus)

Renal portal vessel or system

Renal tubule

Proximal convoluted tubule

Loop of Henle

Distal convoluted tubule

Collecting tubule and duct of Bellini

Ureter 
FIELDS $\mathrm{H}-1$ and $\mathrm{H}-2$

\section{Columns 29, 30, 31,}

32,33 , and 34

73

731

74

75

76

77

78

79

$67 \mathrm{D}$

8

81

811

CJ

CK

814

D31

D32

815

816

817

818

819

$81 \mathrm{~A}$

$81 \mathrm{~B}$

$67 \mathrm{D}$

$81 \mathrm{C}$

82

821

822

823

824

825

826

D4 I

827

D43

D44

828

829

$82 \mathrm{~A}$

$82 \mathrm{~B}$

83

84

841

842

843

85

851

86

861

862

863

864

Bladder (urinary)

Bladder sphincter

Urethra

Contractile vacuole (Protozoa)

Flame cell (helminths)

Nephridium (annelid)

Malpighian tubule (insects)

Green gland (Crustacea)

Cloaca

Reproductive system

Female reproductive system, in toto

Ovary, in toto; ovariole (egg tube) of insects

Graafian follicle

Corpus luteum

Oviduct; fallopian tube

Shell gland

Yolk gland of helminths (= vitellaria)

Seminal receptacle

Uterus (of man); uterus (of flatworms). (For the divided uterus [cornua] of the rat, e.g., use Symbol 817.)

Uterine horn (= cornua [of the rat, e.g. J)

Cervix

Placenta

Vagina

Vulva, external genitalia, ovipositor

Cloaca

Egg (unfertilized)

Male reproductive system, in toto

Testis; spermary; in toto

Interstitial cells of the testis; cells of Leydig. (Use this symbol only when this part of the testis is affected in size or form by the test compound or when it is the site of a pathology or a tumor. When the test compound specifically affects endocrine function of the interstitial cells, use Symbol CL.)

Seminiferous tubule

Vasa efferentia (= vas efferens)

Epididymis

Vasa deferentia (= vas deferens)

Prostate gland

Seminal vesicle; male sperm storage sac. (For seminal vesicles which are totally secretory in function, as in man, use Symbol D42.)

Bulbo-urethral gland

Para-urethral gland (= Glands of Littre)

Ejaculatory duct

Scrotum

Penis; cirrus (of flatworms)

Sperm; spermatogonium, spermatocyte, spermatid, spermatozoon

Ovotestis (of snails, e.g.)

Accessory structures

Brood chamber

Clitellum (of earthworms)

Cirrus sac (of flatworms)

Asexual reproductive structure of animals. (Excluded are the asexually-produced bud or other immature stage itself.)

Blastostyle (of the coelenterate gonangium)

Special structures of embryonic stages (either sexually--or asexually--produced stages)

not elsewhere in the list with other organ systems

Spore wall (Sporozoa)

Gemmule wall (Porifera)

Statoblast wall (Bryozoa)

Brood pouch of sporocysts (Trematoda) 
Musculo-skeletal system (locomotor system)

91 Notochord

92 Internal skeleton (Chordata), in toto

96 External skeleton (Invertebrata), in toto

921 Skull, in toto

922 Teeth, in toto (vertebrate)

923 Auditory ossicles, in toto

924 Mandible, vertebrate

925 Maxilla, vertebrate

926 Antler; horn; in toto

927 Beak, in toto

$(928-92 E)$ (Reserved for addition to the Code of bones of the skull)

$92 \mathrm{~F} \quad$ Vertebra

(92G-92I)(Reserved for vertebral parts)

92J Clavicle

$92 \mathrm{~K}$ Scapula

92L Rib

$92 \mathrm{M}$ Sternum

Skeletal joint (of internal, chordate skeleton)

931 Joint capsule. (For a specific ligament, use a symbol of the 95- series.)

94 Tendon, unspecified

95 Ligament, unspecified

External skeleton (invertebrate supportive structure)

Skeletal muscle, unspecified; striated muscle, unspecified. (To be used for specific skeletal muscle organ only. The tissue defined as skeletal muscle tissue is coded in Field I.)

Optic muscles, in toto

Gluteus muscle

Subscapularis

Intercostal muscles, in toto

Cartilage, unspecified. (To be used for specific cartilaginous organs only. The tissue defined as cartilage is coded in Field I. )

Nasal cartilages, in toto

Costal cartilages, in toto

Thyroid cartilage

Periosteum (considered as an organ associated with a specific bone)

Dental periosteum (= periodontal membrane)

Bursa

Plantar bursa

Prepatellar bursa

Olecranon bursa

A

Skeletal joints (of invertebrate external skeletal structures)

Skin (integument) and derivatives, in toto. (This excludes actual hard, completely enveloping exoskeletal structures of arthropods, coelenterates [corals], and Protozoa [Foraminifera], e.g. , though integument tissues secreting these supportive coats are included. For the exoskeletal structures, use a symbol of the 9-- series.) Use Symbol A to code the organism's surface, in toto. Skin; integument (includes simple cuticular layers and local horny skin derivatives) Hair; feather; scale; spicules and spines formed of or by skin

Hair follicle; feather follicle

\section{Sebaceous gland}

Teeth

Wattle, comb (birds)

Nail; claw; hoof

D16 for beak, in toto, use Symbol 927.)

(B) Body regions. (Use Symbol A to code the organism's surface, in toto. Symbol B is used to refer to the organism's mass and surface. For example, Symbol Bl refers to the entire mass [and surface] of the head, etc.) 
FIELDS $\mathrm{H}-1$ and $\mathrm{H}-2$

Columns 29, 30, 31,

32,33 , and 34

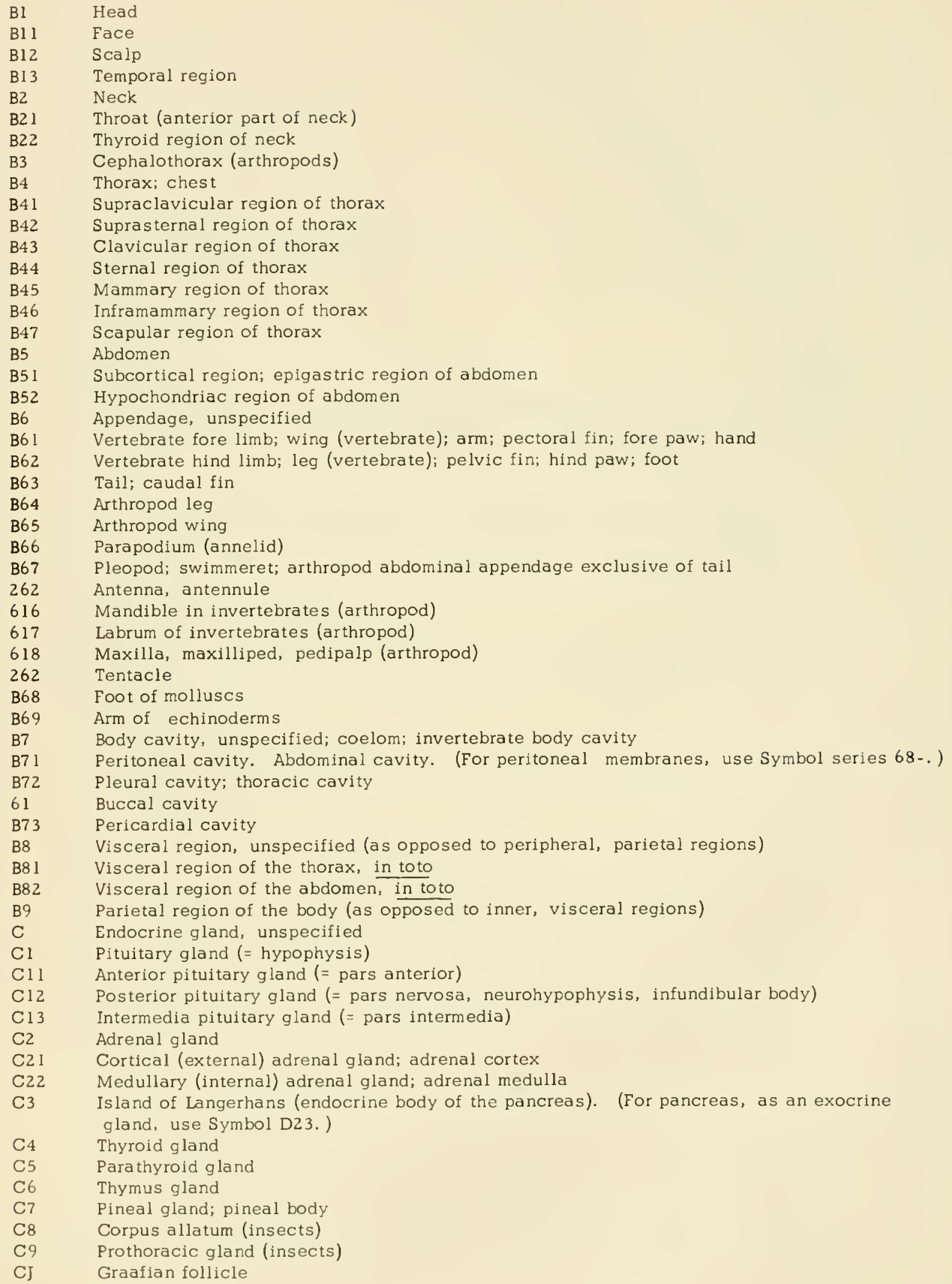


FIELDS $\mathrm{H}-1$ and $\mathrm{H}-2$

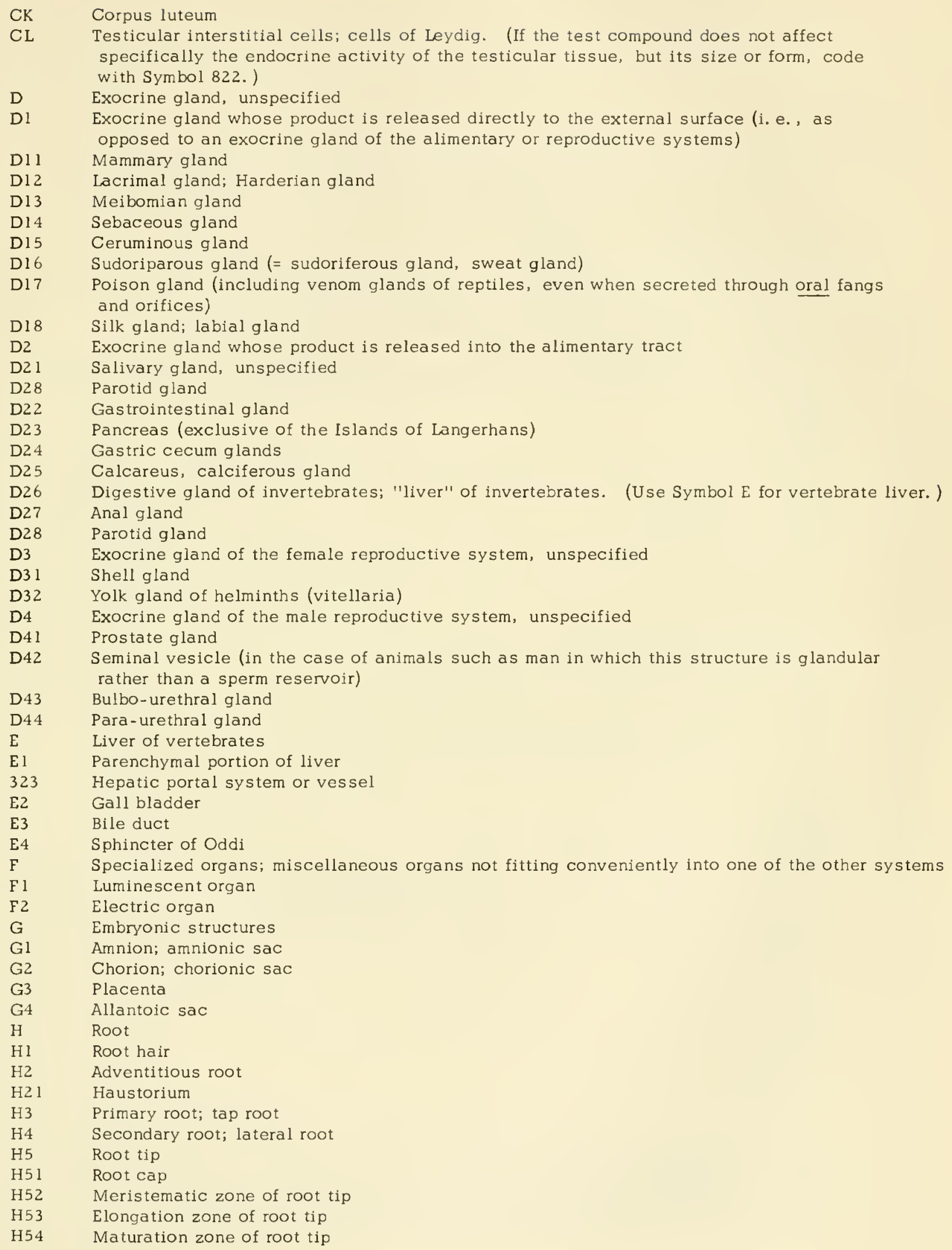


FIELDS $\mathrm{H}-1$ and $\mathrm{H}-2$

Columns 29, 30, 31,

32,33 , and 34

H6

I

II

K

II

I2

Root primordium

Stem; shoot (unspecified as to whether it is a main stem, branch, aerial, subterranean, or otherwise specially modified). (Use this symbol also for plants having only one of the two stem types, aerial or subterranean. See Symbols I7 and I8.)

Node

Leaf

Axillary bud (or J2 or J3)

Internode, otherwise unspecified

(To be used in Field H-l only.) Internode below a site of local application of the test compound. (Code the plant part to which application is made [e.g. , internode, node, leaf, or branch] in Field H-2.)

(To be used in Field $\mathrm{H}-1$ only.) Internode above a site of local application of the test compound; internode developed after the test compound is applied locally to a plant part or after general application (e. g., spraying). (Code the plant part to which application is made [e. g., internode, node, leaf, or branch] in Field H-2.)

Main stem (as opposed to secondary stems branching from the main stem)

Secondary stem; branch

Terminal portion of stem (including stem tip or stem bud and young nodes and internodes) Inflorescence stem (only stem structures of the flower), in toto; pedicel and receptacle, in toto

Pedicel (exclusive of receptacle)

Receptacle

Underground stem. (To be used only for plants which normally have both specific aerial and specific subterranean stems--to distinguish which of these responds or is treated. See also Symbol I. )

Aerial stem. (To be used only for plants which normally have both specific subterranean and specific aerial stems--to distinguish which of these responds or is treated. See also Symbol I.)

Lenticel of stem

Bud (an organization of meristematic tissue which, by formation of typical plant tissues and organs, is the focus of formation of new stems or modified stems with associated appendages)--dormant or actively developing

Axillary, lateral stem bud with only leaf primordia (axillary leaf bud)

Axillary, lateral stem bud with only flower primordia (axillary flower bud)

Axillary, lateral stem bud with both leaf and flower primordia (axillary mixed bud)

Terminal stem bud with only leaf primordia (terminal leaf bud)

Terminal stem bud with only flower primordia (terminal flower bud)

Terminal stem bud with both leaf and flower primordia (terminal mixed bud)

Bud scale

Adventitious bud ( $a$ bud other than a terminal bud and other than a bud arising from a node)

Adventitious stem bud arising from the root

Adventitious stem bud arising from the leaf petiole or leaf blade

Adventitious stem bud arising from a stem site other than a node (e.g., a bud arising from the tissues of old stems in which nodal and internodal distinctions have been submerged by secondary thickenings). (For an adventitious "flower bud", use Symbol J74.)

Adventitious stem bud, having only one or more flower primordia, arising from a stem site other than a node

Leaf; mature, typical leaf. (Use Symbols $\mathrm{K} 4$ and $\mathrm{K} 5$ for typical seedling leaves.)

Stoma and guard cell

Petiole; leaf stalk (exclusive of stipules); sheath (of grass leaf)

Leaf blade

Leaf tip; leaflet tip

Leaf margin; leaflet margin

Cotyledon

Primary leaf ( $=$ first true leaf of a seedling; first leaf above cotyledon; leaf at the first node above the cotyledon)

Typical leaf, after the primary leaf, unspecified as to whether it is second, third, etc. Second true leaf of a seedling (= leaf at the second node above the cotyledon)

Third true leaf of a seedling (= leaf at the third node above the cotyledon)

Fourth true leaf of a seedling (= leaf at the fourth node above the cotyledon) 
KM

L

LI

L2

L3

L3 1

L32

L33

L4

L4 1

L42

L43

L44

L45

L46

I62

161

I6

M

I6 1

MI

Mll

M12

M1 3

$\mathrm{N}$

Nl

N11

$\mathrm{N} 12$

N 13

N 14

N2

N3

N31

N32

N33

N34

N35

Stipule

Bract

Leaf primordium

Bud scale

Leaf base forming a segment of a bulb (e.g., a segment of an onion bulb). (For use with plants whose bulbs are formed of leaves whose upper parts are aerial.)

Leaf, in toto, forming a segment of a bulb (e.g., a segment of a lily bulb). (For use with plants whose bulbs are formed of modified leaves [scales] that are totally subterranean and which form aerial stems usually with typical aerial leaves.)

(To be used in Field $\mathrm{H}-\mathrm{l}$ only.) Leaf other than the treated leaf and unspecified as to whether it is above or below the treated leaf. (The treated leaf, Symbol K, K4, or K5, will always be coded in Field $\mathrm{H}-2$ when Symbol $\mathrm{KN}$ is in Field $\mathrm{H}-1$. )

(To be used in Field $\mathrm{H}-\mathrm{l}$ only.) Leaf below (older than) the site of local application of the test compound. (Code the plant part to which application is made [e.g., internode, node, leaf, or branch] in Field $\mathrm{H}-2$ when Symbol KNI is in Field $\mathrm{H}-1$.)

(To be used in Field $\mathrm{H}-\mathrm{l}$ only.) Leaf above (distal to and younger than) the site of local application of the test compound. (Code the plant part to which application is made [e.g. , internode, node, leaf, or branch] in Field $\mathrm{H}-2$ when Symbol $\mathrm{KN} 2$ is in Field $\mathrm{H}-1$.)

Flower

Sepal

Petal

Stamen

Anther

Pollen

Filament

Pistil

Carpel; carpel wall; ovary

Ovule and placental tissue

Integument (a!so, N1l and N12)

Style

Stigma

Nucellus

Embryo sac

Receptacle

Pedicel

Receptacle and pedicel, in toto

Fruit

Pedicel

Pericarp

Exocarp

Mesocarp

Endocarp

Seed

Integument; testa; seed coat

Outer integument

Inner integument

Hilum

Micropyle

Endosperm

Embryo

Plumule

Hypocotyl

Radicle

Cotyledon; scutellum

Coleoptile

(The symbols beginning with $\varnothing$ are not to be used with plants of the phylum Spermatophyta. They represent structures of the gametophyte generation of more primitive plant groups.)

(ळ)

(Structure of a gametophytic generation plant) 
FIELDS $\mathrm{H}-1$ and $\mathrm{H}-2$

Columns 29, 30, 31,

32,33 , and 34

$\varnothing 1$ Antheridium; microgametangium

$\varnothing 11 \quad$ Microgamete

$\phi_{2}$ Archegonium; oogonium; megagametangium

ф21 Megagamete

(The symbols beginning with $\mathrm{P}$ are not to be used with plants of the phylum Spermatophyta. They represent structures of the sporophyte generation of more primitive plant groups.)

(P) (Structure of a sporophyte generation plant)

Pl Sporangium

P2 Spore (of the sporophyte generation of plants)

P3 Sporangiophore

P4 Sporophore

(Q) (Special plant structures)

Q1 Thallus

Q2 Mycelium

S Organ (plant or animal) unspecified. (This symbol is to be used in Field H-2 only, when the test compound is applied to an unspecified organ which is not the primary organ in Field $\mathrm{H}-1$ and the coding in Field S-3 does not adequately indicate that the organ to which the test compound was administered is not the organ in Field $\mathrm{H}-1$.) 
Epithelium

11 Simple squamous epithelium

12 Endothelium (of blood vessels and heart)

Mesothelium (of peritoneal, pericardial, and pleural cavities)

Columnar epithelium

Cuboidal epithelium (= low columnar epithelium)

Glandular epithelium (= a modified columnar [or cuboidal] epithelium)

Pseudostratified epithelium

Ciliated epithelium (usually a type of pseudostratified epithelium)

9 Stratified squamous epithelium

Epidermis (= stratified squamous epithelium of the skin) (19).

(For plant epidermis, use Symbol 74.)

$1 \mathrm{~A}$

Stratified columnar epithelium

Transitional epithelium

Basement membrane of epithelial tissue

Epithelial duct of the gland coded in Field H-1 (as contrasted to the "glandular" epithelium of the gland, Symbol 16)

Connective tissue, unspecified as to type

Fibrillar connective tissue

Areolar fibrillar connective tissue (= fibro-elastic)

White fibrous connective tissue

Elastic connective tissue (fibrillar connective tissue with preponderance of elastic fibers)

Reticular connective tissue

Adipose connective tissue (= fat tissue)

Pulp of teeth (dental pulp)

Fibroblast (cells forming connective tissue fibers)

Histiocyte (= macrophage)

Pigment cells of connective tissue

Muscle tissue, unspecified; contractile tissue

Skeletal muscle; striated muscle

Smooth muscle; visceral muscle, unspecified as to whether the fibers are arranged as oblique,

longitudinal, or circular muscle

Longitudinal smooth muscle (fibers parallel to the longitudinal axis of the organ)

Circular smooth muscle (fibers encircling the long axis of the organ)

Oblique smooth muscle (fibers oblique to the long axis of the organ)

Cardiac muscle

Nervous tissue

Sensory nerve fiber; afferent nerve fiber (supplying the organ coded in Field H-1)

Motor nerve fiber; efferent nerve fiber (supplying the organ coded in Field $\mathrm{H}-1$ )

Preganglionic fiber (of the nerve coded in Field $\mathrm{H}-1$ )

Postganglionic fiber (of the nerve coded in Field $\mathrm{H}-\mathrm{l}$ )

Ganglion (of the nerve coded in Field $\mathrm{H}-1$ )

White matter (= myelinated nervous tissue) of the central nervous system part coded in Field H-1 Grey matter (= non-myelinated nervous tissue) of the central nervous system part coded in

Field $\mathrm{H}-\mathrm{l}$

Neuron; nerve cell

Nerve cell body

Axon (defined as a nerve cell process conducting impulses from the nerve cell body, regardless of the physical structure of the process. By this definition, all motor nerve fibers are axons.) Dendrite (defined as nerve cell process conducting impulses to the nerve cell body, regardless of the physical structure of the process. By this definition, all sensory nerve fibers are dendrites.)

Nerve fiber (= nerve cell process including any sheaths)

Motor end plate

Sensory ending

Neuroglia 
FIELD I

\section{Columns 35 and 36}

$4 \mathrm{G}$

$4 \mathrm{H}$

5

51

52

53

54

55

Myelin sheath (= medullary sheath)

Neurilemma (= sheath of Schwann)

Supportive tissue, unspecified

Cartilage, unspecified

Hyaline cartilage

Elastic cartilage

Fibrous cartilage

Bone tissue, unspecified

Intramembranous bone tissue (to be used when a test compound affects this bone tissue type differently than it affects intracartilaginous bone)

Intracartilaginous bone tissue (to be used when a test compound affects this bone tissue type differently than it affects intramembranous bone)

Dentine of teeth

Enamel of teeth

Pulp of teeth

Body fluid, unspecified; plant fluid, unspecified

Extracellular fluid ( = intercellular fluid; intercellular lymph); tissue juice.

(Lymph: This liquid tissue, contained in lymphatic vessels, is not coded in Field I, but

always in Field $H$ as an organ. See Field $H$, symbol series $35-$ )

(Blood: This liquid tissue and its components [plasma and cells], contained in circulatory vessels, are not coded in Field I, but always in Field $\mathrm{H}$ as an organ and its parts. See Field $\mathrm{H}$, symbol series $33-$. )

Synovial fluid (= synovia)

Cerebrospinal fluid (to be used when the cerebrospinal fluid of a particular part of the central nervous system [coded in Field $\mathrm{H}-1$ ] is affected. When the cerebrospinal fluid, as a whole, is affected, it is coded in Field $\mathrm{H}-\mathrm{l}$ [Symbol 155].)

Secretion (product of a gland) (to be used only when a test compound affects the composition of a gland's secretion. When only the volume of secretion is affected, the effect is adequately coded by indicating increase or decrease of secretion in Field $\mathrm{T}$ and the gland affected in Field $\mathrm{H}-1$. )

Thyroid gland colloid substance

Plant tissues, in toto

Meristem

Sclerenchyma

Cortex; cortical parenchyma; collenchyma; cortical sclerenchyma

Epidermis; cuticle (--in leaves, unspecified as to whether it is upper or lower epidermis or cuticle or both upper and lower). (For upper or lower epidermis specifically, use Symbols $7 R$ or 7S.)

"Bark". (This term is defined to include all tissues outside the cambium layer.)

Pith; pith parenchyma

Endodermis

Cambium; vascular cambium. (For cork cambium, use Symbol 7E.)

Pericycle

Xylem. (For specific xylem elements, use Symbols 7F, 7G, 7I, $7 \mathrm{M}$, and 7N.)

Phloem. (For specific phloem elements, use Symbols 7J, 7K, $7 \mathrm{~L}, 7 \varnothing$, and $7 \mathrm{P}$.)

Mesophyll of leaves

Cork

Cork cambium

Xylem vessel

Xylem tracheid

Resin duct; latex vessel (= lactiferous duct)

Wood parenchyma; xylem parenchyma

Phloem sieve tube

Phloem companion cell

Phloem parenchyma cell

Primary xylem

Secondary xylem

Primary phloem

Secondary phloem

Vascular bundle, in toto

Upper epidermis of leaf 
BH

BI

DI

D2

D3

D4

D5

D6

D7

D8

D9
Lower epidermis of leaf

Parenchyma (tissue of origin unspecified)

Reserved for additional specific tissues

Cells. The items of this symbol series ( $\mathrm{A}_{-}$) are to be used to distinguish between cells differing in the characteristic specified (e.g., dye affinity) or to distinguish particular unique cells of an organ coded in Field $\mathrm{H}$. Symbol A, alone, is not intended for coding use. Acidophile; eosinophile Basophile Neutrophile; chromophobic cell; heterophile (including "polymorphs" of blood) Reticulo-endothelial cell; Kupffer cell of the liver

Cell components and cell inclusions. Symbol B, alone, is not intended for coding use.

Nucleus, in toto

Nucleolus

Nucleoplasm; karyoplasm

Nuclear membrane

Cytoplasm

Cell membrane (protoplasmic membrane)

Cell wall of plants (of cellulose, lignin, etc.)

Middle lamella (of plant cell wall)

Primary wall (of plant cell wall)

Secondary wall (of plant cell wall)

Plasmodesma

Mitochondria; chondriosome

Golgi body; Golgi apparatus

Fibril (including neurofibril and myofibril)

Basophile granule; Nissl granule

Cilium; flagellum

Vacuole

Intracellular fluid; cell sap

Secretion granule; zymogen

Plastid (including chloroplast, leukoplast, chromoplast, and pyrenoid)

Structures (other than specific tissue types) which are components of an organ coded in Field H. Blood vessel

Capillary; capillary bed; capillary plexus

Artery

Vein

Lymph vessel

Lymphoid nodule (of a specific body area)

Lymphoid tissue

Venous sinus

Mucous membrane

Acinus (of the gland coded in Field $\mathrm{H}-\mathrm{I}$ )

Dermis, in toto (of the body part coded in Field $\mathrm{H}-1$ )

Embryonic tissue

Ectoderm

Endoderm

Mesoderm

Mesenchyme

Embryonic membrane, unspecified

Allantoic sac

Yolk sac

Amnion

Chorion 
HOST ORGANISM OR TEST ENVIRONMENT

\section{LIVING HOSTS}

1

11

111

112

113

114

115

12

13

14

15

2

3

4

5

6

B

C

D

7

E

F

G

9

A!

A2

A3

A4

A5

A6

A61

A611

A61101

A6 12

A61201

A61202

A61203

A6 1204

A61205

A61206

A61207

A62

A63

A631

A63101

A63102

\author{
Protozoa \\ Sarcodina \\ Amoebozoa \\ Foraminifera \\ Heliozoa \\ Radiolaria \\ Mycetozoa \\ Ciliata \\ Sporozoa \\ Mastigophora \\ Suctoria \\ Porifera \\ Coelenterata \\ Platyhelminthes \\ Nemathelminthes \\ Echinodermata \\ Acanthocephala \\ Entoprocta \\ Ectoprocta \\ Mollusca \\ Annelida \\ Echiuroidea \\ Sipunculidoidea \\ Priapulidoidea \\ Arthropoda \\ Chordata \\ Petromyzones \\ Myxini \\ Fish \\ Amphibians \\ Reptiles \\ Birds \\ Galliformes \\ Meleagrididae \\ Turkey, unspecified as to variety \\ (Meleagris gallopavo, breed \\ unspecified)
}

Phasianidae

Chicken, unspecified as to variety

(Gallus domesticus, variety

unspecified)

White Leghorn chicken

White Plymouth Rock chicken

Rhode Island Red chicken

White Wyandotte chicken

Jersey Black Giant chicken

Barred Rock chicken

Struthioni formes

Anseriformes

Anatidae

A6 4

A641

A64101

A64102

A65

A651

A65101

A7

A7 1

A711

A7 1101

(A71102

through

A7110Z)

A7 1111

(A71112

through

A7 1112)

A71121

(A71122

through

A7112Z)

A72

A721

A72101

(A72102

through

A72112)

A72121

(A72122

through

A72125)

A72126

(A72127

through

A7212A)

A7212B

A7212C

A722

A72201

(A72202

through A72202)
Columbiformes

Columbidae

Pigeon, unspecified as to species or variety

Columba livid; pigeon

Passeriformes

Fringellidae

Canary, unspecified as to strain (Serinus canarius, strain unspecified)

Mammals

Artiodactyla

Bovidae

Domestic cow, breed unspecified (Bostaurus, breed unspecified)

(Reserved for domestic cow breeds)

Domestic goat, breed unspecified (Capra hircus, breed unspecified)

(Reserved for domestic goat breeds)

Domestic sheep, species or breed unspecified (Ovis species, unspecified)

(Reserved for domestic sheep species or breeds)

Carnivora

Canidae

Dog (Canis domesticus, breed unspecified)

(Reserved for dog breeds)

Wolf, Canis nubilis, variety unspecified

(Reserved for Canis nubilis varieties)

Coyote, Canis latrans, variety unspecified

(Reserved for Canis latrans varietles)

Fox, variety and species unspecified (Urocyon species)

Gray fox (Urocyon cenereoargenteus scotti)

Felidae

Domestic cat, breed unspecifled (Felis catus, breed unspecified)

(Reserved for cat breeds) 
A73

A731

A73101

A73102

(A73103 through

A73109)

A7310A

(A7310B

through

A7317Z)

A7310B

A7310C

A7310D

A7310E

A7310F

A7310G

A7310H

A7310I

A7310J

A73 1 OK

A7310L

A7310M

A7310N

A7310

A7310P

A7310Q

A73 10R

A7310S

A7310T

A7310U

A7310V

A7310W

A7310X

A7310Y

A7310Z

A73111

A73112

A73113

A73114

A73115

A73116

A73117

A73118

A73119

A7311A

Rodentia

Muridae, unspecified

Rat, unspecified as to species or breed

Black rat, variety unspecified (Rattus rattus, variety unspecified)

(Reserved for Rattus rattus varieties)

Norway rat, strain unspecified (Mus norvegicus, variety and strain unspecified)

(Reserved for varieties and strains of the Norway rat, Mus norvegicus) Norway rat, variety Albino (Mus norvegicus albinus, strain unspecified)

Albino; P. Aptekman inbred strain (King Albino)

Albino mutant strain (no further specification)

August variety (line unspecified)

August variety, line 990

August variety, line 7322

August variety, line 28807

August variety, line 35322

AxC variety (strain or line unspecified)

AxC variety, 9935 Hooded strain

AxC variety, 9935 Irish strain

Bagg

Buffalo

Copenhagen

Fischer variety, strain unspecified

Fischer variety, line 230

Fischer variety, line 344

Gray Norway

Albino waltzer

Black

Blue

Chocolate

Chocolate shaggy

Cinnamon

Curly-coated

Fawn

Tawny

White shaggy

Yellow black eye

Yellow red eye

A7311B

A7311C

A7311D

A7311E

A7311F

A7311G

A7311H

A7311I

A7311J

(A7311K

through

A7317Z)

A73181

\section{(A73182 \\ through \\ A73 1KZ)}

A73182

A73183

A73184

A73185

A73186

A73187

A73188

A73189

A7318A

A7318B

A7318C

A7318D

A7318E

A7318F

A7318G

A7318H

A7318I

A7318 J

A7318K

A7318L

A7318M

A7318N

A.7318 $\varnothing$

A7318P

A7318Q

A7318R

A7318S

A7318T

A7318U

A7318V

A7318W

A7318X

A7318Y

A7318Z

A73191

A73192

A73193

A73194

A73195

A73196

A73197

A73198
Osborn-Mendel

Sherman

Slonaker

Sprague-Dawley

White

Wistar albino ("Wistarat")

Spotted Wistar

Yale

Zimmerman

(Reserved for additional varieties, strains, lines, etc. , of the Norway rat)

Mouse, Mus musculus, strain unspecified

(Reserved for varieties, strains, and lines of Mus muscuius)

85

89

101

129

1194

1394

3 CAMG

$\mathrm{A}$

$\mathrm{AB}$ (Albino-Bluhm)

ADW

$A_{f} B$

$\mathrm{A} / \mathrm{He}$

A/L (A subline Lilly)

$\mathrm{A} / \mathrm{x}$

AK/Gl

$\mathrm{AK} / \mathrm{Jax}$

A/Jax

$\mathrm{AK} / \mathrm{M}$

$A K / N(A K-n)$

AKA

$\operatorname{AKR}(A K, A K M, A f B$, R. I. L. , RIL)

AK4

AKR/Du

ANOPH B

$\mathrm{AKR} / \mathrm{Fu}$

AKR/Jax

AKR/LW

AKR/M

BL (Bagg L)

BALB (Bagg, Bagg Albino)

$B A L B / C$ ( $B$ alb c, c inbred)

$\mathrm{BALB} / \mathrm{GW}$ ( $\mathrm{Ba}$. inbred)

BALB/ci (BALB/Lafayette)

$\mathrm{BCHP}$

BUC

BDP

BLCP (BLcp, Blcp)

$B R S(B R-S, B R-s)$

BRSUNT (Br Sunt)

BTRU

BTWB (BTwb)

BUA 

40,41 , and 42

\begin{tabular}{|c|c|}
\hline A73199 & $\mathrm{BUB}$ \\
\hline A7319A & BUD \\
\hline A7319B & C \\
\hline $\mathrm{A} 7319 \mathrm{C}$ & CAF \\
\hline A7319D & CBA $(X X X I X)$ \\
\hline A7319E & $\mathrm{CBA}_{\mathrm{f}}\left(\mathrm{ABC}, \mathrm{CBA}_{\mathrm{f}} \mathrm{C} 3 \mathrm{H}\right)$ \\
\hline A7319F & CBAN \\
\hline A7319G & CBAN $-\underline{p}^{r}$ \\
\hline A7 $319 \mathrm{H}$ & $\operatorname{CDE}(\mathrm{cd} E, D E)$ \\
\hline A7319I & $\mathrm{CE}(\mathrm{ce})$ \\
\hline A7319J & CF 1 \\
\hline A7319K & CFCW \\
\hline A7319L & CFW \\
\hline A7319M & $\mathrm{CHI}$ \\
\hline A7319N & $\mathrm{CHI}-\underline{s}$ \\
\hline A7319 & $\mathrm{CHI}-\overline{\mathrm{ps}}$ \\
\hline A7319P & $\mathrm{C} 3 \mathrm{H} \overline{(\mathrm{Z})}$ \\
\hline A7319Q & $\mathrm{C} 3 \mathrm{H} /$ Andervont \\
\hline $\mathrm{A} 7319 \mathrm{R}$ & $\mathrm{C} 3 \mathrm{H} / \mathrm{Ks}$ \\
\hline A7319S & $\mathrm{C} 3 \mathrm{H} / \mathrm{He}$ \\
\hline A7319T & $\mathrm{C} 3 \mathrm{H} / \mathrm{JFe}\left(\mathrm{C} 3 \mathrm{H}_{\mathrm{b}}\right)$ \\
\hline A7319U & $\mathrm{Cl} 121(\mathrm{He})$ \\
\hline A7319V & C57BL (C57 black) \\
\hline A7319W & $\mathrm{C} 57 \mathrm{BL}-\mathrm{a}^{\mathrm{t}}$ \\
\hline A7319X & C57 BL- $\bar{b}$ \\
\hline A7319Y & $\mathrm{C} 57 \mathrm{BL} \sqrt{6}$ \\
\hline A73192 & $\mathrm{C} 57 \mathrm{BL} / 6 \mathrm{Ks}$ \\
\hline A731Al & $\mathrm{C} 57 \mathrm{BL} / 10$ \\
\hline A731A2 & C57 BR \\
\hline A731A3 & $\mathrm{C} 57 \mathrm{BR} / \mathrm{a}$ \\
\hline A731A4 & $\mathrm{C} 57 \mathrm{BR} / \mathrm{Cd}$ \\
\hline A731A5 & C57L (M, L, LN) \\
\hline A731A6 & C58 \\
\hline A731A7 & $C 58-a^{t}$ \\
\hline A731A8 & $d a-a \bar{b}$ \\
\hline A731A9 & DBA (dba, dbr, D) \\
\hline A731AA & $\mathrm{DBA}_{\mathrm{f}}$ \\
\hline$A 731 \mathrm{AB}$ & $\mathrm{DBA} / 1$ \\
\hline A731AC & $\mathrm{DBA} / 2(=\mathrm{DBA} / 2 \mathrm{~J})$ \\
\hline A731AD & $\mathrm{DBA} / 2_{\mathrm{f}}$ \\
\hline A73 $1 \mathrm{AE}$ & $\mathrm{DBA} / \mathrm{Wa}$ \\
\hline A731AF & $\mathrm{DBA} / 2 \mathrm{bWy}$ \\
\hline A731AG & $\mathrm{E}$ \\
\hline A731AH & Edinburgh \\
\hline A731AI & F \\
\hline A731AJ & Flex \\
\hline A731AK & FUCFW \\
\hline A731AL & G \\
\hline A731AM & GFF \\
\hline A731AN & $\mathrm{H}$ \\
\hline $\mathrm{A} 731 \mathrm{~A} \varnothing$ & $\mathrm{HD}$ \\
\hline A731AP & I \\
\hline $\mathrm{A} 731 \mathrm{AQ}$ & $I-c^{c h}$ \\
\hline A731AR & $\mathrm{IF}$ \\
\hline A731AS & IFS \\
\hline A731AT & IVB \\
\hline A731AU & $\mathrm{JK}$ \\
\hline A73 IAV & $\mathrm{K}$ \\
\hline A731AW & KInk \\
\hline A731AX & $\mathrm{KICF}$ \\
\hline
\end{tabular}

A731AY KL

A731AZ L (LCW)

A731Bl Line 11 (LP)

A731B2 Longacre

A731B3 MA

A73 I B4

A731B5

A731B6

A731B7

A7 31 B8

A7 31 B9

A731 BA

A7 $31 \mathrm{BB}$

A7 31 BC

A731 BD

A731 BE

A731 BF

A7 31 BG

A7 $31 \mathrm{BH}$

A731 BI

A731 BJ

A731BK

A73 I BL

A731BM

A73 I BN

$A 731 B \varnothing$

A7 $31 \mathrm{BP}$

A7 $31 \mathrm{BQ}$

A73 I BR

A731 BS

A731 BT

A7 $31 \mathrm{BU}$

A731 BV

A7 31 BW

A7 $31 \mathrm{BX}$

A731 BY

A731 BZ

A731Cl

$\mathrm{A} 731 \mathrm{C} 2$

A731C3

A731C 4

A731C5

A731C 6

A731C7

A731C 8

A731C9

A73 1 CA

A73 $1 \mathrm{CB}$

A731CC

A731CD

A731 CE

A73 ICF

A731CG

$\mathrm{A} 731 \mathrm{CH}$

A73 $1 \mathrm{CI}$

A731CJ

A73 1CK

A731 CL

A731 CM

A731 CN

ST (Street)
$N$

NB

NBT

$\mathrm{ND}(\mathrm{MA} / \mathrm{MY})$

$\mathrm{NH}$

NIH General purpose 0

020 Leewenhoek-Huis

$P$

$\mathrm{PBR}(\mathrm{pBr})$

PK

PL (PL[B])

PLA

PMG

RI

RIET

RIII

$\mathrm{RIII}_{\mathrm{f}} \mathrm{B}$ (RIILX)

$\mathrm{RII} / \mathrm{Jax}$

$\mathrm{RIII/La}$

$\mathrm{RIII} / \mathrm{Wy}$

RF

RI

$S$

SEA/Gn-se

$\mathrm{SEA} / \mathrm{se}(\overline{\mathrm{Sese}}-\mathrm{Ab})$

SEC/dse (Sese-C)

SEC/Gn-dse

$\mathrm{SEC} / \mathrm{l}$ - se (Sese-Cl)

SEC/I0n-se

$\mathrm{SEC} / 2-\mathrm{d}$ (Sese-C2)

$\mathrm{SEC} / 2 \mathrm{gn}-\mathrm{d}$

Short-talled

Snowy

STOLI

STR

Strong A

SWR (Swiss)

TG

WHL/Br (White Label)

WG

WHL/Kr (Kreyberg)

WR

XVII

XXXV

XLII

XLV

XLVIII

XLIX

$Y$

YBL

$Y B L / R r$

YBL/WI

$\mathrm{Z}$ 


\author{
A731C $\varnothing$ \\ A73 1CP \\ (A73 ICQ \\ through \\ A73 1 KZ)
}

A732

A73201

(A73202

through

A7321Z)

A733

A73301

A73302

(A73303

through

A73309)

A7330A

A7 4

A741

A7 4101

A7 42

A7 4201

A7 5

A751

A75101

(A75102

through

A75112)

A76

A77

A771

A77101

(A77102

through

A7711Z)

A7 8

A781

A78101

B

C

C

F

G

J

J 1

$\mathrm{J} 2$

J3

J4
ZR (Zr/Chase)

ZRD

(Reserved for additional

varieties, lines, strains,

Caviidae etc. , of Mus musculus)

Guinea pig, variety unspecified

(Cavia porcellus, variety

unspecified)

(Reserved for varieties and strains

of Cavia porcellus)

Geomyidae

Hamster (Large European), variety unspecified (Cricetus cricetus, varlety unspecified)

Golden hamster, variety unspecified (Mesocricetus auratus, variety unspecified)

(Reserved for Mesocricetus auratus varieties)

Cotton rat, unspecified variety (Sigmodon hispidus, variety unspecified)

Primates

Hominidae

Man

Cercopithecidae

Macaca (species unspecified)

Perissodactyla

Equidae

Domestic horse (Equus caballus, breed unspecified)

(Reserved for breeds of domestlc horses)

Marsupalia

Lagomorpha

Leporidae

Domestic rabbit, breed unspecified (Oryctolagus cuniculus, unspecified)

(Reserved for breeds of domestic rabbits)

Insectivora

Talpidae

Mole, European (Talca europaea)

Acanthocephala

Entoprocta

Ectoprocta

Echiuroidea

Spiunculidoidea

Priapulidoidea

Thallophyta

Myxothallophyta

Lichens

Phycomycetes

Ascomycetes

J5
J6
J7
JF
JA
JB
JC
JD

JE
JF

Basidiomycetes

Fungi Imperfecti

Fungi (otherwise unspecified)

Algae (otherwise unspecified)

Brown Algae (Phaeophyceae)

Blue-Green Algae (Cyanophyceae)

Red Algae (Rhodophyceae)

Yellow-Green Algae

(Chrysophyceae)

Green Algae (Chlorophyceae)

Algae (otherwise unspecified)

(The bacteriophage hosts in this list are taken from the CBCC data sheet files and from the American Type Culture Collection, Catalog of Bacteriophages, 1957. For the ATCC numbered entries, the following items are given in sequence for each entry: the name of the host organism, its ATCC accession number, name and address of the donor, donor's designator for the host strain, his designator [in parentheses] of the phage strain, and the year deposited in the ATCC. )

IS

JS 1

JS 11

JS 1101

JS 1102

JS 1103

JS 12

JS 1201

JS 1202

JS 1203

JS2

JS3

JS 4

JS 41

JS 4101

JS 4102

JS4 103

JS 42

JS4201

JS 4202

(JS4203 through JS 4209)

JS 420A

JS $420 B$

JS 43

JS 4301
Schizomycetes

Pseudomonadales

Pseudomonadaceae

Pseudomonas, unspecified

Pseudomonas aeruginosa, unspecified

Pseudomonas aeruginosa, strain $\mathrm{C}_{10}$

Spirillaceae

Vibrio, unspecified

Vibrio comma, unspecified

Vibrio sp. ATCC \#11985. A. P.

Krueger, U. Cal., 1954

Chlamydobacteriales

Hyphomicrobiales

Eubacteriales

Azotobacteraceae

Azotobacter, unspecified

Azotobacter vinelandii, unspecified

Azotobacter vinelandii, ATCC \#12518. O. Wyss, U. Texas. (Strain 0) 1956

Rhi zobiaceae

Rhlzobium, unspecified

Rhizobium leguminosarum, unspecified

(Reserved for Rhizoblum species and strains)

Agrobacterium, unspecified Agrobacterium tumefaciens, unspecified

Enterobacteriaceae

Escherichla, unspecified 
JS 4302

JS 4303

JS4304

JS 4305

JS 4306

(JS4307

through

JS43 IF)

JS43 I G

JS $431 \mathrm{H}$

JS 4311

JS43 I J

(JS $431 \mathrm{~K}$

through

JS 432B)

JS $432 \mathrm{C}$

JS432D

(JS 432E

through

IS $432 \mathrm{~L}$ )

JS432M

JS $432 \mathrm{~N}$

JS $432 \varnothing$

JS $432 \mathrm{P}$

JS432Q

(JS432R

through

JS 4362)

JS 4371

JS 4372

JS4373

JS 44

JS 4401

JS 4402

JS 45

JS450 I

JS 4.502
Escherichia coli, unspecified

Escherichia coli, B/URBANA

Escherichia coli, ATCC \#11303.

S. E. Luria, U. Ill., Strain B

(complete t phage series). 1952

Escherichia coli, ATCC \#12404.

I. N. Asheshov Collection, N.Y.

Botanical Garden. Strain alpha

(phage strain 2 and 4). 1955

Escherichia coli, ATCC \#12141.

I. N. Asheshov Collection, N.Y.

Botanical Garden. Strain C

(phage strain 5) (from J. Ward

McNeal Collection). 1955

(Reserved for Escherichia coli strains)

Erwinia, unspecified

Erwinia amylovora, unspecified

Erwinia cartovora, unspecified

Erwinia aroideae, unspecified

(Reserved for Erwinia species and strains)

Serratia, unspecified

Serratia marcescens, unspecified

(Reserved for Serratia species and strains)

Salmonella, unspecified

Salmonella paratyphi, unspecified

Salmonella Type Poona, ATCC

\#12177. I. N. Asheshov

Collection, N. Y. Botanical

Garden. (From J. Ward McNeal

Collection) (2 phage strains, 1

and 2) 1955

Salmonella schottmuelleri, ATCC

\#12178. Same sources as above.

Strain 2, 1955

Salmonella schottmuelleri, ATCC

\#12410. Same source as above.

Strain 1, 1955

(Reserved for Salmonella species strains)

Shigella, unspecified

Shigella dysenteriae, unspecified

Shigella dysenteriae, ATCC

\#11456a. G. Bertani, U. Ill.,

URBANA Strain Sh (phage strain

P2). 1953

Brucellaceae

Pasteurella, unspecified

Pasteurella pestis, unspecified

Micrococcaceae

Staphylococcus, unspecified

Staphylococcus aureus var.

aureus, unspecified
JS 52

JS 5201

JS5202

JS 4503

JS 4504

JS 46

JS 4601

JS4602

JS 4603

JS4604

JS4605

JS 47

JS 4701

JS 4702

JS4703

JS 48

JS 4801

JS 4802

JS 4803

JS 4804

JS5

JS 51

JS 5101

IS 5102

JS 5103

JS 5203
Staphylococcus aureus var. aureus, Oxford $\mathrm{H}$ strain, \#657 1A

Staphylococcus sp. ATCC \#12145. I. N. Asheshov, N. Y. Botanical Garden. (D'Herelle Labs. , Paris). 1955

Lactobacillaceae

Streptococcus, unspecified

Streptococcus cremoris, unspecified

Streptococcus cremoris, ATCC $\# 11602$. C. C. Prouty, Wash. State College, Pullman, Washington. Strain HP (phage strain hp). 1954

Streptococcus sp. ATCC \#12164. I. N. Asheshov Collection, N. Y. Botanical Garden. (From D'Herelle Labs., Paris) Strain 3. 1955

Streptococcus sp. ATCC \#12168. Same source as above.

Enterococcus strain 5/7 S. 1955

Corynebacteriaceae

Corynebacterium, unspecified

Corynebacterium diphtheriae, unspecified

Corynebacterium sp. ATCC \#12052. D. H. Howard, U. Cal. Strain DLC $842 / 50$ (phage strain DLC 2921/49). 1954

Bacillaceae

Bacillus, unspecified

Bacillus megaterium, unspecified Bacillus cereus var. mycoides, ATCC \#11986. A. P. Krueger, U. Cal. Strain N. 1954

Bacillus subtilis ATCC \#12139.

I. N. Asheshov Collection,

N.Y. Botanical Garden. Strain CSC (from Commercial Solvents

Corp.). 1955

Actinomycetales

Mycobacteriaceae

Mycobacterium, unspecified

Mycobacterium phlei, unspecified Mycobacterium phlei, ATCC

\#11728. J. M. Desranleau, Ministry of Health, Montreal, Canada. 1954

Streptomycetaceae

Streptomyces, unspecified

Streptomyces griseus, unspecified Streptomyces griseus, ATCC

\#11984. F. Carvajal, Schenley Labs., Laurenceburg, Ind. (Strain SL-842) 1954 


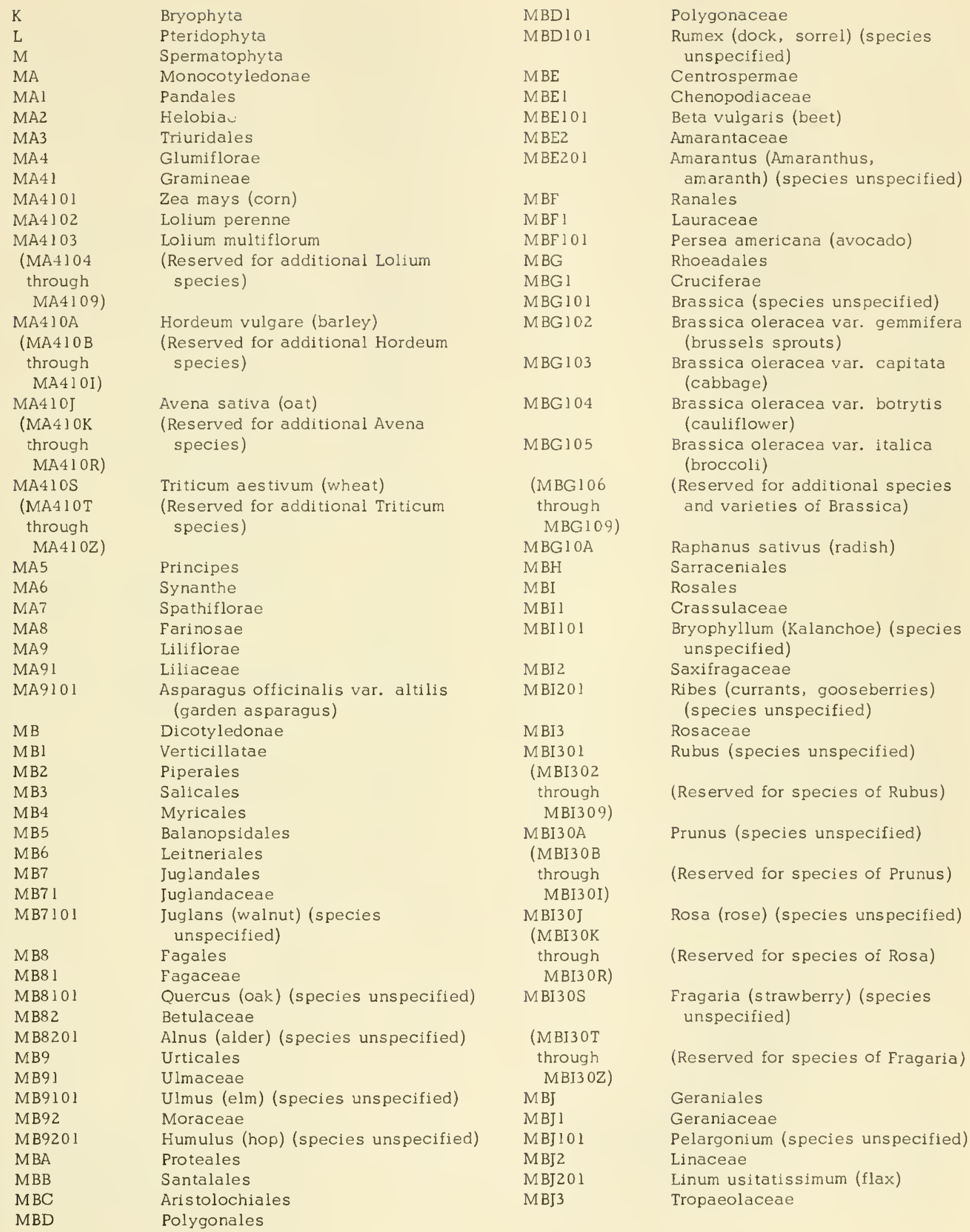


Columns $37,38,39$, 40,41 , and 42

\begin{tabular}{|c|c|c|c|}
\hline MBJ301 & $\begin{array}{l}\text { Tropaeolum major (garden } \\
\text { nasturtium) }\end{array}$ & $\begin{array}{l}\text { (MBY10B } \\
\text { through }\end{array}$ & $\begin{array}{l}\text { (Reserved for species and strains } \\
\text { of Citrullus vulgaris) }\end{array}$ \\
\hline $\mathrm{MBJ} 4$ & Rutaceae & MBY10I) & \\
\hline MBJ401 & Citrus (species unspecified) & MBY10J & Cucumis sativus (cucumber) \\
\hline $\mathrm{MBJ} 403$ & Citrus aurantifolia (lime) & (MBY10L & (Reserved for additional species \\
\hline $\mathrm{MBJ} 404$ & Citrus paradisi (grapefruit) & through & and strains of Cucumis) \\
\hline MBJ 405 & Citrus sinensis (sweet orange) & MBYIOS) & \\
\hline MBK & Sapindales & & (marguerite, Paris daisy) \\
\hline MBK1 & Aceraceae & (MBY202 & (Reserved for species and \\
\hline MBK101 & Acer (maple) (species unspecified) & through & strains of Chrysanthemum) \\
\hline MBL & Rhamnales & MBY209) & \\
\hline MBLl & Vitaceae & MBY20A & Helianthus annuus (sunflower) \\
\hline $\mathrm{MBN}$ & Parietales & (MBY20K & (Reserved for species and \\
\hline $\mathrm{MB} \varnothing$ & Opuntiales & through & strains of Lactuca) \\
\hline MBP & Myrtiflorae & MBYZOR) & \\
\hline $\mathrm{MBQ}$ & Umbelliflorae & MBY2OS & Xanthium (cocklebur) (species \\
\hline MBQI & Umbelliferae & & unspecified) \\
\hline MBQIOI & Daucus carota var. sativa (carrot) & $\mathrm{MN}$ & Gymnospermae \\
\hline MBQ102 & $\begin{array}{l}\text { Apium graveolens var. dulce } \\
\text { (celery) }\end{array}$ & $\begin{array}{l}\text { MN1 } \\
\text { MN1 } 1\end{array}$ & $\begin{array}{l}\text { Coniferales } \\
\text { Pinaceae }\end{array}$ \\
\hline MBR & Ericales & MNIIOI & Pinus (pine) (species unspecified) \\
\hline MBS & Primulales & (MN1102 & (Reserved for species and \\
\hline MBT & Ebenales & through & strains of Pinus) \\
\hline MBVI & Convolvulaceae & through & strains of Picea) \\
\hline MBVIOI & Ipomoea batatas (sweet potato) & MNIIOR) & \\
\hline MBV2 & Solanaceae & & \\
\hline MBV20 I & Lycopersicon esculentum (tomato) & & \\
\hline $\mathrm{MBV} 202$ & Nicotiana tabacum (tobacco) & \multicolumn{2}{|c|}{ NON-LIVING HOSTS } \\
\hline (MBV203 & (Reserved for species and strains & & \\
\hline through & of Nicotiana) & $\mathrm{S}$ & Gaseous mixture \\
\hline MBV209) & & $\mathrm{Sl}$ & Air \\
\hline MBV20A & Solanum tuberosum (potato) & $\mathrm{T}$ & Water \\
\hline MBV2OB & $\begin{array}{l}\text { Solanum melongena var. esculentum } \\
\text { (eggplant) }\end{array}$ & $\begin{array}{l}\mathrm{T} I \\
\mathrm{~T} 2\end{array}$ & $\begin{array}{l}\text { Fresh water } \\
\text { Sea water }\end{array}$ \\
\hline MBW & Plantaginales & T3 & Brackish or Tidal water \\
\hline MBX & Rubiales & $\mathrm{T} 4$ & Saline solution \\
\hline MBY & Campanulatae & $\mathrm{T} 41$ & Ringer's solution \\
\hline MBYI & Cucurbitaceae & $\mathrm{T} 42$ & Locke's solution \\
\hline MBYIOI & $\begin{array}{l}\text { Cucurbita mixima (autumn squash, } \\
\text { winter squash) }\end{array}$ & $\begin{array}{l}\mathrm{T} 43 \\
\mathrm{~T} 44\end{array}$ & $\begin{array}{l}\text { Tyrode's solution } \\
\text { Ringer-Locke solution }\end{array}$ \\
\hline MBY 102 & Cucurbita pepo (pumpkin) & T5 & Buffer solution (unspecified) \\
\hline (MBYI03 & (Reserved for species and strains & T5 1 & Blcarbonate buffer solutions \\
\hline through & of Cucurbita) & T5 11 & Kreb's bicarbonate buffer solution \\
\hline MBY109) & & T52 & Phosphate buffer solution \\
\hline MBYIOA & Citrullus vulgaris (watermelon) & T521 & Kreb's phosphate buffer solution \\
\hline
\end{tabular}


Sugar solution

Glucose solution

Soil, potting media, etc. (unspecified as to composition)

\section{Gravel}

Washed gravel (washed with dilute acid to remove mineral nutrients)

Unwashed gravel (not washed with

$$
\text { dilute acid) }
$$

Sand

Washed sand (washed with dilute acid to remove mineral nutrients)

Unwashed sand (not washed with dilute acid)

Loam soil

Sandy loam soil

Sandy soil

Clay loam soil

Clay soil

Vermiculite

Perlite

Humus

Compost or compost soil mixture

Manure

Plant products

Wood (timber, lumber)

Bark

Heartwood

Sapwood

Paper

Straw

Latex

Dried seeds (as in storage)

Grains (wheat, corn, barley, rice, etc.)

Legumes (beans, peas, peanuts, etc.)

Processed plant products

Rolled or cracked grain

Flour or meal

Macaroni products

Chocolate and cocoa products

Tobacco products

Dried fruits (raisins, prunes, etc.)

Yeast concentrates

Animal products

Meat and meat products

\section{Eggs}

Animal fiber (raw hides, fur, feathers, silk)

Honeycomb

Processed animal products

\section{Cheese}

Dried milk products

Egg powder

Leather

Medium (culture medium, nutrient medium)
Medium prepared chiefly from natural products; includes complex, or ill-defined media, or media described only as "minimal" (e.g., meat extract, broth). If the natural product is a body fluid, such as blood, use Symbol X12.

Medium as in Xl (exclusive of specific body fluids), but including organisms whose association (other than as a host) is essential for successful maintenance of the test organism. Use Xll only if the associated organism is not identified specifically--as a bacterium, protozoan, or other form.

Medium as in X1, with Bacteria as the associated organism

Medium as in X1, with Protozoa as the associated organism

Medium containing blood, serum, plasma, albumin, etc. (body or plant cavity fluids or fractions of the same)

Medium as in X12, but including organisms whose association (other than as a host) is essential for successful maintenance of the test organism. Use X121 only if the associated organism is not identified specifically-as a bacterium, protozoan, or other form.

Medium as in $\mathrm{X} 12$, with Bacteria as the associated organism

Medium as in X12, with Protozoa as the associated organism

Medium consisting chiefly of a mixture of essential inorganic compounds in water (or other non-nutritive medium); mineral nutrient solutions (plant sciences, including bacteriology)

Medium as in X2, but including organisms whose association is essential for successful maintenance of the test organism. Use X2l only if the associated organism is not identified specifically--as a bacterium, protozoan, or other form. Medlum as in X2, with Bacteria as the associated organism
Medium as in X2, with Protozoa as the associated organism 
FIELD I

Columns 37, 38, 39,

40,41 , and 42

$Y$

Y 1

Yll

Y12

$\mathrm{Y} 13$

Y14

$\mathrm{Y} 2$

Y 21

$\mathrm{Y} 22$

Y23

$\mathrm{Y} 3$

$\mathrm{Y} 4$

Y5

Y6

Z

Z1

$\mathrm{Z} 2$

Fabricated products

Plant, animal, or mixed origin

Cloth

Clothing (includes shoes)

Upholstery

Rubber goods

Synthetics

Plastics

Film or sheet plastic

Fiber or woven plastic

Paint

Masonry

Metal

Glass

Buildings

Storage houses

Shower rooms 
SEX AND STAGE OF DEVELOPMENT OF THE HOST ORGANISM

The code symbols for Field $\mathrm{K}$ (the sex and stage of development of the host in Field J) can be found by consulting Field F (pp. 88-93), since the items for the two fields are the same.

Note that the Symbols $\mathrm{S}$ through $\mathrm{Z}$ are never used in Field $\mathrm{K}$. 


\author{
PRETREATMENT OR \\ EXPERIMENTAL STATE OF THE \\ HOST ORGANISM OR OF THE ORGAN, \\ TISSUE, OR CELL (OF THE HOST ORGANISM ) \\ WHICH IS THE SITE OF THE \\ PARASITE, NON-INFECTIOUS PATHOLOGY, \\ OR TUMOR CODED IN FIELD E \\ Symbol Z only: \\ EXPERIMENTAL TREATMENT OF THE \\ HOST OTHER THAN TREATMENT \\ WITH THE TEST COMPOUND \\ AND COMPOUND CODED IN FIELD D
}

HOST (OR ORGAN, TISSUE, OR CELI SITE OF THE PATHOLOGY) IS EXPERIMENTALLY ADAPTED (i.e., conditioned) to a particular environment or situation (to facilitate its acceptance of the test organism or test compound, e.g.). Any exposure to particular environments which do not result in specific adaptations, are coded by Symbols 3 or 4.

HOST (OR ORGAN, TISSUE, OR CELL SITE OF THE PATHOLOGY) IS PRETREATED SURGICALLY (as in the states of Symbols $P, Q$, and R), CHEMICALIY, BY ELECTRIC SHOCK, ETC., but (in contrast to Symbols $\mathrm{P}, \mathrm{Q}$, and R) for any purpose other than isolation of the host and an anatomical unit. Includes staining with dyes, surgical exposure of an organ only to facilitate observation, treatment for rendering an animal host quiet or otherwise recepiive to treatment with the test compound. Also, special pretreatment for making the host more receptive to introduction of an infectious organism or the chemical treatment, such as special diet, removal of hair, feathers, or scales, skin laceration, etc.

HOST (OR ORGAN, TISSUE, OR CELL SITE OF THE PATHOLOGY) IS EXPOSED TO AN ABNORMAL PHYSICAL OR CHEMICAL ENVIRONMENT, preparatory for or during the test, to which adaptation is not intended. (Included are high atmospheric pressures, changes in $\mathrm{O}_{2}: \mathrm{CO}_{2}$ ratio, temperature changes, changes in gravitational pull, anaerobic culture conditions, etc.) For radiation exposure, use special Symbol 4. When the host has become adapted to such an environment (prior to the test), Symbol 1 must be used rather than Symbol 3 .

HOST (OR ORGAN, TISSUE, OR CELI SITE OF THE PATHOLOGY) IS EXPOSED TO RADIATION which is not intended as treatment or part of the treatment for the parasite or pathology or tumor coded in Field E. If radiation is administered as part of the treatment of the host instead of a pretreatment (i.e., administered with the test compound so that both the chemical and radiation factors are expected to be responsible for the response coded in Field T), Symbol $\mathrm{z}$ must be used.

HOST IS EXPERIMENTALLY OR NATURALLY INFECTED or parasitized with an organism other than the parasitic or infectious organism specifically treated by the test compound, or in addition to the non-infectious pathology or tumor being specifically treated. (For non-infectious pathological states of the host, other than the pathology or tumor coded in Field E, use Symbol 7, B, C, D, or $E$ ). If this incidental infection is restricted to a single organ, use Symbols $N$ or $\phi$. HYPERSENSITIVE to the test compound. (For a host strain sensitive to the test compound, use Symbol H. Use Symbol I for the state of induced resistance to the test compound. )

HOST IS IN AN EXPERIMENTAL PATHOLOGICAL STATE other than the pathology coded in Field E and not otherwise specified by speclal symbols--5 (infectious disease), B (hormone deficiency), $\mathrm{C}$ (hormone excess), D and E (dietary deficiencies), P (loss of an anatomical part), and S (bearing an implant). Symbol 7 is used for all other non-infectious pathologies (other than the pathology in Field E), including spontaneous tumors (but not implanted tumors). Also, it includes general experimental stress either brought about by administration of excesses of a specific material (e.g., $\mathrm{H}_{2} \mathrm{O}$, salt, $\mathrm{CO}_{2}$, etc.), or removal of an organ (to be described in the written 
abstract and not coded in Field H-2), etc., or a natural or unspecified physiological stress. (If the host has had removed from it an organ for any purpose other than to produc $\geq$ stress, the condition is coded by Symbol P.) If the pathology of Field E is specifically of an organ or tissue (coded in Field $\mathrm{H}-\mathrm{l}$ or I) and that structure has a second pathological state, use Symbol $\mathrm{N}$ or $\mathrm{S}$. If the host has an organ or tissue, other than the organ or tissue site of the pathology (therefore, not coded in Field H-1 or I) which is in a pathological state different from the pathological state coded in Field E, use Symbol $\varnothing$ and, if the structure in this secondary pathological state is an organ, code it in Field $\mathrm{H}-2$ (if it is a tissue, it can not be coded in Field I).

HOST (OR ORGAN, TISSUE, OR CELL SITE OF THE PATHOLOGY) IS IN AN INACTIVE STATE; e. g., hypnosis, estivation, diapause, dormancy, bacterial resting stage, hibernation.

\section{PARABIOTIC}

\section{PARTHENOGENETIC}

HOST (OR ORGAN, TISSUE, OR CELL SITE OF THE PATHOLOGY) IS HORMONE DEFICIENT (the deficiency not being the condition treated). Symbol B has priority over Symbol P in Field L and is used for any experimental hormone deficiency. When an endocrine gland is extirpated to produce the hormone deficient state (when the deficiency is not a condition being treated), code the gland removed or modified in Field H-2. This includes situations in which the hormone deficiency is relative only to the developmental state of the host being treated with the test compound.

HOST (OR ORGAN, TISSUE, OR CELL SITE OF THE PATHOLOGY) HAS A HORMONE EXCESS (the excess not being the condition treated). This includes situations in which the excess is relative only to the developmental stage of the host being treated with the test compound.

HOST (OR ORGAN, TISSUE, OR CELL SITE OF THE PATHOLOGY) IS DEFICIENT IN ONE OR MORE VITAMINS, ONE OR MORE MINERALS, ONE OR MORE SPECIFIC NUTRIENTS, OR WATER. (The symbol is not used for general deficiency in nourishment. See Symbol E.) Symbol D is used to code incidental dietary deficiencies of normal host organisms. It is not a device for indicating that the host is a special strain which can not synthesize the nutrient, vitamin, or inorganic compound. Any special strain, such as one dependent on exogenous nutrient or vitamin sources, is indicated by Symbol $\mathrm{F}$.

HOST (OR ORGAN, TISSUE, OR CELL SITE OF THE PATHOLOGY) IS UNDERNOURISHED; generally deficient in nutrients; fasted, deficient in caloric intake. For the deficiency of a specific essential dietary component, use Symbol D.

HOST IS OF A SPECIAL STRAIN, selected, adapted, derived, mutant. (This excludes those special strains for which are provided the specific symbols, G, H, I, or Y below. It also excludes designation of taxonomic strains which have been adequately distinguished by special host symbols in Field J. Symbol F (and Symbols G, H, I and Y) are used only to designate physiological strains not distinguished by a unique strain name in Field J. (See also the Key, Specific Directions and Explanations, Division 9.)

HOST IS OF A STRAIN RESISTANT TO THE TEST COMPOUND (Use Symbol $J$ for an individual host organism, of a non-resistant strain, made resistant by prior exposure to the test compound. ) A strain resistant to the test organism is indicated by Symbol Y.

HOST IS OF A STRAIN SENSITIVE TO THE TEST COMPOUND. (Use Symbol 6 for an individual host organism, of a non-resistant strain, sensitized to the test compound by previous exposure.)

HOST IS OF A STRAIN DEPENDENT ON THE TEST COMPOUND.
Use Symbol $\mathrm{F}$ for an organism of a strain resistant to, sensitive to, or dependent on compounds other than the test compound

HOST (OR ORGAN, TISSUE, OR CELL SITE OF THE PATHOLOGY), IS OF A NON-RESISTANT STRAIN AND IS MADE RESISTANT TO (I. E. , TOLERANT OF) THE TEST COMPOUND. (Use Symbol 6 for the state of sensitization to the test compound. For a resistant strain, use Symbol G). A host made resistant to the test organism is indicated by Symbol Y. 
FIELD L

Column 44

K

L

M

$\mathrm{N}$

\title{
PREGNANT
}

VIRGIN

\author{
HOST (OR ORGAN, TISSUE, OR CELL SITE OF THE PATHOLOGY) IS CONGENITALLY ABNORMAL.
}

ORGAN OR TISSUE OF THE HOST (SPECIFIED IN FIELD H-1 OR I AS THE SITE OF THE PATHOLOGY OR TUMOR BEING TREATED) IS IN A PATHOLOGICAL STATE other than the pathological state being treated (specified in Field $E$ ). Use of this symbol includes indication of physiological stress on the organ when this stress is not a condition being treated by the test compound; e.g. , the removal of one of a pair of organs of the host, or part of an organ, or an entire organ, or any other special pretreatment to produce the exaggerated condition of in situ experimental stress of an organ specified in Field $\mathrm{H}-1$ or of the tissue specified in Field I. The description of the specific treatment to produce stress is not coded (e. g., the organ removed to produce stress is not coded in Field $\mathrm{H}-2$, but it is included in the written abstract). The symbol is used only if that secondary pathology or infectious organism which is not being specifically treated is restricted to that organ or tissue or if the organ or tissue is excised (indicated by Symbol $R$ in Field $G-1$, placing Symbol $N$ in Field G-2); if the secondary pathology is more general and the organ or tissue is in situ, use Symbol 5 or 7.

ORGAN OF THE HOST (TO BE SPEGIF IED IN FIELD H-2 AS AN ORGAN OTHER THAN THE SPECIFIC SITE OF THE PATHOLOGY BEING TREATED, IN FIELD H-1) IS IN A PATHOLOGICAL STATE OTHER THAN THE PATHOLOGICAL STATE BEING TREATED (SPECIFIED IN FIELD E). This includes the state of experimental physiological stress on an organ (Field $\mathrm{H}-2$ ) other than the site of the pathology being treated (Field $\mathrm{H}-\mathrm{l}$ ), when this stress is not a condition being treated by the test compound. (Symbol $\mathrm{N}$ indicates stress on the organ in Field H-1.) This symbol is used only if the secondary pathology is confined to an organ; if the secondary pathology is more general, Symbol 5 or 7 will be used and nothing will be coded in Field H-2.

HOST (CONSIDERED AS A WHOLE) HAS HAD REMOVED--PRIOR TO INFECTION OR PRIOR TO THE TEST--AN ORGAN, TISSUE, OR FLUID, FOR ANY REASON OTHER THAN SERVING AS A PART OF THE TREATMENT FOR THE PATHOLOGY CODED IN FIELD E. (The organ removed from the host is not a specific site of the pathology and is therefore coded in Field H-2.) Symbol B is used if an endocrine gland is removed to produce a hormone deficiency. Symbol $\mathrm{P}$ is not used to indicate removal of an organ to produce experimental stress on the organism; this can be indicated only by Symbol 7 . If the removal of an organ is part of the treatment of the pathology in Field $\bar{E}$, of which the test compound treatment represents the other part, never use Symbol P, but only Symbol $\mathrm{Z}$.

ORGAN OR TISSUE OF THE HOST, IN SITU (SPECIFIED IN FIELD H-1 AS THE ORGAN OR IN FIELD I AS THE TISSUE WITH THE INFECTION OR PATHOLOGY TREATED WITH THE TEST COMPOUND) ISOLATED IN SOME SPECIFIC WAY FROM THE HOST ORGANISM (denervation, circulatory obstruction, etc.), isolated from the material it normally processes, surgically altered solely for the facility of observation, or isolated from one of its tissue components, etc. See the Key for a discussion of uses of Symbols 2, P, Q, R, and B.

ORGAN, TISSUE, OR FLUID OF THE HOST, EXCISED (specified in Fleld $\mathrm{H}-1$ or I as the organ or tissue in the pathological condition coded in Field $E$ ), isolating it from influences of all other factors of the host organism, and maintained in a "secondary, non-living host" (saline bath, nutrient medium, perfusate, etc. ) described in the written abstract.

HOST (OR ORGAN OR TISSUE SITE OF THE PATHOLOGY) HAS AN ORGAN OR TISSUE (EITHER NORMAL OR PATHOLOGICAL) INCIDENTALLY IMPLANTED IN IT, but this implant is not the pathology being treated nor is it part of the treatment for the pathology coded in Field $\mathrm{E}$. (E.g., rats with a tumor implant are treated with a candicate anthelmintic [coded as the test compound] for tapeworm prophylaxis. The tumor implant would be indicated better by Symbol $S$ than by Symbol 7.) Excluded are situations when the implant is an endocrine gland implanted in the host to produce a hormone excess (Symbol C) or an organ implanted to produce special stress (Symbol ?, N, or $\varnothing$ ). Such an implant can be coded in Field H-2, if it is an organ; if it is a tissue or a tumor, it can not be coded, but should be included in the written abstract. The site of implant can not be coded, but should also be included in the written abstract. 
THE HOST ORGANISM IS IN A SECONDARY HOST ORGANISM OR NON-LIVING SECONDARY HOST, described in the written abstract. If a plant is the host and is maintained in an artificial medium or water, e. g., instead of its usual soil, indicate it by use of Symbol $T$ rather than by Symbol 3. (Symbol $\mathrm{T}$ is never used to indicate that a specific organ or tissue [site of the pathology] has been transplanted to a secondary host.)

$\mathrm{U}$ HOMOGENATE, BREI, OR
TISSUE OF THE HOST.

V EXTRACT OF A TISSUE OR ORGAN OF THE HOST.

W CULTURE OF A TISSUE OR ORGAN OF THE HOST. SIICE OF A TISSUE OR ORGAN OF THE HOST.
The organ or tissue of the definitions of these symbols is the organ or tissue specifically the site of the parasite, non-infectious pathology, or tumor and therefore is coded in Field $\mathrm{H}-\mathrm{l}$ or $\mathrm{I}$.

HOST HAS PARTIAL RESISTANCE TO THE TEST ORGANISM due to previous exposure or due to being a strain that has more resistance than other strains of the species. (Use Symbol G for strains resistant to the test compound and Symbol $\mathrm{J}$ for individual host organisms made resistant to the test compound.)

\author{
Second use of Field L (one symbol only): \\ EXPERIMENTAL TREATMENT OF THE HOST OTHER THAN \\ WITH THE TEST COMPOUND OR SECONDARY COMPOUNDS
}

Z ANY TREATMENT OF THE HOST (OR ORGAN, TISSUE, OR CELL SITE OF THE PATHOLOGY) AGAINST THE PARASITE, NON-INFECTIOUS PATHOLOGY, OR TUMOR CODED IN FIELD E, OTHER THAN TREATMENT WITH THE TEST COMPOUND (OR OTHER THAN TREATMENT WITH THE TEST COMPOUND AND SECONDARY COMPOUND) AND ACCOMPANYING THE TREATMENT WITH THE TEST COMPOUND (OR ACCOMPANYING THE TREATMENT WITH THE TEST COMPOUND AND SECONDARY COMPOUND). Examples are radiation, thermal, and mechanical treatments and administration of anti-toxins specific for the test organism, etc. To qualify for being coded by Symbol Z, such treatment must be considered as in part responsible for the action coded in Field $\mathrm{T}$ to the degree coded in Field $\mathrm{Y}$. 


\section{DOSAGE (CONCENTRATION COMPONENT)}

\section{UNIT OF \\ MEASURE \\ Column 45}

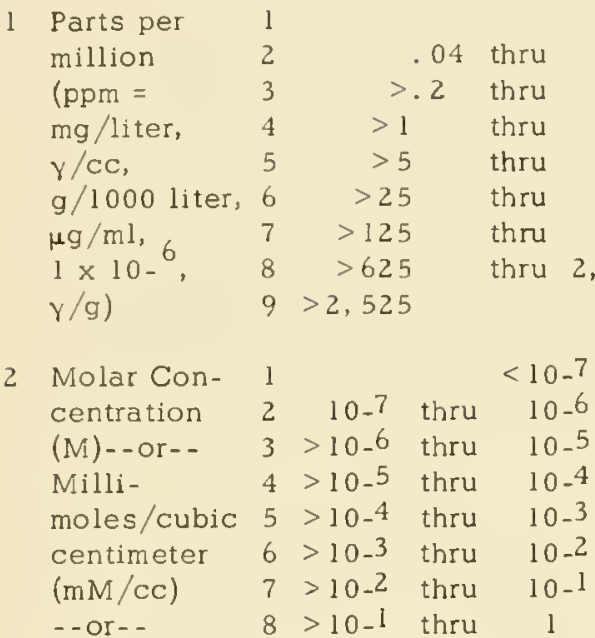

3 Molal con- $9>1$

centration

4

$\begin{array}{llclc}\text { Per cent } & 1 & & <.000001 \% \\ \text { weight or } & 2 & >.000001 & \text { thru } & .00001 \\ \text { volume; } & 3 & >.00001 & \text { thru } & .0001 \\ \text { also } & 4 & >.0001 & \text { thru } & .001 \\ \mathrm{~g} / 100 \mathrm{cc} & 5 & >.001 & \text { thru } & .01 \\ & 6 & >.01 & \text { thru } & .1 \\ & 7 & >.1 & \text { thru } & 1 \\ & 8 & >1 & \text { thru } & 10 \\ & 9 & >10 & \text { thru } 100\end{array}$

5 Pounds/100 1

gallons 2

(lbs $/ 100$ gal.)

UNIT OF

MEASURE

Column 45

QUANTITATIVE VALUE

Column 46

$7 \%$ satura- $1<10$

tion 210 thru 20

$3>20$ thru 30 (Do not

$4>30$ thru 40 use grid

$5>40$ thru 50 with this

$6>50$ thru 60 scale)

$7>60$ thru 70

$8>70$ thru 80

$9>80$ thru 90

$0>90$ thru 100

8 Milli- $1<1.56$

grams $2 \quad 1.56$ thru 3.12

per $3>3.12$ thru 6.25

liter $4>6.25$ thru 12.5

of air $5>12.5$ thru 25

(mg/1) $6>25$ thru 50

$7>50$ thru 100

$8>100$ thru 200

$9>200$

9 Nor-

mality 2 10-7 thru $10-6$

(N) $\quad 3>10-6$ thru $10-5$

$4>10.5$ thru 10.4

$5>10-4$ thru $10-3$

$6>10-3$ thru $10-2$

$7>10-2$ thru $10-1$

$8>10-1$ thru 1

$9>1$

$\begin{array}{rrrr}1 & & & <.39 \\ 2 & .39 & \text { thru } & .65 \\ 3 & >.65 & \text { thru } & 1.09 \\ 4 & >1.09 & \text { thru } & 1.81 \\ 5 & >1.81 & \text { thru } & 3.02 \\ 6 & >3.02 & \text { thru } & 5.04 \\ 7 & >5.04 & \text { thru } & 8.4 \\ 8 & >8.4 & \text { thru } & 12 \\ 9 & >12\end{array}$

6 Units/milli- 1

liter

(units/ml) 3

$\begin{array}{cccc}1 & .01 \text { thru } & <.01 \\ 2 & >.1 & \text { thru } & 1 \\ 3 & >1 & \text { thru } & 10 \\ 4 & >10 & \text { thru } & 100 \\ 5 & >100 & \text { thru } & 1,000 \\ 6 & >1,000 & \text { thru } & 10,000 \\ 7 & >10,000 & \text { thru } & 100,000 \\ 8 & >100,000 & & \end{array}$

A Micro 1

curies 2

per 3

milliliter 4

( $\mu$ curies/ 5

ml)

6
7
8

$<.001$

.01

. 1

1

10

100

100

thru 1,000

thru 10,000

$>1,000$

$>10,000$

B $\mathrm{mg} / \mathrm{ml}$


Column 46: Symbol

* (= 12 zone punch) The dosage is in terms of the biologically active portion of the molecule.

\# (= 11 zone punch)

(a) When Fjeld J is coded: The dosage coded is not the dosage administered to the host, but is the dose to which the test organism is exposed.

(b) When Field J is not coded: The dosage coded is not the dosage administered to the test organism, but is the dosage to which the organ or tissue of the test organism is exposed.

$0 \quad(=0$ zone punch) Only when Field $\mathrm{J}$ is coded (with symbols other than $\mathrm{S}$ through $\mathrm{Z}$ in Column 37 ): The dosage coded is not the dosage administered to the host but is the dose to which the organ or tissue of the test organism is exposed. 


\section{DOSAGE (QUANTITY COMPONENT)}

\section{UNIT OF \\ MEASURE}

Column 47

1 Micrograms $(\mu g)$

(ү)

\section{QUANTITATIVE VALUE Column 48}

2 Milligrams (mg) - - or- -

3 Microliters (k1)

4

$\begin{array}{crrrr}\text { Grams } & 1 & 2 & \text { thru } & 4 \\ \text { (g) } & 2 & >4 & \text { thru } & 8 \\ \text {--or-- } & 3 & >8 & \text { thru } & 16 \\ \text { Milli- } & 4 & >16 & \text { thru } & 32 \\ \text { liters } & 5 & >32 & \text { thru } & 64 \\ \text { (ml) } & 6 & >64 & \text { thru } & 128 \\ & 7 & >128 & \text { thru } & 256 \\ & 8 & >256 & \text { thru } & 512\end{array}$

thru 81

thru 729

thru 2,187

1

4

$\begin{array}{rrr}>243 & \text { thru } & 729 \\ >729 & \text { thru } & 2,187\end{array}$

$<0.012$
0.036
0.11
0.33
1
3
9
27
81

UNIT OF

MEASURE

Column 47

9 Microliters 1 centimeter $3 \quad>2$ thru 4 $(\mu \mathrm{l} / \mathrm{sq} \mathrm{cm}) \quad 4 \quad>4$ thru 8

$>8$ thru 16 $>16$ thru 32 $>32$ thru 64 $>64$ thru 128 $9>128$

A Micro- 1

liters 2

per 3

kilogram 4 $(\mu \mathrm{l} / \mathrm{kg}) \quad 5$

thru 27

thru 243

Column 48

$$
128
$$

6 Milligrams 1 perkilo- 2 gram 3 $\begin{array}{ll}(\mathrm{mg} / \mathrm{kg}) & 4 \\ (=\mathrm{Micro}- & 5\end{array}$ grams per gram 7 $[\mu \mathrm{g} / \mathrm{g}])$

$\begin{array}{clc} & & <0.04 \\ >0.04 & \text { thru } & 0.2 \\ >1 & \text { thru } & 1 \\ >5 & \text { thru } & 25 \\ >25 & \text { thru } & 125 \\ >125 & \text { thru } & 625 \\ >625 & \text { thru } & 2,525\end{array}$

$9>2,525$

7 Micrograms 1

per square 2 centimeter 3 $(\mu \mathrm{g} / \mathrm{sq} \mathrm{cm}) \quad 4$ - - or - - 5

8 Milligrams 6 per square 7 foot ( $\mathrm{mg} / \mathrm{sq} \mathrm{ft}$ )

$\begin{array}{clc} & & <0.06 \\ >0.06 & \text { thru } & 0.25 \\ >1 & \text { thru } & 4 \\ >4 & \text { thru } & 16 \\ >16 & \text { thru } & 64 \\ >64 & \text { thru } & 256 \\ >256 & \text { thru } 1,024\end{array}$

\section{QUANTITATIVE VALUE}

$\begin{array}{clc} & & <0.04 \\ >0.04 & \text { thru } & 0.2 \\ >1 & \text { thru } & 1 \\ >5 & \text { thru } & 25 \\ >25 & \text { thru } & 125 \\ >125 & \text { thru } & 625 \\ >625 & \text { thru } & 2,525 \\ >2,525 & & \end{array}$

B $\mathrm{cc} / \mathrm{ft}^{3} \quad 1$

$\begin{array}{ll}\text { (soil, } & 2 \\ \text { etc.) } & 3\end{array}$

$\mathrm{g} / \mathrm{ft}^{3}$

$\begin{aligned} & .03 \\ &> .087 \\ &> .261 \\ &> .782 \\ &> 2.35 \\ &> 7.04 \\ & 21.12 \\ & 63.34\end{aligned}$

$$
<.03
$$$$
\begin{array}{ll}
\text { thru } & .087 \\
\text { thru } & .261
\end{array}
$$$$
\text { thru } \quad .782
$$$$
\text { thru } 2.35
$$$$
\text { thru } 7.04
$$$$
\text { thru } 21.12
$$$$
\text { thru } 63.34
$$

C Pounds 1 per acre 2 (1bs/acre)

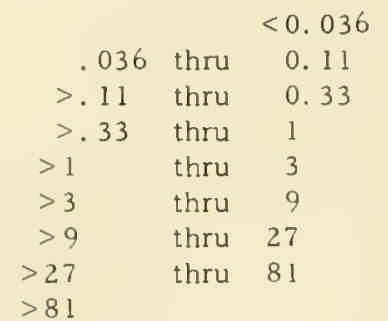
D Gallons 1 per acre 2 (gal/acre) 3<smiles>C1CC[GeH2]C1</smiles> 
UNIT OF

$\frac{\text { MEASURE }}{\text { Column } 47}$

E Units

\section{$\frac{\text { QUANTITATIVE VALUE }}{\text { Column } 48}$}

UNIT OF

$\frac{\text { MEASURE }}{\text { Column } 47}$

QUANTITATIVE VALUE

Column 48

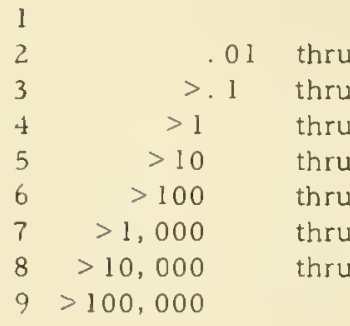

Units/gram
(units/g)
--or--
Units per
kilogram
(units/kg)

1
2
3
4
5
6
7
8
9
.001
$>.01$
$>.1$
$>1$
$>10$
$>100$
$>1,000$
$>10,000$

H Millimols

per

kilogram

$(\mathrm{mM} / \mathrm{kg})$

$\begin{array}{cccc}1 & & & <.04 \\ 2 & >.2 & \text { thru } & .2 \\ 3 & >1 & \text { thru } & 1 \\ 4 & >5 & \text { thru } & 5 \\ 5 & >25 & \text { thru } & 125 \\ 6 & >125 & \text { thru } & 625 \\ 7 & >625 & \text { thru } & 2,525 \\ 8 & >2.525 & & \end{array}$


(1) DOSAGE FREQUENCY

(2) SEQUENCE OF ADMINISTRATION OF

THE SECONDARY COMPOUND

AND THE TEST COMPOUND

Single administration, when a continuous supply to the test organism is not insured. (No entry in Field P.)

Single administration, when a continuous supply to the test organism is insured. (Duration of application of the dose is specified in Field P.) Ad libitum administration. (Consult the Key for a discussion of the use of Symbol 2.)

3 Repeated doses at intervals more frequent than specified below. (Duration of treatment specified in Field P.)

4 Hourly administration of the dose in Field $\mathrm{M}$ and/or N. (Duration of treatment specified in Field P.)

5 Three-times-daily administration of the dose in Field M and/or N. (Duration of treatment specified in Field P.)

6 Twice-daily administration of the dose in Field M and/or N. (Duration of treatment specified in Field P.)

7 Daily administration of the dose in Field $M$ and/or N. (Duration of treatment specified in Field P.)

8 Every-other-day administration of the dose in Field $M$ and/or N. (Duration of treatment specified in Field P.)

9 Every-three-days, or less frequent, administration of the dose in Field M and/or N. (Duration of treatment specified in Field P.)

0 Test compound given before the secondary compound. (The time period is specified in Field $\mathrm{P}$ and the secondary compound is specified in Field D. )

\# Test compound given after the secondary compound. (The time period is specified in Field $\mathrm{P}$ and the secondary compound is specified in Field D.)

* Test compound given simultaneously with the secondary compound. (The secondary compound is specified in Field $\bar{D}$. No entry is made in Field P, unless one of Symbols $I$ through 9 is also coded in Field $O$, in which case Field $P$ is coded with the duration of treatment with the test compound.) 
- or -

TIME BETWEEN ADMINISTRATION OF THE TEST COMPOUND AND A SECONDARY COMPOUND

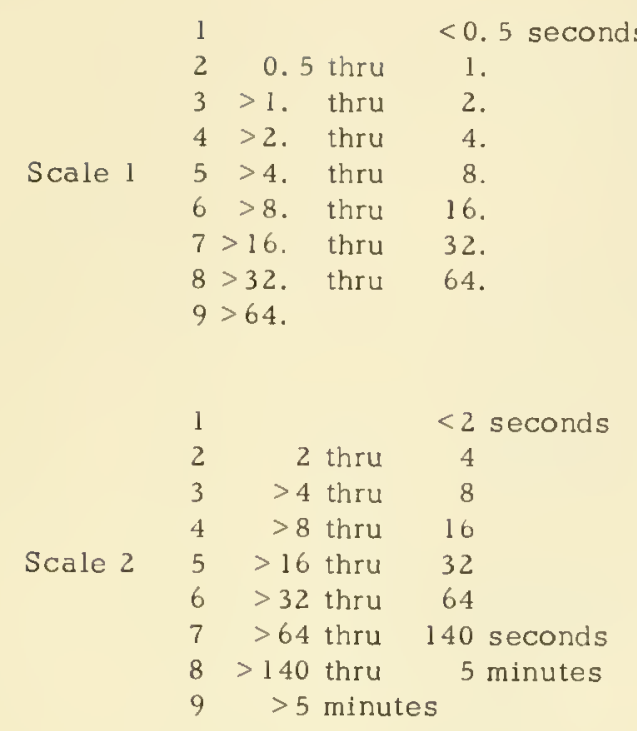

$\begin{array}{cccc} & 1 & & <16 \text { seconds } \\ & 2 & 16 \text { thru } & 32 \\ & 3 & >32 \text { thru } & 64 \\ \text { Scale } 3 & 4 & >64 \text { thru } & 140 \text { seconds } \\ & 5 & >140 \text { thru } & 5 \text { minutes } \\ & 6 & >5 \text { thru } & 10 \\ & 7 & >10 \text { thru } & 20 \\ & 8 & >20 \text { thru } & 45 \\ & 9 & >45 \text { minutes }\end{array}$

$\begin{array}{cccc} & 1 & & <45 \text { minutes } \\ & 2 & 45 \text { thru } & 90 \text { minutes } \\ & 3 & >90 \text { thru } & 3 \text { hours } \\ \text { Scale } 6 & 4 & >3 \text { thru } & 6 \\ & 5 & >6 \text { thru } & 12 \\ & 6 & >12 \text { thru } & 24 \\ & 7 & >24 \text { thru } & 48 \\ & >2 \text { thru } & 4 \text { days } \\ & 9 & >4 \text { days } & \end{array}$

$\begin{array}{ccrc} & 1 & & <6 \text { hours } \\ & 2 & 6 \text { thru } & 12 \\ & 3 & >12 \text { thru } & 24 \\ \text { Scale } 7 & 4 & >24 \text { thru } & 48 \\ & 5 & >2 \text { thru } & 4 \text { days } \\ & 6 & >4 \text { thru } & 8 \\ & 7 & >8 \text { thru } & 16 \\ & 8 & >16 \text { thru } & 32 \\ & 9 & >32 \text { days }\end{array}$

$\begin{array}{cccc} & 1 & & <24 \text { hours } \\ & 2 & 24 \text { thru } & 2 \text { days } \\ & 3 & >2 \text { thru } & 4 \text { days } \\ & 4 & >4 \text { thru } & 8 \\ \text { Scale } 8 & 5 & >8 \text { thru } & 16 \\ & 6 & >16 \text { thru } & 32 \\ & 7 & >32 \text { thru } & 2 \text { months } \\ & 8 & >2 \text { thru } & 4 \text { months } \\ 9 & >4 \text { months }\end{array}$

$\begin{array}{rrrl} & 1 & & <8 \text { days } \\ & 2 & 8 \text { thru } & 16 \\ & 3 & >16 \text { thru } & 32 \text { days } \\ \text { Scale } 9 & 4 & >32 \text { thru } & 2 \text { months } \\ & 5 & >2 \text { thru } & 4 \\ & 6 & >4 \text { thru } & 8 \\ & 7 & >8 \text { thru } & 16 \\ & 8 & >16 \text { thru } & 32 \\ & 9 & >32 \text { months }\end{array}$




\section{Number of cells}

-or-

number of larvae or number of individuals

of any parasitic stage of the implanted test organism

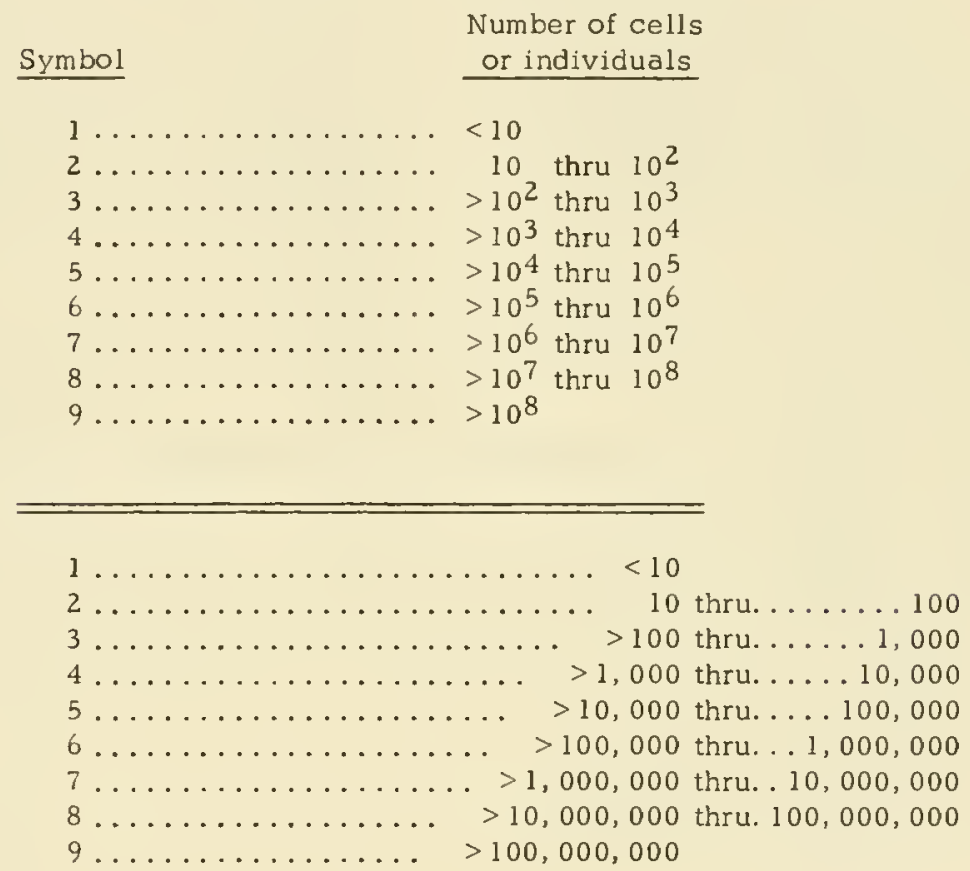


(1) INOCULATION

(2) TUMOR IMPIANTATION

(3) SENSITIZATION

(4) INCITATION OF NONINFECTIOUS PATHOLOGY dose[s]):

Administration of the test compound occurs (single dose) or begins (multiple or continuous

I at the same time as infection, tumor implantation, inoculation, sensitization, or initiation of a test. (This includes any time up to [but not including] one hour after infection, etc.)

21 thru 24 hours after infection, etc.

$3>24$ thru 48 hours after infection, etc.

$4>2$ thru 3 days after infection, etc.

$5>3$ thru 4 days after infection, etc.

$6>4$ thru 5 days after infection, etc.

$7>5$ thru 6 days after infection, etc.

$8>6$ thru 7 days after infection, etc.

$9>7$ thru 8 days after infection, etc.

A $>8$ days after infection, etc.

B after infection, etc., but time not specified in the data.

Administration of the test compound is discontinued after infection and occurs (single dose) or ends (multiple or continuous dose[s])

1 at the same time as infection, tumor implantation, inoculation, sensitization, or initiation of a test. (This includes any time up to [but not including] one hour before infection, etc.)

C $\quad 1$ thru 24 hours prior to infection, etc.

D $>24$ thru 48 hours prior to infection, etc.

E $\quad>2$ thru 3 days prior to infection, etc.

F $>3$ thru 4 days prior to infection, etc.

$\mathrm{G}>4$ thru 5 days prior to infection, etc.

$\mathrm{H}>5$ thru 6 days prior to infection, etc.

I $>6$ thru 7 days prior to infection, etc.

$\mathrm{J}>7$ thru 8 days prior to infection, etc.

$\mathrm{K}>8$ days prior to infection, etc.

L prior to infection, etc., but time not specified in the data.

Administration of the compound occurs or begins:

M prior to infection and continues after infection, etc. (The time prior to and after infection is not further considered with this symbol.) 
ROUTE AND MANNER OF ADMINISTRATION OF:

(1) INOCULUM OR IMPLANT (FIELD S-1)

(2) SECONDARY COMPOUND (FIELD S-2)

(3) TEST COMPOUND (FIELD S-3)

Any symbol of this list not otherwise marked may be used for coding Field S-1, Field S-2, or Field S-3. Certain symbol definitions relate in a specific manner to Fields S-2 and S-3 and those are designated in each case by a separate definition for Field S-I (Symbols 8, B, E, G, J, and R) or by a notation that the symbol as it is defined is not applicable to Field S-1 (Symbols C and M).

FIELD S-3 ONLY: Certain of the items of this list can employ Field $\mathrm{H}-2$ to indicate more specifically the route of the test compound. In the case of each of these items with which Field H- 2 is used, this is indicated at the end of that definition. (There is no similar way by which the manner of administration can be more specifically coded, except that the information about the state of the test compound coded in Field A often contributes to an understanding of the coded manner of administration. However, none of the symbols of Field S-3 make special reference to coding in Field A. This is discussed in Division 4 of the section on Specific Directions and Explanations for Field S-3, in the Key.)

Note that certain of the symbols $(0,1$ through $9, A$ through $I, P$ and $Q$, and $S$ through Z) represent routes and methods of application directly to the organism or some part of the organism. Symbols $\mathrm{J}$ through $\varnothing$ and Symbol R represent methods by which application is to the environment as well as, or instead of, to the organism so that the organism receives--or may receive--all or part of the material from the environment (with the possible exception of Symbol L, since the organism in that case is removed from the treated environment). This latter method most frequently permits less control of the quantity the organism receives, but often represents a more natural method for evaluation of the chemical for use in practical field application.

When the words "dose" and "compound" (or "chemical") appear in these definitions, they should be interpreted, for Field S-2, as "dose of the secondary compound" and, for Field S-3, as "dose of the test compound"; for Field S-1, however, substitute "quantity of " and "inoculum" for the expressions "dose of" and "compound".

0 Parenteral. (Any manner of administration by parenteral route.) This symbol is to be used only when the parenteral route is not more specific, such as intravenous, subcutaneous, etc. (Opposed to parenteral are the enteral [alimentary tract] routes, Symbols 1, 2, 3, 4, and T.)

1 Oral route, method unspecified. (For specific methods of oral administration, see Symbols 2 and 4 . For other enteral routes, use Symbol 3 or T.)

2 Oral route, administration of a measured dose by feeding or placing in the oral cavity the free compound, undiluted or mixed with food or other materials. (For administration techniques whereby the compound is not free to contact the oral parts, use Symbol 3. For unmeasured doses by either oral method, use Symbol 4.)

3 Postoral enteral route by which is administered a measured dose by by-passing the oral cavity; examples: stomach tube, capsule (even when the capsule is taken orally and voluntarily swallowed), duodenal tube, or other means (Including surgical) of introduction into a specific part of the alimentary lumen (except by anal approach, Symbol T). (Use Symbol 3 also for injection of a measured dose into the lumen of an exteriorized intestinal loop.) (For unmeasured doses, use Symbol 4.) Field S-3: Field H-2 may be used to specify the part of the alimentary 
tract into which administration of the test compound is directly made, if it is not the specifically responding part coded in Field $\mathrm{H}-\mathrm{I}$.

Oral route or postoral route, administration of an unmeasured dose (uncontrolled feeding, for example). Use Symbol 4 for ad libitum feeding, but only when no final measure of the intake is made; when a measure of the intake is made after ad libitum feeding, use Symbol 2 . Use Symbol $\mathrm{N}$ when a treated environment is consumed (or potentially consumed) by the test organism (e.g., cloth impregnated against moth larvae). Field S-3: Almost without exception administration of an unmeasured dose of a test compound is oral, but if it is postoral, Field H-2 can be used with Symbol 4 as it is used with Symbol 3

Intravascular injection, unspecified or specified as intravenous, intra-arterial, intraportal, or intracardial. (Use Symbol 5 for injections into closed vascular systems. Use Symbol 6 for invertebrate, "open" vascular systems [e.g., insect vessels].) Field S-3: With Symbol 5, Field H-2 can be used to distinguish the intravascular injections by coding in it the vein, artery, portal vessel, heart, or other specific vessel to which injection is made, unless that vessel is also the organ specifically responding to the test compound and coded in Field H-l.

Intraperitoneal injection. Also, injection into an invertebrate body cavity (e. g. , insect body cavity) or into an invertebrate "open" vascular system. Coelomic injection.

Intramuscular injection. Field S-3: Field $\mathrm{H}-2$ can be used to specify the body area or specific muscle into which the test compound was injected, if this is not the anatomical part specifically responding coded in Field $\mathrm{H}-\mathrm{I}$.

Subcutaneous injection; intradermal, intracutaneous injection. Use Symbol 8 for iontophoresis and for injection into lymph sacs of frogs. Field S-1: Use Symbol 8 for exposure to active cutaneous penetration of parasites (larval nematodes, trematodes, insects, etc.) Field S-3: Field H-2 can be used to specify the body area into which the test compound was injected, if this is not the anatomical part specifically responding, coded in Field $\mathrm{H}-\mathrm{I}$.

Tracheal injection.

A Intracellular injection.

Injection in--or topical application on--or dipping of--an EXPOSED OR ISOLATED ORGAN OR TISSUE (when application is single or repeated, but not when it is continuous for which use Symbol C). I. e., use Symbol B for applications which do not assure exposures (of the isolated or exposed organ or tissue) to a constant level of the test compound. If administration is made by single, non-continuous injection into a vessel of an'exposed (but not isolated) organ, use Symbol 5 rather than Symbol B. Also, a single or repeated "injection" into a flowing, but non-circulating liquid perfusing an EXPOSED OR ISOLATED ORGAN OR TISSUE (but not into a static or circulating [i.e., a closed-system] bathing liquid for which use Symbol $\overline{C \text { ). }}$ (Use Symbol $\mathrm{C}$ for administration by which the organ or tissue is exposed to a relatively constant quantity--e.g., administration to a static bath or a closed-system, circulating perfusate [coded in Field J, if the isolated part is of a test organism, or written in Field J, if the isolated part is of a host].) Field S-1: Use Symbol B to code an injection of, or topical application of, an inoculum into an exposed or isolated organ or tissue. Field S-3: A specific, exposed (but not isolated) organ to which single or repeated (but not continuous) application is made can be coded in Field $\mathrm{H}-2$, if that organ is not the organ specifically responding to the test compound and coded In Field $\mathrm{H}-1$.

C Application as (or as a constituent of) a perfusion or bath (circulating or non-circulating, open or closed flowing system) of an ISOLATED OR SURGICALLY EXPOSED ORGAN OR TISSUE, thereby providing a relatively constant concentration and continuous exposure. This includes the Warburg technique for an organ,-tissue, homogenate, or any enzyme preparation. Symbol C is also used for topical applications to isolated or surgically exposed organs or tissues, such as a salve, smear, ointment, etc., which provides a constant coat and exposure. (For single or repeated injections to an isolated or surgically exposed organ or tissue, which do not provide a constant dose level, use Symbol B. For topical application to the intact organism, use Symbol G. For immersion of the intact organism use Symbol E (brief immersion) or Symbol $\mathrm{N}$ 
FIELDS S-1, S-2, and S-3

Columns 54,55 , and 56

(continuous immersion). When the perfusion or bath is not the pure chemical, treat the bathing or perfusing medium (e.g. , normal saline, glucose solution, etc.) as a host of the organ or tissue: if the organ or tissue is of a test organism, code this medium in Field J, but if the organ or tissue is of a host organism, the medium can only be written in the abstract for Field J. Field S-1: Symbol C as it is defined here is applicable only for Fields S-2 and S-3 and is not intended for use in Field S-1. Application of an inoculum to an exposed or isolated organ or tissue is coded by Symbol B. Field S-3: A specific, exposed (but not isolated) organ to which continuous (but not single or repeated) application is made can be coded in Field $\mathrm{H}-2$, if that organ is not the organ specifically responding to the test compound and coded in Field $\mathrm{H}-1$. If the bath or perfusing medium is coded in Field J, the concentration of the test compound should be coded in Field $N_{i}$ with Symbol \# in Column 46 (or in Field $N$, if the dosage is expressed in "units", with Symbol \# in Column 48).

D Administration to a relatively INTACT PLANT by adding the compound to (or substituting the compound, if a liquid, for) water, nutrient medium, or soil, so that it is carried through the

(Plants root, stem, and other parts. Also, use Symbol D for "injection" into plants (ordinarily a only) continuous administration, from a reservoir, through a fixed injection tube or needle). Field S-3: The specific plant organ through which the test compound enters or is injected can be coded in Field $\mathrm{H}-2$, if that part is not the part specifically responding coded in Field $\mathrm{H}-1$.

E Brief, direct exposure to the surface or part of the surface of the intact organism; for example, dipping (i.e., essentially a surface exposure by relatively brief immersion) of the whole, intact organism or of a specific surface (an organ or tissue forming part of the body surface) of the intact organism. Also, a wash of brief duration, such as eye or nose drops which are rather quickly washed from the mucosal surfaces. (If an organ or tissue is isolated or an internal organ or tissue has been surgically exposed, use Symbol B, rather than Symbol E, to code its being given only brief surface exposure, e.g., dipping. Symbol E is opposed also to Symbols $\mathrm{N}$ and $\mathrm{G}$ in that $\mathrm{N}$ is used to code prolonged, continuous immersion and perfusion and $\mathrm{G}$ is used to code a more or less prolonged exposure to a material applied to the surface as a smear, ointment, salve, etc., even if that surface coating which provides a continuous exposure is applied by dipping. Symbol $\mathrm{E}$ also differs from Symbols $\mathrm{K}$ and $\mathrm{L}$ in that $\mathrm{K}$ and $\mathrm{L}$ are ordinarily for coding mass applications to a group of organisms [i.e., to a population]; in any case, $\mathrm{K}$ and $\mathrm{L}$ are not used to code specific controlled treatment of a single individual organism. ) The dipping medium or wash (solvent or carrier) is never considered to be a host and is not coded in Field J. Field S-1: Use Symbol E to code the introduction of the test organism to the surface of the intact host by relatively brief exposure of the host, such as dipping or washing with the inoculum. If the test organism actually actively penetrates the skin rather than attaches locally, use Symbol 8 rather than Symbol E or G. Fiel $\bar{d}$ S-3: If brief exposure (e.g., dipping) is restricted to only a specific part (organ or tissue) of the intact organism, Field $\mathrm{H}-2$ can be used to code that specific part, if it is not the part specifically responding coded in Field $\mathrm{H}-1$.

Prolonged, continuous exposure by direct application to the surface--or to some specific part of the surface--of the intact individual organism. Such direct surface applications are referred to as topical, local, percutaneous, etc. Examples; inunction, ointment applications, application by lanolin paste, screw worm smears, etc. For such application to excised organs (e.g., an orange, considering the fruit as an organ), use Symbol B. Symbol G is not used to code immersion of the intact organism for continuous exposure (e.g., for administration as part of the liquid environment of the organism) for which there is the special Symbol N. Field S-l: Use Symbol G to code the introduction of the test organism to the surface of the intact host by relatively protracted exposure of the host, - -for example, by lorcing the host to stand partly submerged in the inoculum. If the test organism actually actively penetrates the skin rather than attaches locally, use Symbol 8 rather than Symbol E or G. Field S-3: In the case of Symbol G, the application is usually restricted to the area coded in Field H-l rather than to the entire surface of the organism. However, if application is to the entire body surface (Symbol A of Field $\mathrm{H}$ ) or to a restricted area other than the area coded in Field H-1, that area (organ or body region) should be coded in Field $\mathrm{H}-2$.

Administration through respiratory organs. Field S-3: If the test compound is administered to a specific part of the respiratory tract, that part should be coded in Field $\mathrm{H}-2$ if it is not the organ specifically responding in Field H-1. 
J Fumigation (i.e., administration as a gas, aerosol, or mist) of the HABITAT with the organism present. Under the conditions for which Symbol J should be used, the administration is not implicitly by inhalation (Symbol I), nor does the administration involve determined direct application to the surface of the organism (Symbols $\mathrm{K}$ and L), nor is the administration to an environment prior to the organism's contact with the surface of the habitat (Symbol M). The administration to a habitat in which the administered material is absorbed or mixed, i.e., a habitat through which it is dispersed and therefore diluted, is coded by Symbol $\mathrm{N}$, except that if this is accomplished by the process of fumigation and the organism is present at the time of fumigation, Symbol J should be used. Field S-1: It is possible that administration of the test organism (microorganisms) might be made by a process of dispersing a suspension of the organism in a mist, etc. (i. e., by a dispersion analogous to "fumigation" with a test compound or secondary compound). For such an administration of the test organism, Symbol J should be used.

Direct application to both the surface of an organism (implying the total surface, not any specific part of the surface) and its environment when the dose per individual is not controlled and the organism is not removed from the treated environment. For example, spraying of PLANTS and the soil and other environmental components of the plants, or spraying of INSECTS and the plants on which the insects are as well as other environmental components of the insects, etc., when the organisms are not removed from the treated environment. Use Symbol L for this application method, when the treated organism is removed from the environment. See the definitions for Symbols $\mathrm{G}$, I, and $\mathrm{N}$ to further distinguish the uses of Symbol K.

L Application as defined for Symbol K, but the treated organism is removed from the environment after the treatment. Examples: Peet-Grady fly spray technique, certain settling tower methods, etc. See the definitions for Symbols $\mathrm{E}$ and J to further distinguish the uses of Symbol L.

Application to the habitat prior to the organism's contact with the SURFACE of that environment. (The application may be either to the surface only [a glass plate, e.g.]--or to an absorbent environmental material [paper, e.g.,] which nevertheless retains on its surface some of the applied compound.) Examples (Fields S-2 and S-3): the panel test for house flies, an application to foliage or other surface for residue tests, impregnated paper barriers for rodent repellency (also other similar repellency tests), the apple-plug technique, a pre-emergency herbicide test, etc. (Use Symbol $N$ or J when the application is to an environment throughout which the applied material is dispersed and IN which (not on which) the organism is, or will be, living and which the organism may consume $\overline{a s}$ food. Use Symbols $\mathrm{K}$ or $\mathrm{L}$ when the application is to the surface [or mixed with] the environment with the organism present.) (Note: For Field S-1, it is so improbable that an inoculum would be administered to a host by such a circuitous route as that described by Symbol M, the symbol is considered as inapplicable to Field S-1.)

N Application to the habitat throughout which the applied material is dispersed and diluted (i. e. , impregnation of, mixing with, diffusion in, saturation of the habitat), in which the intact organism is, or will be, living (mosquito larvae in water or nematodes or plant seeds in soil) and which it may consume (moth larvae in cloth). Examples: wood impregnation as protection against or treatment for infesting organisms (termites, fungi, marine borers, etc.), treatment of flour or grain for action against weevils or other infesting organisms (except by fumigation for which Symbol J is specially provided), addition to water in which aquatic organisms are living, addition to media in which are microorganisms, etc. (If the organism contacts only the surface of the habitat subsequent to application, use Symbol M. Symbol M is always used for repellency studies involving such applications. If the application as described for Symbol $\mathrm{N}$ is by fumigation and the organism is present at the time of application, use Symbol J which is specially provided for this. Symbol $\mathrm{N}$ differs from Symbol $\mathrm{K}$ in that Symbol $\mathrm{K}$ refers to applications which are essentially to the test organism and incidentally to whatever structures and materials of the habitat on which the applied material falls (there is implication that the environment has the applied material evenly distributed in it by diffusion, saturation, or impregnation), whereas Symbol $\mathrm{N}$ refers to applications essentially to the habitat through which the applied material is diffused to reach the organism. If the applied material is added to a liquid and this mixture is applied only briefly as a dip or wash, use Symbol E.) 
the developing offspring rather than indirectly through its parent, use an appropriate symbol other than Symbol $\varnothing$. If administration is by injection directly to the embryonic membranes, use Symbol S.) Field S-3: The parental structure to which the test compound is administered (if known) should be coded in Field $\mathrm{H}-2$, the developmental stage of the offspring at the time of application should be coded in Field $F$, and the dose given to the parent should be coded in Fields $\mathrm{M}$ and $\mathrm{N}$ (unless the dose to which the embryo is exposed is determined, in which case that dose should be coded in Fields $M$ and $N$ with Symbol \# in Columns 46 and/or 48). See Field F, Key, Specific Directions and Explanations, Division 3, paragraph 3.

Administration to and through meninges and to the central nervous system, manner unspecified (ordinarily by injection). Examples: intramedullary, subdural, intraspinal, intracranial, intrathecal, intracisternal. For intracerebral application, use special Symbol V. Field S-3: The specific structure to which the test compound is applied should be coded in Field H-2 if that organ is not the organ specifically responding coded in Field $\mathrm{H}-1$.

Q Administration intra-sinusoidal to paranasal sinuses, manner unspecified

R Application to a single point on or in an environmental medium through which the applied chemical diffuses to establish a diffusion gradient to which the test organism (present at the time of application or introduced subsequent to application) is exposed. Example: Oxford Plate Technique. (When such an application results in no gradient i.e., results in complete mixing with the medium], only Symbol $\mathrm{N}$ can be used.) Field $\mathrm{S}-1$ : Application of the inoculum to a single restricted area on a culture medium over or through which it subsequently grows.

Injection directly into embryonic membranes of the developing organism. Example: injection into allantois of chick embryo. Field S-3: The specific embryonic membrane to which the test compound is applied can be coded in Field $\mathrm{H}-2$, if that membrane is not the specifically responding structure coded in Field $\mathrm{H}-1$.

Intra-osseous injection. Field S-3: The specific bone structure to which the test compound is applied can be coded in Field $\mathrm{H}-2$, if that structure is not the specifically responding structure coded in Field $\mathrm{H}-1$.

Intra-pleural injection

Vaginal administration

Intra-cerebral administration

Intra-ocular

Intra - tumoral

Intra-organal (organ other than specified above and other than introduction directly into any part of the alimentary lumen [Symbols 3 or T]). Field S-3; Use Field $\mathrm{H}-2$ to name the specific organ to which the test compound was applied if that organ is not the specifically responding structure coded in Field $\mathrm{H}-1$. 


\section{SPECIFIC ACTION OF THE TEST COMPOUND \\ ON THE BIOLOGICAL STATE, QUALITY, OR PROCESS \\ CODED IN FIELD T-2}

The test compound:

I Increases, stimulates, facilitates, lowers threshold (for the physiological phenomenon of Field T-2), enlarges.

Speeds, accelerates, increases rate or progress (of the physiological process or pathological condition of Field T-2).

Decreases, depresses, raises threshold (for the physiological phenomenon of Field T-2), reduces, partially inhibits, partially blocks, partially stops, partially prevents. Slows, retards, delays, decreases rate or progress (of the physiological process or pathological condition of Field T-2).

(Note: When the test compound causes complete stoppage or completely inhibits or prevents the physiological process or pathological condition of Field T-2, use Symbol 3.)

Stops, blocks, inhibits (completely), prevents, abolishes, cures.

(Note: This symbol indicates complete stoppage of a process. However, Symbol 3 can never be used to indicate the complete kill of a group of organisms, i. e., the complete reduction of the number of organisms; the test compound's causing death is indicated in Field T-I only by Symbol 7 and the fact that the compound caused $100 \%$ kill is indicated only by appropriate coding in Field Y.)

Increases, speeds, etc. (see Symbol 1) and subsequently decreases, slows, etc. (see Symbol 2). I. e., the biological condition or process of Field T-2 is first increased or speeded then is reversed to be decreased or slowed, as a complex response to a single administration of the test compound.

Decreases, slows, etc. (see Symbol 2) and subsequently increases, speeds, etc. (see Symbol 1). I. e., the biological condition or process of Field T-2 is first decreased or slowed then is reversed to be increased or speeded, as a complex response to a single administration of the test compound.

Makes irregular, arrythmic, acyclic, fluctuating.

(Note: Symbol 6 suggests disruption of control, due to the test compound, causing the biological process or behavior to proceed in a fashion more irregular than can be described by Symbols 1, 2, 3, 4, or 5 . Use Symbol 6 also when the test compound effect is to disrupt a balanced biological system or process [e.g., acid-base balance, blood cell proportion, nitrogen balance]; Symbols 1, 2, 3, 4, or 5 would not appropriately express the balance disruption.)

Produces, causes, does, initiates, induces, brings about (also, stimulates, in the sense of initiating, not in the sense of accelerating for which Symbol 1 is used).

(Note: Use Symbol 7 in the passive sense, when the test compound "undergoes" some alteration [Field T-2 Symbol series FE--] and when the test compound "is" excreted, synthesized, stored, absorbed, etc. [Field T-2 Symbols FF-B, FAB, FBB, FGB, and FIB]. Use Symbol 7 also when the test compound "permits" or "initiates" a secondary compound's alteration, excretion, uptake as a nutrient, synthesis, etc. [Field T-2 Symbols FE--, FF--, F6--, etc. ].)

Synergizes or potentiates the biological response (identified only as a biological condition or process in Field T-2) to the secondary compound (coded in Field D). Use Symbol 8 also to indicate that the test compound is essential for (permits or initiates) the action of a secondary compound (coded in Field D). However, when the test compound permits or is essential for the synthesis, alteration, or metabolism of a secondary compound (Field T-2 Symbols FE--, FF--, F6-, F8 -, etc.), use Symbol 7 instead of Symbol 8.

(Note: When Symbol 8 is used, Field T-1 can not indicate the synergized action of the secondary compound; always include the secondary compound's action synergized in the written abstract portion of Field T-2.) 
9 Antagonizes, antidotes, inhibits, neutralizes, decreases, blocks the biological response (identified only as a biological condition or process in Field $\mathrm{T}-2$ ) to the secondary compound (coded in Field D). (Field T-2: Write the secondary compound's antagonized action.) in Field T-2; the secondary compound is coded in Field D.

Has an additive effect with the secondary compound (coded in Field D) to produce or affect the biological response (coded as a biological condition or process in Field T-2). I. e. , the test compound and secondary compound summate (with a single, coincidental administration of both) to increase, decrease, stop, induce, or make irregular the biological condition or process coded in Field T-2; when Symbol C is used, Field T-1 can not indicate which of these effects is the result of the summative action of the two compounds (write the action in Field T-2).

D Inhibition of nerve action on its end organ, when the nerve is an accelerator or initiates the end organ's activity. (Reduces normal biological response to the action of the nerve indicated in Field $\mathrm{H}-1$, as evidenced by the test compound's allowing the biological condition or physiological process [Field T-2] to be produced or increased by the stimulated and chemically treated nerve only to a degree less than that to which it is normally increased or caused by the stimulated but chemically untreated nerve.)

E Inhibition of nerve action on its end organ, when the nerve is an inhibitor of the end organ's activity. (Reduces normal biological response to the action of the nerve indicated in Field $\mathrm{H}-\mathrm{l}$, as evidenced by the test compound's allowing the biological response or physiological process [Field T-2] to be decreased by the stimulated and chemically treated nerve only to a degree les $\dot{s}$ than that to which it is normally depressed or prevented by the stimulated but chemically untreated nerve.)

Intensification of nerve action on its end organ, when the nerve is an accelerator or initiates the end organ's activity. (Intensifies the normal biological response to the action of the nerve indicated in Field $\mathrm{H}-1$, as evidenced by increase of the biological condition or physiological process [Field T-2] by the stimulated and chemically treated nerve beyond the degree to which it is normally increased or caused by the stimulated but chemically untreated nerve.)

Intensification of nerve action on its end organ, when the rerve is an inhibitor of the end organ's activity. (Intensifies the normal biological response to the action of the nerve indicated in Field $\mathrm{H}-1$, as evidenced by decrease of the biological condition or physiological process [Field T-2] by the stimulated and chemically treated nerve below the degree to which it is normally decreased by the stimulated but chemically untreated nerve.)

The following six symbols, $J$ through $R$, can be used only when Field $\mathrm{E}$ is coded with a pathological state and when a symptom is coded in Field T-2 by a symbol whose definition represents a normal biological condition or process which, however, (1) has been made abnormal by the pathology coded in Field $E$ and which (2) is specifically treated or affected by the test compound. If the Field T-2 entry (a pathology symptom) is a symbol whose definition identifies it specifically as a pathological condition or process and if it is tested or affected by the test compound, Symbol 3 must be used instead of Symbol J, K, or L; Symbol 2 instead of Symbol M, N, or $\emptyset$; or Symbol 1 instead of Symbol P, Q, or R. Consult the Key.

Returns the subject to normal (i. e., cures the host in Field J) by increasing or speeding the pathologically reduced or retarded biological condition or process coded in Field T-2. Symbol J implies complete relief from the pathological symptom coded in Field T-2; if only improvement but not cure is provided by the test compound, use Symbol M.

$\mathrm{K}$ Returns the subject to normal (i.e., cures the host in Field J) by decreasing or slowing the pathologically intensified or accelerated biological condition or process coded in Field T-2. Symbol K implies complete relief from the pathological symptom coded in Field T-2; if only improvement but not cure is provided by the test compound, use Symbol N. 
L Returns the subject to normal (i.e., cures the host in Field J) by affecting the pathological biological condition or process coded in Field T-2, when restoration of normalcy is not a matter of correcting an abnormally intensified (or speeded) or decreased (or slowed) condition or process. For example, a disturbed nitrogen balance or specific behavior of the host of the disease can not properly be described as being returned to normal by "increasing" or "decreasing" the balance or behavior, but only by restoring its normalcy. Symbol L can also be used when the test compound re-initiates a normal physiological process stopped by the pathology coded in Field $E$ and thereby restores the process to its normal state or rate (i. e., when a cure is effected). Symbol L implies complete relief from (i. e., cure of) the pathology symptom (e.g., balance or behavior) coded in Field T-2; if only improvement but not cure is provided by the test compound or if a pathologically totally suspended process is re-initiated but not restored to the normal state, use Symbol $\varnothing$.

M Returns the subject toward normal (1. e. , improves but does not cure the host in Field J) by increasing or speeding the pathologically reduced or retarded biological condition or process coded in Field T-2. Symbol $M$ implies only partial relief from the pathological symptom coded in Field T-2; if the test compound cures the host, use Symbol J.

Returns the subject toward normal (i.e., improves but does not cure the host in Field J) by decreasing or slowing the pathologically intensified or accelerated biological condition or process coded in Field $\mathrm{T}-2$. Symbol $\mathrm{N}$ implies only partial relief from the pathological symptom coded in Field T-2; if the test compound cures the host, use Symbol K.

$\varnothing \quad$ Returns the subject toward normal (i. e., improves but does not cure the host in Field J) by affecting the pathological biological condition or process coded in Field T-2, when restoration of normalcy is not a matter of correcting an abnormally increased (or speeded) or decreased (or slowed) condition or process. (See the examples with the definition of Symbol L.) Symbol $\varnothing$ is also used when the test compound initiates again a normal physiological process stopped by the pathology coded in Field $E$ but does not thereby restore it to its fully normal state or rate. Symbol $\varnothing$ implies only partial relief from the pathological symptom (e.g. , balance or behavior) coded in Field T-2; if the host is restored to normalcy or if a pathologically totally suspended process is re-initiated and thereby restored to normalcy, use Symbol L.

Exacerbates the subject's pathological state (i.e., intensifies the pathological condition of the host in Field J) by further decreasing or slowing the depressed or slowed biological condition or process coded in Field T-2.

Q Exacerbates the subject's pathological state (i.e., intensifies the pathological condition of the host in Field J) by further increasing or speeding the intensified or accelerated biological condition or process coded in Field $\mathrm{T}-2$.

R Exacerbates the subject's pathological state (i. e., intensifies the pathological condition of the host in Field J) by making further deviant the pathological disbalance or behavior coded in Field T-2 (i.e., when the exacerbation is not adequately expressed as "increasing" or "decreasing" the pathologically affected condition or process coded in Field T-2). (See the examples with the definition of Symbol L.)

Causes no effect. To be used only when the test compound was not tested for a specific action on any specific biological condition or process of Field T-2 and it did not produce any specific action. This symbol is used only with Symbol 1 of Field T-2 which is a symbol for a collective general term, in contrast to all other items of Field T-2 which are specific conditions or processes. Consult the Key. 


\section{BIOLOGICAL STATE, QUALITY, OR PROCESS \\ ACTED ON OR PRODUCED BY THE TEST COMPOUND \\ OR SECONDARY COMPOUND}

Gross response. (Use Symbol 1 only with Symbol 0 of Field $\mathrm{T}-1$; together, the symbols mean "does not cause response of any type".)

Death caused by the test compound (Symbols 11 and 111, below) when administration has been by a single dose (not continuous) or when the administration has been continuous or by repeated doses for a maximum of 24 hours or less. The time to death may be $>24$ hours, if the administration is by a single dose, but if administration is continuous or multiple, death must occur within 24 hours in order to be coded by Symbols 11 or 111 .

11 Death produced under the conditions described above, but only when the lethal dose has not been determined for the individual treated (or not determined for the individual of a group treated collectively).

111 Death produced under the conditions described above, but only when the lethal dose has been determined for the individual treated (or for the individual of a group treated collectively). ACUTE TOXICITY

Death caused by the test compound (Symbol 112) when administration has been only by continuous or multiple doses for more than 24 hours and when the time to death is more than 24 hours.

112 Death produced under the conditions described immediately above, whether the lethal dose has or has not been determined for the individual treated (or for the individual of a group treated collectively).

CHRONIC TOXICITY
Note: Use of Symbols 11, 111, and 112 is restricted to coding death caused in larger organisms, including arthropods not infesting a living host. Death of parasitic, pathogenic, and all microorganisms is coded by symbols of the 17 - and 18-- series. Death in a population of arthropods infesting a living host is coded by symbols of the 13-series. Consult the Key.

113 Local toxicity. (In addition to these states of toxic response, there are other pathological states listed throughout Field T-2, especially in the symbol series $4-.-$.)

1131 Irritation

1132 Inflammation

1133 Depilation

1134 Vesication

1135 Pruritus

1136 Scorching, burning

1137 Abscess

1138 Contact dermatitis (primary irritation)

1139 Allergic dermatitis (sensitization)

$113 \mathrm{~A}$ Foreign body giant cell formation

$113 \mathrm{~B}$ Water-soaking or water-logging (plant tissues or organs)

114 Systemic toxicity

1141 Acute toxic symptoms

1142 General, non-acute toxic symptoms; "side effect" such as general malaise, lassitude, sleepiness, headache, dizziness, nausea, vomiting, etc.

115 Paralysis

1151 Undefined paralysis; catalepsy. (Use this symbol for "knockdown" effect of insecticide tests.)

1152 Flaccid paralysis

1153 Spastic paralysis

1154 Collapse; prostration

1155 Syncope

9E Coma; stupor

116 Convulsion

1161 Tonic convulsion

1162 Clontc convulsion 
1163 Epileptiform convulsion

1164 Opisthotonos

117 Shock, unspecified

1171 Shock, hemorrhagic. To code hemorrhage, use Symbol 871 .

1172 Shock, anaphylactic. To code sensitization, use Symbol 58. To code the anaphylactin-anaphylactogen combination itself, use Symbol 8AI. Use Symbol 1172 to code the complex reactions of the organism resulting from the anaphylactin-anaphylactogen combination and known as anaphylactic shock.

1173 Photosensitive reaction

$9 \mathrm{Al}$ Motor coordination

I2 Viability; ability to survive (resistance to death due to) environmental hazards to which the organism (coded in Field $E)$, or the developmental stage of the organism (coded in Field F), is normally exposed; survival time, as a measure of viability described above. Note: Do not use Symbol 12 for an organism's ability to survive pathology (pathology in Field $\mathrm{E}$ and the host in Field J); instead use Symbol 1621, 1631, 1753, or 1754. See the Key discussion of Symbol 12.

13 Reduction of the degree of arthropod infestation of living hosts, when general application is made to the host or hosts bearing the arthropod and the arthropod thereby receives the same application as the surface of the host. Use Symbol 131 or 132, according to the terms in which the results are expressed.

131 Reduction of the number of arthropods infesting a living host (one or many infested host individuals treated). Use Symbol 131 when results are expressed in terms of a percentage of arthropods affected.

132 Reduction of the degree of arthropod infestation of a living host (one or many infested host indlviduals treated). Use Symbol 132 when results are expressed in terms of the degree of the host's relief from the infestation, rather than in terms of the number or percentage of arthropods disposed of.

14 A biological state or process indicated by the coding of the general type of action in Field T-3. (Use Symbol 14 only when the biological state or process is of a nature that can not be expressed as a single specific response, such as repulsion or attraction to the test compound and when the author describes the test compound effect only by a general term of Field T-3. See the Key.) An unspecified process of the organ or tissue coded in Field $\mathrm{H}-\mathrm{l}$ or I. (Use Symbol 15 only when the author does not state the blological process responding more specifically than by reference to an anatomical structure's unspecified functions. See the Key.)

Symbols of the following two series, $16--$
and $17--$, are used for coding effects on
any infectious or non-infectious pathol-
ogy coded in Field E, EXCLUDING: (1)
effects on tumors coded in Field E, for
which Symbols 44 through 47 are used,
(2) effects on infestation by any arthro-
pod, for which ordinarily only Symbol 131
or 132 is used, and (3) effects on any
pathogenic organism which is not on its
living hosts; effects on pathogens or any
microorganism on a non-living host are
coded by symbols of the $18--$ series.

16 Exacerbation of (intensification of) the pathological condition in Field $E$.

161 Increase in numbers of individuals of the pathogenic organism species coded in Field E. (See Symbol 1611 for a maximum degree of increase of numbers and Symbol 1612 for an increase in numbers due to the test compound's causing a reduction of resistance of the host to the pathogen.)

1611 Increase in number of individuals of the pathogenic organism species to the lethal level of the disease. Evaluation in Field $Y$ is to be based on the dose of the compound needed or the time needed for the compound to bring about death, due to its influence in increasing the number of pathogen individuals.

1612 Increase in number of individuals of the pathogenic organism species due to the test compound's causing a reduction of resistance of the host to the pathogenic organism.

162 Acceleration of the progress of the dis ease (toward the normal peak of the disease).

Note: Use Symbol 162 only for the exacerbation of diseases which are in themselves ordinarily not fatal; if the disease is also fatal in untreated controls, code the acceleration as a decrease in survival time, Symbol 1621. Acceleration of the progress of a nonfatal disease (Symbol 162) must be evaluated by a criterion other than 12 or 57 . 
1621 Hastening of death due to the pathology (in Field E) which is lethal to untreated controls; decrease in survival time. Acceleration of the progress of a fatal disease is ordinarily evaluated in Field $Y$ by Criterion 12 or 57 , coding the decrease in survival time in Field $U$.

163 Intensification of the disease by specifically increasing the disease beyond its normal peak intensity; i. e. , intensification by influencing the disease to a greater intensity than that to which it would normally progress.

1631 Decrease of the number of survivors of the pathology (in Field E) which causes a known mean mortality rate when untreated; increase in the number of deaths due to such a pathology which is lethal to untreated controls. With Symbol 1631, evaluation in Field $Y$ is based on the percentage decrease of survivors and the expression, decrease of the number of survivors, should be in the written portion of Field T-2.

164 Increase in duration of the pathology; prolongation of the symptoms beyond the normal duration.

17 Relief (general or unspecified) from the pathology condition in Field E. (See the note prior to Symbol 16.) Use other symbols of this 17 -- series for specific degrees of alleviation of the pathology and for preventive actions.

171 Decrease in number of individuals of the pathogenic organism species coded in Field E. This symbol is used for effects on infectious diseases only. Evaluation in Field $Y$ is to be based on the decrease of the number of pathogens, Criterion 62 or 01 (or 03 or 04). Use Symbol 171 if the reduction of pathogens is incomplete; when the reduction is complete, use Symbol 1711 ; when reduction is due to an increase in the resistance of the host to the pathogen, use Symbol 1712.

1711 Biological cure (infectious diseases). Demonstrated, $100 \%$ decrease in the number of individuals of the pathogenic organism species coded in Field E; sterilization of the host coded in Field J. Evaluation in Field $\mathrm{Y}$ is to be based on the potency of the test compound for bringing about cure, not on the percentage of decrease $\overline{I n}$ individuals of the infecting pathogen.

1712 Decrease in the number of individuals of the pathogenic organism species due to the test compound's causing an increase in the resistance of the host to the pathogenic organism.
172 Clinical cure (non-infectious diseases as well as infectious); permanent eradication of symptoms. (In the case of clinical cure of infectious diseases, use Symbol 172, if sterilization is not demonstrated but symptoms do not reappear. Use Symbol 1711, if sterilization is demonstrated. Use Symbol 1721 , if the pathogen is demonstrated to persist in spite of clinical cure. Use Symbol 173, if the pathogen is demonstrated to persist after disappearance of symptoms and subsequently causes symptoms again.)

1721 Carrier state (infectious diseases). Use Symbol 1721 for clinical cures caused by the test compound in which the pathogenic organism remains demonstrable in the host but the symptoms prove to have been permanently eradicated.

173 Temporary cure. (Non-infectious diseases: use Symbol 172, if the disease is demonstrated to be permanently clinically cured. Infectious diseases: use Symbol 1721, if the pathogen remains with its host but produces no symptoms thereafter, due to the test compound's effect; however, use Symbol 173 , if the pathogen remains with its host but produces symptoms subsequent to a clinical cure.)

174 Prevention of the infectious or noninfectious pathology. If the test compound acts only after the disease has been contracted, use Symbol 176 or other symbols. If application results in the test compound's being a physical barrier on the skin or mucous membrane preventing penetration by pathogenic organisms, or preventing damage due to physical agents such as radiation, use Symbol 178.

175 Repression of either an infectious or non-infectious existing pathology treated by the test compound. Use Symbols 1751 or 1752 , if the nature of repression is demonstrated and fits the description of one of those symbols.

1751 Retardation of progress of the infectious or non-infectious existing pathology. (Slowing of the development of the disease which nevertheless progresses to 1 ts normal peak.)

Note: Use Symbol 1751 only for retardation of diseases which are in themselves ordinarily not fatal; if death is the ultimate result of the disease in untreated controls, the retarding effect should be coded as an 
increase in survival time, Symbol 1753. Slowing of progress of a non-fatal disease must be evaluated by criteria other than 12 or 57.

1752 Restraint of the infectious or noninfectious existing pathology. (Restriction of the disease intensity to a given level or to a given range of intensity indefinitely, not permitting it to progress to a normal peak or to cause death.)

1753 Delay of death due to the pathology (in Field E) which is fatal to untreated controls; increase in survival time. If death is prevented in all individuals which are affected with the disease and to which the test compound is administered, use another symbol to describe the amelioration (Symbol 1711 , 172, or 1752). Delay of death is ordinarily evaluated in Field $Y$ by Criterion 12 or 57 , coding the increase in survival time in Field $U$.

1754 Decrease in the number of deaths due to the pathology (in Field E) which is lethal (or which causes a known mean mortality rate) to untreated controls; increase of the number of survivors of such a pathology. If all treated organisms are permitted to survive such a pathology or if the increased number of survivors is known to be also an increase of cure or restraint, use Symbol 1711,172 , or 1752, instead of Symbol 1754. If Symbol 1754 is used, evaluation in Field $Y$ must be on the basis of per cent decrease of deaths and the expression, decrease of the number of deaths, should be used in the written portion of Field T-2.

176 Abortion of early infection. Use Symbol 174 rather than 176 to code prevention of an infection.

177 Decrease of the effect of a specific toxin of a pathogenic organism.

(Administration of the test compound with the extract of, or killed cells of, a pathogenic organism.) The toxin, which should have been given a speciflc code identity, should be coded in Field D. If the test compound antidotes the toxic action $100 \%$, use Symbol 1771 .

1771 Prevention of the effect of a specific toxin (coded in Field D) of a pathogenlc organism. (If the effect of the toxin is only decreased less than $100 \%$, use Symbol 177.)
Protection (for skin and mucous membranes, coded in Field $\mathrm{H}-\mathrm{I}$ or I). Prevention of damage due to physical agents such as radiation, temperature extremes, etc. Use Symbol 178 also for coding the chemical's prevention of penetration by pathogenic organisms such as trematode larvae, nematode larvae, or arthropod larvae. Use Symbol 1781 or 1782 only when the specific nature of the protection, as defined by those symbols, is known.

1781 Protection that is essentially mechanical in character. (See Symbol 178.)

1782 Protection that is essentially chemical in character. (See Symbol 178.)

Symbols of the following series, $18--$,
are used generally only for indicating
normal growth, reproduction, etc., of
pathogenic or non-pathogenic micro-
organisms maintained on non-living
hosts such as nutrient agar or broth.
(Use symbols of the 17 -- serles for
pathogenic microorganisms on living
hosts.) If, for any reason, a non-
pathogenic microorganism were treated
on a living host, this $18--$ series might
be used.

Growth of the microorganism colony; number of individuals in a cultured colony. Symbol 181 or 1812 is always preferred to Symbol 18, except when the author does not distinguish an inhibitory chemical action as being lethal (1812) or merely repressive (181), in which case Symbol 18 may be used (with Symbol 3 of Field T-1).

181 Growth of the microorganism colony; number of individuals in a cultured colony. Use Symbol 181 for either general decrease (stasis) or general increase in the microorganism on the non-living host; if the decrease is demonstrated to be specifically a lethal effect on all or any percentage of the microorganisms in the colony, use Symbol 1812. Use Symbol 1, 2, or 3 in Field $\mathrm{T}-1$.

1812 Death of the microorganism. (Use only with Symbol 7 of Fleld T-1.) Use Symbol 1812 if a lethal ('cldal) action has been demonstrated on any percentage of the microorganism individuals or on any percentage of the colony. 

is in terms of the number, size, or frequency of the units, or total mass of the substance, of the crop.

191 Number of crop units (number of fruits, number of flowers, number of leaves, etc.). The organ is coded in Field $\mathrm{H}-1$.

192 Size of crop units (size of fruits, size of flowers, size of leaves, etc.). Use Symbol 281, rather than Symbol 192, if the size is not in terms of a quality of a crop but in terms of the unit as an organ or as the organism.

193 Frequency of bearing of crop units (frequency of production of fruit, flowers, leaves, or other units) Total amount of crop yield (when the "crop" is produced as a mass of a substance rather than as units such as in 191, 192, and 193)

Change in flavor or odor of the organism or of the product of the organism. (Symbol 7 of Field T-1.) Use Symbol lA when the change is qualitative rather than quantitative or when the quantitative change is not expressed either as increase or decrease.

IAl Intensification of flavor or odor (Symbol 7 of Field $\mathrm{T}-1$ )

IA2 Diminution of flavor or odor (Symbol 7 of Field $\mathrm{T}-1$ )

\section{Growth and differentiation}

Cell division

Mitosis

Prophase

Metaphase

Anaphase

Telophase

Spindle activity

Meiosis

Cell growth; growth and normal form of the cell and of its essential structures.

Ultimate size of the cell

Elongation of the cell. Plant "curvature": Symbol 2211 may be used to code curvature of plant parts due to elongation of cells of one side of the plant structure (stem, petiole, etc.).

Shape of the cell

Formation of membranes of the cell

Thickening of the cell wall

Sculpturlng of the cell wall

Chemical composition of the cell wall

Cytoplasmic volume of the cell

Nuclear size

Nuclear shape

Nuclear number

Nucleolar size

Nucleolar shape

Nucleolar number
Cell differentiation. Use Symbol 23 for the process of differentiation of certain cell parts. Use Symbol 27 for general differentiation of a cell from a nonspecific embryonic type to its mature form (e.g., differentiation to become a unit of a specific type of tissue).

Cell inclusion, unspecified. Symbols of the 231 - series represent the character of certain cell parts differentiated within the cell during its development.

Vacuole size

Vacuole number

Plastid size

Plastid number

Number (or activity) of mitochondria, Golgi bodies, etc.

Spore germination (including pollen and megaspore "germination"). See Symbol AA2 for spore formation.

Percentage of spore germination

Length of germ tube

Seed germination. (Use Symbol 26 only if it can not be determined whether the process affected is in terms of the germinative process or the total gross process ending with emergence.)

Seed germination, regardless of emergence

Emergence of seeds from the soil or other material in which they were planted. Use Symbol 262 for the activity of germinating seeds in emerging from the soil, as well as for germination expressed in terms of the emerged seedlings.

Tissue differentiation. For tissue degeneration, use Symbol 4l8D (histolysis) or a symbol of the atrophy series, 411 -.

Tissue formation (organization from embryonic origins)

Tissue regeneration (e. g., wound healing)

Granulation; the formation of granulation tissue

Organization of regenerative tissue

Cicatrization

Fibrosis, the formation of fibrous tissue

Fibrosis specifically for adhesion

Replacement fibrosis, specifically replacing fatty tissue

Replacement fibrosis, tissue replaced unspecified

28 Organ formation; organ growth; organ size. Use Symbol 28 only when the data do not clearly indicate whether it is the formation, growth process, or ultimate size of the organ that is affected.

281 Organ size; ultimate dlmension

2811 Organ weight 
282

Organ shape. (Use only with Symbol 6 of Field T-1.)

283 Organ growth. (If the rate of growth is the aspect affected, use Symbol 2831.)

2831 Rate of growth of the organ

284 Organ formation from undifferentiated tissues

29 Molting; metamorphosis; the process of an individual's change from any juvenile stage to another or to the adult. Consult the Key.

291 Ecdysis

2A Organism development, growth, size; (multicellular organisms only; for growth of individuals of unicellular Protozoa, Fungi, etc., use symbols of series 22--; for growth of the mass or colony of individuals of a unicellular organism, use a symbol of the 17 -- or 18 -- series). Use Symbol 2A only when the data do not clearly indicate whether it is the development (structural organization during growth, 2A2) or growth (increase in size in terms of linear measure or mass, 2Al; weight, $2 \mathrm{All}$; etc. ) that is affected.

2Al Organism size (mass) and form; ultimate normal dimensions and shape

2All Organism weight

$2 A 12$ Organism surface area

$2 A 13$ Organism volume

2Al4 Organism shape, normal proportions

2A.2 Organism development (structural organization during growth, disregarding increase in mass)

2A3 Organism growth process; increase in mass in normal proportions

2A4 Regional growth of the entire plant; growth of speclfic anatomical areas of the plant. For plant growth expressed as weight, volume, etc., use symbols of series $2 \mathrm{Al}$.

$2 A 41$ Terminal growth of the entire plant (as opposed to lateral growth, Symbol 2A42). The "terminal" part includes all structures (leaf, stem, flower) at the apex of the plant and does not refer to any one of these parts such as terminal leaf; however, Symbol $2 \mathrm{~A} 4 \mathrm{l}$ can be used for coding terminal growth of the primary "stem" or "trunk". Use Field T-1 Symbol 1, 2, 3, etc.

$2 \mathrm{~A} 42$ Lateral growth of the entire plant (as opposed to terminal growth, Symbol 2A41). The "lateral" part includes all structures (leaf, branch, flower) growing below the apical region of the entire plant. Use Field T-I Symbol I, 2,3 , etc.
Maturing process of the organism; assumption of the mature acult characteristics, in animals and annual and biennial plants usually associated with maturing of reproductive organs, but in perennial plant individuals, it is more a matter of age and size limitations imposed by genetic constitution. For certain organisms (certain arthropods and amphibia), maturing may be coded by Symbol 29, if expressed specifically as "metamorphosis".

$2 \mathrm{C}$

Aging; the process of degeneration of both reproductive and somatic parts and activities, following maturation of the indivldual multicellular organism, ending in death.

2D Inactive state, unspecified

2D1 Dormancy, hibernation, estivation

2D2 Diapause. (This term refers only to arrests of insect development.)

$2 \mathrm{E} \quad$ Hatching process

2F Blooming process. Use Symbol $2 \mathrm{~F}$ for the normal opening and functioning of the flower or flower crop of a plant. (Use a symbol of the 28-- series for the general development of the flower as an organ [size, weight, etc. ] and symbol F924, FA24, or 416 for color of the flower.)

2G Excystment process. Use Symbol 2G for successful emergence from a protective coating, the cyst wall or capsule, of a quiescent stage (described as the "cyst" stage of certain organisms), at the beginning of a new active stage. Do not use Symbol $2 \mathrm{G}$ for the emergence of insects from the pupa case which would be more appropriately an item under the 29-- series.

3 Genetic change, unspecified. Symbols of the 3-.. series are concerned with modification of the material or structures of cells which are genetic determiners, chromatin, chromosomes, genes. Included are (a) the specific modifications, (b) the normal incidence of these modifications, and (c) specific changes in the anatomy or physiology of the organism (for which a chromosome is the determiner) due to a known modification of the chromosome or gene.

31 Structural change of the cellular elements which are determiners for the organism's characteristic structure and physiology.

311 Polyploidy, haploidy

312 Chromosome modificatlon, unspecifled, involving the normal number of chromosomes 
3121 Translocation

3122 Inversion

3123 Deletion

3124 Fragmentation

3125 Gene mutation

32 Physiological change of the organism, unspecified, due to a specific genetic modification

33 Incidence of an unspecified genetic change. (Use with Symbol 1 or 2 of Field T-1.)

34 Somatic mutation

35 Anatomical change of the organism, unspecified, due to a specific genetic mutation

4 Pathological states involving abnormal growth and differentiation or degeneration

41 Abnormal morphological states, exclusive of tumors and unspecified concrements and casts (see Symbols $42 \overline{1,43}$, etc.)

411 Atrophy, including toxic atrophy. (Use Symbol 411 only if the atrophy is not specified according to a general type indicated by Symbol 4111,4112 , etc.) For abnormally diminutive morphological structures due to faulty development (e. g. , hypoplasia), use symbols of the 28-- or 2A-- series.

4111 Simple atrophy

4112 Pyknosis

4113 Inflammatory atrophy

844 Cytolysis

$418 \mathrm{D}$ Histolysis

412 Hypertrophy (a process or state of the component cells' enlarging or being enlarged rather than an abnormal increase in number of cells)

413 Hyperplasia other than tumors (Symbol 43--, 44--, etc.). A process or state of the component cells' increasing in number, yet essentially retaining their normal character.

414 Altered form. Abnormal form of the organism or the structure in Field $\mathrm{H}$ or I, due to abnormal growth of some part or parts of the organism or structure.) Monstrosity. Abnormal caste form (e. g. , abnormal body form of the individual of a bee or ant colony). Abnormal type of colony (fungal or bacterial colony form, e.g.). Use Symbol 414 for abnormal form of plant parts, such as leaf roll, petal roll, abnormal leaf or petal shape, or abnormal leaf or petal pattern. If the change is a plant "curvature" due to unequal cell elongation, use Symbol 2211 rather than 414.
Texture change, unspecified (abnormal thickness, stiffness, harshness, elasticity). For specific texture changes, use a specific symbol such as 4151 (abnormal hardness, abnormal softness, abnormal thickness, etc.)

Abnormal hardening; sclerosis Discoloration (different hue or intensity than normal to the individual or variety). See also Symbols 877 l, FA24, etc. Russeting (of fruits)

Chlorosis, unspecified as to cause

Abnormal increase in depth of green color of plants

Icterus (with bile coded in Field D)

Cyanosis

Flushing, erythema (skin)

Pallor due to blood withdrawal from the skin

Pallor due to anemia

Melanosis

Lesion (e.g., a wound or mechanical injury or toxic lesion), destructive process or state other than those indicated by other symbols of the 4-.- series and by symbols of the 113 - and 114 - series. This symbol is generally used only for symptoms (of a disease coded in Field E) treated by the test compound, rather than injury caused by the test compound. Symbol 417 is used for destructive injury that is unspecified yet can not be indicated by Symbol 41 because the latter indicates only unspecified change including hypertrophy as well as destructive change.

Degeneration, unspecified

Necrosis, unspecified

Necrosis, liquefactive

Necrosis, coagulative

Necrosis, hemorrhagic

Necrosis, caseous

Caries

Cloudy swelling (parenchymatous degeneration)

Hydropic degeneration

Fatty degeneration and/or fatty infiltration

Hyaline degeneration

Amyloid degeneration

Mucinoid degeneration

Fibrinoid degeneration

Cirrhosis

Necrosis, liquefactive

Necrosis, coagulative; infarction; thrombotic or embolic necrosis, unspecified. (See Symbol series $87--$.)

Histolysis or unspecified autolysis

Cytolysis

Necrobiosis 
Karyolysis or karyorrhexis

$418 \mathrm{G}$ Fibrinoid degeneration

$418 \mathrm{H}$ Demyelination

$418 \mathrm{~J}$ Necrosis, hemorrhaglc

$418 \mathrm{~K}$ Necrosis, caseus

2724 Fibrosis; the formation of fibrous tissue

2725 Fibrosis specifically for adhesion

2726 Replacement fibrosis, specifically replacing fatty tissue

2727 Replacement fibrosis, tissue replaced unspecifled

421 Casts, concretions, unspecified. Use Symbol 421 only if specifle casts or concretions are not identified (Symbols FA2 -, FA3 -, or FA4-, for mlneral deposits, calclfications, urate or cholesterol deposits).

43 Neoplasia (the formation of a new, abnormal growth [neoplasm] the component cells Increasling in number and being altered from a normal character though they may retain some similarity to the normal cells from which they are derived). Use Symbol 413 for hyperplasia (enlargement of a part due to increase of cells which retain their normal character, not a neoplasm). Use Symbol 43 only with Symbol 7 (or 8, 9, $A$, or C) in Field $\mathrm{T}-1$ and identify the tumor or tumor type produced in Field $E$; i. e., use Symbol 43 only when the test compound produces (or is tested to produce) a tumor (indicating carcinogenic action). If a pre-existing tumor is treated with the test compound, use Symbol 44, 45, or 46 .

44 Tumor growth: size of a pre-exlsting tumor (treated by the test compound) or rate of tumor growth. Use Symbol 44 only with Symbol 1, 2, or 3 (or 8,9 , A, or C) of Fleld T-1. Code Fleld E with the tumor identity, if known, or the tumor type or with Symbol S. (Use only Symbol 43 for tumor production by the test compound. ) Acceleration or retardation of a lethal tumor is always evaluated in Field $Y$ by Criterion 12 or 57, using Symbol 44 in Fleld T- 2 and Symbol 1, 2, or 3 in Fleld T-1.

Tumor regression; reduction in size of a pre-existing tumor treated by the test compound. Symbol 45 will ordinarily be reasonably used only with Symbol 7 (or $8,9, \mathrm{~A}$, or $\mathrm{C}$ ) in Field T-1. Its use w1th Symbol 1 or 2 of Fleld T-1 to code slowing or speeding of a naturally regressing tumor is Improbable. Code Field $E$ with the tumor Identity, if known, or tumor type, or with Symbol S.

(Use only Symbol $\underline{43}$ for tumor production by the test compound.)

Tumor metastasis (process of); spread of a pre-existing tumor treated by the test compound (not the growth rate of any one secondary growth). Use Symbol 46 with Symbol 7, 1, 2, or 3 (or $8,9, \mathrm{~A}$, or $\mathrm{C}$ ) in Field $\mathrm{T}-1$. Code Field $\mathrm{E}$ with the tumor identity, if known, or tumor type, or with Symbol S. Code the primary site of the tumor in Field $\mathrm{H}-1$; do not code the site of metastaslzing. (Use only Symbol 43 for tumor production by the test compound.)

Tumor incidence; incidence of spontaneously occurring tumors or incidence of tumors induced by physical factors other than the test compound. Use Symbol 47 only with Symbol 1 or 2 (or 8, 9, A, or C) of Field T-1. Code Field $\mathrm{E}$ with the tumor ldentity, if known, or tumor type, or with Symbol S. (Use only Symbol 43 for tumor production by the test compound.)

Adaptive effects. (Symbol 5 is of improbable use; specific adaptive effects are indicated by $51,511,512$, etc.)

Tolerance; resistance; refractoriness; lack of sensitivity. Use Symbol 51 only when it is not known whether the phenomenon occurs in an individual of the test organism species during 1 ts lifetime (Symbol 512 or 513 ) or occurs to the species due to selection over several generations (Symbol 511). Consult the Key for an explanation of the use of Symbol 51 and the coding of Field $\mathrm{T}-1$ when this symbol $1 \mathrm{~s}$ in Field $\mathrm{T}-2$. Inheritable tolerance; production of a race tolerant to the test compound due to exposure to the test compound. Consult the Key for an explanation of the use of Symbols 51, 511, and 512 .

Individual tolerance (physiological tolerance); increase in tolerance to the test compound during the lifetime of the Individual of the test organism species due to administration of the test compound. Consult the Key for an explanation of the use of Symbols 51,511 , and 512 .

Tolerance by tachyphylaxis. Consult Key for an explanation of the use of Symbols 51, 511, 512, and 513 .

Cross - tachyphylaxis; tolerance to a secondary compound (Field D) due to tachyphylaxis by the test compound. Consult the Key. 
514 Cross-tolerance; tolerance to a secondary compound (Field D) due to administration of the test compound. (Consult the Key.)

$5 \mathrm{C}$ Resistance (tolerance) of an organism (host) to a pathogen, parasite, noninfectious pathology, or tumor. (See Symbol Series 5C. For tolerance of the test compound or secondary compound, use Symbol 51,511,512, 513, 5131, or 514. )

52 Pathogenicity of the parasite; virulence. Use only Symbol 1 of Field T-2 with Symbol 52 to code the increase of virulence of the pathogen. Use Symbol 2 in Field T-1 with Symbol 52 to code attenuation (decrease of virulence) of the pathogen. Use Symbol 52 itself only if it is not known whether the effect is on the virulence of the individual of the species within its lifetime (Symbol 522) or an inheritable effect on the virulence of the species (Symbol 521). Use Symbols 52, 521, and 522 to include all aspects of successful infection by the parasite, as well as ultimate intensity of symptoms it can cause, such as the ability to penetrate the host, the ability to establish in the host, etc.

521 Inheritable pathogenicity of the parasite. (See the definition of Symbol 52.)

522 Pathogenicity of the individual parasite. (See the definition of Symbol 52.)

53 Motillty

54 Tropistic response, unspecified

541 Phototropism or phototaxis (unspecified as to whether negative or positive)

5411 Positive phototropism; positive phototaxis

5412 Negative phototropism; negative phototaxis

542 Photophobia

543 Chemotropism or chemotaxis (unspecified as to whether negative or positive)

5431 Positive chemotroplsm or positive chemotaxis

5432 Negative chemotroplsm or negative chemotaxis

55 Behavior of the individual. (Use Symbol 55 only with Symbol 6 [or L, O, or R] of Field $\mathrm{T}-1$.)

56 Behavlor of the group. (Use Symbol 56 only with Symbol 6 [or $L$, O, or R] of Field T-1.)

Abscission (e.g., leaf or flower abscission) or autotomy (separation by an animal of one of its parts)

Sensitization. Use Symbol 58 only for the phenomenon which results from the administration of certain test compounds (ordinarily non-toxic proteins), develops

during an incubation period following administration, and which results in a characteristic and more or less violent reaction on a subsequent administration of the test compound. This sensitization is a process known to involve stimulating production of antibodies and the sensitive reaction (e. g. , anaphylactic) is due to the antigen-antibody combination. For sensitivity increases not falling within the specific definltion of sensitization, use symbols of the 51 -series.

Anaphylactic sensitization; stimulation of anaphylactin by anaphylactogen

Anaphylactic shock

Photosensltization

Lag period (recovery period) following inoculation. Use Symbol 59 only to indicate the period between introduction of a microorganism into a nutrlent medi um and the time at which it begins to grow. Symbol 59 is not to be used for latent periods following muscle or nerve stimulation (Symbol Series 81 - - and 9---).

Addiction, habituation, dependence Photoperiodism. Use Symbol 5B only with Symbol 6 (or 8, 9, A, C, L, O, or R) of Field T-1.

Resistance (tolerance) of an organism (the host, coded in Field J) to a pathogen, parasite, tumor, or noninfectious disease (coded in Field E), unspecified as to cause. Do not use Symbol 5C itself with Symbol 1 or 2 of Field $\mathrm{T}-1$. Use Symbol $5 \mathrm{C}$ only if the test compound causes resistance to the pathogen, tumor, or non-infectious pathology of Field E (Symbol 7 of Field $\mathrm{T}-1$ ). Use Symbol $5 \mathrm{Cl}, 5 \mathrm{C} 2$, or $5 \mathrm{C} 3$ for an effect of the test compound on a specific type of resistance to pathology.

Resistance of an organism to a pathogen, parasite, tumor, or non-infectious pathology, due to exposure to a vaccine or other chemical coded in Field D. (Use Symbol $5 \mathrm{Cl}$ only with Symbol 1 or 2 of Field T-1.)

Resistance of an organism to a pathogen, paraslte, tumor, or non-infectlous pathology, due to exposure to the pathogen, tumor, or pathology in Field E. (Use Symbol 5C2 only with Symbol 1 or 2 of Field T-1.)

Natural reslstance of an organism to a pathogen, parasite, tumor, or noninfectious pathology. (Use Symbol $5 \mathrm{C} 3$ only with Symbol 1 or 2 of Field T-1.) 

note below.)

Note: If the test compound affects, or is tested to affect, metabolic action of any enzyme (including any metabolic action for which there is a specific Fleld T- 2 symbol), Field $\mathrm{T}-2$ is always coded with the specific enzyme (see the special Enzyme Code of Fleld T-2) rather than the metabolic activity of the enzyme disturbed by the test compound. See the Key.

8 Tissues, cells, fluids (speclfic conditions or processes of tissues, cells, fluids). Symbol 8 is not intended particularly for use for coding even unspecified conditions or processes. It is intended here merely as a heading for this series dealing with the structures indicated.

81 Muscle activity

811 Excitability

8111 Refractory period. Do not use Symbol 8111 for the normal latent period following muscle stimulation.

812 Conduction (transmission)

813 Contraction. Use Symbol 813 only for normal muscle contraction. Use other symbols for abnormal contraction (e.g. , contracture, Symbol 818; muscle spasm, Symbol 8136, and muscle rigor, Symbol 819).

8131 Force of normal contraction

8132 Rate of normal contraction

8133 Amplitude of normal contraction

8134 Peristalsis

8135 Spontaneous contraction other than peristalsis

8136 Muscle spasm (including muscle twitching)

814 Normal relaxation of muscle

815 Action of specific anatomical muscles or muscle groups, unspecified. (Use symbols of the 815 - series to code a result of muscle contraction or of mus cle relaxation, which may be caused or affected by the test compound. For example, flexions, extensions, constrictions, dilations, etc. of the body of the animal or its parts.

8151 Vasoconstriction (of the vessel specified in Field $\mathrm{H}-\mathrm{l}$ or Field $\mathrm{H}-2$ ). Contraction of the muscular coats of blood vessels. Thls is not tantamount to increase in blood pressure (Symbol 8211).

8152 Vasodilation (of the vessel specified in Field $\mathrm{H}-\mathrm{I}$ or Field $\mathrm{H}-2$ ). Relaxation of

the muscular coats of blood vessels. This is not tantamount to decrease in blood pressure (Symbol 8212 ).

8153 Extension of the invertebrate (e.g. , molluscan) body from its encasement, shell, or tube. (Consult the Key.)

817

818 Contracture (prolonged contraction which is reversible; irreversible [permanent] contraction is not contracture but rigor, Symbol 819)

819 Rigor

$81 \mathrm{~A}$ Muscle fatigue

$81 \mathrm{~B}$ Tetany

$81 \mathrm{C}$ Fibrillation of skeletal muscle. (For cardiac muscle fibrillations, see Symbol Series C....)

9 A3 Tremor

82 Body fluid pressure, unspecified as to which fluid.

821 Blood pressure, unspecified as to whether increased, decreased, venous, arterial, etc. Symbol 1 or 2 of Field T-1 may not be used with Symbol 821 . Consult the Key.

8211 Increased blood pressure (above the pressure characteristic of the individual treated) due only to vasopressor action which causes the increase in pressure through vasomotor stimulation and vascular constriction. (Vasoconstriction, however, is not tantamount to an increase in blood pressure. Use Symbol 8151 for the specific state of vasoconstriction.) Use Symbol 8211 for any vasopressor effect resulting in increased blood pressure and caused by the test compound (Symbol 7 of Field $\mathrm{T}-1$ ) or (as a symptom of a pathology) affected by the test compound (Symbol $\overline{1 \text { or } 2 \text { of }}$ Field T-1). Do not use Symbol 8211 for increased blood pressure due to any cause other than vasopressor effect (e. g., do not use 8211 for increased pressure due to increase in blood volume). Identlfy the vessel, artery or vein, in Field $\mathrm{H}-1$.

8212 Decreased blood pressure (below the pressure characteristic of the individual treated) due only to vasodepressor action which causes the decrease in pressure through vasomotor depression and vascular dilation. (Vasodilation is not tantamount to decrease in blood pressure. Use Symbol 8152 for the specific state of vasodilation.) Use Symbol 8212 for any vasodepressor effect resulting in decreased blood pressure and caused by the test compound (Symbol 7 of Field 
T-1) or (as a symptom of a pathology) affected by the test compound (Symbol 1 or 2 of Field T-1). Do not use Symbol 8212 for decreased blood pressure due to any cause other than vasodepressor effect (e. g., do not use 8212 for decreased pressure due to a decrease in blood volume). Identify the vessel, artery or vein, in Field $\mathrm{H}-1$.

824 Spinal fluid pressure

825 Intraocular pressure

83 Protoplasmic state, protoplasmic processes, and general activity of the protoplasmic unit, the cell. Symbol 83 itself is not intended to be used for a state that can be affected by the test compound; only the symbols of this series, 831, 832, etc., indicate specific protoplasmic states or processes that may be caused or affected by the test compound.
Streaming of protoplasm

Viscosity of protoplasm

Sol-gel transformation

Coagulation of protoplasm. (Coagulation of blood is coded by Symbol 873. Coagulation precipitation of a precipitinogen is coded by Symbol 837.)

Agglutination of cells other than blood cells. Use Symbol 854 rather than 835 for blood cell adherence. (Use only Symbol 7 [or 8, 9, A, or C] with Symbol 835.)

Phagocytic activity of cells

Precipitation by the production of precipitin by cells

Osmotic pressure of the cell

Spreading factor

Birefringence of protoplasm

$\mathrm{X}$-ray diffraction of protoplasm

Opacity of protoplasm

Reactivation of cells (after inactivation, by irradiation, e. g.)

Photoreactivation (recovery [from irradiation damage] by exposure to white light)

Membrane character; membrane activity. (If the membrane is of a tissue or cell of a multicellular test organism, specify the tissue in Field I. )

Surface activity of membranes

Permeability. (Use Symbol 842 when the character of the membrane's permeability is demonstrated to have been altered by the test compound. When the test compound effect is observed to be selectively on the passage of a particular secondary compound across the membrane, the effect should be coded by use of Symbol FG-- rather than Symbol 842.)
95

844

845

4112

85

8531

854

8541

8542

855

86

861
Bioelectric (resting) potential

Cytolysis. (Use Symbol 844 to code hemolysis, with red blood cell coded in Field $\mathrm{H}-\mathrm{I}$.)

\section{Karyolysis; karyorrhexis}

Pyknosis

Blood cells, unspecified. (Use only Symbol 851,852 , etc. , for specific qualities of blood cells. Symbol 85 itself has no particular use.)

Normal number of blood cells. (Use Symbol 851 for the normal blood cell number which may be affected by the test compound. Use Symbol 853 for any decreased number of blood cells, which condition may be relieved or exacerbated by the test compound. )

Normal proportion of blood cells. (Use Symbol 852 only with Symbol 6 of Field T-1.)

Anemia, unspecified as to belng a decrease in blood cells, or a decrease in hemoglobin, or both.

Pallor of anemía

Blood cell adherence (exclusive of thrombosis, embolism, and clotting)

Rouleaux formation

Blood cell clumping; blood sludging

Blood cell fragility

Cell-plasma ratio of blood, hematocrit. (Use Symbol 86 only with Symbol 6 of Field T-1.)

Sedimentation rate

Blood, plasma, body fluid; state and activity of fluid tissues, unspecified. This symbol is not intended so much for use in coding as it is intended as a heading for a category of symbols. For example, for decrease in blood, use Symbol 871; for effects on blood clotting, use Symbol 873, etc.

Decrease in blood volume; hemorrhage; bleeding; diminished blood volume

Hemorrhagic shock

Collapse (associated with depression and circulatory failure)

Syncope

Abnormal extravascular accumulation of body fluid, unspecified

Edema, unspecifled; dropsy, unspecified Ascites

Clotting processes, unspecified

Prothrombin time

Clotting time

Thrombosis

Embolism

Bleeding time

Cyanosis

Dehydration 
Hyperemia (active or passive); blood congestion of specific body parts (specify the body part in Field $\mathrm{H}-1$ ), except skin; use Symbol 8771 specifically for blood congestion in skin.

8771 Flushing of skin; erythema; hyperemia of skin. (Do not use Symbol 8771 for the flash or temporary flushing of the skin due to vasodllation and increased blood flow, but only for actual blood congestion of some longer duration.)

878 Ischemia; temporary blood deficiency, chiefly due to local constriction of blood vessels (name the body part in Field H-1), except skin; use Symbol 8781 specifically for temporary blood deficiency of the skin. For permanent blood deficiency (leading to infarction), use Symbol $418 \mathrm{~B}$.

8781 Pallor due to drainage of blood from the skin

418B Obstruction of circulation (permanent blood deficiency of a specific body part), leading to necrosis of the affected part; infarction; coagulation necrosis; thrombotic or embolic necrosis, unspecified.

87A Exudation

87B Filtration of blood or lymph; selective filtration and removal of specific blood components or lymph components, unspecified

88 Normal chemical balance of protoplasm, cells, tissues, and body fluids, unspecified $\mathrm{pH}$

882 Eh (oxidation-reduction potential)

883

884

89

Alkaline reserve

Acid-base balance

Serum. (Note; The items listed under Symbol 89 describe and are related to serum and its components, their properties, and their normal and abnormal states. Use symbols of the $8 \mathrm{~A}--$ series for coding the phenomena associated with specific serum components involved in immunological activity. )

891 Antibody production (except histaminespecific antibody production, Symbol 8911)

8911 Histamine-speclfic antibody production. Use Symbol 8911 only with Symbol 1, 2, or 3 (or 8, 9, A, or C) of Field T-1. 892 Complement

$8 \mathrm{~A}$ Immunity; immunological reactions (involving specific substances of the serum [as well as cells of the organism in general], whose production 15 coded by symbols of Series 89--), unspecified.
Note: The general processes of an organism's becoming more tolerant or more sensitive to the test compound, secondary compound, or other organisms or of being sensitized are coded as adaptive processes by symbols of the 5 -.- series (51_-, 5C--, and 58). The complex of reactions resulting from administration of the test compound to an organism made sensitive or sensitized is generally more suitably coded with special symbols of the 115-, 116-, or 117 - series (e.g., Symbol 1172). Use Symbols of the $8 \mathrm{~A}$ series only for the reactions at the cellular/tissue level.

8Al Anaphylaxis. Use Symbol 8Al only for the actual combination of anaphylactinanaphylactogen. Use Symbol 581 for the particular sensitlzation process stimulating anaphylactin production. Use Symbol 1172 for response to the anaphylactin-anaphylactogen combination, anaphylactic shock.

581 Anaphylactic sensitization

1172 Anaphylactic shock

8A2 Allergic manlfestations other than anaphylaxis, unspecified. See the notes accompanying Symbols $8 \mathrm{~A}$ and $8 \mathrm{Al}$.

582 Photosensitization

1173 Photosensitive reaction

51 Reduction of sensitivity. (See all symbols of the 51 -- series.)

8B Organelle function, unspecified.

(Function of special structure of a cell.)

8Bl Trichocyst discharge; nematocyst discharge

9 Function (normal or abnormal) of nerve tissue or of the nervous system, unspecified

91 Psychlc state, unspecified

911 Disorientatlon, confusion

912 Hallucination; hallucinosis

93 Excitation and transmission in nerve tissue

931 Threshold

932 Accommodation, adaptation

933 Refractory period of nerve

934 Supernormal period

94 Chronaxie

95 Action potential and resting potential

96 Brain wave

97 Synaptic transmission, unspecified; ganglionic transmission, unspecified
Presynaptic transmission

Postsynaptic transmission

Neuromuscular transmission

End-plate potential

Muscle potential 
$\begin{array}{ll}983 & \text { Neuromuscular delay } \\ 99 & \text { Reflex activity, unspecified } \\ 991 & \text { Patellar reflex (knee jerk) } \\ 992 & \text { Light reflex } \\ 993 & \text { Crossed extension reflex } \\ 994 & \text { Conditioned reflex, unspecifled } \\ 995 & \text { Flexor reflex } \\ 996 & \text { Herring Breuer reflex } \\ 9961 & \text { Herring Breuer inflation reflex } \\ 9962 & \text { Herring Breuer deflation reflex } \\ 997 & \text { Tonic neck reflex } \\ 998 & \text { Pressoreceptor reflex (carotid sinus, }\end{array}$

998 Pressoreceptor

9981 Carotid sinus reflex

9982 Aortic body reflex

9983 Aortic depressor reflex

9984 Cardiac reflex, left

9985 Cardiac reflex, right

9986 Bainbridge reflex

9987 Pulmonary depressor

9988 Coronary chemoreflex (Bezold-Jarisch effect)

9989 Pulmonary chemoreflex

999 Respiratory chemoreceptor reflex

9991 Carotid body chemoreceptor reflex

$99 \mathrm{~A}$ Righting reflex

99B Swallowing reflex. Use Symbol FFA- for coding emesis (vomiting). Use Symbol $99 \mathrm{~F}$ for the vomiting reflex.

$99 \mathrm{C}$

$99 D$

$99 \mathrm{E}$

$99 \mathrm{~F}$

$99 \mathrm{~F} 1$

Clonus

Corneal reflex (wink, lid reflex)

Scratching reflex

Vomiting reflex. Use Symbol FFA- for the process of vomiting as a method of elimination or loss of foreign materials from the organism.

Retching movement

99G Cough reflex

9A Motor activity, unspecified. (Note that general motility is coded with Symbol 53.)

9A1

$9 A 2$

$9 A 3$

9 A4

$9 A 5$

$9 A 6$

$9 A 7$

$9 A 8$

$9 B$

$9 \mathrm{Bl}$

$9 \mathrm{B2}$

$9 \mathrm{B3}$

$9 \mathrm{~B} 4$

$9 \mathrm{~B} 5$

$9 \mathrm{~B} 6$

$9 \mathrm{~B} 7$

$9 B 71$

$9 \mathrm{~B} 72$

Motor coordlnation

Nystagmus

Tremor

Hyperactivity

Asthenta, weakness, fatigue

Lethargy, apathy

Shivering

Decerebrate rigidity

Sensory activity, unspecifled

Perception of stimulus (irritability, excitability)

Discrimlnation

Photoreception (vision)

Hearlng

Equllibrium

Vertigo

Chemoreception

Gustatory chemoreception

Olfactory chemoreception.
Pain

Tactile sensation

Temperature change perception Nausea

Appetite

Proprloreception

Sedation

Coma, stupor

Hypnosis, sleep production

Stimulation, analepsis, insomnia

Reproductive process or activity, unspecified

Gamete formation, unspecified

Spermatogenesis

oögenests

Gamete motility

Gamete release

Ovulation

Fertilization; gamete fusion

Oviposition, egg-laying

Implantation of ovum

Sexual activity, unspecified; function of gonads and accessory organs, unspecified

Abortion

Parturition

Menstruation

Self sterility (of monoecious or hermaphroditic organisms)

Asexual reproduction

Vegetative reproduction; budding

Spore formation

Parthenogenesis

Parthenocarpy

Ventilation process, unspecified

Gross respiratory activity, unspecified as to phase or quality

Depth of intake

Minute volume

Rate

Cough

Dyspnea

Orthopnea

Hyperpnea

Cheyne-Stokes respiration

Sneeze

Hiccough

Spiracular movement

Gaseous diffusion

Cardiovascular activity

Cardiac rate

Aurlcular functional abnormality, unspecified

Auricular premature contraction

Auricular tachycardia

Auricular fibrillation

Auricular flutter

Ventricular functional abnormality, unspecified 
C121 Ventricular premature contractions, extra systoles, idioventrlcular coupling, ectopic beats

C122 Ventricular tachycardia

C123 Ventricular fibrillation

C13 Pace maker and conduction abnormality, unspecified

C131 Sinus arrhythmia

C132 Sinus bradycardia

C133 Sinus tachycardia

C134 Sino-auricular block

C135 Sinus arrest

C136 Auricular-ventricular block

C137 Nodal rhythm

C2 Amplitude of heart beat

C21 Force of contraction; systolic force

C22 Cardiac output

C23 Ballistocardiogram

C4 Electrlc activity (electrocardiogram)

C6 Circulatory rate

C8 Circulation (specify the organ in

$$
\text { Fjeld } \mathrm{H}-1 \text { ) }
$$

C81 Blood flow

C811 Acceleration of blood flow

C812 Retardation of blood flow

C9 Standst111, heart arrest

C91 Systolic standstill

C92 Diastollc standstill

F Metabolic activity, unspecified

Fl Resplration and fermentation, unspecified. Symbol $F 1$ is used for metabolic respiration; to code ventilation, breathlng, etc., use symbols of series B.... If an enzyme is specified, use the symbol for the enzyme (Enzyme Code) rather than a symbol of the F -.series.

Enzyme and enzyme action. (See the note accompanying Symbol 7 , following the 5--- series.)

Fil Oxygen uptake

F12 Carbon dioxide uptake

F121 Aerobic respiration

F122 Anaerobic respiration

F13 Respiratory quotient

F14 Bioluminescence

F15 Gas formation, unspecifled

F16 Acld production, unspeclfied

F17 Nitrogen utllization

Fi71 Nitrogen balance. Use Symbol F171 only with Symbol 6 of Field T-1.

F18 Carbohydrate and phosphate utilization

Fi9 Fat utilization

F2 Function of a vitamin or mineral "trace element", unspecified. Use symbols of the F2-- series only for functions of those dletary components needed in relatively minute quantitles and which frequently serve more as regulatory substances than as materials for growth and energy source. For functions of proteins, fats, carbohydrates, water, major minerals (elements, ions, salts) which serve as energy sources, as materials for structural growth, or as regulatory or osmotic and acid-base balance, etc., use symbols of series F4...

Dietary intake; intake of all components of the diet; ingestion. (For coding the plant process of taking in materials from the soil, water, or other medium in which the plant grows, use Symbol F6 - rather than Symbol F3.)

F4 Function of protein, carbohydrate, fat, water, or major sait, either as an energy source (catabolism) or as a material for growth (anabolism). Symbols of the F4-- series are generally for use only with Symbol A of Field T-1 to indicate that the test compound can replace the specific energy source (F41 -) or replace the material normally incorporated for growth (F42). (The compound replaced is identified in Fleld D.) Symbol 7 of Field T-1 may be used with these symbols, however, to indicate that the test compound "has" the function as defined by $\mathrm{F} 41$ - or F 42 -.

F41 Function of components of the biological organism as sources of energy (catabolism). (Proteln, carbohydrate, or fat--functioning as sources of energy.) Unspeclfied. (See the definition for Symbol F4.)

F42 Function of components of the biological organism, or of its diet, as materials for growth (anabolism). (Protein, carbohydrate, fat, salt, water, etc. , as materials eligible for incorporation. for protoplasmic growth or specific deposit.) Unspecified. (See the definition for Symbol F4.)
F5
Basal metabolism

Photosynthesis

Photosynthetic $\mathrm{CO}_{2}$ uptake

Photosynthetic $\mathrm{O}_{2}$ output

Body temperature. To code "fever" or hypothermia, use Field T-1 Symbols 1, $\mathrm{K}, \mathrm{N}$, or $\mathrm{Q}$ or Symbols 2, J, M, or $\mathrm{P}$, respectively. 
Columns $\frac{\text { FIELD T-2 }}{58,59,60}$, and 61

The code symbols on this page, Symbols F6--, F8_-, F9--, FA--, FB--, FC--, FG--, FH--, and FI--, require appending one of the code symbols of the opposing list (Symbols --1, - - 11, etc.) to indicate the chemical whose metabolic handling is affected by the test compound. They are coded with Symbols 7, 1, 2, or 3 of Field T-1 (only Symbol 7, in the case of Symbol FH--), unless the test compound affects a secondary compound's effect on the metabolic handling of compounds of the opposing list (Symbols 8, 9, A, or C of Field T-1). Symbol FA-- and FB-- (and, when a pathology is coded in Field E, Symbols F8-- and FI--) can be combined with Symbol --B (to make Symbols FAB, FBB, F8B, and FIB) and coded with Symbol 7 (never with Symbols 8, 9, A, or C) of Field T- 1 to indicate that the test compound is stored, absorbed, synthesized, or withdrawn. Each of the nine symbols is defined only briefly here to permit all nine being on a single page for convenience in matching and combining them with the symbols of the opposing list. The Key continues the definition for each separately, indicating specifications and limitations of their use; reference must be made to those Key definitions and explanations to use the symbols correctly.

In each case, identify in Field $\mathrm{D}$ the specific secondary compound (indicated in Field T-2 only by type, by the last two units of the symbol), If known, except when Fleld T- 1 is coded with Symbol 8 , 9 , A, or C, when the secondary compound (whose effect on the metabolism of the compound indicated by one of the symbols of the following list is affected by the test compound) is coded in Field D and the specific identity of the compound whose metabolism is affected is only written, not coded, in Field T-2.

F6-- Nutrient uptake; uptake of the type of nutrient indlcated by the last two units of the symbol.

F8-- Chemosynthesis; synthesis of the type of secondary compound Indicated by the last two units of the symbol; synthesis of the test compound indicated by Symbol F8B (ONLY when synthesis of the test compound is a symptom of a pathology coded in Field E).

F9-- Distribution of the type of secondary compound Indicated by the last two units of the symbol.

FA- Storage, deposit, concentration, or tissue level of the type of secondary compound indicated by the last two units of the symbol; storage, deposit, or tissue level of the test compound, indicated by Symbol FAB.

FB-- Absorption of the type of secondary compound Indicated by the last two units of the two unlts of the symbol; absorption of the test compound, indicated by Symbol FBB.
FC-- Excretion, secretion, guttation, or exudation (resulting in loss or with the objective of discard) of the type of normal secondary compound indicated by the last two units of the symbol. For endocrine secretion or other secretion not representing loss or discard, use symbols other than FC--. Consult the Key. (Use Symbol FC-- only for excretion or secretion of compounds normal to any of the normal excretory or secretory organs or tissues.) Use Symbol FF-- (defined after symbols of the FE-series) to code excretion or secretion of the test compound or any other compound not normal to the excretory or secretory tissue or organ.

FG-- Ability to permeate or penetrate; ability, of the type of secondary compound indicated by the last two units of the symbol, to permeate or penetrate cells, tissues, or membranes.

FH - - Incorporation of the test compound per se into the type of secondary compound indicated by the last two units of the symbol.

FI- - Withdrawal of the type of secondary compound indicated by the last two units of the symbol; withdrawal of the test compound indicated by Symbol FIB (ONLY when this withdrawal of the test compound is a symptom of a pathology coded in Field E). 


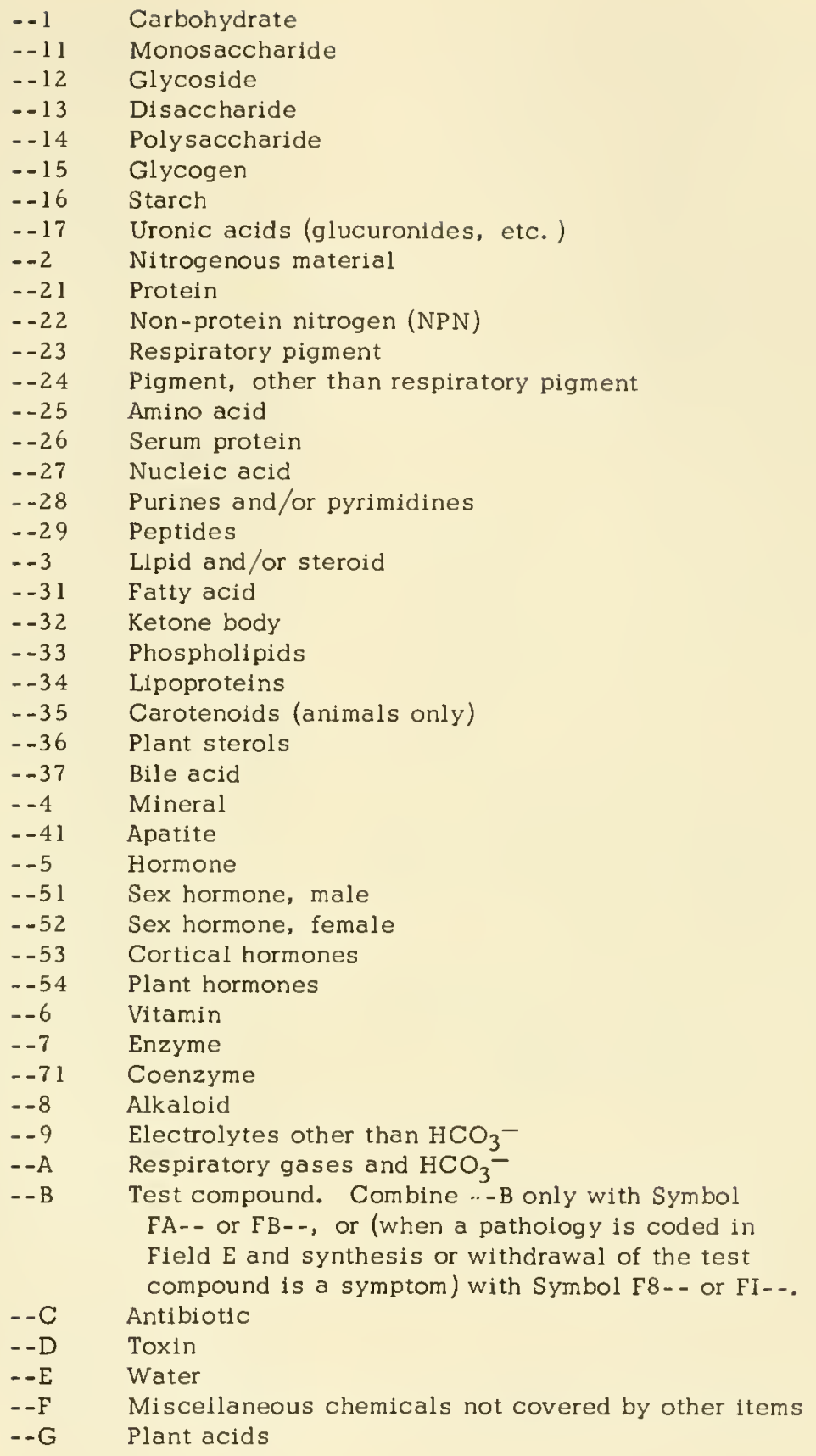


The following symbols of the FE-- serles are to be used for coding specific alterations of the test compound. They are also used for coding specific alterations of secondary compounds when that alteration is affected (increased, decreased, stopped) by the test compound or when the test compound is essential for the secondary compound's alteration. Finally, they are used for coding specific alterations of a third compound which are affected by a secondary compound when that effect of the secondary compound is affected (synergized, antagonized, etc. ) by the test compound. In the case of each of the last two uses of symbols of the FE-- series, Symbol * must be coded in Column 61. The specific directions for the coding procedure when these symbols are used are very important. They are included only in the Key which must be consulted to assure coding Fields $\mathrm{T}-\mathrm{I}$ and D correctly with these symbols.

FE Alteration, unspecified. (Symbol FE can be used to indicate that the test compound is a precursor for [and altered to] a specific biological product coded in Field D. )

FE1 Detoxification, unspecified

FE2 Oxidation, unspecified (Symbol FE2 is not used for C-C bond cleavage.) Use Symbol FEA for glucose oxidation, etc.

FE2 1 Aliphatic hydrocarbon $\rightarrow$ alcohol

FE22 Alcohol $\rightarrow$ aldehyde or ketone

FE23 Aldehyde $\rightarrow$ acid

FE24 Alcohol $\rightarrow$ acid

FE25 Dehydrogenation of an aliphatic chain or carbocyclic ring (unsaturation)

FE26 Peroxidation

FE27 Aromatic hydrocarbon $\rightarrow$ phenol

FE28 Phenol $\rightarrow$ quinone

FE29 Sulfhydryl $\rightarrow$ sulfide

FE2J S-O bond formation or oxidation (e. g. , $\mathrm{SO}_{4}$ from $\mathrm{SO}_{3}$, sulfone formation)

FE2K Valence change (e.g., ++ to +++ ), for elements other than $\mathrm{N}, \mathrm{O}, \mathrm{P}$, and $\mathrm{S}$

FE2L $\beta$-oxidation

FE2M Omega oxidation

FE3 Reduction, unspecified

FE3 I Alcohol aliphatic hydrocarbon

FE32 Aldehyde or ketone $\rightarrow$ alcohol

FE33 Acid $\rightarrow$ aldehyde

FE34 Acid $\rightarrow$ alcohol

FE35 Hydrogenation of an aliphatic chain (saturation)

FE36 Hydrogenation of an aromatic ring (loss of aromaticity)
FE37

FE3 8

FE39

FE3 J

FE3K

FE4

FE4 I

FE42

FE43

F E44

FE4 5

FE5

FE5 1

FE52

FE53

FE6

FE6 1

FE62

FE6́3

FE7

FE7 1

FE72

FE73

FE7 4

FE7 5

FE76

FE77

FE7 8

FE79

FE8

FE8 1

FE82

FE83

FE84

FE9

FE91

FE92

FEA

FEA 1

FEA2

FEA3

FEA4

FEA5

FEA6

FEA7
Quinone $\rightarrow$ phenol

Imino $\rightarrow$ amino

Sulfide $\rightarrow$ sulfhydryl

Reduction of S-O compounds (e. g. , $\mathrm{SO}_{4} \rightarrow \mathrm{SO}_{3}$ )

Valence change (e.g. +++ to ++ ) for elements other than $\mathrm{N}, \mathrm{O}, \mathrm{P}$, and $\mathrm{S}$

Conjugation, combination, unspecified

Conjugation with glucuronic acid or other sugar acid

Conjugation with glycine or other amino acid

Conjugation with sulfate

Formation of mercapturic acids

Detoxification with glutamine

Acylation, unspecified

Acetylation

Acylation with other aliphatic acids (e.g. , formylation)

Acylation with aromatic acids

(e.g., benzoylation)

Esterification, unspecified

Esterification with phosphoric acid

Esterification with ATP, ADP

Esterification with COA

Hydrolysis, unspecified

Hydrolysis of a simple ester

Hydrolysis of a peptide bond

Hydrolysis of a sulfur-carbon bond (e.g. , Acetyl coenzyme A)

Deacylation (e.g., hydrolysis of acetylcholine)

Deconjugation (e.g., hydrolysis of glucuronides)

Hydrolysis of phosphate ester linkages; dephosphorylation (e. g. , Glucose-6$\mathrm{PO}_{4}$ )

Hydrolysis of pyrophosphate linkages (e. g. , ATP, ADP)

Hydrolysis of N-P linkages (e.g., phosphocreatine)

Hydrolysis of acetal linkages (e.g. , sucrose)

Deamination, unspecified

Oxidative deamination

Transamination

Deamidation

Deamidination

Binding

Chelation

Protein-binding

Degradation, unspecified

Degradation to unidentified products

Carbon bond cleavage; loss of carbon atoms

Decyclization, ring cleavage and opening

Ring contraction

Decarboxylation

Oxidative decarboxylation

Depolymerization 


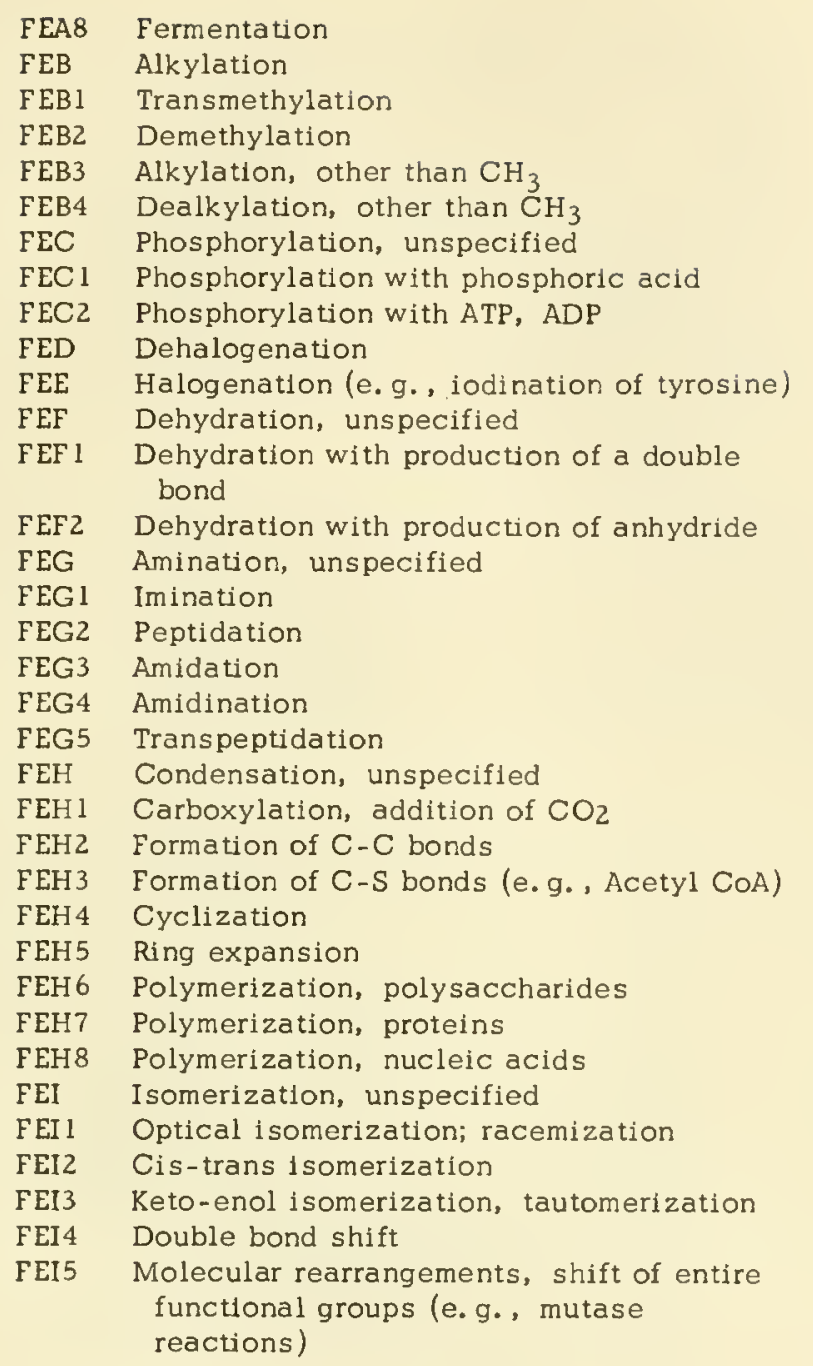


FIELD T-2

Columns $\overline{58,59,60}$, and 61

FF - Excretion, secretion, guttation, exudation of the test compound or any other type of foreign compound (indicated by the last unit of the symbol) via the excretory or secretory path indicated by the third unit of the symbol. Symbol FF is never used alone (with no coding in Columns 60 and 61 ), but only as one of the FF- series (FF1, FF2, FF3, etc.), combined with a symbol of a second series (-- $-1,--2$, etc. ). Note that symbols of the FF-- series are used only when the material excreted or secreted is the test compound or when it is any material not normally excreted or secreted over the specific excretory or secretory path involved. (It may be a material normally excreted or secreted by the organism, but if it is over an abnormal path, it should be coded by a symbol of the FF - - series.) If it is not the test compound whose excretion or secretion is being coded or if it is a material normally excreted or secreted over the secretory or excretory path, use Symbol FC - - instead of Symbol FF - . The two symbol series referred to above, by which symbols of the FF-- series are composed, are presented together, below, for convenience in referring to both.

The items of each of the following two lists are represented by incomplete symbols. Any symbol of one list must be combined with one of the symbols of the other to form a complete symbol. In other words, any of the materials of the first list (the test compound, -.-B, or any other foreign material, - - 1, ..-2, etc. ) can be indicated as being excreted or secreted over any excretory or secretory path (FF1-[FFl], FF 12, etc.], FF2-[FF21, FF22, etc.], etc.). See the preceding definition of FF--. If the foreign material secreted or excreted is not the test compound and if its specific identity is determined, code the specific material secreted or excreted in Field D.

General types of materials foreign to the test organism (including the test compound); materials which may not be foreign to the test organism, but are secreted or excreted over paths over which they are not normally excreted or secreted. If known, code the specific identity in Field D. (Use only Symbol FC-- for excretion or secretion of normal materials, excreted or secreted over normal paths.)

\section{--1 Carbohydrate}

-2 Ketone body

-.-3 Lipld and/or steroid

-.-4 Mineral

-.-5 Hormone

$--6 \quad$ Vitamin

- - 7 Enzyme

- - B Test compound

-.-E Water

---F Miscellaneous chemicals not covered by other items

---G Metabolite of the chemical specified in Field D

--H Metabolite of the test compound

---I Pigment (including protein pigment); dyes

- - J Protein (other than pigments)

-.-K Amino acid

-- L Non-protein nitrogen (NPN)
Secretory or excretory path. The following items are anatomical structures, the products of structures, or processes, each of which represents a path over which the test compound or other material of the opposing list may be eliminated. Use of an item of this list does not supplant coding in Fields $\mathrm{H}-\mathrm{l}$ and/or I and the specific structure indicated by the symbol used from this list must be coded in Fields H-l and/or I. Of this 11st, Symbol FFA- (vomiting) represents a rejective elimination and not excretion or secretion. It is used in preference to any other symbol, however, to code such elimination of the test compound or other foreign material ingested.

FF 1 - Urine

FF2 - Feces

FF3 - Lungs

FF4 - Sweat

FF5 - Bile

FF6 - Cuticle

FF7 - Milk

FF8 - Saliva

FF9- Transpiration

FFA- Emesis, vomiting

FFB - Roots

FFC - Tears

FFD- Gastric juice 
$\underline{\underline{71}}$

71

710

7101

7102

7103

7104

7105

7106

7107

7108

7109

$710 \mathrm{~A}$

$710 \mathrm{~B}$

$710 \mathrm{C}$

$710 \mathrm{D}$

$710 \mathrm{E}$

$710 \mathrm{~F}$

$710 \mathrm{G}$

$710 \mathrm{H}$

7101

$710 \mathrm{~J}$

$710 \mathrm{~L}$

$710 \mathrm{M}$

$710 \mathrm{~N}$

$710 \mathrm{P}$

$710 \mathrm{R}$

$710 \mathrm{~S}$

$710 \mathrm{~T}$

$710 \mathrm{U}$

$710 \mathrm{~V}$

711

7111

7112

7113

712

7121

7122

7123

7124

7125

7126

7127

7128

7129

713

714

7141

715

716

7161

717

7171

718

719

7191

7192
Proteases

Proteinases

Peptidase, tobacco

Polypeptidase, yeast

Salmon pepsin

Prolidase

Prolinase

Protaminase

Renin

Rennin

Trypsin

Solanain

Streptokinase

Thrombin

Tabernamontanain

Antistreptokinase

Antifibrinolysin

Profibrinolysin

Prorennin

Trypsinogen

Antiprofibrinolysin

Prothrombin

Antithrombin

Thromboplastin

Anti thromboplastin

Fibrinokinase

Venom thrombin

Venom thromboplastin

Platelet factors

Ac-globulin

Aminopolypeptidases

Leucine aminopeptidase

Aminotripeptidase

Lymphopeptidase

Arachain

Aspergillus oryzae proteinase

Streptococcus A proteinase

Streptococcus A proteinase precursor

Bacillus subtilis gelatinase

Bacillus amyloliquefaciens proteinase

Clostridium histolyticum collagenase

Clostridium welchii collagenase

Micrococcus lysodeikticus gelatinase

Bacillus pyocyaneus proteinase

Asclepain $\mathrm{m}$

Asclepain $\bar{s}$

Syriana asčlepain

Bromelin

Bacterial peptidase

Bacillus botulinus proteinase

Carboxypeptidase

Carboxypolypeptidase

Cathepsin I

Cathepsin II

Cathepsin C

Cathepsin V
$71 \mathrm{~A}$

$71 \mathrm{~B}$

$71 \mathrm{D}$

$71 \mathrm{Dl}$

$71 \mathrm{D} 2$

$71 \mathrm{D} 3$

$71 \mathrm{D} 4$

$71 \mathrm{D} 5$

$71 \mathrm{D} 6$

$71 \mathrm{D} 7$

$71 \mathrm{D} 8$

$71 \mathrm{E}$

$71 \mathrm{El}$

$71 \mathrm{~F}$

$71 \mathrm{G}$

$71 \mathrm{Gl}$

$71 \mathrm{G} 2$

$71 \mathrm{G} 3$

$71 \mathrm{G} 4$

$71 \mathrm{G} 5$

$71 \mathrm{G} 6$

$71 \mathrm{H}$

711

$71 \mathrm{~J}$

$71 \mathrm{~K}$

$71 \mathrm{~L}$

$71 \mathrm{M}$

$71 \mathrm{Ml}$

$71 \mathrm{M2}$

$71 \mathrm{~N}$

$71 \varnothing$

$71 \mathrm{P}$

$71 \mathrm{Q}$

$71 \mathrm{R}$

$71 \mathrm{~S}$

$7 \mathrm{lSl}$

$71 \mathrm{~S} 2$

$71 \mathrm{~T}$

$71 \mathrm{Tl}$

$7 \mathrm{IU}$

$7 \mathrm{IV}$

$7 \mathrm{IW}$

$71 \mathrm{X}$

$71 \mathrm{Y}$

712

$\underline{\underline{72}}$

72

721

722

723

724

725

726
Cathepsin III

Cathepsin IV

Chymotrypsins

a-Chymotrypsin

$\beta$-Chymotrypsin

Chymotrypsinogen

$\gamma$-Chymotrypsin

$\triangle$-Chymotrypsin

Pi-Chymotrypsin

B-Chymotrypsin

Chymotrypsinogen-B

Dehydropeptidase I

Dehydropeptidase II

Dermopeptidase

Depeptidases

Glycylglycine dipeptidase

Glycyl-L-Ieucine dipeptidase

Carnosinase

Alanylglycine dipeptidase

Glutathionase

Cysteinylglycinase

Enterokinase

Erepsin

Euphorbain

Ficin

Fungi peptidase

Gelatinase

Collagenase

Elastase

Hurain

Hypertensinase

Keratinase

Leucoprotease

Mexicanain

Papain

Papain peptidase I

Papain peptidase II

Pepsin

Pepsinogen

D-Peptidase

L-Peptidase

Pinguinain

Fibrinolysin

Papain a-trypsinase

Papain $\beta$-trypsinase

Esterases

Acetylesterase

Renal acylase I

Acetanilide acylase

Meperidine esterase

Diisopropyl fluorophosphate esterase

Succinic daecylase 
73 Amidases

732 Adenosine deaminase

7321 Adenase

733 5-Adenylic acid deaminase

7331 3-Adenylic acid deaminase

734 Allantoicase

736 Arginase

7361 Guanidodesimidase

737 Asparaginase I

7371 Asparaginase II

738 Benzamidase

739 Canavanase

73A Creatinase

73B Cytidine deaminase

73C Glutaminases

$73 \mathrm{C} 1$ Glutaminase I

73C2 Glutaminase II

73C3 Brain glutaminase

73C4 Bacterial glutaminase

73D Guanase

73Dl Cytosine deaminase

$73 \mathrm{E}$ Guanosine deaminase

$73 \mathrm{~F}$ Guanylic acid deaminase

$73 \mathrm{G}$ Hlppuricase

$73 \mathrm{H}$ Histidase

731 Phosphoaminase

7311 Kidney phosphoamidase

7312 Venom phosphoamidase

7313 Rice bran phosphoamidase

7315 DPN pyrophosphatase

$73 \mathrm{~J}$ Urease

$73 \mathrm{~K}$ Urocanase

73L Creatininase

$73 \mathrm{M}$ Hydantoinase

$73 \mathrm{~N}$ Glycocyaminase

73P Acetamidase

73Q Histidine a-deaminase

73R Formylisoglutaminase

73S Isoglutaminase
Glycosidases

Protopectinase

Prunase

Seminase

Stachyase

Synthiase

$\beta$-Thloglucosidase

Trehalase

Xylanase

Amygdalase

a-Amylases

Hog pancreas a-amylase

Human pancreas a-amylase

Salivary a-amylase

Malt a-amylase

Bacillus subtilis a-amylase
7426

7427

7428

7429

743

7431

7432

7433

7434

7435

7436

744

7441

7442

745

746

747

748

$74 \mathrm{~A}$

$74 \mathrm{~B}$

$74 \mathrm{Bl}$

$74 \mathrm{~B} 2$

$74 \mathrm{C}$

$74 \mathrm{D}$

$74 \mathrm{E}$

$74 \mathrm{El}$

$74 \mathrm{~F}$

$74 \mathrm{G}$

$74 \mathrm{H}$

$74 \mathrm{HI}$

$74 \mathrm{H} 2$

$74 \mathrm{I}$

74 II

$74 \mathrm{I} 2$

7413

$74 \mathrm{~J}$

$74 \mathrm{~K}$

$74 \mathrm{~L}$

$74 \mathrm{Ll}$

$74 \mathrm{~L} 2$

$74 \mathrm{~L} 3$

$74 \mathrm{~L} 4$

$74 \mathrm{~L} 5$

$74 \mathrm{~L} 6$

$74 \mathrm{~L} 7$

74 L 8

74 L9

$74 \mathrm{M}$

$74 \varnothing$

$74 \mathrm{P}$

$74 \mathrm{Pl}$

$74 \mathrm{P} 2$

$74 \mathrm{P} 3$

$74 \mathrm{P} 4$

$74 \mathrm{P} 5$

$74 \mathrm{~Pb}$

$74 \mathrm{P} 7$

$74 \mathrm{P} 8$

$74 \mathrm{Q}$

$74 \mathrm{R}$
Aspergillus oryzae a-amylase

Muscle amylase

Liver a-amylase

Bee amylase

$\beta$-Amylases

Barley $\beta$-amylase

Wheat $\beta$-amylase

Sweet potato $\beta$-amylase

Malt $\beta$-amylase

Rye $\beta$-amylase

Rhizopus delemar $\beta$-amylase

Bacillus macerans amylase

Dextranase

Isoamylase

Amylokinase

Arabanase

$a-D$-Arabinosidase

$\beta$-D-Arabinosidase

Cellulase

Chitinase

Chitodextrinase

Chitobiase

Clarase

Cytases

Glucosaccharase

Invertase

Fructopyranosidase

a-D-Galactosidase

$\beta$-D-Galactosidases

Almond $\beta-D-G a l a c t o s i d a s e$

Yeast $\beta-D-g a l a c t o s i d a s e$

$\beta$-D-glucosidases

Almond emulsin

Yeast emulsin

Animal $\beta$-glucosidase

$\beta$-(N-acetyl)-Glycosaminidase

$\beta$-D-Glucosaminidase

a-D-Glucosidases

Yeast maltase

Barley maltase

Aspergillus oryzae maltase

Intestine mucosa maltase

Skeletal muscle maltase

Bacterial maltase

a-Methylglucosidase

Amylo-1, 6-glucosidase

$\mathrm{Z}$ enzyme

$\beta$-Glucuronidase

Mucases

Hyaluronidases

Bacterial hyaluronidase

Anlmal hyaluronidase

Hyaluronate mucodextrinase

Hyaluronic acid oligomucase

Bacterial sulfomucase

Heparinase

Sulfomucodextrinase

Oligosulfomucase

Inulase

Lichenase 


\begin{tabular}{|c|c|}
\hline $74 \mathrm{~S}$ & Lysozyme \\
\hline $74 \mathrm{~T}$ & a-D-Mannosidase \\
\hline $74 \mathrm{U}$ & a-L-Mannosidase \\
\hline $74 \mathrm{~V}$ & $\beta$-D-Mannosidase \\
\hline $74 W$ & $\beta-\mathrm{L}$-Mannosidase \\
\hline $74 x$ & Polygalacturonase \\
\hline $74 Y$ & Pectln depolymerase \\
\hline 742 & Polidase \\
\hline \multicolumn{2}{|l|}{75} \\
\hline 75 & Oxidases \\
\hline 751 & Ascorblc acid oxidase \\
\hline 752 & Butyric oxidase \\
\hline 753 & Catalase \\
\hline 754 & Cytochrome a \\
\hline 7541 & Cytochrome $a_{1}$ \\
\hline 7542 & Cytochrome $\mathrm{a}_{2}$ \\
\hline 7543 & Cytochrome $\mathrm{a}_{4}$ \\
\hline 755 & Cytochrome b \\
\hline 7551 & Cytochrome $\mathrm{b}_{1}$ \\
\hline 7552 & Cytochrome $\mathrm{b}_{2}$ \\
\hline$* 7501$ & Glutathione reductase \\
\hline 7553 & Cytochrome f \\
\hline 756 & Cytochrome $\mathrm{C}$ \\
\hline 757 & Cytochrome c peroxidase \\
\hline 758 & Cytochrome oxidase \\
\hline 759 & Histaminase \\
\hline $75 \mathrm{~A}$ & Dioxymaleic acid oxidase \\
\hline $75 B$ & DOPA oxidase \\
\hline $75 \mathrm{C}$ & Glutathione oxidase \\
\hline $75 \mathrm{Cl}$ & Desulfinase \\
\hline $75 \mathrm{C} 2$ & Cysteine oxidase A \\
\hline $75 \mathrm{C} 3$ & Cystelne oxidase B \\
\hline $75 \mathrm{C} 4$ & Cystine oxidase \\
\hline $75 \mathrm{C} 5$ & Thiocyanate oxidase \\
\hline $75 \mathrm{C} 6$ & Cystine disulfoxide decarboxylase \\
\hline $75 \mathrm{C7}$ & Cysteine sulfinic acid decarboxylase \\
\hline $75 \mathrm{C} 8$ & Aliinase \\
\hline $75 \mathrm{C} 9$ & Cystathionase \\
\hline $75 \mathrm{D}$ & Laccase \\
\hline $75 E$ & Lipoxldases \\
\hline $75 \mathrm{El}$ & Plant llpoxidase \\
\hline $75 \mathrm{E} 2$ & Animal lipoxidase \\
\hline $75 E 3$ & Lipoxidase activator \\
\hline $75 \mathrm{~F}$ & Monoamine oxidase \\
\hline $75 \mathrm{G}$ & Ortophenolase \\
\hline $75 \mathrm{H}$ & Peroxidases \\
\hline $75 \mathrm{H} 1$ & Plant peroxidase \\
\hline $75 \mathrm{H2}$ & Milk peroxidase \\
\hline $75 \mathrm{H} 3$ & Myeloperoxidase \\
\hline $75 \mathrm{H} 4$ & Paraperoxidase \\
\hline $75 \mathrm{H} 5$ & Peroxidase II \\
\hline $75 \mathrm{H} 6$ & Salivary peroxidase \\
\hline $75 \mathrm{H} 7$ & Tryptophan peroxidase \\
\hline $75 I$ & Tyrosinase \\
\hline $75 \mathrm{~J}$ & Monophenol oxidase \\
\hline $75 \mathrm{~K}$ & Polyphenol oxldase \\
\hline $75 \mathrm{~L}$ & Cytochrome system \\
\hline $75 \mathrm{M}$ & Kidney laccase \\
\hline
\end{tabular}

$\begin{array}{ll}75 \mathrm{~N} & \text { Phenol dehydrase } \\ 75 \mathrm{P} & \text { a-Hydroxacid oxidase, animal } \\ 75 \mathrm{Pl} & \text { a-Hydroxacid oxidase, plant } \\ 75 \mathrm{Q} & \text { Indoleacetic acid oxidase } \\ 75 \mathrm{R} & \text { Inositol oxidase } \\ 75 \mathrm{Rl} & \text { Lactose oxidase } \\ 75 \mathrm{~S} & \text { Choline oxidase } \\ 75 \mathrm{Sl} & \text { Betaine aldehyde oxidase } \\ 75 \mathrm{~T} & \text { Glycollic acid oxidase } \\ 75 \mathrm{U} & \text { Succinoxidase system } \\ 75 \mathrm{~V} & \text { Slater factor } \\ 75 \mathrm{~W} & \text { Quinine oxidase } \\ 75 \mathrm{X} & \text { B-Hydroxybutyric acid dehydrogenase, } \\ & \quad \text { bacterial } \\ 75 \mathrm{Y} & \text { Sarcosine oxidase } \\ 75 \mathrm{Z} & \text { Phenylalanine oxidase system }\end{array}$

$\underline{\underline{76}}$

76

761

7611

7612

7613

7614

762

7621

7622

7623

7624

7625

7626

7627

7628

7629

764

77

77

771

7711

7712

7713

7714

7715

7716

772

7721

7722

773

778

779

$77 \mathrm{~A}$

$77 \mathrm{Al}$

$77 \mathrm{~B}$

$77 \mathrm{C}$

$77 \mathrm{D}$

$77 \mathrm{E}$

$77 \mathrm{~F}$
Nucleases

Desoxyribonucleases

Thymus desoxyribonuclease

Pancreas desoxyribonuclease

Yeast desoxyribonuclease

Streptococcal desoxyribonuclease

Nucleosidases

Purine nucleosidase

Pyrimidine nucleosidase

Ribonucleic acid phosphorylase

Nucleotide- $\mathrm{N}$-ribosidase

Coenzyme I nucleosidase

Inosine phosphorylase

Thymidine phosphorylase

Uridine phosphorylase

Uridine nucleosidase

Ribonuclease

\section{Phosphorylases}

a-1,4-Phosphorylases

Animal phosphorylase

Plant phosphorylase

Muscle phosphorylase a

Muscle phosphorylase b

PR enzyme

Liver phosphorylase

$\beta-1,6$ - Phosphorylase

$\beta-1,6$ - Phosphorylase, animal

$\beta-1,6$ - Phosphorylase, plant

a-Glucosan phosphorylase

Sucrose phosphorylase

Maltose phosphorylase

$Q$ enzyme, potato

$Q$ enzyme, protozoan

Amylosucrase

Amylomaltase

Maltose transglucosidase

Transfructosidase

$P$ enzyme 
Isomaltomal tase

Inulosucrase

Trans-N-glycosidase

Laminarinase

Transacetylase

CoA transphorase

CoA pyrophosphate transacetylase

Acetoacetate-synthesizing enzyme

Glutamo-transferase

Asparto-transferase

Glutamo-transphorase

Phosphatidic acid transferase

\section{Transphosphorylases}

Creatine kinase

ADP-Creatine transphosphorylase

ATP-Arginıne transphosphorylase

Phosphoglyceric phosphokinase

Pyruvic phosphokinase

TPN kinase

Phosphofructokinase I

Phosphofructokinase II

Glucokinase

Hexokinase

Myokinase

Acetokinase

Adenosine kinase

Acetyl kinase

Pyridoxal kinase

DPN kinase

Choline phosphokinase

Xylokinase

Triosekinase

CoA kinase

Flavokinase

FAD-synthesizing enzyme

Thiamine kinase

Galactokinase

Mannokinase

Ribokinase

Arabokinase

Gluconokinase

Fructokinase, liver

Fructokinase, muscle

Phosphoglucokinase

Glutamine-synthesizing system

Glycerol kinase

Hydrase or dehydrase

\section{Aconitase}

Aspartase I

Aspartase II

Carboric anhydrase

Cysteine desulfhydrase

Enolase

Fumarase

\section{$7 \mathrm{~B}$}

$7 \mathrm{~B}$

$7 \mathrm{Bl}$

$7 \mathrm{~B} 2$

$7 \mathrm{~B} 3$

$\underline{\underline{7 C}}$

$7 \mathrm{C}$

$7 \mathrm{Cl}$

$7 \mathrm{C} 2$

$7 \mathrm{C} 4$

$7 \mathrm{C} 5$

$7 \mathrm{C} 6$

$\underline{7 D}$

$7 \mathrm{D}$

$7 \mathrm{Dl}$

$7 \mathrm{D} 2$

$7 \mathrm{D} 3$

$7 \mathrm{D} 4$

$7 \mathrm{D} 5$

$7 \mathrm{D} 6$

$7 \mathrm{D} 7$

$7 \mathrm{D} 8$

$7 \mathrm{D} 9$

7D91

$7 \mathrm{D} 92$

$7 \mathrm{D} 93$

$7 \mathrm{DA}$

$7 \mathrm{DB}$

$7 \mathrm{DC}$

$7 \mathrm{DD}$

$7 \mathrm{DE}$

$7 D G$

$7 \mathrm{DG}$

$7 \mathrm{DH}$

$7 \mathrm{DH} 1$
Glyoxalase

Serine dehydrase

Exocystine desulfhydrase

Homocysteine desulfhydrase

Threonine deaminase

Maleáse

\section{Mutase}

Aldehyde mutase

Phosphoglucomutase

Phosphoglyceromutase

Pyruvic dismutase system

Phosphofructomutase

Phosphoribomutase

Phosphodesoxyribomutase

\author{
Lipases \\ Castor bean lipase \\ Gastric lipase \\ Pancreatic lipase
}

Isomerases

Phosphohexoisomerase

Phosphotrioseisomerase

Phosphopentose isomerase

Phosphomannose isomerase

Phosphogalactose isomerase

\section{Desmolases}

Acetoacetic acid carboxylase

a-Acetolactic carboxylase

L-Alanine decarboxylase

Aspartlc acid decarboxylase

Pyruvic carboxylase

Condensing enzyme

Decarboxylase, animal

Decarboxylase, plant

Desoxyribose phosphate aldolase

Hydrogenase

Pyrldine nucleotlde transhydrogenase

Ribose phosphate aldolase

a-Ketoglutaric carboxylase

Oxaloacetic carboxylase

Oxalosuccinic carboxylase

L-Arginine decarboxylase

Cysteic acid decarboxylase

L-3, 4-Dihydroxyphenylalanine decarboxylase

Phenylalanine decarboxylase

L-Glutamic acid decarboxylase, bacterial

-Glutamic acid decarboxylase, plant 
7DH2 L-Glutamic acid decarboxylase, animal

7D L-Histidine decarboxylase, bacterial

7DIl L-Histidine decarboxylase, plant

7DJ L-Lysine decarboxylase

7DK L-Ornithine decarboxylase

7DI Pyruvate oxidase system

$7 \mathrm{DM} \quad$ L-Tyrosine decarboxylase, bacterial

$7 D M 1$ L-Tyrosine decarboxylase, animal

7 DM2 p-Hydroxyphenylserine decarboxylase

7DN Tryptophan decarboxylase, bacterial

7DNl Tryptophan decarboxylase, animal

$7 D \varnothing \quad$ Aldolase

7DP Carboligase, yeast

7DPl Aerobacter aerogenes carbollgase

7DP2 Animal carboligase

7DP3 Formaldehyde-pyruvate carboligase

7DP4 Succinic acid decarboxylase

7DQ Tryptophanase

7DR Tryptophan desmolase

7DS Kynureninase, bacterial

7DS1 Kynureninase, animal

7DT 6-Phosphogluconate oxidase system

$7 \mathrm{DU}$ a-Ketoglutarate-isocitrate carboxylase system

7DU1 a-Ketoglutarate-1socitrate carboxylase system, yeast

7 DV Glyoxylic acld carboxylase

$7 \mathrm{DW}$ Lactic carboxylase

7DX Malic enzyme, liver

7 DXl Malic enzyme, bacterial

\section{E}

$7 \mathrm{E} \quad$ Dehydrogenases

7E01 Xanthine oxidase

$7 \mathrm{El}$ Alcohol dehydrogenase

7 Ell Alcohol dehydrogenase, animal

$7 \mathrm{El} 2$ Alcohol dehydrogenase, plant

$7 \mathrm{E} 13$ Aldehyde dehydrogenase

$7 \mathrm{El} 4$ Retinene reductase

7 El 5 Acetaldehyde dehydrogenase

$7 \mathrm{E} 2$ D-Amino acid oxidase

7 E21 D-Amino acid oxidase, molds

7 E22 D-Amino acld oxidase, bacterial

7 E23 D-Aspartic actd oxidase

$7 \mathrm{E} 3$ L-Amino acid oxidase

7 E31 Ophio-L-amino acid oxidase

$7 \mathrm{E} 32$ L-Amino acid oxidase, molds, insoluble

7 E33 L-Amino acid oxidase, molds, soluble

7 E34 L-Amino acid oxidase, bacterial

7 E35 L-Proline oxidase

7E5 Citric acid dehydrogenase

7 E51 Nitrate reductase

$7 \mathrm{E} 52$ Nitro reductase

7 E6 Cytochrome c reductase I

7 E7 Cytochrome c reductase II

7 E8 Diaphorase I

7E9 Diaphorase II

$7 \mathrm{EA}$ Fatty acid dehydrogenase

7EB Formic acid dehydrogenase

$7 \mathrm{~EB} 1$ Formic dehydrogenase, bacterial

7 EC Fumaric hydrogenase

$7 E D \quad$ Glucose dehydrogenase

7 EDl Sorbitol dehydrogenase

7ED2 Glycerol dehydrogenase

$7 \mathrm{EE} \quad$ Glucose oxidase

$7 \mathrm{EF}$ Glucose-6-phosphate dehydrogenase

$7 E F 1$ Ribose-5-phosphate dehydrogenase

7EG Glutamic acid dehydrogenase, liver

$7 \mathrm{EG} 1$ Glutamic acid dehydrogenase, yeast

7 EG2 Glutamic acid dehydrogenase, animal

7EG3 L-Amino acid dehydrogenase

7 EG4 Choline dehydrogenase

7 EG5 Glyoxal dehydrogenase

7EG6 Glycollic acid oxidase

$7 \mathrm{EH}$ Glycine oxidase

7EI a-Glycerophosphate dehydrogenase

7EJ a-Glycerophosphate dehydrogenase I

7 EK a-Glycerophosphate dehydrogenase II

$7 \mathrm{EM} \quad \beta$-Hydroxybutyric dehydrogenase

$7 E N \quad$ Isocitric acid dehydrogenase

$7 \mathrm{ENI}$ Isocitric acid dehydrogenase, plant

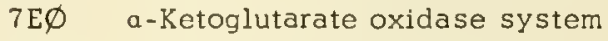

7EP Lactic acid dehydrogenase

$7 \mathrm{EPl}$ Lactic acid dehydrogenase, animal

7EP2 Lactic dehydrogenase, yeast

$7 \mathrm{EQ}$ Liver aldehyde oxidase

7ER Malic acid dehydrogenase I

7 ES Malic dehydrogenase II

7ET New yellow enzyme

7 EU Old yellow enzyme

7EV Phosphogluconic dehydrogenase

$7 \mathrm{EW}$ Triosephosphate dehydrogenase, yeast

$7 \mathrm{EY}$ Succinic dehydrogenase

$7 \mathrm{EZ}$ Triosephosphate dehydrogenase, muscle

$\underline{\underline{7 F}}$

$7 \mathrm{~F}$

$7 \mathrm{Fl}$

$7 \mathrm{~F} 2$

$7 \mathrm{~F} 3$

$7 \mathrm{~F} 4$

$7 \mathrm{~F} 5$

$7 F 6$

$7 \mathrm{G}$

$7 \mathrm{Gl}$

$7 \mathrm{G} 2$

$7 \mathrm{G} 3$

$7 \mathrm{G} 5$

$7 \mathrm{G} 51$

$7 \mathrm{G} 52$

$7 \mathrm{G} 6$

$7 \mathrm{G} 7$

$7 \mathrm{G} 8$

$7 \mathrm{G} 9$

$7 \mathrm{GA}$
Transaminases

Glutamic-alanine transaminase

Glutamic-aspartic transaminase

Ornithine-pyruvate transaminase

Ornithine-oxalacetic transaminase

Ornithine-a-ketoglutaric transminase

Pyridoxamine phosphate-pyruvate transaminase

\section{Antinvasin I}

Antinvasin II

Dextransucrase

Lactic acid racemase

Alanine racemase

Glutamic acid racemase

Levansucrase

Luciferase

Nitrilase

Oxynitrilase

Penicillinase 
$7 \mathrm{~GB}$

$7 \mathrm{GC}$

$7 \mathrm{GD}$

$7 \mathrm{GE}$

$7 \mathrm{GF}$

$7 \mathrm{GG}$

$7 \mathrm{GH}$

7GJ

$7 \mathrm{GL}$

$7 \mathrm{GM}$

7GN

$7 \mathrm{G} \varnothing$

$7 \mathrm{GP}$

$7 \mathrm{GQ}$

$7 \mathrm{GR}$

$7 \mathrm{GS}$

$7 \mathrm{GT}$

$7 \mathrm{GU}$

$\underline{\underline{X}}$

$7 \mathrm{~K}$

$7 \mathrm{KOI}$

$7 \mathrm{~K} 02$

$7 \mathrm{~K} 05$

7K06

$7 \mathrm{~K} 07$

7K08

$7 \mathrm{KI}$

$7 \mathrm{~K} 2$

$7 \mathrm{~K} 21$

$7 \mathrm{~K} 22$

$7 \mathrm{~K} 23$

$7 \mathrm{~K} 24$

$7 \mathrm{~K} 25$

$7 \times 26$

$7 \mathrm{~K} 3$

$7 \mathrm{~K} 4$

$7 \mathrm{~K} 5$

$7 \times 6$

$7 \mathrm{~K} 7$

$7 \mathrm{~K} 7 \mathrm{I}$

$7 \mathrm{~K} 72$

$7 \mathrm{~K} 73$

$7 \mathrm{~K} 74$

$7 \mathrm{~K} 75$

$7 \mathrm{~K} 76$

$7 \mathrm{~K} 9$

$7 \mathrm{KAI}$

$7 \mathrm{KA} 2$

7KA3

$7 \mathrm{KA} 4$

7KA5

$7 \mathrm{KA6}$

7KA7

$7 \mathrm{KA} 8$

$7 \mathrm{~KB}$

$7 \mathrm{KC}$

$7 \mathrm{KC1}$
Pitocinase

Proinvasin I

Pyrocanase

Rhodanase

Saturase

Thiaminase

Transmethylases

Uricase

Citrulline-arginine enzyme

Cyanase

Streptomycinase

Triacetic enzyme

Pantothenic acid-synthesizing enzyme

Choline-homocysteine transmethylase

Methionine-nicotinamide transmethylase

Methionine-guanidoacetlc transmethylase

Methionine-ethanolamine transmethylase

a-Methyltryptophan demethylase

Phosphatases

Acid nucleotidase

Alkaline nucleotidase

Phosphomonoesterase III

Phosphomonoesterase IV

Ethyl phosphatase

2,3-diphosphoglycerate phosphatase

Adenosinediphosphatase

Adenosinetriphosphatases

Ophio-adenosinetriphosphatase

Apyrase

Brain adenosinetriphosphatase

Liver adenosinetriphosphatase

Muscle adenosinetriphosphatase

Yeast adenosinetriphosphatase

Amylophosphatase

Phospholipase D

Phospholipase C

Glucose-6-phosphatase

Metaphosphatases

Yeast metaphosphatase

Mold metaphosphatase

Yeast hexametaphosphatase

Erythrocyte hexametaphosphatase

Liver trimetaphosphatase

Yeast tetrametaphosphatase

Nucleotidases

Phosphomonoesterase II

Phosphomonoesterase I

Hexose diphosphatase

Glycerophosphatase

5-Nucleotidase

Diphosphopyridine nucleotidase

Nonphosphatasic diphospyridine nucleotidase

Flavinadenine dinucleotidase

Phos phoproteinphosphatase

Phosphodiesterases

Serum phosphodiesterase

$7 \mathrm{KC} 2$ Liver phosphodiesterase

7KC3 Dialkylfluorophosphatase

7KD Phosphomonoesterases

7KE Phytase

7KF Pyrophosphatases (inorganic)

7KFI Pyrophosphatase I

7KF2 Pyrophosphatase II

7KF3 Pyrophosphatase III

$7 \mathrm{KH}$ Thiamine pyrophosphatase

7KJ Acetylphosphatase

7KK Polyphosphatases

$\underline{\underline{7 S}}$

$7 \mathrm{~S}$

$7 \mathrm{~S} 1$

$7 \mathrm{~S} 2$

$7 \mathrm{~S} 3$

$7 \mathrm{~S} 4$

7541

$7 \mathrm{~S} 42$

$7 \mathrm{~S} 5$

756

$7 \mathrm{~S} 7$

758

759

$7 \mathrm{SA}$

$7 \mathrm{SB}$

$7 \mathrm{SC}$

$7 \mathrm{SD}$

$7 \mathrm{SE}$

$7 \mathrm{SF}$

$7 \mathrm{SG}$

$7 \mathrm{SH}$

$7 \mathrm{SI}$

7SJ
Phospholipases

Acetylmorphinesterase

Cholesterolesterase

Choline acetylase

Cholinesterases

Cholinesterase, true

Cholinesterase, pseudo

Chlorophyllase

Chondrosulfatase

Glucosulfatase

Phospholipase A

Phospholipase B

Myrosulfatase

Pectin-methylesterase

Phenol sulfatase

Tannase

Procainesterase

Tropacocainesterase

Acetylsalicylate esterase

Atropinesterase

Cocainesterase

Succinyl deacylase 


\section{CATEGORY OF THE TEST COMPOUND'S EFFECT REPRESENTING PRACTICAL USE}

Series 1--

Categories of agents candidate for practical use in controlling populations of the test organism (i.e., in causing death, repulsion, or attraction of the test organism).

101 Air disinfecting agent

102 Water disinfecting agent

103 Anti-fouling agent

104 Anti-viral activity

105 Rickettsicide

106 Antibacterial agent; bactericide or bacteriostat

107 Antifungal (fungitoxic) agent; fungicide or fungistat

108 Herbicide (referring to killing of higher plants only)

109 Antimalarial agent

110 Protozoacide (exclusive of antimalarial agents for which Symbol 109 is used)

111 Vermicide; anthelmintic

112 Molluscacide

113 Insecticide

114 Acaricide

115 Rodenticide

116 Repellent

117 Attractant

118 Gametocide; spermatocide

Series 2--

Categories of agents candidate for practical pharmacological use In controlling certain physiological processes or pathological conditions.

201 Analgesic; a compound which relieves pain without producing unconsciousness

202 Androgenic: a compound which promotes development of secondary sex organs of the male, spermatogenesis, descent of testes, etc.

203 Anesthetic, general: a compound which produces reversible loss of the sense of touch, pain, and other modalities of sensation and consciousness by action on the central nervous system

204 Anesthetic, local: a compound which reversibly blocks excitation and conduction in nerve tissue

205 Anti-arthritic; a compound which decreases signs and symptoms of arthritis

206 Anti-coagulant: a compound which prevents coagulation or gelation of plasma or other tissue fluid. (Use Symbol 238 to classify a compound as a blood coagulant.)

207 Anti-convulsant: a compound which reduces or prevents convulsions (natural or drug induced); Antl-epileptic

208 Anti-histaminic: a compound which antagonizes any of histamine's actions; prevents allergic reaction

209 Ant1-metabolite: a compound which prevents or abolishes effects of a normally occurring metabolite specified as the secondary compound in Field D

210 Anti-motion sickness; a compound which relieves or prevents syndromes of dizzlness, vertigo, nausea, and vomlting due to rhythmic motion (e.g., airplane, ship, swing)

211 Anti-rheumatic: a compound which decreases signs of rheumatic disease

212 Anti-spasmodic: a compound which reduces or prevents contractions of smooth muscle, whether natural or drug induced contractions (except acetylcholine and histamine induced contractions, the reduction or prevention of which is coded by Symbols 225 and 208 by priority) 
213 Anti-thyroid: a compound which increases the size of the thyroid, or causes hyperplasia, hypertrophy, or decreases the iodine content of the thyroid gland; a compound which decreases the activity of the thyroid gland

214 Anti-vitamin: a compound which prevents or abolishes effects of a vitamin specified as a secondary compound in Field D

215 Astringent: a compound which draws tissues together by precipitating proteln

216 Blood substitute: a compound which restores blood volume (exclusive of cellular or formed elements) via osmotic properties such as those of plasma proteins for treatment of shock

Diuretic: a compound which increases formation of urine

218 Estrogenic: a compound that promotes development of secondary sex organs of the female, feminization of pubic hair distribution, growth of mammary glands, etc.

219 Fibrinolytic: a compound that destroys fibrin

220 Keratolytic: a compound that destroys the horny layer of the skin

221 Miotic: a compound which decreases the size of the pupil either by contracting circular muscles or relaxing radial muscles of the iris

222 Mydriatic: a compound that increases the size of the pupil either by contracting radial muscles or by relaxing circular muscles of the iris

Narcotic: a compound that produces relief from pain accompanied by sleep or stupor

Oxytocic: a compound that produces contraction of the uterus both in vivo and in vitro

Parasympatholytic; cholinergic blocking agent (an agent showing anti-muscarine-like activity): a compound which antagonizes muscarine-like effects of acetylcholine and cholinergic compounds and which prevents effects of post-ganglionic stimulation of parasympathetic nerves. E. g., atropine and atropine-like compounds.

Parasympathomimetic; cholinergic agent (an agent showing muscarine-like activity): a compound that simulates or synergizes acetylcholine's peripheral action; simulates the effect of post-ganglionic stimulation of parasympathetic nerves. E. g. , mecholyl.

227 Sympatholytic: a compound that antagonizes the effect of adrenaline (epinephrine) or noradrenaline (norepinephrine or arterenol) or other sympathomimetic drug; blocks the effects of sympathetic nerve stimulation. E. g., dibenamine, priscoline.

228 Sympathomimetic: a compound that simulates or synergizes effects of adrenaline (epinephrine) or noradrenaline (norepinephrine or arterenol). Adrenergic drug; simulates the effects of sympathetic nerve stimulation.

229 Curariform: a compound that competitively blocks the motor-end plate or myoneural junction; simulates the effects of curare, d-tubocurarine, etc.

230 Antipyretic: a compound that produces a fall in temperature in fever; tends to return the body temperature of a hyperpyrexic animal to normal. E. g. , antipyrine.

231 Depressant of the central nervous system only; hypnotic; sedative: a compound that produces sedation and sleep (exclusive of narcotic type of effect, Symbol 223). E. g., paraldehyde.

232 Analeptic: a compound that reverses the effects of hypnotics and narcotics; stimulates medullary centers of the brain. E. g. , picrotoxin, metrazol.

233 Cardiac: a compound that stimulates or depresses the heart directly; digitalis-like effect. E. g. , cardiac glycosides, khellin.

234 Gastro-intestinal drug: a compound that affects various functions of the gastro-intestinal system; anorexics; cathartics; emetics; constipating agents; and anti-emetics

235 Ganglionic blocking agent: a compound that antagonizes the nicotine-like action (ganglionicstimulating effects) of acetylcholine and cholinergic compounds; prevents the effects of preganglionic nerve stimulation. E. g., TEAC (tetraethyl ammonium chloride).

236 Nicotine-like drug: a compound that simulates or synerglzes nicotine actions of acetylcholine and cholinergic drugs; simulates the effects of pre-ganglionic nerve stimulation

237 Anti-anemic: a compound that prevents, or cures anemia or reduces the severity of the disease; returns the blood picture of an anemic organism to normal.

238 Coagulant: a compound that promotes blood coagulation; prevents, antagonizes, or reduces the actions of anti-coagulants

239 Thyroxin-like drug: a compound that simulates the effects of hormone(s) of the thyroid gland, such as a rise in B. M. R., an increase in oxygen consumption, etc. E. g. , tri-iodothyronine.

240 Adrenal-corticoid: a compound that simulates effects of adrenal cortical hormones on electrolyte, carbohydrate, protein, and skin pigment metabolism; simulates effects on collagenous tissue

270 Carcinogenic agent; carcinogen: a compound that induces neoplastic growth, mallgnant or benign (exclusive of non-neoplastic hypertrophy). Use Symbol 270 only with Symbol 43 or 47 of Field T-2. 
271 Co-carcinogenic: a compound that possesses no carcinogenicity of its own, but causes an increase in the carcinogenic action of another agent. Use Symbol 271 only with Symbol 8 coded in Field T-1 with Symbol 43 or 47 coded in Field T-2 (or, if a virus is the cause of the neoplasm, Symbol 1 coded in Field T-1 with Symbol 43 or 47 coded in Field T-2).

272 Carcinostatic: a compound that temporarily or permanently slows or halts the growth of a tumor, but does not cause its regression. Use Symbol 272 when Symbol 44, 46, or 47 of Field T-2 is coded with Symbol 2 of Fleld T-1; also, when Symbol 44 or 46 of Field T- 2 is coded with Symbol 3 of Field T-I; and when Symbol 43 or 47 of Field T-2 is coded with Symbol 9 of Field T-1. Do not use Symbol 272 for compounds that cause a tumor to regress. Carcinoclastic: a compound that produces a lasting destructive effect on a tumor as judged by regression (degeneration) attributable to the action of the test compound. Use Symbol 273 only when Field T-2 is coded with Symbol 45 and Field T-1 is coded with Symbol 1 or 7 (or when Field T-2 is coded with symbols of the 418 - series and this degeneration coded in Field $\mathrm{T}-2$ refers to the tumor coded in Field $\mathrm{E}$ ).

\section{Series 3--}

Categories of agents candidate for practical use in affecting growth and development and physiological processes of plants. (For control of plant populations, see symbols of series 1--, Symbols 104, 107, and 108.)

301 Plant growth-affecting agent; stimulant or depressant of plant growth. Use Symbol 301 in Field T-3 when any of the following specific processes or qualities (Field T-2) are increased or decreased above or below the normal (Symbol 1 or 2 of Field T-1):

Field T-2 symbols, inclusive

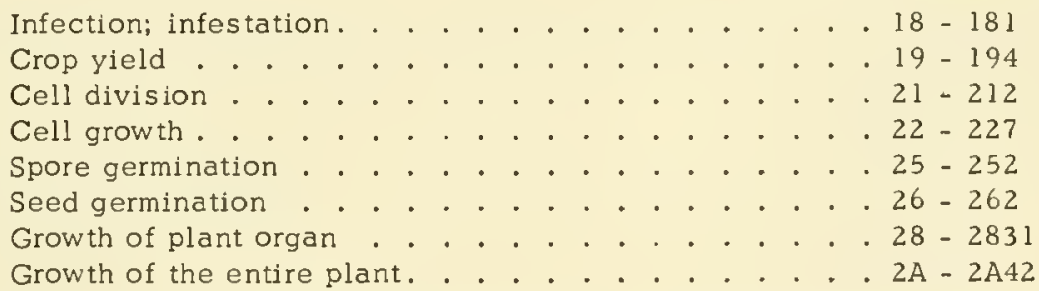

Also use Symbol 301 for growth-influencing agents which are essential for (Symbol 7 of Field $\mathrm{T}-1$ ) or decrease or prevent (Symbol 2 or 3 of Field $\mathrm{T}-1$ ) any of the following specific processes or qualities (Field T-2):

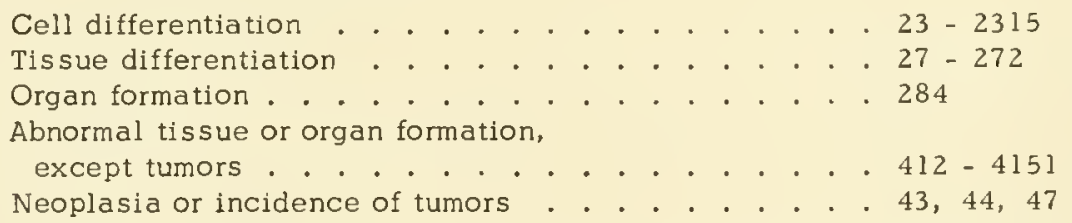

302 Maturation agent. Use Symbol 302 for agents which promote, decrease, or prevent (Symbol l, 2 , or 3 of Field T-1) any of the following specific processes of Field T-2. (For agents affecting flower formation or formation of any other specific organ's development and maturation, use Symbol 301; for agents affecting reproductive maturation of the organism, use Symbol 305.)

Field T-2 symbols, inclusive

Ripening, maturing process . . . . . . . . 2B

Aging symptoms . . . . . . . . . . . . . . 2C

Normal pigmentation and coloring as

indication of maturation . . . . . . . . . F824 and FA24 
303 Agents affecting normal distribution and translocation within plants. Use Symbol 303 for agents which promote, decrease, or prevent (Symbol I, 2, or 3 of Field T-1) any of the following processes or qualities of Field T-2:

Field T-2 symbols, inclusive

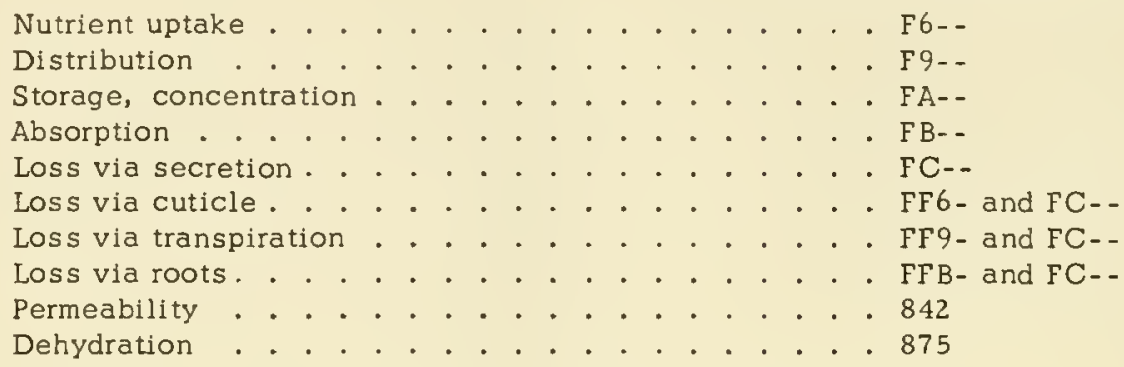

304 Agents affecting normal chemosynthesis by plants. Use Symbol 304 for agents which increase, decrease, or prevent (Field T- I, Symbol 1, 2, or 3) any of the following chemical processes of plants:

Field T-2 symbols, inclusive

Photosynthesis . . . . . . . . . . . . . . . . . . F7 - F72
Chemosynthesis . . . . . . . . . . . . . . . . . . F8-
Alteration . . . . . . . . . . . . . . . . . . FE - FEI

305 Agents affecting reproductive processes of plants. Use Symbol 305 for agents which increase, decrease, or prevent (Symbols 1, 2, or 3 of Field T-1) any of the following Field T-2 reproductive functions:

Field T-2 symbols, inclusive

Reproductive activities.............. Al - AA4 


\section{MISCELLANEOUS TIME VALUES}

\section{A. Duration of response}

(time after response begins)

1. Duration of response

2. Duration of delay of death

(alteration of survival time)

B. Duration of the period

3. Time to response:

preceding response

3a. Time to any response other than death

3b. Time to death (killing time)

C. Duration of a compound's ability to produce response

\section{Persistence of the activity of a} residue of the test compound

Place the Symbol * in Column 66 when the data deal with persistence of activity of a residue of the test compound.

\begin{tabular}{|c|c|c|c|}
\hline & 1 & & $<0.5$ secon \\
\hline & 2 & 0.5 thru & 1. \\
\hline & 3 & $>1$. thru & 2. \\
\hline & 4 & $>2$. thru & 4. \\
\hline Scale I & 5 & $>4$. thru & 8. \\
\hline & 6 & $>8$. thru & 16. \\
\hline & 7 & $>16$. thru & 32. \\
\hline & $\begin{array}{l}8 \\
9\end{array}$ & $\begin{array}{l}>32 . \\
>64 .\end{array}$ & 64. \\
\hline & 1 & & $<2$ seconds \\
\hline & 2 & 2 thru & 4 \\
\hline & 3 & $>4$ thru & 8 \\
\hline & 4 & $>8$ thru & 16 \\
\hline Scale 2 & 5 & $>16$ thru & 32 \\
\hline & 6 & $>32$ thru & 64 \\
\hline & 7 & $>64$ thru & 140 seconds \\
\hline & 8 & $>140$ thru & 5 minutes \\
\hline & 9 & $>5$ minute & \\
\hline & 1 & & $<16$ seconds \\
\hline & 2 & 16 thru & 32 \\
\hline & 3 & $>32$ thru & 64 \\
\hline & 4 & $>64$ thru & I 40 seconds \\
\hline Scale 3 & 5 & $>140$ thru & 5 minutes \\
\hline & 6 & $>5$ thru & 10 \\
\hline & 7 & $>10$ thru & 20 \\
\hline & 8 & $>20$ thru & 45 \\
\hline & 9 & $>45$ minutes & \\
\hline
\end{tabular}

\begin{tabular}{|c|c|c|c|}
\hline & 1 & & $<64$ seconds \\
\hline & 2 & 64 thru & 140 seconds \\
\hline & 3 & 140 thru & 5 minutes \\
\hline & 4 & $>5$ thru & 10 \\
\hline Scale 4 & 5 & $>10$ thru & 20 \\
\hline & 6 & $>20$ thru & 45 \\
\hline & 7 & $>45$ thru & 90 \\
\hline & 8 & $>90$ thru & 3 hours \\
\hline & 9 & $>3$ hours & \\
\hline & 1 & & $<10$ minutes \\
\hline & 2 & 10 thru & 20 \\
\hline & 3 & $>20$ thru & 45 \\
\hline & 4 & $>45$ thru & 90 minutes \\
\hline Scale 5 & 5 & $>90$ thru & 3 hours \\
\hline & 6 & $>3$ thru & 6 \\
\hline & 7 & $>6$ thru & 12 \\
\hline & 8 & $>12$ thru & 24 \\
\hline & 9 & $>24$ hours & \\
\hline & 1 & & $<45$ minutes \\
\hline & 2 & 45 thru & 90 minutes \\
\hline & 3 & $>90$ thru & 3 hours \\
\hline & 4 & $>3$ thru & 6 \\
\hline Scale 6 & 5 & $>6$ thru & 12 \\
\hline & 6 & $>12$ thru & 24 \\
\hline & 7 & $>24$ thru & 48 \\
\hline & 8 & $>2$ thru & 4 days \\
\hline & 9 & $>4$ days & \\
\hline
\end{tabular}




\section{MISCELLANEOUS TIME VALUES}

(Continued)

\begin{tabular}{|c|c|c|c|}
\hline & 1 & & $<6$ hours \\
\hline & 2 & 6 thru & 12 \\
\hline & 3 & $>12$ thru & 24 \\
\hline & 4 & $>24$ thru & 48 \\
\hline Scale 7 & 5 & $>2$ thru & 4 days \\
\hline & 6 & $>4$ thru & 8 \\
\hline & 7 & $>8$ thru & 16 \\
\hline & 8 & $>16$ thru & 32 \\
\hline & 9 & $>32$ days & \\
\hline & 1 & & $<24$ hours \\
\hline & 2 & 24 thru & 2 days \\
\hline & 3 & $>2$ thru & 4 days \\
\hline & 4 & $>4$ thru & 8 \\
\hline Scale 8 & 5 & $>8$ thru & 16 \\
\hline & 6 & $>16$ thru & 32 \\
\hline & 7 & $>32$ thru & 2 months \\
\hline & 8 & $>2$ thru & 4 months \\
\hline & 9 & $>4$ months & \\
\hline
\end{tabular}

$\begin{array}{crrr} & 1 & & <8 \text { days } \\ & 2 & 8 \text { thru } & 16 \\ & 3 & >16 \text { thru } & 32 \text { days } \\ \text { Scale } 9 & 4 & >32 \text { thru } & 2 \text { months } \\ & 5 & >2 \text { thru } & 4 \\ & 6 & >4 \text { thru } & 8 \\ & 7 & >8 \text { thru } & 16 \\ & 8>16 \text { thru } & 32 \\ & 9 & >32 \text { months }\end{array}$




\section{TIME TO EVALUATION}

\section{Group 1}

$\begin{array}{cccc}1 & & & <0.5 \text { seconds } \\ 2 & 0.5 & \text { thru } & 1 \\ 3 & >1 & \text { thru } & 2 \\ 4 & >2 & \text { thru } & 4 \\ 5 & >4 & \text { thru } & 8 \\ 6 & >8 & \text { thru } & 16 \\ 7 & >16 & \text { thru } & 32 \\ 8 & >32 & \text { thru } & 64 \\ 9 & >64 & \text { thru } & 120 \text { seconds }\end{array}$

\section{Group 2}

$\begin{array}{lrll}A & >2 & \text { thru } & 5 \text { minutes } \\ \mathrm{B} & >5 & \text { thru } & 10 \\ \mathrm{C}>10 & \text { thru } & 20 \\ \mathrm{D}>20 & \text { thru } & 45 \\ \mathrm{E}>45 & \text { thru } & 90 \text { minutes } \\ \mathrm{F}>90 & \text { thru } & 3 \text { hours } \\ \mathrm{G}>3 & \text { thru } & 6 \\ \mathrm{H} & >6 & \text { thru } & 12 \\ \mathrm{I}>12 & \text { thru } & 24 \text { hours }\end{array}$

\section{Group 3}

$\begin{array}{lrll}\mathrm{J} & >1 & \text { thru } & 2 \text { days } \\ \mathrm{K} & >2 & \text { thru } & 4 \\ \mathrm{~L} & >4 & \text { thru } & 8 \\ \mathrm{M} & >8 & \text { thru } & 16 \\ \mathrm{~N} & >16 & \text { thru } & 31 \text { days } \\ \varnothing & >1 & \text { thru } & 2 \text { months } \\ \mathrm{P} & >2 & \text { thru } & 4 \\ \mathrm{Q} & >4 & \text { thru } & 8 \\ \mathrm{R} & >8 & \text { thru } & 16 \text { months }\end{array}$

\section{Group 4}

$\mathrm{S}>16$ thru $\begin{array}{r}32 \text { months } \\ \mathrm{T}\end{array} \quad 32$ months

Indefinite time expressions:

$\begin{array}{ll}\text { U } & \text { Several seconds } \\ \text { V } & \text { Several minutes } \\ \text { W } & \text { Several hours } \\ \mathrm{X} & \text { Several days } \\ \mathrm{Y} & \text { Several months } \\ \mathrm{Z} & \text { Immediately after treatment } \\ & \text { (no quantitative time } \\ & \text { measure given) }\end{array}$




\title{
A. QUALIFICATION OF THE NEGATIVE AND POSITIVE CHARACTER OF TEST RESULTS AND QUALIFICATION OF THE CODED DOSE
}

\section{B. INFORMATION ABOUT SLOPE OF THE DOSAGE-RESPONSE CURVE}

\author{
Introduction to Field $W$ \\ Symbols J through $Q$ and *
}

A. The basic objective of the symbols of Field W, with the exception of Symbol *, is to classify the character of the negative or positive biological response (whose quantitative measure or evaluation is coded in Field $Y$ according to a criterion coded in Field $X$ ) and of the dose (coded in Fields $M$, $N$, $O$, and $\mathrm{P}$ ) according to whether the test coded demonstrated:

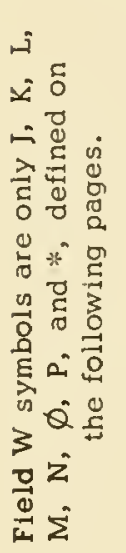

(1) Inability of the test compound to produce the response when administered to the test organism at any level below a toxic level or below any level impractical to administer: Symbol K (Symbol J indicates that the test did not prove the test compound was unable to produce the response even though the response did not occur at the dose administered);

(2) The maximum intensity of test organism response which the test compound is capable of inducing; Symbol $M, N$, or $\varnothing$ (Symbols $L$ and $P$ indicate that the test did not prove that the intensity of response was maximal, since a dose larger than the largest tested might cause a higher response intensity);

(3) The minimum dose of test compound needed for the intensity of response produced in the test organism, whether or not it is the maximum intensity of which the compound is capable: Symbol P (if the intensity of response is threshold intensity or any intensity below maximum intensity or if the intensity is not known to be maximum intensity) or Symbol $\varnothing$ (if the intensity of response is known to be maximal). (Symbols $\mathrm{L}, \mathrm{M}$, and $\mathrm{N}$ indicate that the test did not prove that the coded dose was the minimal needed.)

The classification will be seen to be dependent at certain points (Symbols J, K, L, and M) on whether information is known about the toxic character of the chemical tested and the limitations placed on the chemical's application by that character. Whether the test compound has such limitations can ordinarily be determined only by having performed, prior to or contemporary with the test being coded, one or more other tests at different dose levels, the limiting toxic effect being revealed by one of the higher dose levels in one of the tests. Thus, incidentally, Field W conveys further information about the character of the dose coded in Flelds $\mathrm{M}, \mathrm{N}, \mathrm{O}$, and $\mathrm{P}$ as follows:

(4) The dose coded in Fields $\mathrm{M}, \mathrm{N}, \mathrm{O}$, and $\mathrm{P}$ is known to be the maximum tolerated or (if the test compound causes no toxic effect at any dose) the largest dose that can be administered, for any reason other than toxicity and limitation of availability: Symbol $\mathrm{K}$ or $\mathrm{M}$ and (only if Symbol $2 \mathrm{l}$ is in Field X) Symbol $\varnothing$ or $\mathrm{P}$; the use of Symbol $\mathrm{N}$ or $\varnothing$ implies that the coded dose is known not to be the MTD, except when Symbol 21 is in Fleld X with Symbol $\varnothing$ in Field W; (Symbol J, L, or P: the coded dose is not known either to be or not to be the MTD, unless Symbol 21 is in Field $X$ with Symbol $P$ in Fleld W).

For sake of clarity, the definition for each of Symbols J through $Q$ is presented as a set of brief statements, the statements collectively setting forth the concitions under which the symbol is used and the impllcations made by it. The definition and use of each of the symbols are discussed in more detail in the Key section on General Use of Fields W, X, and Y.

B. One Field $W$ symbol is also provided to be used when the data (of a journal article, laboratory report, etc.) include information on the slope of the dosage-response curve. This symbol (Symbol *) does not itself code information about the curve, but is only a key to the fact that the information exists with the data. The written abstract on the Code Sheet must be consulted to find the information or reference must be made to the orlginal data. 


\section{A. QUALIFICATION OF THE NEGATIVE AND POSITIVE CHARACTER OF TEST RESULTS AND QUALIFICATION OF THE CODED DOSE}

\section{B. INFORMATION ABOUT SLOPE OF THE DOSAGE-RESPONSE CURVE}

\section{Negative Response}

The following two symbols, $\mathrm{J}$ and $\mathrm{K}$, are used only when the response coded in Field $\mathrm{T}$ has not been produced by the test compound. Thus, when these symbols are used, Field X must be coded with Criterion 01, 02, or 62 and Field $Y$ must be coded with Symbol 1. With any other coding in Fields $X$ and $Y$, only Symbol L, M, N, $\varnothing$, or P can be used in Field W.

J The response does not occur at the coded dose. (When the response is "death", refer to the final statement in parentheses, below.)

The maximum tolerated dose level has not been determined; the coded dose is not known to be the MTD.

The dose administered (the coded dose) has not been determined to be the largest dose that could be administered.

The compound is not demonstrated to be inactive below the toxic level (or other level) that prohibits administration of larger doses.

(If "death" is coded in Field T-2 and is not caused by any doses administered, use Symbol J if it seems that administration of a larger dose is possible and therefore death at a larger dose might be possible. I. e., use Symbol J only if it seems not to have been demonstrated that the test compound could not cause death. When Criterion 21 , maximum tolerated dose, is used in Field $X$, the dose coded is the dose not causing the toxic effect or death coded in Field T-2, for which reason there may be temptation to use Symbol J [or K] in Field W; do not use Symbol J [or K] when Criterion 21 is used, but use only Symbol $\varnothing$ [or P] to indicate that the toxic effect or death has been demonstrated even though the dose coded is just below the threshold dose. )

K The response does not occur at the coded dose. (When the response is "death", refer to the final statement in parentheses, below.)

The maximum tolerated dose level has been determined; the coded dose is known to be the MTD.

The dose administered (the coded dose) is demonstrated to be the largest that can be administered, for reasons of associated toxicity, e. g.

The compound is demonstrated to be inactive below the toxic level (or other level) that prohibits administration of larger doses.

(If "death" is coded in Field T-2 and is not caused by any doses administered, use Symbol K if it seems that administration of a larger dose is impractical or even impossible. I. e., use Symbol $K$ only if it seems to have been demonstrated that the test compound could not cause "death" under conditions of the test. When Criterion 21 , maximum tolerated dose, is used in Field $X$, do not use Symbol $\mathrm{K}$ in Field $W$, for reasons explained in the definition for Symbol J.) 


\section{Positive Response}

The following five symbols, L, M, N, $\varnothing$, and $P$, are used only when the response coded in Field $T$ has been positively produced by the test compound. Thus, when one of these symbols is used in Field W, Field X must not be coded with Criterion 01, 02, or 62 with Symbol 1 in Field Y. With the latter coding in Fields $X$ and $Y$, only Symbol J or $K$ or possibly $Q$ can be used in Field $W$.

I Only one dose level has been tested (the coded dose). (When the response is "death", refer to the final statements in parentheses, below.)

The maximum tolerated dose level has not been determined; the coded dose is not known to be the MTD.

The response intensity has not been demonstrated to be the maximum intensity of which the compound is capable.

The dose tested has not been demonstrated to be the minimum dose needed to cause the response intensity produced.

(When "death" [coded in Field T-2] is the response to the single dose level tested, Symbol L can not be used in Field W, unless [1] the single test dose level has been applied to a population, [2] the percent kill is less than $100 \%$, and [3] the dose level is not, or is not known to be, the largest dose practical or possible to administer; if the dose level is known to be the largest dose practical or possible to administer and response is less than $100 \%$ kill, use Symbol M. When death is produced in the individual organism, when only a single organism is treated, or in $100 \%$ of the organisms of a population treated, when only a single dose level is tested [i.e., the dose is not demonstrated to be the minimum needed], use Symbol M. )

M Only one dose level has been tested (the coded dose), but it is known from previous tests to be the maximum tolerated dose. (When the response is "death", refer to the final statements in parentheses, below.)

Because the dose administered is the MTD, the response intensity is the maximum possible, even though it is not known whether, barring its associated toxicity, the compound would not produce greater response with a larger dose.

The coded dose has not been demonstrated to be the minimal needed to cause the response intensity produced in the test being coded.

(When "death" [coded in Field T-2] is the response to the single dose level tested, Symbol M is used whether or not the dose level tested is known to be the largest dose that can be administered--if the death has been caused in a test using a single individual or if the death occurs in $100 \%$ of a population treated. However, if application is to a population and "death" [coded in Field T-2] occurs in less than $100 \%$ of the population, Symbol M is used only if the test compound was applied at the dose level known to be the largest practical or possible to administer; if this is not known or 1 s known not to be the case, Symbol L must be used for less-than-100\% kill.)

N Two or more tests have been performed, each with a different dose level. (When the response is "death", refer to the final statements in parentheses, below.)

All those doses tested have produced the response and at the same intensity.

Because all doses tested produce the same response intensity, the response intensity of the test being coded is maximal (barring a complex dosage-response curve which rises after a plateau on which the tested doses have fallen).

The dose administered (the coded dose) is not demonstrated to be the minimum needed to cause the response intensity produced. 
(If "death" [of the individual or of a percentage of a population] is the response for which the minimum dose needed has not been demonstrated [demonstrated by ali of the two or more dose levels tested having caused death to the individual or caused death to the same percentage of a treated population], Symbol $\mathrm{N}$ is used in Field W, with some criterion other than Criterion 20 or 21 in Field X.)

$\varnothing$ Three or more tests have been performed, each with a different dose level. (When the response is "death", refer to the final statement in parentheses, below.)

Two or more of the doses tested produce the same intensity of response and one or more of the doses tested produce a lower intensity of response.

The maximum intensity of response of which the test compound is capable has been demonstrated (the intensity on which the coded evaluation is based).

The minimum dose needed to cause the maximum intensity of response has been demonstrated (the coded dose). Do not use Symbol $\varnothing$ when Criterion 20 is used in Field $x$, unless "death" (or other "all-or-none" response) is coded in Field T-2, as explained below.

(If "death" [of the individual or of a percentage of a population] is the response for which the minimum dose needed has been demonstrated [demonstrated by one of the doses administered not having caused death to the individual or not having caused any deaths when the next larger dose (the threshold dose) causes $100 \%$ kill in a treated population], Symbol $\varnothing$ is used in Field $W$ and Criterion 20 or 21 may be used in Field $X$. If maximum response is $100 \% \mathrm{kill}$ and the minimum dose for causing $100 \% \mathrm{kill}$ is demonstrated, yet the threshold dose causes less than $100 \%$ kill, use of Criterion 20 or 21 demands a coded dose smaller than the minimum dose needed to cause maximum response and Symbol $\varnothing$ can not be used in Field W, but only Symbol P.)

$\mathrm{P}$ Two or more tests have been performed, each with a different dose level. (When the response is "death", refer to the final statement in parentheses, below.)

All of the doses tested produce different response intensities (the larger the dose, the greater the response intensity).

The maximum response intensity of which the test compound is capable has not been demonstrated; the intensity produced by the largest dose tested (the intensity on which code evaluation is based) may or may not be the maximum intensity which the test compound is capable of producing.

For each intensity produced in any of the tests, the dose producing it is the minimum needed (i. e., for the test being coded, a reasonable relationship exists between the dose coded and the response intensity produced). When the threshold dose has been demonstrated and Symbol 20 is used in Field X, Symbol P must be used in Field W except under special conditions when "death" is coded in Field T-2, as explained in the final statements defining the use of Symbol $\varnothing$.

(When "death" is coded in Field T-2 and administration is to a population and each dosage level administered causes a different percentage kill, symbol $\bar{P}$ is used in Field $W$ and some criterion other than Criterion 20 or 21 must be used in Field X. [See the final statements below for the situation in which the threshold percentage kill by any dose administered to a population is determined, when Symbol P is used with Criterion 20 or 21. ] "Death" to a single treated individual or "death" to $10 \overline{0 \%}$ of a treated population represent non-variable response intensities [they must either occur as totalities or do not occur at all, at any dose] and Symbol P can not be used to apply to them; use only Symbol $\mathrm{N}$ or $\varnothing$ [or Symbol $\mathrm{M}$, if the compound is tested at only one dose level, or Symbol J or K, if death did not occur]. Symbol $P$ is used when Criterion 20 is coded in Field $X$ and the response for which the dosage coded and shown by the test to be the threshold quantity is not death; Symbol $\mathrm{P}$ is used with Criterion 20 or 21 when the response is "death" but only when application of the chemical has been to a population, the threshold response is shown to be less than $100 \% \mathrm{kill}$, and increasingly larger doses cause increasingly greater percentages of kill, meaning that the coded dose is not the minimum causing the maximum response [for which Symbol $\varnothing$ is used], 
but is the dose causing minimum response [minimum kill, Criterion 20 with Symbol P] or the dose just lower than the dose causing any deaths [MTD, Criterion 21 with Symbol P]. Finally, Symbol $\mathrm{P}$ is used when Criterion 21 is used to evaluate a test compound on the basis of the dose level just below the threshold dose causing a toxic response other than "death" [regarding MTD as the maximum dose tolerated without causing non-lethal toxic effects, as well as without causing death, prohibiting its use]. )

\section{Questionable Response}

Q The occurrence or non-occurrence of the response coded in Field $\mathrm{T}$ (non-toxic response, non-lethal toxic response, or death), as reported by the author, is questionable, due to limiting factors of the test method and observation. This symbol should be used only rarely and ordinarily only when the author has expressed doubts and reasons for the doubts as to whether the evidence is valid for the response being positive or negative.

Second use of Field W:

Information about Slope of the

Dosage-response Curve

* Information about the slope of the dosage-response curve is included with the original data. Reference to the Code Sheet should be made for this information. (When coding Symbol* in Field W, the written abstract of the field should include the information about the slope, as defined and discussed in the Key.) 
FIELD X: THE CRITERION FOR EVALUATION OF THE TEST COMPOUND'S BIOLOGICAL ACTIVITY

FIELD Y: THE EVALUATION OF THE TEST COMPOUND'S BIOLOGICAL ACTIVITY (RELATIVE TO THE SPECIFIC BIOLOGICAL RESPONSE)

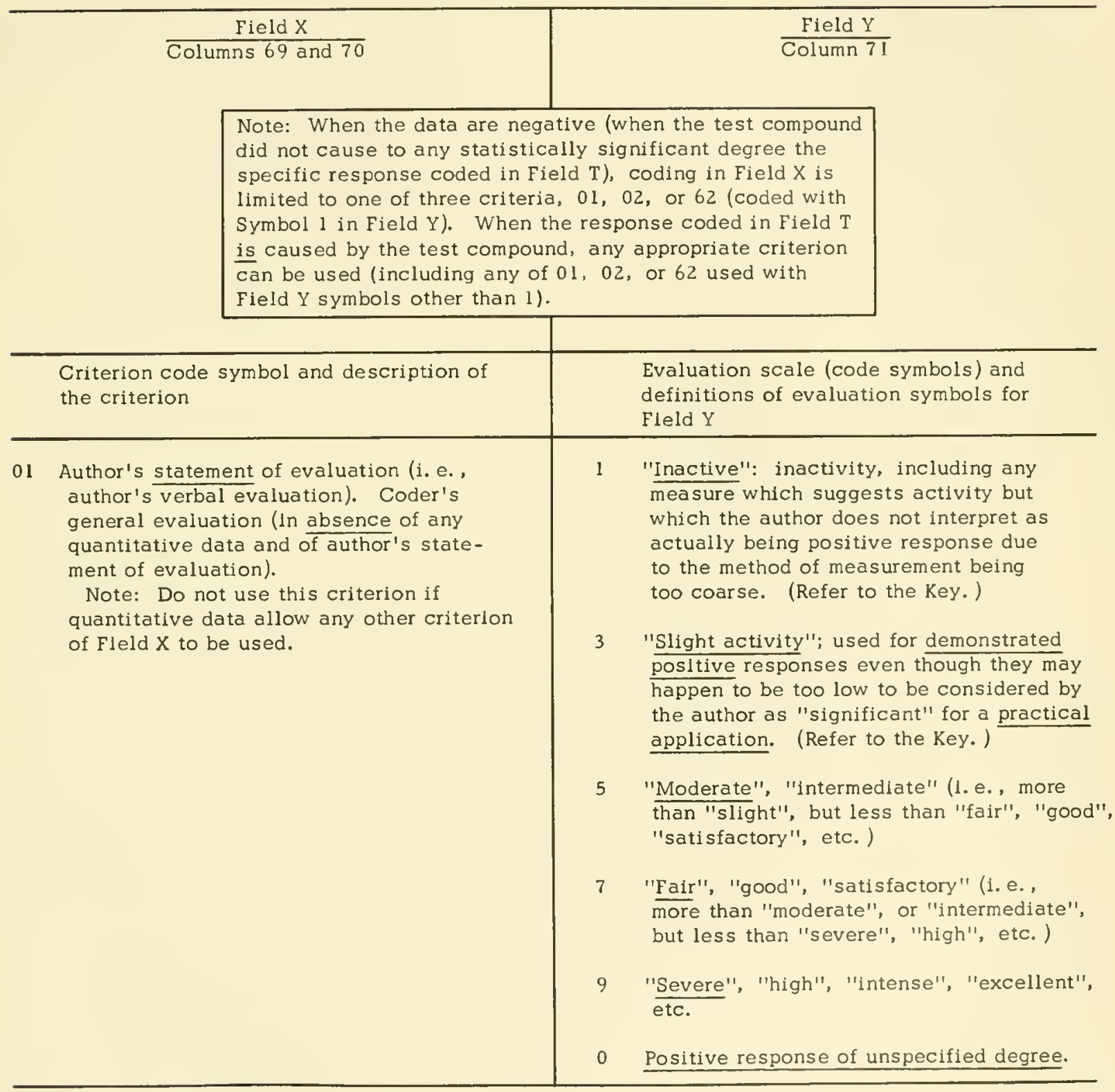


FIELD Y

Column 71

Field X

Field $Y$

02 Author's scoring system. (Two samples of such scoring schemes are shown, with the author's scoring units assigned code symbols. )

- or-

Evaluation according to an author's statement of an estimate expressed in terms of percentage of maximum response. (E. g. , "about half", "approximately a third", "nearly all", "in the neighborhood of $25 \%$ ", etc.)

Note: When an exact measure or count is made, providing a precise percentage expression, use Criterion 62 .

03 The degree of biological response caused by the test compound--compared to the degree of biological response caused by a specific standard compound, when the test compound is administered (in the test being evaluated) in the same quantity as was the standard compound (tested separately).

Note: The standard compound must be named and coded in Field D and Symbol * must be coded in Column 17 of Field D.

\footnotetext{
Degree of response to the

Ratio: test compound

Degree of response to the standard compound
}

$1<.05$ thru. 05 (1/20 of the biological response made to the standard compound, or less)

$3>.05$ thru $0.5(>1 / 20$ thru $1 / 2)$

$5>0.5$ thru $5(>1 / 2$ thru 5 times the biological response made to the standard compound)

$7>5.0$ thru 50 (>5 times thru 50 times)

$9>50 \quad$ (>50 times)

When the data are not sufficiently quantitative to permit the calculation of the values of the scale above, but only general verbal comparisons are made, use the following scale:

4 The biological response to the test compound was less than to an equal quantity of the standard compound.

5 The biological response to the test compound was equal to the response to an equal quantity of the standard compound.

6 The biological response to the test compound was greater than to an equal quantity of the standard compound. 
04 The quantity (preferably minimum) of test compound needed to cause the same degree of response as a standard compound --compared to the quantity (preferably minimum) of standard compound causing that degree of response.

Note: The standard compound must be named and coded in Field D and Symbol * must be coded in Column 17 of Field D.

Ratio:

Dosage of standard compound causing "X" degree of response

Dosage of test compound causing " $X$ " degree of response
$1<.05$ thru. 05 (20 times more, or more than 20 times more, test compound than standard compound is needed to cause the same degree of response as the standard compound)

$3>.05$ thru 0.5 (<20 thru 2 times more test compound than standard compound)

$5>0.5$ thru $5.0(<2$ times as much thru $1 / 5$ as much test compound as standard compound)

$7>5.0$ thru $50(<1 / 5$ thru $1 / 50$ as much test compound as standard compound)

$9>50$ ( $<1 / 50$ as much test compound as standard compound)

When the data are not sufficiently quantitative to permit the calculation of the values of the scale above, but only verbal comparisons are made, use the following scale:

4 A quantity of test compound greater than the quantity of standard compound is required to cause a given intensity of biological response.

5 A quantity of test compound equal to the quantity of standard compound will cause the same intensity of biological response as the standard compound.

6 A quantity of test compound smaller than the quantity of standard compound is adequate to cause a glven intensity of biological response. 
FIELD X

Columns 69 and 70

FIELD $Y$

Column 71

10 Time to specific action other than death. (Killing time as a criterion is coded with Symbol 11 as defined below.) Speed with which the test compound produces the specific action. Time from beginning of administration of the test compound to the first appearance of the response.

i1 Killing time. Speed with which the test compound kills. Time from the beginning of administration of the test compound to the death of the organism.

12 Alteration of survival time. The test compound's increase or decrease of the time taken by some lethal factor (other than the test compound, e.g. , a pathogen, poison, or radiation) to kill the test organism.

13 Duration of action. The length of time over which the test compound causes the specific response in the test organism.
Criteria 10 and 11 only:

In the case of these two criteria, the brevity of the time periods (Field U, Symbols 1, 2, and 3, e.g:) is a measure of the test compound's ability to cause the response. I. e., the shorter the time period, the greater is the test compound's activity.

Therefore, transfer the reciprocal of the symbol coded in Field U (Column 66) to Field Y.

If Column 66 is coded with Symbol: - -code Field Y with Symbol:

\begin{tabular}{ll}
1 & 9 \\
2 & 8 \\
3 & 7 \\
4 & 6 \\
5 & 5 \\
6 & 4 \\
7 & 3 \\
8 & 2 \\
9 & 1 \\
\hline
\end{tabular}

Criteria 12 and 13 only:

In the case of these two criteria, the longer the time period (Field $U$, Symbols 9, 8, 7, e.g.) the greater is the test compound's activity indicated to be.

Therefore, transfer the symbol coded in Column 66 of Field $U$ to Field $Y$ as the measure of the compound's comparative intensity of activity. 
FIELD X

Columns 69 and 70

FIELD Y

Column 71

Field $X$

14 Therapeutic index:

Minimum fatal dose Minimum curative dose
Field $Y$

$$
\begin{aligned}
& 1<4 \text { thru } 4 \\
& 3 \quad>4 \text { thru } 16 \\
& 5>16 \text { thru } 64 \\
& 7>64 \text { thru } 256 \\
& 9>256
\end{aligned}
$$

$1>0.25$

Minimum curative dose Minimum tolerated dose

$3>0.03$ thru 0.25

$5>0.0035$ thru 0.03

$7>0.0004$ thru 0.0035

$9<0.0004$ thru 0.0004

16 Chemotherapeutic index:

Dose killing $50 \%$ of individuals to which it is administered Dose therapeutically effective (to a given degree, curative or otherwise) in 50\% of individuals to which it is administered

$$
\frac{\mathrm{LD}_{50}}{\mathrm{ED}_{50}}
$$

l $<4$ thru 4

$3>4$ thru 16

$5>16$ thru 64

$7>64$ thru 256

$9>256$

17 Repellency index:

Note: This is a special criterion used for coding tests on rats only. The index and its description are included in the Key.
$1<80$ thru 80

$3>80$ thru 87

$5>87$ thru 91

$7>91$ thru 96

$9>96$ thru 100

18 Tolerance increase ("tolerance production" or "sensitivity decrease"):

Final tolerated dose (or, preferably,

Ratio: final maximum tolerated dose) Intial maximum tolerated dose

Tolerance increase is indicated only when the above ratio value is more than 1.0 .

$\begin{array}{lrr}1 & >1.0 \text { thru } & 1.5 \\ 2 & >1.5 \text { thru } & 2.0 \\ 3 & >2.0 \text { thru } & 5.0 \\ 4 & >5.0 \text { thru } 10.0 \\ 5 & >10.0 \text { thru } & 25.0 \\ 6 & >25.0 \text { thru } & 50.0 \\ 7 & >50.0 \text { thru } 75.0 \\ 8 & >75.0 \text { thru } 100.0 \\ 9 & >100.0\end{array}$

$3>2.0$ thru 5.0

$4>5.0$ thru 10.0

$5>10.0$ thru 25.0

$6>25.0$ thru 50.0

$7>50.0$ thru 75.0

$9>100.0$ 
FIELD X

Columns 69 and 70

FIELD Y

$\overline{\text { Column } 71}$

Field X

Field $Y$

19 Sensltivity production ("sensitivity increase" or "tolerance decrease"):

Final dose not producing the toxic

Ratio: $\frac{\text { symptom }}{\text { Initial maximum dose not producing }}$ the toxic symptom

- or-

Final threshold dose producing the

$\frac{\text { toxic symptom }}{\text { Initial threshold dose producing the }}$

Ratio: toxic symptom

Sensitivity production is indicated only when the above ratio value is less than 1. 0 .

20 Threshold dose size. Minimum effective dose size. Evaluations according to:

(a) threshold concentration, Field $\mathrm{M}$, or

(b) threshold quantity, Field $\mathrm{N}$, or (c) threshold duration of administration,

Field P.

Note: If the data reveal the variatlon in and distribution of the threshold of response in a group of individuals (i. e., several threshold doses and the percentage of organisms showing threshold response with each), use Criterlon 5I, 52, or 53.

When Criterion 20 is used, only Symbol P or, when "death" is coded In Fleld T-2 (and then only under certain circumstances), Symbol $\varnothing$ is coded in Fleld $W$. Consult the Code definltions and instructions for Symbols $\varnothing$ and P of Fleld W.

The smaller the quantity of test compound needed to cause a given intensity of response (threshold response, in this case), the greater is the potency of the test compound. Therefore, code Field Y with the reciprocal of the symbol coding the dose (Column 46 of Field $M$ or Column 48 of Field $\mathrm{N}$ or Column $5 \mathrm{I}$ of Field P).

If Column 46 (or $48 \quad$--code Field $Y$ or 5 I) is coded with: with Symbol: 
21 Maximum tolerated dose (abbreviation: MTD).

Most frequently this is understood to be the greatest quantity that can be adminlstered without causing death (Field T-2, Symbol 11, 111, or 112) of the test organism; i. e., the dose just smaller than the minimum lethal dose. (Consult the Key's discussion of Criterlon 21.)

The maximum tolerated dose (coded in the dosage fields, $M, N$, and $P$ ) can be more specifically defined as: (a) maximum tolerated concentration, Field $M$, (b) maximum tolerated quantity, Field $N$, (c) maximum tolerated duration of administration, Field P.

Note: If, in a group of individuals, test data demonstrate the variation in and dis tribution of the individuals' maximum tolerances for the test compound (i.e. , several MTD levels for each of which is determined the percentage of individuals for which it represents the MTD), use Criterion 51, 52, or 53.

When Criterion 21 is used, only Symbol P or, when "death" is coded in Field T-2 (and then only under certain circumstances), Symbol $\varnothing$ is used in Field W. Consult the Code definitions and instructions for Symbols $\phi$ and P of Field W.

22 Antagonism of the biological action of a secondary compound. In other words, dosage of the test compound needed to prevent the test organism's demonstrated response to the secondary compound alone, when both compounds are adminlstered together.

Note: Evaluation by Criterion 22 of a test compound's ability as an antagonist of the specific action of a given secondary compound is not modified by the degree of antagonism (i.e., partial reduction of the response to the secondary compound). Criterion 22 should be used only when antagonism of the secondary compound's action has been totally prevented $100 \%$ reduction of response to the secondary compound).

If, In a group of individuals, the data reveal the varlation and distribution of antagonism ratio (see the evaluation of antagonism, Field Y), use Criterion 55.
The greater the quantity of test compound tolerated, the greater is the test compound's rating as a safe therapeutic agent. Therefore, code Field $Y$ with the same symbol coding the dose (Column 46 of Field M, Column 48 of Field N, or Column 51 of Field P).

If Column 46 (or $48 \quad$--code Field $Y$ or 51) is coded with: with Symbol:

$\begin{array}{ll}1 & 1 \\ 2 & 2 \\ 3 & 3 \\ 4 & 4 \\ 5 & 5 \\ 6 & 6 \\ 7 & 7 \\ 8 & 8 \\ 9 & 9\end{array}$

Evaluation of antagonism with Criterion 22 is on the basis of the amount of secondary compound antagonized per unit of test compound. The greater the amount of secondary compound antagonized per unit quantity of test compound, the greater is the test compound's potency for antagonizing the action of that secondary compound.

Amount of secondary compound whose effect is antagonized

Ratio: $100 \%$ (1.e. , prevented)

Minlmum amount of test compound (antagonist) needed to antagonize the secondary compound's effect $100 \%$

The value from the calculation above is used to derive a code evaluation for Fleld $Y$ according to the following scale:

$$
\begin{aligned}
& 1<0.05 \text { thru } 0.05 \\
& 3>0.05 \text { thru } 0.5 \\
& 5>0.5 \text { thru } 5 \\
& 7>5 \text { thru } 50 \\
& 9>50
\end{aligned}
$$


FIELD $X$

Columns 69 and 70

FIELD Y

Column 71

30 Weight of the thyroid gland, expressed in terms of milligrams of thyroid gland per 100 grams of body weight.
The evaluation with Criterion 30 is based on the ability of the test compound to decrease the thyroid activity, as indicated by the gland's hypertrophy. Thus, the greater the gland's hypertrophy, the greater should be the test compound code evaluation.

$$
\begin{aligned}
& 1<8 \text { thru } 8 \\
& 3 \quad>8 \text { thru } 16 \\
& 5>16 \text { thru } 24 \\
& 7>24 \text { thru } 32 \\
& 9>32
\end{aligned}
$$

The evaluation with Criterion 31 is based on the ability of the test compound to decrease iodine in the thyroid. Therefore, the smaller the quantity of iodine in the gland, the more is the test compound's anti-thyroid ability.

$$
\begin{aligned}
& 1>40 \\
& 3>20 \text { thru } 40 \\
& 5>10 \text { thru } 20 \\
& 7>5 \text { thru } 10 \\
& 9<5 \text { thru } 5
\end{aligned}
$$

51 Concentration expressed in Field $M$ vs. cumulative percentage of individuals responding.

52 Quantity expressed in Field N vs. cumulative percentage of individuals responding.

53 Duration of administration expressed in Field P vs. cumulative percentage of organisms responding.
Consult the Key for the explanation of the use of the Grid and the use of these three criterla with which Field $Y$ is coded with one of five symbols:

$$
\begin{array}{lllll}
1 & 3 & 5 & 7 & 9
\end{array}
$$

These five symbols represent positive response from "low" (large dose and/or few individuals responding) to "high" (small dose and/or most or all individuals responding), regardless of the intensity of response in the individual (e.g., percentage increase of heart rate, percentage change of rate of development). Criteria 51,52 , and 53 are used mostly for evaluating the test compound's lethal activity on a group of individuals of the test organism. 
54 Duration of response (the time period coded in Field U) vs. the cumulative percentage of individuals in which the response endures the period coded in Field U.
With Criterion 54, the evaluation to be coded in Field $Y$ is based on the point at which the response has ended for any given percentage of individuals. (Study the example given in the Key, Specific Directions and Explanations for Fields W, $X$, and Y, Division 20.) Evaluation symbols: $1,3,5,7$, or 9 , according to the Grid area involved.
57 Survival time increase or survival time decrease (the time period coded in Field $U$, representing the time differential between the survival times of treated and untreated organisms) vs. the cumulative percentage of Individuals whose survival time was affected to the degree indicated in Field $U$.
With Criterion 57, evaluation is based on the cumulative percentage of individuals whose survival time has been increased (or decreased) a given period. (Study the example given in the Key, Specific Directions and Explanations for Fields W, $X$, and $Y$, Division 20.) Evaluation symbols: $1,3,5,7$, or 9 , according to the Grid area involved.

Note: In the case of Criteria 58 and 59, below, the symbol used in Column 66 of Field $U$ is used on the abscissa of the Grid. This is because a short time to the specific action represents a high level of chemical activity; for this same reason, when basing evaluation on the time alone (Criteria 10 and 11 ), the reciprocal of the symbol coded in Fleld $U$ is used in Field $Y$ as an evaluation.

58 Time to specific action other than death (the time period from beginning of administration to the first appearance of the response, coded in Field U), vs. the cumulative percentage of Individuals responding within the time period coded in Field U.
With Criterion 58, evaluation is based on the cumulative percentage of Individuals responding (other than by dying) after a given period of time. (Study the example given in the Key, Specific Directions and Explanations for Fields $W, X$, and $Y$, Division 20.) Evaluation symbols: 1, 3, 5, 7, or 9, according to the Grid area involved. 
FIELD Y

Column 71

59 Killing time (the time period from beginning of administration to the point of death. coded in Field U), vs. the cumulative percentage of individuals killed within the time perlod coded in Field $U$.
With Criterion 59, evaluation is based on the percentage of individuals killed after a given period of time. (Study the example given in the Key, Specific Directions and Explanations for Fields $W, X$, and $Y$, Division 20.) Evaluation symbols: 1, 3, 5, 7, or 9. according to the Grid area involved.

For Criterion 55, the two quantitative dosage values are related by the following ratio:

Minimum amount of test compound (antagonist) needed to antagonize the Ratio: secondary compound's action $100 \%$ secondary compound vs, the cumulative percentage of individuals in which that dosage causes antagonism.

Note: Evaluation by Criterion 55, of a test compound's ability as an antagonist of the specific action of a given secondary compound is not modified by the degree of antagonism (i.e., partial reduction of the response to the secondary compound). Criterion 55, as well as Criterion 22, should be used only when the secondary compound's action has been prevented $(100 \%$ reduction of the response to the secondary compound).

If antagonism is demonstrated only in an Individual (the test not demonstrating incidence of antagonism in a group of individ uals), use Criterion 22.
Grid abscissa segment

$\begin{array}{lll}1 & <0.05 \text { thru } 0.05 \\ 2 & >0.05 \text { thru } 0.15 \\ 3 & >0.15 \text { thru } 0.5 \\ 4 & >0.5 \text { thru } 1.5 \\ 5 & >1.5 \text { thru } 5 \\ 6 & >5 & \text { thru } 15 \\ 7 & >15 & \text { thru } 50 \\ 8 & >50 & \text { thru } 150 \\ 9 & >150 & \end{array}$

Each of the nine ranges above represents one of the nine equal segments of the scale of the abscissa of the Grid. The dosage ratio value should be located on the abscissa scale at the appropriate point within the range (i.e., within the abscissa scale segment) indicated in the table above.

Evaluation symbols: 1, 3, 5, 7, or 9, according to the Grld area involved. 
61 Degree of response greater than 100\%; intensity of response; percentage of response. Criterion 61 is used principally to evaluate on the basis of the degree (percentage) of increase of a pre-existing condition (i.e., percent increase of a normal physiological function or a pathologlcal state) in response to the test compound. The criterion is also used to evaluate synergistic responses, the percentage increase $(>100 \%)$ of response to a secondary compound due to the presence of (the action of) the test compound.
Use Criterion 61 only for evaluating the intensity of response in the organism and only when that response is over $100 \%$. For responses of $100 \%$ or under $100 \%$, use Criterion 62.

Code Field $Y$ according to the ranges of the following table:

Symbol for

Field $Y \quad$ Ranges of percentage responses

$>100 \%$ thru $400 \%$

5

$>400 \%$ thru $700 \%$

7

$>700 \%$ thru $1000 \%$

9

$>1000 \%$

Code Field $Y$ according to the ranges of the following table:

intensity of response; percentage of response. Criterion 62 is intended for evaluation on the basis of the degree (percentage) of increase (or decrease) of a pre-existing condition (a normal physiological function or a pathological state) in response to the test compound. The criterion is also used to evaluate synergistic responses, the percentage increase ( $0 \%$ through $100 \%$ ) of response to a secondary compound due to the presence of (the action of) the test compound.

In addition to using Criterion 62 for evaluating on the basis of degree of response of the organism, this criterion is used to record intensity of response expressed as a percentage of individuals responding to the test compound (administered to a group of Individuals) at a given level of intensity of response of the indlvidual.
Symbol for

Field $Y \quad$ Ranges of percentage response

$\begin{array}{lll}1 & 0 \% \\ 0 & >0 \% \text { thru } 10 \% \\ \text { A } & >10 \% \text { thru } 20 \% \\ 2 & >20 \% \text { thru } 30 \% \\ 3 & >30 \% \text { thru } 40 \% \\ 4 & >40 \% \text { thru } 50 \% \\ 5 & >50 \% \text { thru } 60 \% \\ 6 & >60 \% \text { thru } 70 \% \\ 7 & >70 \% \text { thru } 80 \% \\ 8 & >80 \% \text { thru } 90 \% \\ 9 & >90 \% \text { thru } 100 \%\end{array}$





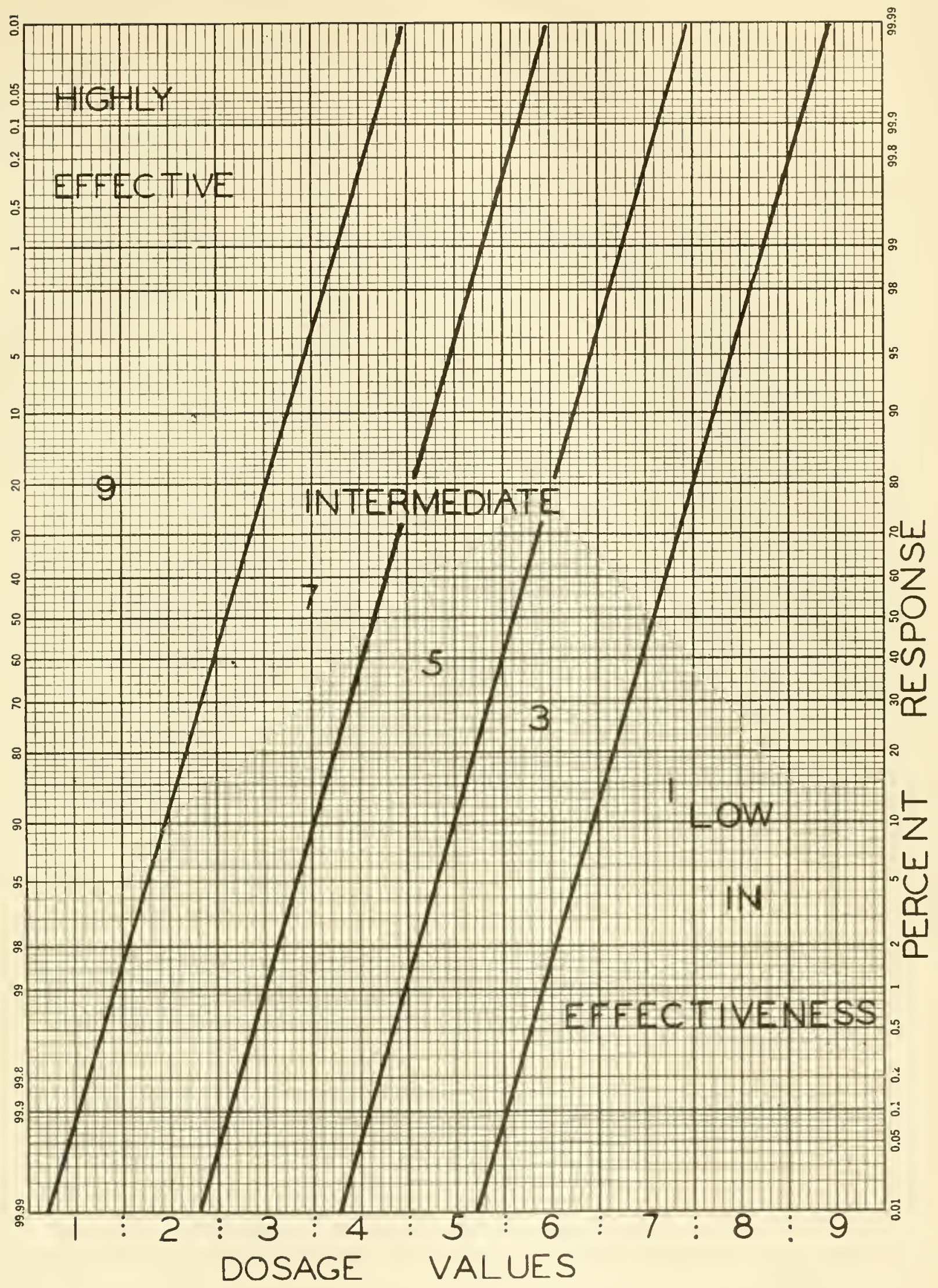





\section{APPENDIXES}

The contents of these Appendixes represent an extension of the descriptions of the Introduction. The Introduction deals particularly with the background and description of the Biology Code, while in Appendix A are described the $\mathrm{CBCC}$ procedures related to the use of the Biology Code, including the procedures of the Center for collecting information for coding, organization for administration of the coding process, and handling of the coded and IBM-punched information.

Finally, in Appendix B, some general observations are made about the Code and Key and the significance of the Center's activities. 


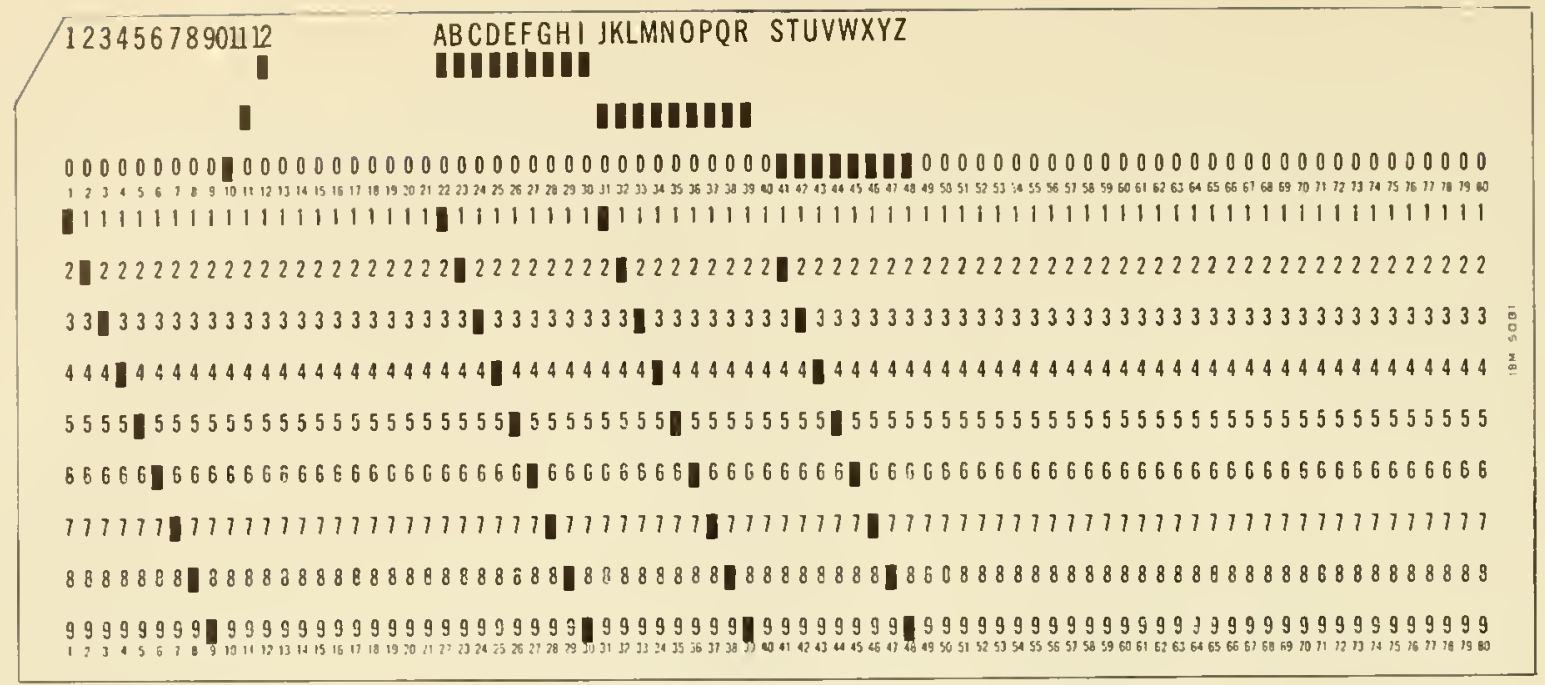

Figure 1 --Standard IBM Punched Card

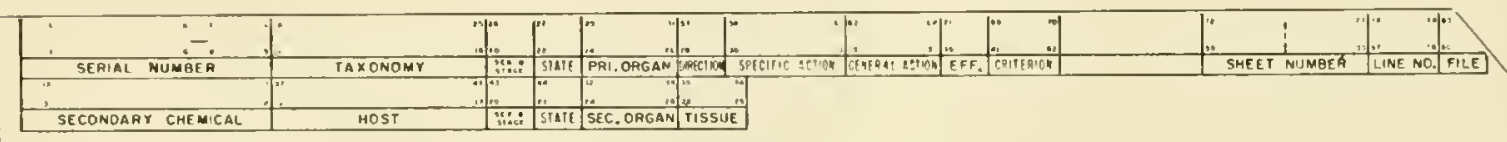

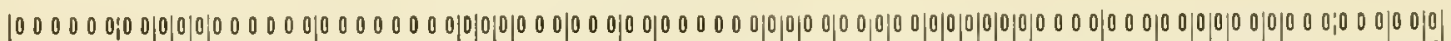

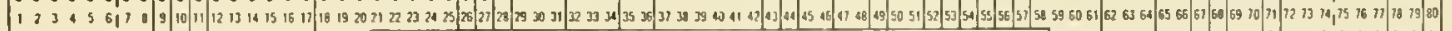

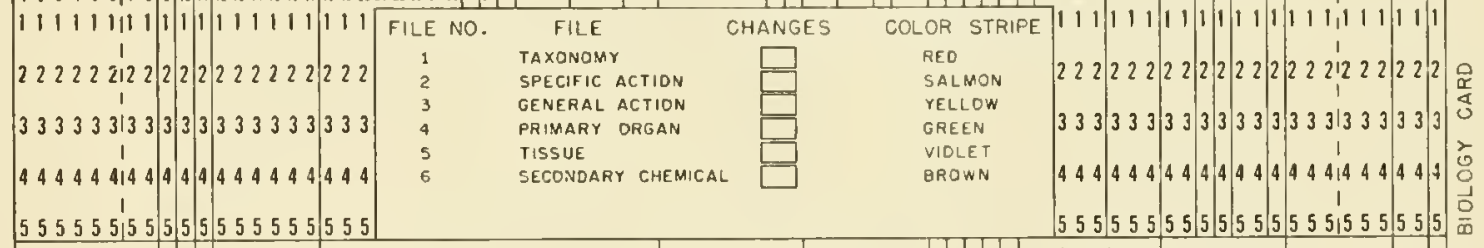

\begin{tabular}{|c|c|c|c|c|c|c|c|c|c|c|c|c|c|c|c|c|c|c|c|c|c|}
\hline \multirow{3}{*}{$\begin{array}{l}\text { SERIAL } \\
\text { NUMBER }\end{array}$} & \multirow{3}{*}{ 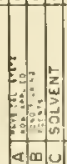 } & \multirow[b]{2}{*}{ 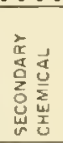 } & \multicolumn{5}{|c|}{ TAXONOMY } & \multicolumn{2}{|c|}{ HOST } & \multicolumn{2}{|c|}{ OOSAGES } & & & \multicolumn{3}{|c|}{ ACTION } & \multicolumn{3}{|c|}{ AESPONSE } & \multirow{3}{*}{$\begin{array}{l}\text { SHEET } \\
\text { NUMBER }\end{array}$} & \multirow{3}{*}{ 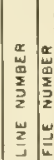 } \\
\hline & & & 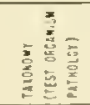 & 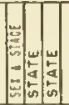 & 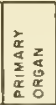 & 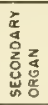 & 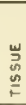 & ta & $=$ & 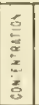 & 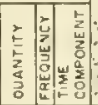 & & $:$ & & $\begin{array}{l}\frac{u}{u} \\
\frac{u}{3} \\
\frac{u}{n}\end{array}$ & 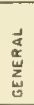 & $\begin{array}{l}z \\
\mathrm{~g} \\
\frac{\mathrm{g}}{\mathrm{a}} \\
\mathrm{a} \\
\mathrm{a} \\
0\end{array}$ & 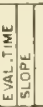 & 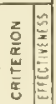 & & \\
\hline & & 0 & 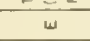 & $4=0$ & $\frac{T}{I}$ & $\frac{i}{4}$ & - & $\Rightarrow$ & $x-$ & $\Sigma$ & 200 & & & $\overrightarrow{5}$ & i & i & 2 & $>3=$ & $x \times$ & & \\
\hline
\end{tabular}

9999999999999999999999999999999999999999999999999999999999999999999999999999999

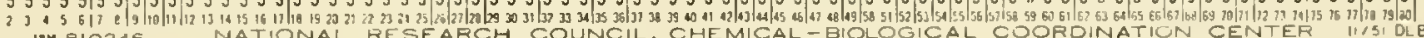
um $8102 \geq 6$

Figure 2--Biology IBM Punched Card

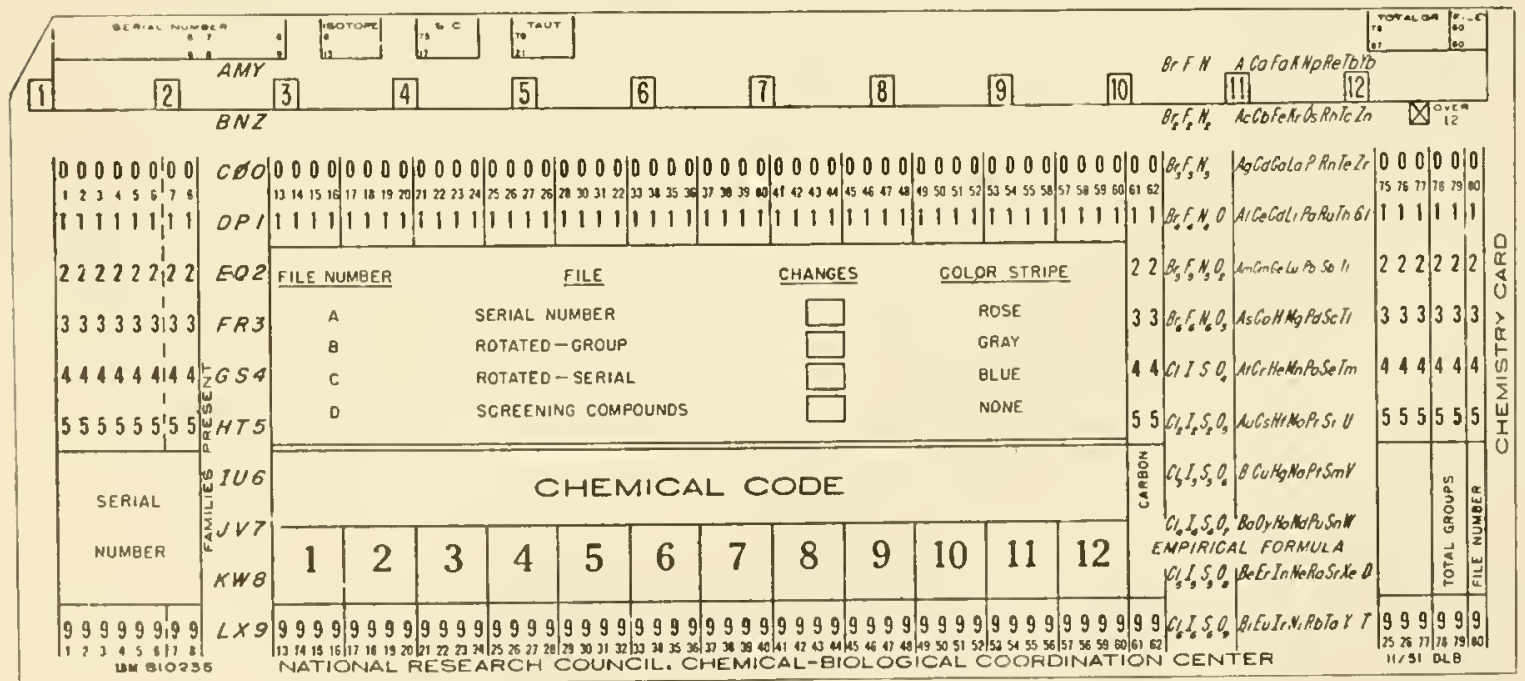

Figure 3--Chemistry IBM Punched Card 


\section{THE BIOLOGY IBM PUNCHED CARD}

It will be noted that the standard IBM card (Figure 1) is divided into 80 columns in each of which are printed the numbers 1 through 9 and, at the top of the column, 0 . Thus, it may be immediately apparent that in each column there are at least ten positions for perforation, representing ten available symbols. The machines can make two additional perforations at the top of the columns beyond the 0 position. These are referred to as the 11 and 12 positions on the column. Therefore, in all, there are actually twelve basic punching positions in each column, representing twelve available symbols.

It is possible to multiply the number of symbols available in any one column by using the three upper positions of the column $(0,11$, and 12) as designators for combination with any one of the remaining number positions. This permits the 26 combinations which are assigned the letters of the alphabet as symbols. Figure 1 illustrates each punch and punching combination which can subsequently be distinguished and interpreted as a symbol. While any or all of these may be used in any one column of the card, each is illustrated in a separate column in the figure, with the interpretation at the top of the column. In each of the first twelve columns, the card in Figure 1 is punched with only a single punch, the punching being interpreted, at the top of the card, as numerical symbols 1, 2, 3, 4, 5, 6, 7, 8, 9, 0 , 11, and 12. In Columns 22 through 39 and 41 through 48, the punching illustrates combinations of position 12,11 , or 0 with position $1,2,3,4,5,6,7,8$, or 9 , this punching being interpreted, at the top of the card, as letters A through Z. It will be noted that the combination of punches in positions 0 and $\mathbf{l}$ is not made, due to the proximity of the two perforations in the same column; punching in adjacent positions in the same column is never recommended, to prevent any possible confusion in machine interpretation and sorting.

The three topmost punching positions (12, 11, and 0) are commonly referred to as "zone punches", the remaining ("low") positions in the column being the "digit punches". The former are sometimes referred to as the "first", "second", and "third" zone punches, but throughout the Code and Key they are referred to as the "12", "l1", and "0" zone punches, respectively.

In addition to using the zone punches in combination with digit punches for 26 alphabetical symbols, it is possible to assign definitions to each of the zone punches alone; in other words, the 0, 11 , or 12 position could be punched, uncombined with any numerical punch, to indicate a specific meaning assigned to that single punch, as well as being used in combination with digit punches to indicate a specific meaning assigned to that combination. In that case, the number of available symbols in any one column would be 38 ( 1 through $9, A$ through $Z$, and the 3 zone punches used alone). The CBCC, however, has never used any zone punch alone as a symbol when it has been used already as a designator for letter symbols. Therefore, in the case of the CBCC Biology Code, any one IBM punched card column may be considered to be limited to a maximum of 35 symbols each. Reference to the following list will make clear the number of symbols available to the CBCC in any one column, according to the use made of the zone punches.

\section{Symbols used}

Number of symbols available in one column

1 through 9 and A through Z (no zone punches used alone). . . . . . . . 35

1 through 9, A through $R$, and the 0 zone punch used alone... . . . . . 28

1 through 9, J through $\mathrm{Z}$, and the 12 zone punch used alone. . . . . . . . . 27

1 through 9, A through I, S through Z, and the 11 zone punch used alone . . 27

1 through 9, A through I, and the 11 and 0 zone punches used alone . . . . 20

1 through 9, S through $\mathrm{Z}$, and the 12 and 11 zone punches used alone . . . 19

1 through 9 and the 12,11 , and 0 zone punches used alone. . . . . . . 12

Some types of information need fewer symbols than others. Consequently, the pattern of zone punch comblnations with digit punches (one of the seven above) varies from column to column, according to the information category, though it can not vary within a given column once it is established. The first of the seven possible combinations might be appropriate for information coded in one column (because more than 28 symbols are needed for the category of information coded in that column), while the second or third or any other of the last six possible combinations could be established for information coded is another column (if 28 or fewer symbols are adequate for that particular information category).

When a zone punch is not used for comblnations with the numerical punches (any of the last six possibilities of the seven listed above), the CBCC has considered it to be available for a specific definition, if needed. However, if a special meaning is assigned to a zone punch, the CBCC considers 
that zone punch unavailable (and not needed) for combination with the numerical punches. For example, if a given column appears to need fewer than 29 symbols and a special meaning is assigned to the 12 zone punch (see the third, sixth, and seventh items of the list above), the letters A through I are never used for symbols in that particular column. In the same column in which the 12 zone punch has been used for a unique meaning, however, if the 11 and 0 zone punches have not also been assigned special meaning (see the third possibility of the list above), the letters $J$ through $R$ and $S$ through $Z$ would be available as symbols.

In cases where the $\mathrm{CBCC}$ has assigned specific meanings to zone punches used alone (any of the last six possibilities listed above, when the major category of information coded in the column needs only 28 or fewer symbols), that specific meaning is of a different category of information than is coded by the remaining symbols of the column. For example, the information category, stage of development of the test organism, has been found to be adequately classified by nine items (nine developmental stages), needing only the nine numeric symbols; thus, a different category of information (sex) has been assigned to zone punches 12 and 11 used alone, the 12 zone punch designating the male sex and the 11 zone punch the female.

The 12 and 11 zone punches used alone are never written on the Code Sheet as Symbol "12" and Symbol "11", since it can be confusing to have a symbol with two digits to be written in one column. Instead, the CBCC always uses the two symbols, "*w" and "\#", respectively. The written Symbol "w" is therefore always represented on the IBM card by a perforation at position 12 (the 12 zone punch) and Symbol "\#" by a perforation at position 11 (the 11 zone punch). The 0 zone punch, however, is always written literally as Symbol "0".

As has been explained above, for each column of the punched card, 35 symbols are potentially available. If, instead of using only one column for a given type of information, two columns are used, the number of symbols available is greatly increased. For example, the CBCC has reserved both of Columns 23 and 24 for indicating the genera belonging to the family indicated by Columns 21 and 22 . Thus, each genus and each family has a symbol of two units. This means that each of the 35 available symbols of one column can be combined with any of the 35 symbols of the second column so that 1225 symbols are avallable for that number of genera (Columns 23 and 24) or families (Columns 21 and 22 ) of test organisms. If three columns were used, the number of symbols available for any given type of information would be correspondingly greater.

The biology IBM punched card (Figure 2) differs from the ordinary card of Figure 1 only in the special CBCC designations printed on the card. The top of the biology punched card is divided into areas in which the IBM Interpreter can enter the code symbols represented by perforations in certain of the columns. All the punched information of the card is not included, but only the serial number of the chemical tested and symbols for the test organism, sex and stage of the test organism, state of the test organism, primary organ, action of the chemical, effectiveness, criterion of effectiveness, secondary chemical, host, sex and stage of the host, state of the host, secondary organ, and tissue. Since room at the top of the card is limited, only that coded information to which reference is most frequently made is included. It will be noted that the interpretation of a punched column need not be directly above the column, but the IBM Interpreter can be wired to inscribe the interpretation at another position. For example, the criterion for evaluation 1 s punched in Columns 69 and 70 (see the lower part of the card), yet the Interpreter can print the interpretation at the top of the card in a position fixed above Columns $54-57$.

The printing which appears horizontally across the 6,7 , and 8 punching positions of the biology card represents a guide to anyone attempting to interpret directly the punching on the card; it shows the division of the card 1nto 31 punching "fields" of information about the biology test and four additlonal punching "fields" which are for other information categories (Chemical Serial Number, Code Sheet Number, Code Line Number, and File Number). The central area of the card is occupied with reference to the several special files of the IBM cards (files supplementary to the principal file of IBM cards arranged by Chemical Serial Number). Since the last revision of these entries on the card, two additional flles were established, the Host File and the Supplementary Taxonomy File. These files and the Code Sheet are described later. The file to which a given card belongs is indicated by a colored strip at the upper edge, a necessary means of distinction, since cards punched identically will be in three of the flles and may be in all of the files. When removed from its file, the manual refiling of the card into its proper cabinet is assured by the color identification. The cards of the principal file, the "Serial File", are distinguished by being entirely blue.

The clipping of the upper right corner of the biology punched card is merely to distinguish the punched card as containing biology information. CBCC chemistry punched cards are cllpped in the opposite corner. 


\section{THE BIOLOGY CODE SHEET}

The earliest CBCC coding was on special 8-1/2" x 11 " sheets referred to as "work sheets". The sheets were redesigned to fit the final pattern of the Code (the fifth edition) and have since been termed "Code Sheets". On these Code Sheets, coders translate the information into code symbols, accompanying the coding with a written abstract. The Code Sheets bear reference to the source of information and the identity of the specific test compound, as well as a reference to themselves, a number which is assigned to each Code Sheet after it is coded and which facilitates its retrieval after being filed in a special Code Sheet File. The Code Sheets are 17" $\times 11^{\prime \prime}$. For filing and ease in handling, they are folded once to become 8-1/2" 11 ". A Code Sheet is 1llustrated on the following pages.

On the inner side of the Code Sheet (Figure 5), sixty-five of the eighty columns of the IBM punched card are depicted (Columns 9 through 71, 78 and 79). These are organized into several areas or "fields", each of which represents a distinct type of information commonly associated with tests for biological responses to chemicals. A description of the type of information assigned to each field is printed at the top of the Code Sheet, as a "title" of the field. Below this area naming the coding fields (regarding the lower long edge of the Sheet as the bottom edge), the Sheet is divided into four equal areas by horizontal rulings. The areas are labelled as I, II, III, and IV on the Code Sheet illustration. Considering only one of these areas, it will be seen to consist of two bands across the Sheet (labelled as $A$ and $B$ in the illustration), the broader of which is divided by vertical rulings according to coding fields and the narrower of which is divided according to the sixty-five IBM columns. In the broader band is written the information about the test; for example, the name of the test organism, tumor, or pathology is written in Field $\mathrm{E}$, a description of the response is written in Fields $\mathrm{T}-1$ and $\mathrm{T}-2$, the exact dose administered is written in Fields $\mathrm{M}$ and/or $\mathrm{N}$, etc. This, then, represents a written abstract of the test, to be filed and to which reference is made from the IBM punched card index. The area is referred to throughout the Code and Key as the "written abstract" portion of the code line or sometimes as the "language" portion. In the narrow band, the information is coded, placing the code symbols from the Biology Code in the appropriate "code boxes", in other words, in the places representing the appropriate IBM punched card columns. Completed, this written abstract and the coding of the information represents one "code line". On each Sheet, then, space is provided for four code lines, each representing one action of a given chemical tested (i.e., one response of an organism) as shown by any one test from any given source of information. As a reference from the IBM punched card to the code line, each line is numbered (at the right end of the line) and this reference number ("Line No. ") is punched in Columns 78 and 79 of the IBM card.

As indicated previously, each Code Sheet is assigned a reference number (the Code Sheet Number) which is placed at the upper right corner of the inner surface of the Code Sheet and is punched in Columns 72 through 77 of the IBM card. This Code Sheet Number has no significance other than a reference number. It is used in filing (see the description of the Code Sheet Files) and it assists in keeping records of the Sheets as they are checked, processed by chemists, punched, etc. The Numbers are assigned strictly by the sequence of the Code Sheets being returned from the coder. In referring to them, the term "serial" has never been applied in order to avoid confusion with the number designations assigned to chemicals which the CBCC commonly refers to as the "CBCC Serial Number".

The "CBCC Chemical Serial Number" referred to above (which has been abbreviated to "CBC Number") is placed in the upper left corner of the inner side of the Biology Code Sheet. This number is a reference to the identity of the chemical tested and will be explained in the next section, discussing the coding of chemical information.

Because one compound may be reported from a single information source as having been demstrated to have caused several responses or it may have been tested in several ways, four code lines are frequently not sufficient. The coder then uses a second Code Sheet (a "continuation Sheet") or as many Sheets as are necessary to record all information about that one compound from that one information source; all of these Code Sheets, the first and all the continuation Sheets, are assigned the same Code Sheet Number. At the top of the Sheet and to the right of the center, the coder indicates the total number of Code Sheets used for this purpose (note the designation, "of Total") and, of that total, the sequential number which the Code Sheet represents ("Sheet No. "), the initial Sheet being Sheet No. 1, the first continuation Sheet being Sheet No. 2, etc.

Finally, a space is provided at the top of the Sheet in which the coder and the person checking the coding enter their identifying initials ("Coded by" and "Checked by"). If it proves that coding 
difficulties make necessary a resident staff member's reviewing the coder's and checker's work, this "arbitrator's" initials are also entered here ("Arbitrated by").

As the illustration of the Code Sheet indicates, this side of the Code Sheet on which the actual coding is entered is considered to be the "inside" of the Sheet. When folded for mailing or filing, then, this coding is on the inner surface and the reverse side (the outer surface) forms a "front" and "back" of the Code Sheet.

The front side (Figure 6) is generally self explanatory of entries to be made identifying the chemical tested, the information source, and the Code Sheet Number. In the space in which coders are instructed not to make an entry, only the CBCC resident chemists enter the name of the chemical tested, using, for consistency, the name by which the chemical has been filed in the CBCC Chemistry Files, generally conforming to Chemical Abstracts nomenclature.

The back side of the folded Code Sheet (Figure 4) is also generally self explanatory, being for the coders' recording of properties of the test compound, whenever such information is given by the information source.

All completed Code Sheets, after being assigned Code Sheet Numbers, checked, arbitrated, and processed by the chemists and IBM punch operators, are filed in a Code Sheet File which serves as a master file of the information collected by the CBCC. This file is described later.

\section{RECORDING OF INFORMATION ABOUT CHEMICALS AND CODING OF CHEMICAL STRUCTURES}

Space does not permit more than an outline of the procedures the Center used for handling information about chemicals used in chemical-biological tests. The Chemistry Code ${ }^{1}$ was published in 1950. By this Code, the CBCC recorded on IBM punched cards the structures of compounds tested for their biological effects. The actual process of coding the chemical information paralleled that of coding biological data. For each compound, every effort was made to determine its molecular structure, all its properties, and the name by which it is indexed in the most universally used reference to current chemical literature, Chemical Abstracts. In addition, the chemists recorded all information given about alternate chemical names, proprietary names, common names, commercial sources, and natural sources. Also, a reference was recorded to the literature article or other source of chemical-biological information in which the chemical was first encountered by the CBCC.

Each identified chemical was assigned a reference number at the time of recording the information about it. The reference number must be understood to be distinct from the coding of chemicals' specific structures; the number represents essentially only the sequence in which the chemical was recorded and coded by the CBCC. The numbers are referred to as the CBCC Chemical Serial Numbers (abbreviated to "CBC Numbers"). This Serial Number is basically of six units; an additional two units can be appended (separated by a dash from the sixth unit) to the basic Serial Number to indicate the compound's various salts, solvates, and isotopes used in biological tests.

All information about a single compound was written on a special sheet, the Chemistry Code Sheet, including the compound's Serial Number and its structure, both as a structural formula diagram and as a coded molecular formula. The Chemistry Code Sheet, front and back, is illustrated by Figures 7 and 8 .

The coded structure of each compound and its Serial Number were punched on IBM cards (occasionally, two IBM cards were needed for a compound of especially large molecular structure). The specially printed IBM card used for punching chemical structures is illustrated in Figure 3 . The files of chemistry IBM punched cards and of the Chemistry Code Sheets are described later.

\footnotetext{
A Method for Coding Chemicals for Correlation and Classification (1950): \$1.50. National Research Council, Washington, D. C.
} 

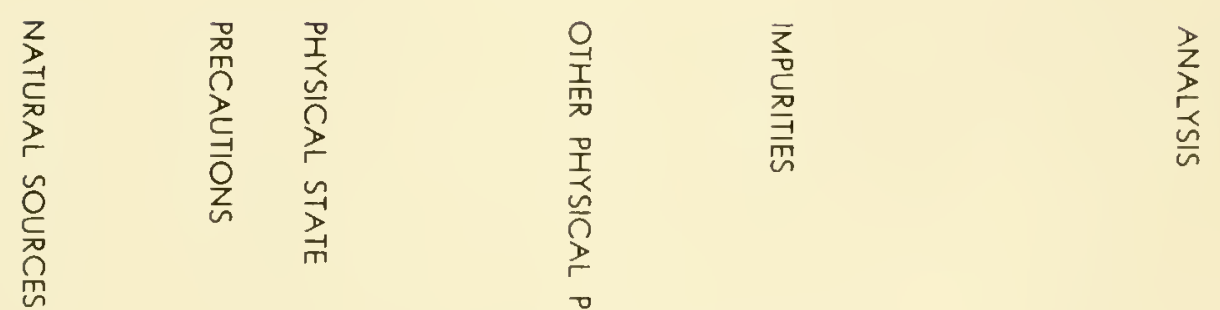

Figure 4

BIOLOGY CODE SHEET

Back side of outer

surface, when folded 


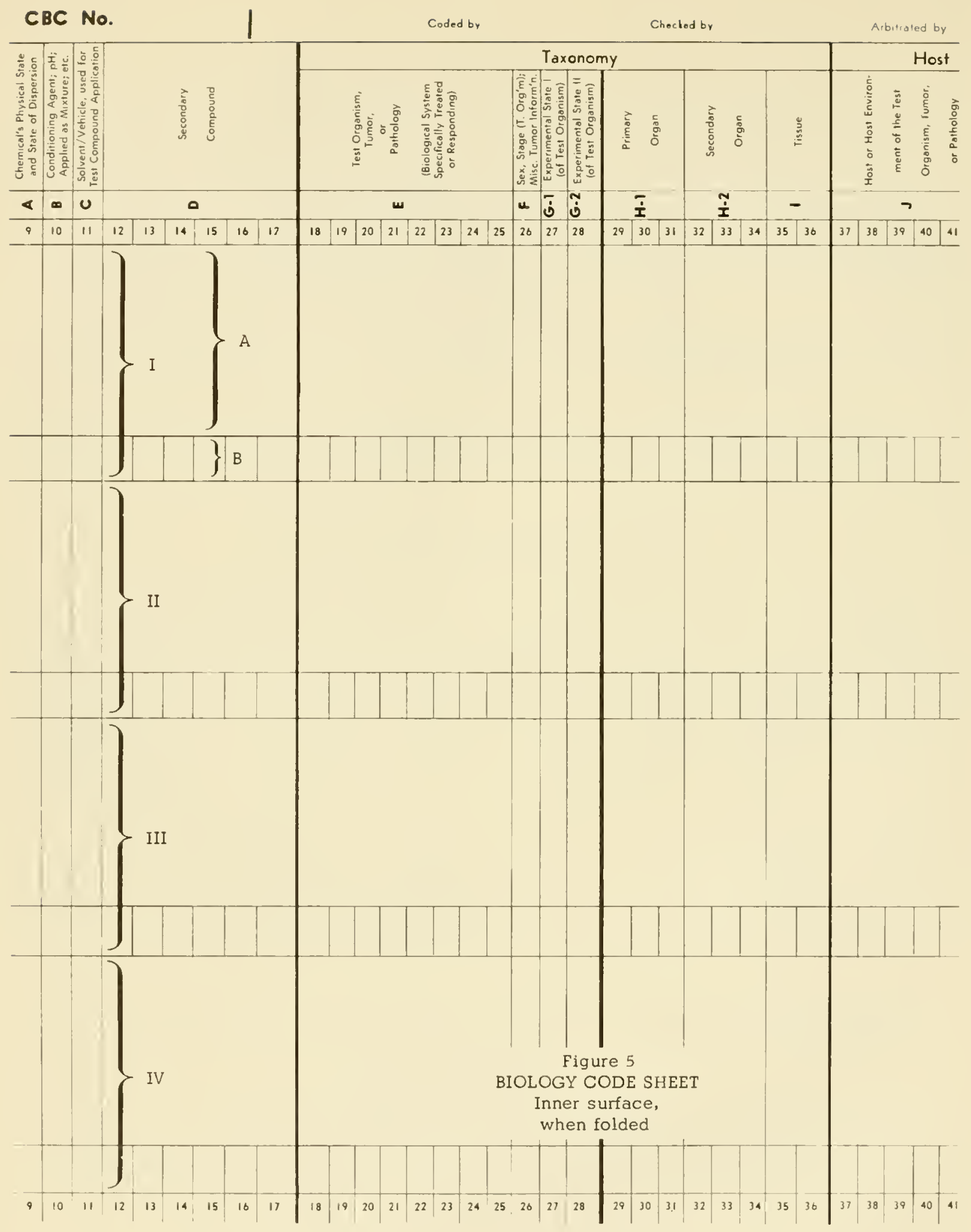


Code Sheef No.

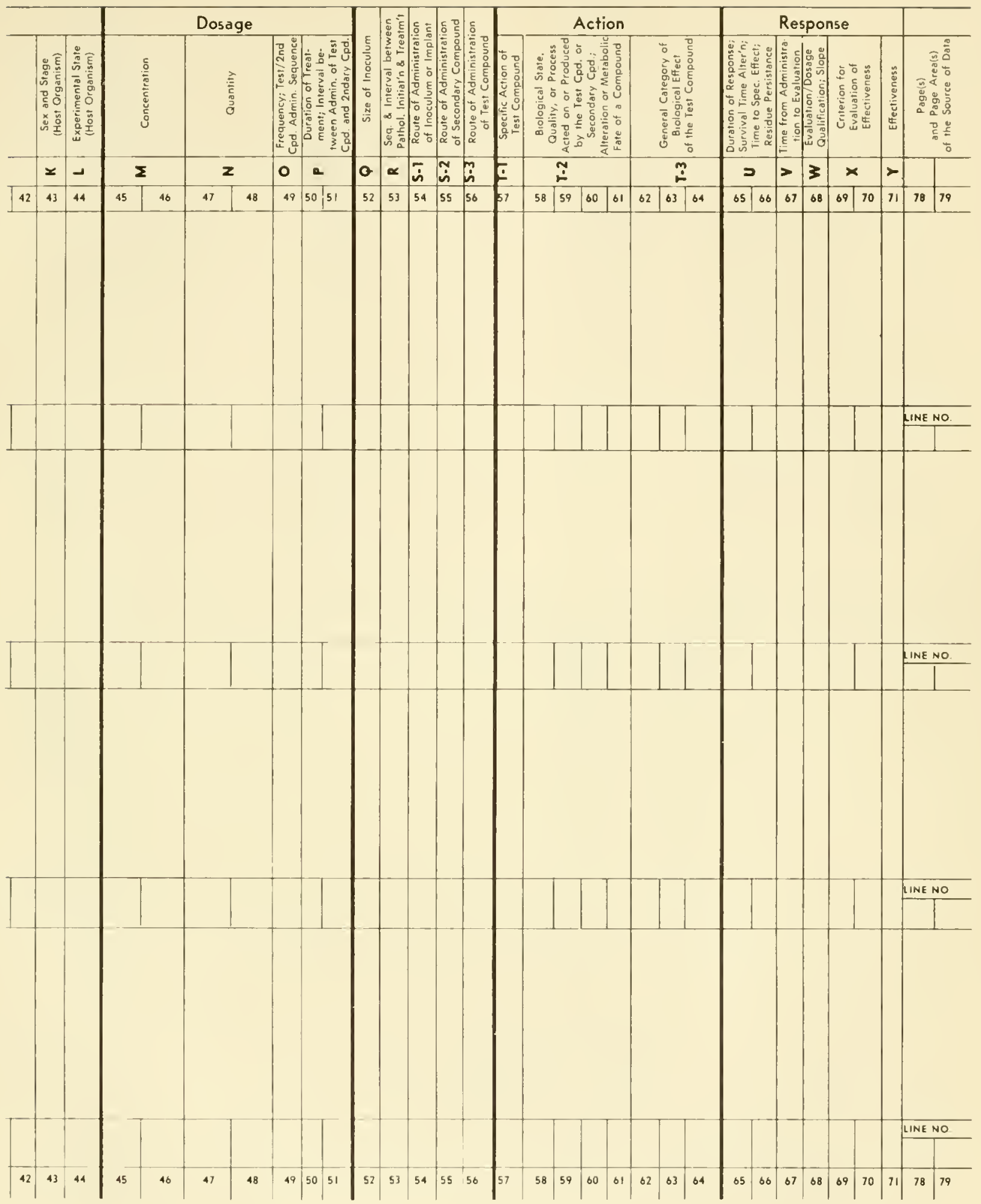




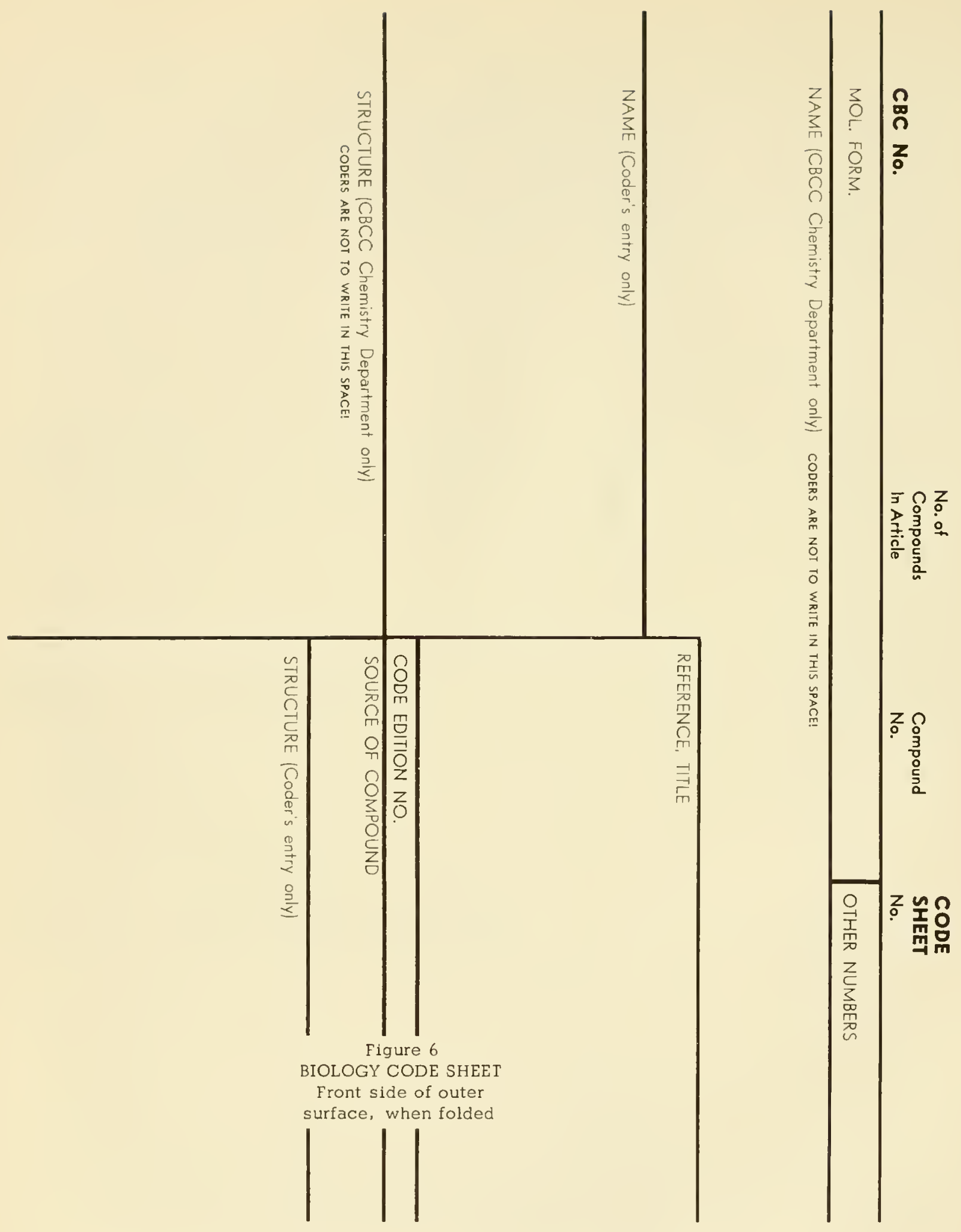




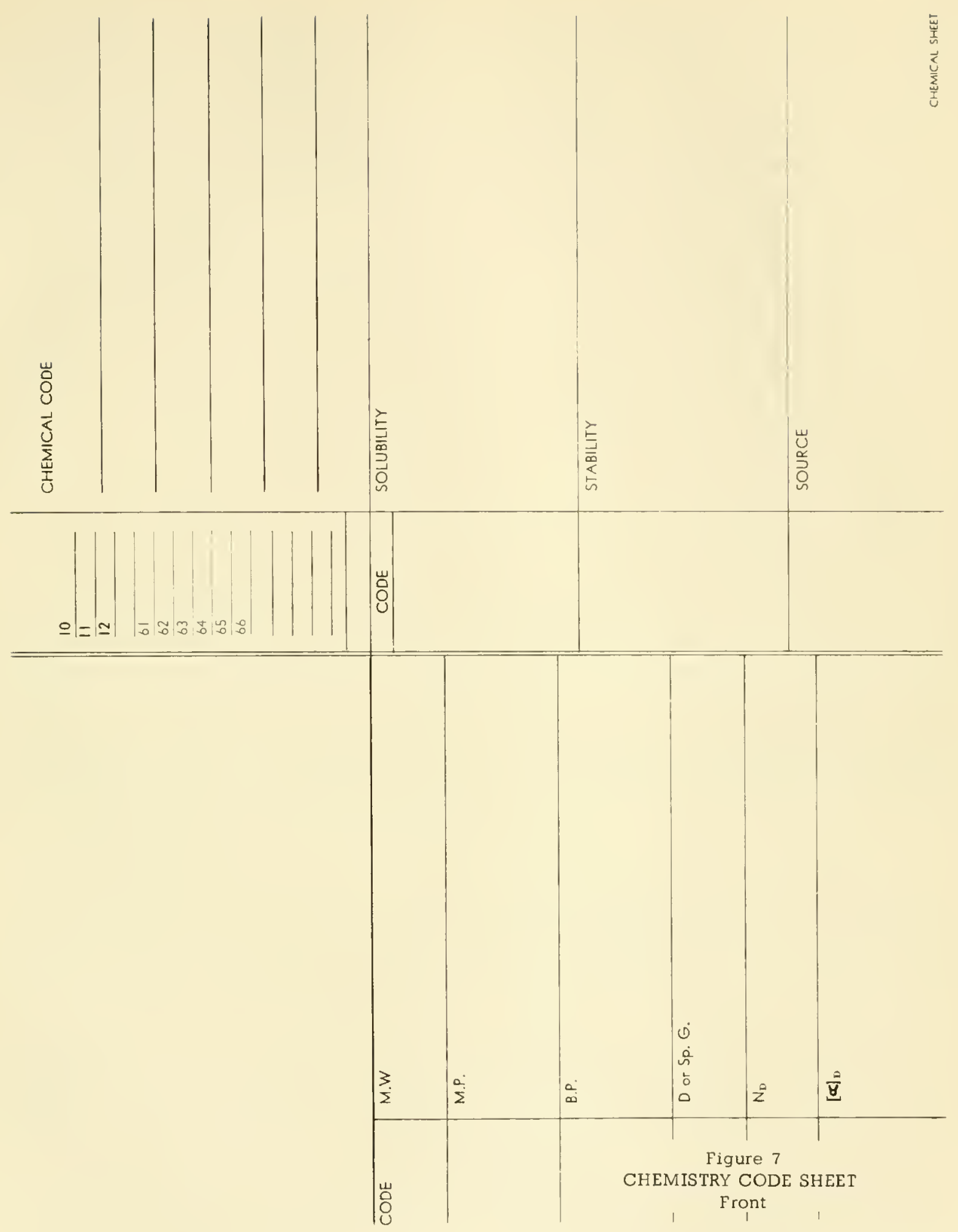




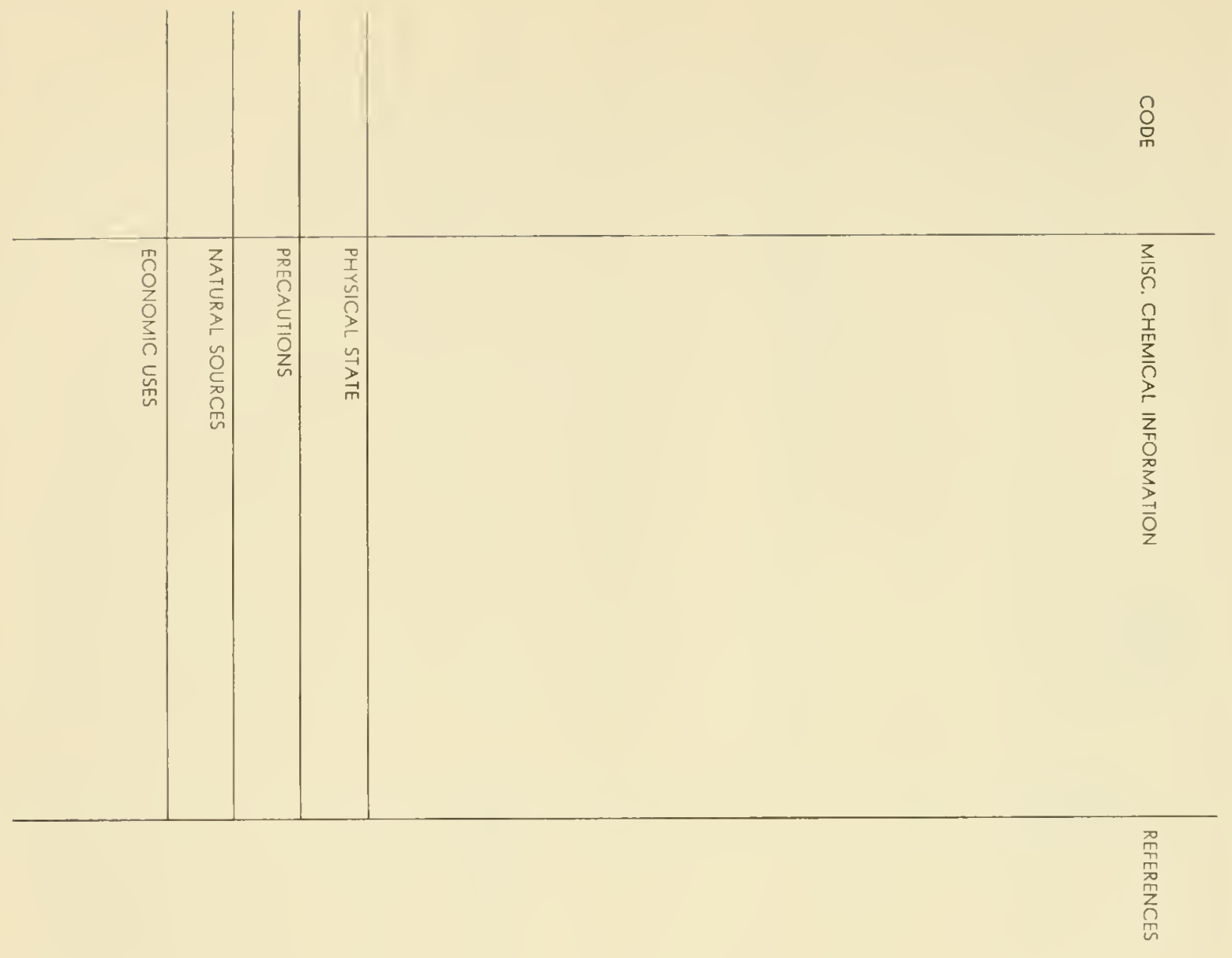

Figure 8

CHEMISTRY CODE SHEET Back

- 206 - 
In addition to the Chemistry IBM Punched Card File and the Chemistry Code Sheet File, Information about each chemical was recorded in a third way, on $3^{\prime \prime} \times 5^{\prime \prime}$ index cards. A card was prepared for each chemical, giving its Serial Number, its molecular formula, the name by which it is indexed in Chemical Abstracts, and, whenever known, its structural formula. A typical Chemistry Index Card is illustrated by Figure 9. The $\mathrm{CBCC}$ maintained three complete files of these index cards; arrangement was by Chemical Serial Number ( $\mathrm{CBC}$ Number) in one, by Chemical Abstracts name in the second, and molecular formula in the third. Duplication of each card (for the three files and for other purposes) was by typing the information originally on a $3^{\prime \prime} \times 5^{\prime \prime}$ Ditto master; all Ditto masters were kept in a fourth file for any future duplication needs.

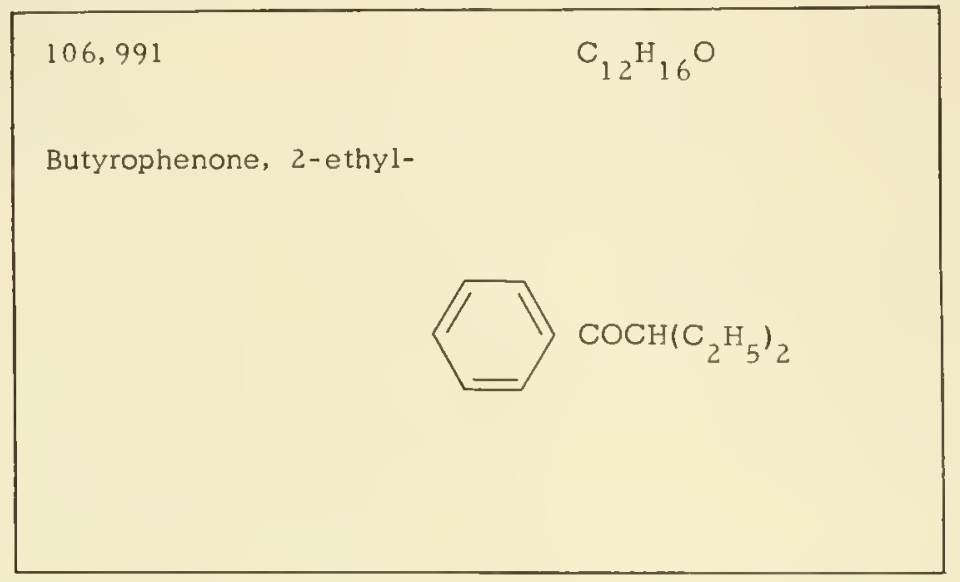

Figure 9

Chemistry Index Card

\section{THE CBCC FILES}

Although the Center's activities have been terminated, the information files, at the date of this publication, have not been destroyed nor placed in permanent storage. On the basis of their being still available and on the assumption that even as static files they will have value for a period of time, the following descriptions imply their current existence.

\section{Code Sheet Files:}

It has been explained that all the biological information recorded by the $\mathrm{CBCC}$ is on the Biology Code Sheets and the Information on specific chemicals is on the Chemistry Code Sheets. These were the prime sources of information at the Center, just as books are the basic sources of information in a library. The Biology Code Sheets and Chemistry Code Sheets are both filed according to CBCC Chemical Serial Numbers in the same cablnets.

Inasmuch as information from tests on any one compound may be derived from several sources, a compound may be represented in the file by many Biology Code Sheets. Under any one Chemical Serial Number, therefore, all Blology Code Sheets bearing that Serial Number are filed according to the Biology Code Sheet Numbers. Each chemical for which there are blological test data in the file is represented by only a single Chemistry Code Sheet, so the total Chemical Code Sheet File is of considerably smaller proportions than the Biology Code Sheet File.

Regarding the Code Sheet File independently (i.e., without the Biology IBM Punched Card Files), Sheets can be associated and retrieved only by the Chemical Serial Number under which they are filed. No index file of Code Sheet Numbers was maintained for the Code Sheet File; therefore, a Sheet known only by its Sheet Number can not be retrieved. (This was occasionally an inconvenience and consideration was given to establishing this index file.) Neither were indexes maintained of authors or information sources (journals and other publications, CBCC Screening Program test reports, etc.) by which Code Sheets might be reassembled to represent all information of a given article, a given screening laboratory, a given author, etc. These are not, however, regarded as deficiencies of the Code Sheet Files, since, operating within its specific objectives, the CBCC found little reason for associating the information in these ways. The only approach to the information on the Code Sheets, beyond the chemical identities by which they are organized, is through the index provided by the IBM Punched Card Files, described below. 
The coded information of the Biology Code Sheets and Chemistry Code Sheets was placed on IBM punched cards and filed in standard IBM card cabinets. The coded and punched information on these cards may be regarded in two ways.

First, the entries on the card serve to index the Biology Code Sheet File which contains the information about chemical-biological tests in detail as a written abstract. The advantages of this index (more correctly, a complex of indexes) have already been discussed in the Introduction and will be continued here and in a subsequent part of the Appendix.

Secondarily, the CBCC considered the information of the Biology Code Sheet File to be coded to such detail that, for some purposes, the information of the Biology Punched Card Files might be regarded reasonably as an adequate substitute for the Code Sheet File. At the same time, it was recognized that the coded information on the punched cards was not adequate for all purposes. Details unique to special tests are often not coded for lack of a coding provision and certain information is abbreviated to code only by expressing it as an approximation; for example, the coded dosage would be known to lie somewhere within a coded range. Furthermore, since the CBCC IBM punched cards were actually designed having in mind only their use at the Center in conjunction with the Code Sheets, no provision was made for including the source of information on the cards. Thus, for final interpretation, it is often necessary to go to the Biology Code Sheet to which reference is made by the punched card. For reference to the original information source, it is always necessary to go to the Code Sheet. This suggests that a desirable eventual refinement would be the design of some means whereby the punched card would include the information source and even a reproduction of the related Code Sheet Line which the punched card represents. Nevertheless, the IBM Punched Card Files can be regarded, for some purposes, as bearing enough information in code to be used independently of the Code Sheets as a medium for transfer of information.

Because the Punched Card Files and their use represents such an important aspect of the CBCC, it is appropriate to dwell on their arrangement and the reasons behind that arrangement, in an effort to make clear their significance and to give a general idea of the way they were used. However, it is not possible here to outline all the patterns for use of the punched card files in searching for specified information. The pattern varies according to the information requested and, except for certain more simple requests, some "programming" for sorting of punched cards is necessary.

Reference has already been made to the Introduction's description of the punching of coded information on cards in terms of indexing the Code Sheet Files in which the information is deposited as a written abstract. The information in the Code Sheet File can be considered as being indexed, not merely by the order by which the punched cards are filed (according to chemicals tested, e.g. ), but according to every category of information coded and punched on the cards (i. e., according to the chemical tested, organism, anatomy, host, response, etc.). Furthermore, it has been pointed out in the Introduction that an advantage to using machines and punched cards is that it permits having all these indexes in a single file rather than having a duplicate set of cards for every index, each arranged according to that index classification. For example, even though the cards were arranged according to the chemical tested, if information were wanted about a given organism or group of oryanisms (e.g., information on Mollusca), the speed of machines makes possible a rapid examination of the entire file and sorting out those cards punched to indicate Mollusca; the results of this machine sort is identical to the result that would be achieved by having a separate file of punched cards arranged according to code symbols for organisms, from which all the cards referring to Mollusca could be taken manually.

These basic observations would lead to the assumption that the CBCC needed but a single file of IBM punched cards to index its information collection. Since the Center actually established several files of its IBM punched cards, differing only by the way they were arranged (according to organism, to response, etc. ), the above observations need modifying to explain, first, why a single file was inadequate for the CBCC and, secondly, that the advantages described above apply and are utilized even though the several card files are needed.

For these explanations, two major factors should be considered, (1) the speed of the machines used and (2) the size of the information collection and the corresponding size of the file of IBM punched cards. Machine sorting for cards on which is punched a specified symbol, from a group of one hundred, or even five hundred, cards is one thing, but sorting by machine from a file of many thousands of cards is quite another. It is not a matter of the machines used by the CBCC not being able to accomplish this, but a matter of speed; compared to the speed by which cards for Mollusca, for example, can be taken manually from a file in which the cards are arranged according to organisms, the time for machine 
sorting all cards of the file arranged according to chemicals is too great to be practical (again, speaking with respect to machines with the speed of those used by the CBCC). Another factor related to this can not be ignored, the vulnerability of the cards to a certain amount of damage with handling and the passage of time. Since their practical "life" is of limited duration even with minimal use, the frequent passage of all the cards of a single file through machines would inevitably demand frequent card replacement due to damage.

The answer to this problem was to reduce to a practical minimum the number of cards to be machine handled in any given card sort. To do this, the CBCC established eight card files, supplementary to the principal file which was arranged according to the Serial Numbers of chemicals tested. For example, for the "Taxonomy Punched Card File", a duplicate was made of every card in the major file (1.e., the "Serial File") and the cards were arranged according to the symbols coded in Field E (organlsm, tumor, or pathology tested); in six other files, the cards were arranged according to the coding in Field T-2 (the biological state, quality, or process affected), in Field T-3 (the category of effect of the test compound reflecting practical use), in Field $H$ (the organ affected), in Field I (the tissue affected), in Field $\mathrm{J}$ (the host of the test organism), and in Field D (a chemical synergized, antagonized, or used as a standard for comparison in evaluating the effect). More recently, an additional (eighth) supplementary file was established which resembles the Taxonomy Punched Card File just described in that the cards are arranged according to symbols coded in Field E; it differs in that its arrangement is not on the basis of the finest classification unit (i. e., species of test organisms), but on the basis of major classification units (e. g., bacteria, dicotyledonous plants, arthropods, etc. ); under each of these major taxonomy classification units, all the cards are arranged by Chemical Serial Number, whereas in the principal Taxonomy Punched Card File, the cards are arranged by Chemical Serial Number under each species.

Thus, in all, there are nine separate Biology Punched Card Files. The nine files are not all of equal size, because certain of the information categories are not represented on every card and, if a card is not punched in a field for which a special punched card file was established, that card is not included in that file. The Serial File and the two files arranged by entries in Field E and Field T-2 are all of equal size, each contalning a card for every code line. On the other hand, the files arranged according to tissues and secondary compounds are small enough to be accommodated by a few cabinet drawers.

It should be noted that, for most of the fields (i.e., indexes), such as Field A (state of the chemical), Field G (experimental state of the organism), Fields $M$ and $N$ (dose size), and Field S-3 (path of administration of the chemical), no special punched card files were established. This is because of the improbability that the entire Serial File would ever need be sorted for that information. In other words, separate punched card files were maintained only for those categories of information most frequently sought and for which a machine sort of the entire punched card file arranged by Chemical Serial Number would be necessary but impractical. For example, if there were wanted all information about tests made on a specified organism or group of organisms, or on a specified organ, or for a specified response, the file search would begin with punched cards bearing the identifying symbol for the organism, organ, or response in question; the cards would be obtained by manual selection from the punched card file arranged according to test organisms, from the file arranged according to the organs responding, or from the flle arranged according to specific responses.

The type of question asked of the CBCC files was seldom so simple as the examples given above, but was most frequently qualified by stipulations of a second or more information categories. For example, a request might be for information about tests made for a specified response on a specified organism; this might be further qualified by stipulating interest in only positive data and in chemicals effective at doses lower than a specified maximum. No special files of IBM punched cards are maintained by the CBCC with cards arranged according to evaluation of effectiveness (negative or positive or the degree of positive activity) and dose size. These are not categories of information for which a primary search through the entire card file would ever be likely. Therefore, the first step would not be to machine sort the entire punched card Serial File, but to go to the appropriate supplementary punched card file, in this case either the file arranged according to test organisms or the file arranged according to responses, or both. At that point, depending on the number of cards which had been found for the specified organism or for the specified response, the decision would be made as to whether the machines could be used to advantage in sorting for the cards meeting the other specifications (data which is positive and at doses lower than a given maximum). It is possible that the cards resulting from the primary step may be so few that, for the secondary sort, reading and sorting the cards manually would take less time than it would take to carry the cards to the machines, make out specifications for machine operators, etc. 
The objective in having the eight supplementary punched card files is demonstrated by the foregoing example; the files permit an initial and efficient manual selection of cards from the total punched card file, resulting in a group of cards which is of a size practical for handling by machines, if necessary.

With the preceding as background, it can now be explained how the CBCC used the machines to the advantage they have been described as offering. Though machines are not used by the $\mathrm{CBCC}$ to sort through the entire punched card file, the advantage of machines is not lost. It is merely transferred to the secondary step. The cards resulting from manual selection might be regarded as a temporary and specialized file of cards; regarded in this way, it is seen to be cross-indexed by punches according to every one of the information categories coded by the Biology Code. All the advantages described earlier for coding and machine handling in general apply to this special small file which results from the initial manual selection. To carry this idea to the example of cards selected from the punched card file arranged according to organisms, we can regard cards resulting from the selection as a special file, the "special" feature in this example being restriction of information to that on one or more specified organisms. If only the cards for one species of organism were selected, the cards in this specialized file resulting from that initial selection would be arranged according to Chemical Serial Numbers, since that is the way the cards are arranged secondarily under any one species in the punched card file. The remaining information punched on the card (i. e., other than test organism identity) represents indexes which, however, can be efficiently used as indexes only by applications of machine sorting of all the cards (unless the cards are so few that inspection of the punches of the card or interpretation at the top of the card would be faster than machines). For example, if the initial manual selection results in five hundred cards (all punched with the symbols for the organism in question), the sorting of those cards for only those which are punched with symbols for a specified response or for a specified organ is made practical by use of machines.

For practical retrieval of information by machines, using only a single file comparable to the CBCC Serial Punched Card File, machines used must have a far greater capacity for rapid selection, assembly, and reproduction from that single file than the IBM equipment used by the CBCC.

\section{Chemistry IBM Punched Card Files:}

The major file of Chemistry IBM Punched Cards is arranged according to the CBCC Chemical Serial Number and is referred to as the "Chemical Serial File". This single file is not sufficient for the most practical retrieval of information about chemicals of specified structure and therefore a subsidiary file is maintained for these cards.

This second file is arranged according to structural components instead of the Chemical Serial Number. For this particular file, the coding of each compound is in most cases necessarily punched on more than one card, the number of cards for any compound being equal to the number of types of structural groups which are contained in the molecule and which are given a distinct code symbol. (The Chemistry Code should be examined to understand the specific structural groups assigned unique symbols.) On these two or more punched cards representing one chemical compound, the punching of the coded structural groups is "rotated". To explain this "rotation" requires first explaining that the punching of code symbols for structural groups of a compound is not fixed to a definite area of the Chemistry Punched Card in the way that a given type of biology information (e.g., the test organism identity) is fixed to one area of the Biology Punched Card (e. g., only Columns 18 through 25 of the Blology Punched Card, for test organisms); instead, on the Chemistry Punched Card, the coding for one structural group can be punched in Columns 13 through 16, or punched in Columns 17 through 20 , or 21 through 24, etc. (Coding of any structural group requires only four IBM punched card columns, three columns for the code identity of the group and a fourth column to indicate the number of times the structural group occurs in the molecule.) Therefore, the punched sequence of the coded structural groups can be varied on the cards for any one compound so that each group appears in turn at the beginning (i.e., at the left of the Chemistry Punched Card, Columns 13 through 16). For example, a compound with three structural components (for which there are three distinct, four-unit code symbols) would occupy Columns 13 through 16, 17 through 20, and 21 through 24 on any punched card (refer to the illustration of the Chemistry Punched Card, Figure 3), but in this special "rotated" file, three cards would be punched, differing only in that the coding for each structural group appears on one of these cards in Columns 13 through 16 . This file is referred to as the "Chemistry Rotated File" and it permits manual selection of all compounds containing any given structural group, because the file is arranged accordling to the coded structural group punched in Columns 13 through 16.

Two other files of Chemistry IBM Punched Cards, indicated on the card illustrated in Figure 3 , are special files maintained more for $\mathrm{CBCC}$ internal convenience than for actual retrieval or correlation 
of information on Code Sheets. In one of these, a duplicate of each of the cards of the Chemistry Rotated File (described immediately above) is filed according to Chemistry Serial Numbers. The fourth file contains the punched cards for only the compounds obtained and distributed for testing by the special CBCC Screening Program and was useful mostly for reference to that program.

Miscellaneous Files:

The process of collecting chemical-biological information (selecting, coding, checking, and otherwise processing it) demanded keeping careful records at the Center and there were several files needed for this. The files maintained for all this processing cannot be described in detail here. One example is the file maintained for each of the journals reviewed for information, to avoid duplication of review and coding and to provide a current record of the segment of literature covered by the collection in the CBCC files. Another example was the file of authors and artlcles coded, though this was used solely for assistance in maintaining Sets of Code Sheets as they were coded, checked, arbitrated, processed by chemists, etc. Neither of these two files was referenced through Chemical Serial Number to the Biology Code Sheet File and they could not (nor were they intended) to be used for reassembling coded information from a given journal or article or by a given author, after the Code Sheets were flled.

The Chemistry 3 " $\times 5^{\prime \prime}$ Index Card Files have already been described in the preceding section dealing with the recording and coding of chemicals.

The Center maintained limited files of original data which had been coded and punched. One file contained miscellaneous publications or unpublished compilations of test results, retained for practical reasons of reference. Also, a file was maintained of the reports from the Center's own Screening Program. The Center did not purchase and maintain any of the many periodical publications from which data was selected, but depended solely on libraries available to its non-resident coders and those of the Washington, D. C. , area.

\section{CBCC PROCEDURES FOR SELECTION, CODING, PROCESSING, AND FILING CHEMICAL-BIOLOGICAL INFORMATION}

The following will be limited to descriptions of procedures used by the CBCC in collecting and storing information. The methods for handling the coded and punched information, once it was integrated into the CBCC files, is dealt with elsewhere in the Appendixes and in the Introduction. In Appendix B, time needed for the procedures described below is discussed under the heading, Currency of the CBCC Files.

Selection of Chemical-Biological Information:

The quantity of information of chemical effects on biological systems is so vast that the CBCC, with its limited staff and means, could not pretend to be able to collect but a part of it. In view of this, emphasis was placed on obtaining information known not to have been published or to have been published obscurely and which is therefore less apt to be indexed in other places. On the other hand, a serious effort was made by the $\mathrm{CBCC}$, within the limits of its means, to review the current literature for all appropriate data. This review regularly included the journals determined by a preliminary survey to be most rewarding in terms of the quantity of information on chemical-biological tests included in them.

A restriction in this selection was that of omitting clinical data on responses to chemotherapy. While this policy was not followed slavishly to the total exclusion of any data that can be conceivably regarded as being clinical, it was adhered to generally. This was not because clinical data were regarded as without value, but because they so frequently lack the experimental control typical of laboratory-conducted tests and tend to be repetitious. Had adequate facilities and staff been available, the CBCC would have collected all clinical data and included them in its coded files.

In 1951, when the procedures for selection of information were established, it was decided to attempt to review back to 1946 all issues of the journals selected for routine review while, at the same time, reviewing current issues. For most of those journals, this was successfully accomplished.

All review of the literature and selection of information from other sources was made by the resident biology staff of the Center. Each staff member assumed responsibility for a quota of scientific journals, including those speciallzed journals of his own field of scientific interest and training. 
Selection of chemical-biological information from the literature is rarely a task which persons with little or no academic background in the biological sciences can do adequately. This is perhaps best realized only through experience.

Examination of the literature for appropriate information amounts to considerably more than a rapid and superficial scanning. While a considerable proportion of the data are revealed by the titles of journal articles, they are by no means always apparent thereby and to select data, it is never enough merely to examine a journal's table of contents. Having found data from chemical-biological tests in the literature, it was necessary for the CBCC reviewer to be able to evaluate it, to note any special problems that might be encountered in coding it and make provision for them, and to omit the data representing information which he happened to recognize as having been placed in the CBCC files already.

In this process of selecting articles from the literature, the staff member recorded any selection on a form especially designed for the purpose, referred to as an Assignment Sheet. A separate Assignment Sheet was used for each journal (and frequently, for each issue), in order to be able to file the Sheets later according to the name of the journal. All articles selected for assignment to coders were entered on an Assignment Sheet, indicating the name of the journal, volume and issue numbers, and date of issue; for each article selected, the Sheet carried the name of the author or authors, pages on which the article appears, and any special instructions or admonitions for the article's coding.

The Assignment Sheets were used also for any data other than that selected from the literature, such as data from the Center's Screening Program which were assigned to coders for coding.

Each Assignment Sheet was typed in triplicate, one copy being retained in a permanent file, described in the previous section, under Miscellaneous Files.

Assignment and Coding of Information:

Most coding of information was done by persons not resident at the Center. Each applicant for CBCC coding (as well as each prospective resident member of the professional staff) was required to study the Biology Code and Key, perform some basic coding according to a set of typical coding problems devised by the Center as a "Primer", and finally to submit a set of approximately 100 lines of coded data from the literature. The applicant's suitability for CBCC coding was determined by the results of the coding of the Primer problems and his first 100 lines. Many applicants were discouraged by finding the analysis of data and its conversion to code a more difficult task than they had supposed, others found that it required more concentrated periods of time than their schedules permitted, and possibly some found the type of work not to their particular disposition. Most of the applicants and many of those who coded regularly for the Center could contribute only part of their professional time to the activity. All coders were persons with considerable biological academic backgrounds, many of them possessing doctorates in their special biological fields. Of most significance, however, were a basic interest in their particular field of biology, their familiarity with experimental methods and statistics, and their ability to find coding a satisfying occupation.

Compensation for coding was made on the basis of the number of code lines submitted; at least fifty lines per month, as a practical minimum, was requested from each coder. If coding fell below this minimum regularly, the coder's accuracy and CBCC efficiency was found to be also below a practical level. It should be said also that, beyond the monetary compensation, many CBCC coders found not a little incentive for their work in the knowledge that they were contributing to the Center as a project with no precise precedent whose objectives they believed to be important. Further observations on the coders and the $\mathrm{CBCC}$ operational procedures are made in Appendix $\mathrm{B}$.

Every month, each coder received from the Center a coding assignment, selected from the accumulated Assignment Sheets; the selection was tailored to the coder's special biological interests, whether botanical, pharmacological, bacteriological, etc. This policy often needed modification for reasons of inaccessibility of certain journals to a coder particularly qualified to code from them; furthermore, because the scope of certain journals is very broad and because it was impractical to complicate assignments further by making them on the basis of an article as an assignment unit rather than an entire journal issue, the asslgnment of an entire lssue of such a journal often confronted one coder with articles of widely varied nature. Duplicates of the Assignment Sheets were retained at the Center for a record.

It was the coder's responsibility to obtain the journals containing the articles assigned for coding. Being located geographically where journals are not readily available on Ioan was unfortunately a situation ordlnarily disqualifying a candidate for coding. 
At the end of every month, each coder mailed to the Center the Code Sheets representing completely coded journal articles (preferably, completely coded journal issues), completely coded sets of Screening Program test reports, etc., accompanied with a record of the number of lines coded and time spent. Also accompanying the Code Sheets were special "Coder's Comment Sheets" on which the coder explained any problems encountered in coding the particular data, etc. These Comment Sheets are discussed later in Appendix B.

Checking of Coding: Arbitrating between Checker and Coder:

The Center treated a shipment of Biology Code Sheets from the coder as a "Set", for convenience in maintaining records. The Set was given a number which, however, was solely for purposes of maintaining its integrity through the several processing steps prior to final filing. Each Code Sheet was at thls point assigned its Code Sheet Number and other records were made for it. The Set of Code Sheets was then ready to be checked.

It was discovered that errors made in interpretation and coding were far too frequent and serious ever to permit coding being punched and the Code Sheets filed without having first been checked once by a second person. Ordinarily, those coders who had developed the most skill and who had demonstrated superior accuracy and comprehension of coding procedures were regularly assigned coding from other coders for checking. However, none of the persons did only checking, but each was always given some coding assignment which was subsequently checked by another of the more experienced coders.

Checked coding was returned from its checker at the end of each month, accompanied by a record of the number of code lines checked, the number of code lines prepared by the coder which the checker had deleted, the number of code lines added by the checker, and coded Sheets added by the checker. Also accompanying the work were comments (on special Checker's Comment Sheets); these were addressed by the checker to the coder of the Set and pointed out errors made in coding, reasons for deletions and additions, etc. Finally, the checker sent with the Set an explanation of any coding problems he was unable to solve, items that needed to be added to the Code or Key, and questions about procedure for which the Key had no explanation.

Upon receipt of the checker's work at the Center, the Checker's Comment Sheets were recorded and mailed to the coder of the Set and the Set was processed (any added Code Sheets were given Code Sheet Numbers, etc.). Each Set was assigned then to one of the resident biology staff members.

It was the policy of the Center that a resident staff member examine at least superficially each Set of checked coding. If the checker had sent comments indicating difficulties or disagreement with the coder, these comments were studied with the Set. Frequently, it was necessary to obtain the original data in order to arrive at a solution of the difficulty or to make a special coding provision. This examination and correction of the coder's and checker's work the Center referred to as "arbitrating". While this might possibly seem to require a minimum of time, it actually was a very tedious and timeconsuming task; the results of any decisions needed to be transmitted to both the checker and coder who pointed out the difficulty (or who erred in coding) and, if additions and changes in the Code and/or Key were necessary, all coders had to be advised of them. An accumulation of such changes was largely responsible for the regular Supplements to the Code and Key, issued to the coders.

Each Code Sheet was initialed by the coder, checker, and arbitrator. When the staff member completed his arbitration of the Set, it was returned to the clerical staff for notation of its having been arbitrated.

Processing of Biology Code Sheets by Chemists:

The arbitrated Code Sheets had all the information about the test compound which the author gave, but only that information. None of the biologists (the coder, checker, or arbitrator) had identified the test compounds with their CBCC Chemical Serial Numbers; the coders and checkers, being non-resident, did not have access to the CBCC chemistry files and the arbitrators, though resident biologists, had no reason to develop the proficiencies in Identifying chemicals which the chemical staff was specialized to do. Therefore, the Set of arbitrated Biology Code Sheets was submitted to the Center's chemistry staff. There all the chemical information recorded on the Code Sheets by the biology coder was used to determine the test compound's identity with one of the compounds already entered in the $\mathrm{CBCC}$ chemistry files. If the information on the Biology Code Sheet were inadequate to ascertain the identity, the chemists frequently wrote to the author for more information. If the chemical were new to the CBCC chemistry files, it was coded on a Chemistry Code Sheet and index cards were made for it. 
On the Biology Code Sheets, the chemists entered the compound's Serial Number and the name by which it is indexed by Chemical Abstracts.

When all of an entire Set of Biology Code Sheets had been processed by the chemists, it was again returned to the clerical staff which recorded the Set's progress toward the final file.

Transfer of Coded Information to IBM Punched Cards:

After being released from both the biology and chemistry staffs, each Set of Biology Code Sheets was submitted to the IBM staff. Special operators, familiar with the CBCC biology and chemistry coding, punched onto IBM cards the code symbols which had been written on the Biology Code Sheets. Each code line on the Biology Code Sheets was punched on a separate IBM card and on each card was also punched the Chemical Serial Number (which the chemists had written on the Biology Code Sheet), the Code Sheet Number (which was assigned to the Code Sheet immediately after coding), and the Line Number (which was written at the end of each line by the coder).

When the punching operation was complete, the Set of Biology Code Sheets was returned to the clerical staff once more.

Final Filing of the Biology Code Sheets and Biology IBM Punched Cards:

After the coding of the Biology Code Sheets was punched onto IBM cards and the Set of Sheets was returned, the Set was released to the person responsible for the Code Sheet Files who filed each Code Sheet under the correct CBCC Chemical Serial Number.

The filing of IBM punched cards was done by the IBM staff.

Correction after Final Filing:

Whenever a change was made in the Biology Code which involved information already coded, it was necessary to retrieve all the Biology Code Sheets and IBM punched cards on which that coding being altered appeared. Such corrections were always made by the resident staff. The IBM staff subsequently re-punched the corrected coding on new IBM cards; the Biology Code Sheets and the new IBM cards were then re-filed.

\section{ADVANTAGES OF THE CBCC SYSTEM FOR CODING AND MACHINE HANDLING OF CHEMICAL-BIOLOGICAL INFORMATION}

The Introduction has described the coding fields in terms of indexes to the information collected by the $\mathrm{CBCC}$ and a preceding section of the Appendix (the description of the Biology IBM Punched Card Files) has described the use of the punched cards for the multiple indexing of information in the Biology Code Sheet File. The following attempts to clarify the specific advantages of the multiple indexes as the means to the ultimate objectives of the Center.

The CBCC was not unique in indexing chemical-biological information in more than one way. Indexing and abstracting services such as Chemical Abstracts, Biological Abstracts, Helminthological Abstracts, etc. , include in their coverage information of this type as it occurs in the published literature and they subject-index it by chemical name and organism name; in some cases, it may be indexed even by response.

The ability to prepare and publish subject indexes by indexing and abstracting services has limitations, however, and a few comparative observations on this subject will be appropriate here, as an introduction to the explanation of the advantages for the multiple indexing attempted by the CBCC.

Published subject index entries (chemical, organism, or response) are necessarily brief and not always or even frequently satisfactorily cross-referenced. Thus, the chemical entry does not necessarily indicate any or all organisms treated or responses produced; the organism entry does not necessarily indicate any or all of the chemicals administered or the organism's responses; the response entry does not necessarily indicate any or all of the chemicals and organisms tested for the response. The entries, of course, do refer directly to a published abstract and subsequently to the original published data. Most frequently, these published indexes are prepared from the published abstracts which the index accompanies or follows, rather than being prepared from the original data. It is 
appropriate, then, to consider the thoroughness of published abstracts with regard to the chemicalblological data with which the Center was concerned.

However high the quality of the published abstract, it yet remains by definition a condensation of the original data, frequently omitting most experimental details; for practical reasons, a published abstract is restrained to the briefest summary of test data. It can not be expected to describe all the information comparable to that coded by the CBCC, partly because of the limitations in publication space and partly because abstracters do not prepare abstracts according to fixed rules comparable in detail to those for $\mathrm{CBCC}$ abstracting. There is often no real assurance that an abstract identifies all the organisms used or all the chemicals tested, or all the responses demonstrated in a given article, not to speak of doses, paths of administration, evaluation detalls, etc.

It would be expected that an agency whose efforts were concentrated on a given type of information would collect that information more assiduously and in greater detail than would an agency whose literature coverage is either far greater in scope or of a different specialization. Thus, in the case of the CBCC, having established exactly the details wanted for its purposes, chemical-biological test data was abstracted to include meticulously all organisms, all compounds, and all responses from any given chemical-biological information source (to restrict the observation for the moment to those three more commonly published subject indexes). This factor of thoroughness is not implied here to be an advantage offered by the CBCC system or procedure precisely, so much as an advantage resulting from the CBCC's specialization.

Sometimes observations of biological responses are reported incidentally in an article. In other words, there occasionally occur, and are mentioned in passing, responses not further discussed or explored by the author nor are they included in the article's summary. Whatever the reasons may be, the fact remains that it is not unusual for such "incidental" observations to be made obscurely in literature articles. Many examples will come to mind of "discoveries" made, such as the inhibitory action of penicillin or the herbicidal action of chlordane, effects which had been observed and more than once noted incidentally in the literature--to be overlooked until favorable circumstances brought about the recognition of the practical significance of the observations. It is not to be expected that published abstracts and indexes would unfailingly include all such incidental observations from each article, nor could the Center claim infallibility in recording all incidental effects in 1 ts files. The abstracting policy of the CBCC, however, intended that chemical-biological information from the llterature (as well as from other sources) should be thoroughly examined and all effects, including those defined as "incidental" should be included, as the previous paragraph has implied. The fact that the Center frequently omitted coding specifically the many subjective effects described as common "side effects" caused by therapeutic administration of test compounds (headache, nausea, dizziness, etc.) should not be interpreted to mean that there are ever omitted observations made in the literature representing specific biological responses to test compounds, however incidental they may be to the original intent of the tests.

The comparative observations of the preceding paragraphs are based essentially on the three criteria by which chemical-biological information is frequently indexed and to some degree crossindexed by subject in published indexes to literature.

There is a practical limit to cross-indexing in a published index as well as a limit to crossindexing in index card files. Indeed, there is a practical limit to all cross-indexing, including that done by a center such as the $\mathrm{CBCC}$ which concentrates on a given type of information. The practical extent of the cross-indexing depends on many factors and is not identical for all purposes, all systems, or all types of data.

In the case of the $\mathrm{CBCC}$, it has already been explained that every coding field of the Biology Code represents essentially a distinct indexing criterion. Beyond indexing according to the chemical affecting the biological system, the biological system affected, and the response, all test information is indexed according to any hosts (of non-infectious pathology, parasitic organisms, or tumors) involved, any organs, any tissues, the quantities of test compounds needed for given effects, any compounds whose biological effects test compounds influence, developmental stages and the sexes of organisms affected, routes of administration, and so on.

Experience with published indexes provides the most convincing evidence of the time necessary to search through volume after volume of the published abstracts to literature or through volumes of the literature itself (to which the published indexes have given reference) to find specific chemicalbiological information. When cumulative indexes are not prepared, the task includes searching through consecutive volumes of the index. Compared to the use of published indexes to find information about 
speclfic chemicals, organisms, and responses, a search in the CBCC punched card files (where chemicals, organisms, and responses, as well as other index subjects, are all cross-indexed) is far more rapid and, with regard to that chemical-biological literature covered by the CBCC, more thorough. That it may not be as thorough as certain published indexes, with respect to the total number of journals covered, must be regarded as reflecting only the limitations of the Center during its developing years for covering that quantity of published information.

The preceding observations have been concerned in general with abstracting published information and indexing it according to chemical, organism, and response, for sake of comparison with published abstracts and indexes. It should be recalled, however, that the CBCC made efforts to collect information that had not been published or that was in more obscure or irregular publications and reports given limited distribution. Many tests of a screening nature remain unpublished because of the low priority ordinarily given to such masses of data under circumstances of high costs of publication and the large volume of technical information competing for publication. One reason for the reluctance to publish data of this type is the general disregard for "negative" data which characterizes much of the information from routine screening tests.

In summary, the multiple-indexing, coupled with the speed afforded by machines for selection of desired index combinations, represents the basic advantage offered by the CBCC system. Added to this are the two further advantages, (1) the fact that the CBCC attempted to collect unpublished or obscurely published information not apt to be covered by published indexes and (2) thoroughness in abstracting and indexing original chemical-biological data, whether published or unpublished, resulting from the Center's concentration on that specific area of information. ${ }^{1}$

By these means and policies, the Center attempted to develop a system of handling chemicalbiological information whereby, having collected the data as thoroughly and carefully as possible, it could be retrieved and correlated as efficiently as possible, by as many subject indexes as that particular information is apt ever to be approached.

\footnotetext{
${ }^{1}$ A particularly fine description of the CBCC, presented against the background of a dissertation on discoveries of therapeutic properties of chemicals, will be found in an article by J. R. M. Innes, The Work of the Chemical-Biological Coordination Center in Relation to Chemotherapy in Veterinary Medicine, J. Am. Vet. Assoc., $116(874) 1950$.
} 


\title{
APPENDIX B
}

\author{
MISCELLANEOUS OBSERVATIONS ON \\ THE BIOLOGY CODE AND KEY AND THE CBCC PROCEDURES
}

\section{Specificity and Adaptability of the Biology Code:}

The CBCC Biology Code makes no pretense at being complete in terms of the categories of information nor of the items of any one category. Furthermore, the classification schemes or organization of items within any one information category (e.g. , the organization of biological states, qualities, and processes in Field T-2) may not be entirely satisfactory for coding every type of biological data. For example, if there were wanted to be established a file of information about certain plants, not especially for information about their responses to chemicals, but about their geographical origins, their products, their diseases, and their cultivation requirements, the CBCC Biology Code would hardly be expected to be used in its entirety; moreover, entire new categories of information, such as factors of cultivation, would need to be organized and assigned symbols. Similarly, a file of clinical information on pathology would demand a code for describing pathological conditions far in excess of the Pathology Code of the Biology Code's Field E which needs to include only those pathologies apt to be experimentally treated with chemicals. At the same time that the Code is not complete in the sense of the foregoing examples, some of the information categories and items within the categories would not be applicable or necessary for coding certain other types of biological data. For example, a file of information restricted to toxic effects on humans would need but a fraction of the terms now included in the Code's Fields T-1 and T-2, nor would a Taxonomy Code and several others of the CBCC Code's fields be needed.

On the other hand, in meeting the objectives of the Center, the CBCC Biology Code is no longer regarded as an experimental code for chemical-biological information, except that any of the existing individual sections is candidate for additions, deletions, or rearrangements of items, or of being omitted entirely, if further experience indicates these changes are appropriate. Establishing in the CBCC system provisions for coding new categories of biological information is not impossible, though it would require deleting present fields of the Code to provide room on the IBM punched card for any new fields, or expanding into a second IBM punched card for each code line, or converting to another mechanical system, such as electronic tape.

Therefore, the CBCC Biology Code must be examined and evaluated in the light of its specialized intent, the coding of information from tests for effects of chemicals on biological systems. However, at the same time that the Code as a whole has been developed, each of its parts has always been regarded as capable of being used independently and, to that extent, being applicable or adaptable for coding many types of biological information. Thus, beyond the specific use for which the total CBCC Biology Code was developed, it should be regarded as a series of coding patterns which this project has found adequate, any of which might be the basis for elaboration or simplification to fit other coding and indexing needs.

\section{Coding of Physical Properties of Chemicals:}

The CBCC had intended to expand its files to include the coding of physical properties of chemicals tested for biological effects, with the objective of making that information on physical properties available for correlation with blological responses. Regrettably, the design of a physical properties code was never accomplished for the CBCC use, though a number of conferences were held to discuss and plan it.

Beyond the significance of physical properties of chemicals as a correlative with biological responses, the $\mathrm{CBCC}$ recognized the need for a central reference depository for information on physical properties. The importance of this is reflected in the fact that there has been recently established a center whose objectives are precisely the collection of this information and developing both a code for thermophysical properties of chemicals and a procedure for storing the coded information for mechanical retrieval. In January of 1957, by coincidence the date immediately subsequent to the closing of the CBCC, the Thermophysical Properties Research Center was established at Purdue University, within the University's School of Mechanical Engineering, cooperatively financed by a large number of industrial organizations and governmental research agencies. This center was conceived quite 
independently of the activities of the $\mathrm{CBCC}$, its objectives having genesis in needs differing from those which the CBCC was established to satisfy. The TPRC has a vigorous program and has developed a coding system for thirty thermophysical properties of all matter. Information about this coding system and the procedures and objectives of the Thermophysical Properties Research Center should be addressed to the Director of the Center, School of Mechanical Engineering, Purdue University, Lafayette, Indiana.

\section{CBCC Experience in Correlation:}

The Introduction explained the objectives of the Center, the ultimate objective being the correlation of chemical structures (and, eventually, physical properties of chemicals) with responses of biological systems.

The CBCC staff earnestly looked forward to seeing correlation studies attempted by investigators, using the information collected by the CBCC. It is a disappointment that, to date, no correlative studies of the scale originally envisioned have been performed with the file of information collected since 1951. The immense task of creating the information file has not permitted the CBCC biologists themselves to use the files for original correlative investigations and, for reasons not all of which are understood, application has not been made to the Center for such studies by other persons and agencies. It has been suggested that, for any intensive correlative study, a special project should be established for coding into the $\mathrm{CBCC}$ files all data of the type to be correlated.

Neither did time permit accomplishing another important aspect, the study and compilation of specific patterns of retrieval of $C B C C$ coded information, based on coding and machine handling patterns. Requests to the Center for information from its files mostly require simple machine sorting or even only manual selection, but a certain percentage have involved making associations which required more broad programming of retrieval and collation.

Qualifications of Coders; Residence vs. Non-residence of Coders:

This particular aspect is to be discussed, because it has played an important role in the Center's efficient functioning and because the Center's experience is expected to be of some value in the deliberations for establishing other coding projects.

The Center experimented at one time with employing students of local universities for coding at the Center under supervision. It also tried persons who had had less training and experience than did the coders the Center finally used. These experiments were comparatively short lived. In each case, the quality of coding was such that the arrangement was obviously impractical. All the coders of the Center's last five or six years were professionally trained biologists, most of whom were not residents of the Washington, D. C. area and who found it convenient to spend part or all of their time coding for the Center.

Since i 952, the number of non-resident coders remained fairly constant, somewhere between ten and fifteen, each submitting monthly a Set of coding varying in quantity according to their schedules.

The procedures for acceptance as a coder have been described in the section discussing selection and coding of information (Appendix A, CBCC Procedures). From the CBCC experience, two observations about finding and training of coders are especially worth mentioning. First, persons with qualifications for being good coders and who coincidentally have access to the literature and can discipline themselves to a regular schedule are not legion. The CBCC had the good fortune to have a number of such persons who remained generally consistent in their work for the Center till its close. It is not to be taken for granted, in establishing a coding program demanding special coders, that finding satisfactory coders, training them, and holding them, as non-resident personnel, is always a simple matter. Secondly, the CBCC experience has been that a minimum period of six months to a year is needed for adequate training of a coder to a point of reasonable efficiency and dependability in coding chemical-biological test data.

The problems inherent in non-residence of coders demand some consideration. Many factors must be balanced in deciding which procedure a project can best support--non-resident coders, demanding a full complement of resident clerical staff to malntain records and a professional staff member's time corresponding with them, as opposed to salaried resident coders. It is impossible here to suggest all the determining factors for this for any given program, but some of the difficulties encountered in the CBCC system and described in the following paragraphs might be enlightening. 
It must be pointed out that non-resident coding of chemical-biological test information by the $\mathrm{CBCC}$ Biology Code can not be strictly compared to the usual non-resident abstracting and indexing which does not involve coding. This is not to say that a simple coding program involving only organisms' identities, or only specific effects, or only specific chemicals might not be comparable to ordinary indexing. However, the extraction and coding of all aspects of a chemical-biologicai test is another and more compiex matter.

Communication between coder, checker, arbitrator, and the Center was without a doubt, one of the more trying aspects of the Center's procedures and if any one factor would influence a decision about the residence of coders, this would probably be the most convincing. Errors in interpretation of literature data, in coding, and in interpretation of the Key to the Code could only be avoided by advising the coder of errors he had already made; an error could only be discovered by the checker and communicated to the Center. Repeated efforts to establish a system of "comment sheets" for this communication was never very successful, partly because of the unavoidabie gaps of time between the material leaving the coder's hands and his receipt of comments about his errors. Furthermore, once the coder or checker received the notification of his errors, he never had the coded Sheets on which the errors occurred so that frequentiy the comments, uniess they were extraordinarily thorough expianations, conveyed iittie. As a resuit, when it was finaily discovered that a coder was consistently making a coding error, a special letter had most frequently to be prepared to point out and discuss the matter.

Remuneration for coders on a regular basis, considering its probiems, was organized to a satisfactory level of efficiency, but never was free of flaws, partly because of the complex system which demanded that payment not be made for code lines which the checker or Center had deleted as unjustifiable or erroneous.

A problem to be considered with resident coders is that of efficiency in an unbroken routine of coding. The staff members 'own experience has been that it is not possibie to restrict professional activity to coding without eventually arriving at a point of ennui and consequent inefficiency.

Tinus, although the CBCC never arrived at a totally satisfactory answer to the matter of coding personnel, it would be strongly recommended that, for thorough and complex coding comparable to that done by the $\mathrm{CBCC}$, an arrangement using resident coders whose routine can be varied might be far preferable to attempting establishment of a system for a staff of non-resident coders.

\section{Checking of Abstracting and Coding:}

It seems impossible to overemphasize the importance of coding information correctly and according to a standardized procedure. Errors in coding and punching can only mean information that is lost to retrieval or retrieval of unwanted information. It must be recognized that this process of information "in-put" is dependent on human intelligence and subject to human error; the success of the result of retrieval and correlation depends on holding that error to a minimum. To assure that information entering the files was coded (indexed) accurately, the CBCC found no alternative to having the coding checked and arbitrated. (See the descriptions of these procedures in Appendix A. )

In estabiishing any new project in which information is coded, the question of checking the accuracy of coders' "translations" into code is apt to be weighed carefully. Checking has been viewed variously by persons contemplating such a program; frequently, the attitude is expressed that checking is desirable but impractical, or even that it is superfluous. Others concede checking to be essential. It would be unreasonable to attempt to formulate, for all prospective coding projects, a fixed recommendation about the extent of checking, since so many variables are invoived. Nevertheless, the CBCC experience would discourage any idea that checking in some form and for some period of time can be avoided, except perhaps in building coded information collections in which the material coded has very little variation and the coding is extremely brief and ail done by the same coder or a continuous coding staff.

in spite of the care exercised in coding and checking, the Center not infrequentiy discovered major coding errors on Code Sheets, even after the coding had been punched and filed. Nevertheless, the $\mathrm{CBCC}$ feit it had arrived at the point of diminishing returns in the process of checking the coded data entering its files. A certain small number of coding errors had to be accepted as unavoidable within its coding system, just as some factor of error must be established for any such-system. 
Frequently, in an effort to understand the Center and evaluate it as a source of chemicalbiological information, the Center was asked how quickly after issuance published data was incorporated into its files, as well as how completely the published literature was represented by the information in the files. This inquiry had the general objective of evaluating the Center's files primarily on the basis of comparison with currency and coverage of published abstracts and indexes, a more obvious criterion perhaps than evaluation on the basis of the other advantages which the Center felt were its multiple indexing and use of machines.

Certainly the factors of currency and completeness of coverage were important ones. To consider the factor of completeness of the literature coverage by the CBCC files first, it should be recognized that the present $\mathrm{CBCC}$ information collection only began in late 1951 and 1952 , prior to which most of the Center's efforts were spent in developing and testing codes and procedures. Starting from essentially nothing, it took a year or so to establish a steady flow of coded information. From early 1953 to the end of 1956 when the Center was closed, the volume of flow of coded information into the files remained generally at the same level. The fact that the volume rate did not increase to any marked degree can be accounted for in part by the fact that the number of the Center's resident staff and its non-resident coding staff remained at about the same level; it is also evidence that the speed of information flow (discussed in the following paragraph) was perhaps near the speed possible for the system at a given staff level. During those initial years, the coverage of the literature, even considering the limitation to specifically chemical-biological data, could not pretend to be complete and, regarded in strict comparison, the coverage in terms of number of journals reviewed, could hardly compete with the old established abstractlng and indexing publications. As was pointed out in another place, the $C B C C$, realizing its initial limited capacities for covering the literature, concentrated on the forty of fifty journals that proved by a preliminary survey to be most productive of chemical-biological information. Also, it attempted especially to include certain information which it knew was not apt to be covered routinely by published abstracts and indexes.

With regard to currency of the files, the Center estimated the average lapse of one year from the date published information was selected for the files to the date the coded and punched information was actually incorporated into the files and thereby made available by the routine CBCC retrieval processes. The several steps in selecting and processing data are described in Appendix A. Certain of these steps may be seen to take a month (or be separated by a month) or longer; by reviewing all the steps, it wlll be understood why the speed of processing data was not much less than a year for any given unit.

The preceding time value expresses the speed by which any given information unit progressed from the date of its selection to the date of its entry into the files. It does not indicate actual time which the coders, checkers, arbitrators, chemists, IBM punch operators, and clerical staff spent on a given unit. From records submitted by coders, checkers, and other staff members involved, the Center estimated that each code line entered into the files took a total of one hour for all steps of its preparation and entry into the files. This included the coder's time in studying the information and constructing the code line, the checking and arbitrating time, a proportion of the clerical time spent on an average Set, a proportion of the chemists' time spent on the average Sheet, the IBM operators' punching time, and a proportion of the time for filing Code Sheets and IBM punched cards.

The Center believed that by enlarging the size of 1 ts biology staff to perhaps twice the number of members (i.e., to approximately eight or ten resident biologists with a corresponding increase in biology coders), the coverage of the published general chemical-biological literature, in addition to the acquisition of unpublished data, could have been more satisfactorily complete and review of this literature made more promptly after its issuance. If, in addition, the system was altered so that coding might have been done by resident coders, the speed of selecting and processing, as well as the volume, might have been increased to give the files an increased currency of published data.

Though abstracts of the literature may be published relatively quickly, the indexes of chemicalbiological literature are at present published only after periods of well over a year after the literature's 1ssuance. Therefore, the Center's ability to have the information coded and incorporated into its files within a year or less, even though it would be desirable to have it entered even more quickly, represents an advantage in currency over most published indexes. 
The CBCC collection of chemical-biological information organized on a mechanical system was offered, as an information source, to any interested scientist or scientific agency. In particular, it was offered as a means for original academic studies in correlations, especially those which have practical scientific and industrial significance.

The Center had perhaps as many requests for the special information of its files as it was capable of handling, carrying on all other activities simultaneously and adequately. This, however, is not equivalent to saying that the Center's files were used sufficiently or that they were used in ways exploiting their greatest potential.

It goes without saying that the $\mathrm{CBCC}$ files had first to be known to exist before they could be consulted. But awareness of the Center's existence, without understanding its specific activities and their scope and limitations, could not stimulate the most efficient use of the files. As a repository for chemical-biological test information, the Center might be compared to a young library whose existence and specialization had gradually to be learned by the scientific community. Paradoxically, the failure of scientists to use the Center frequently and to exploit the system of organization fully has occasionally been regarded as evidence that the information collection had not actually been needed and that the system failed to provide correlation of any significance.

During the first years following 195i, the Center was torn between feeling compelled to provide justifying evidence of its scientific and industrial value and the apprehension that its being consulted before its collection had grown to a significant size would result in dissatisfied users. A considerable effort was made to advertise the Center at meetings of appropriate professional societies and through published articles, activities which in themselves impeded progress by occupying appreciable professional time of staff members.

The results of these efforts were gratifying, but inadequate. While the Center received many requests, the response did not represent the greater magnitude of use which the CBCC was certain exists as a potential.

The Center has not been convinced that lack of education to the Center's files and their values is not primarily the reason they were not more frequently consulted and it was equally convinced that the growth of the files, their continued use, and the spread of information about the results of their use would eventually establish the reputation the files deserved as the single center for data of their nature and the most fully adequate means for correlative studies of either a broad or limited scope.

A related aspect to be considered is that of reliability. A scientist does not place his confidence easily on information sources of unproved reliability and the scientifically trained staff of the $\mathrm{CBCC}$ were fully appreciative of this. The degree to which the information coded by the CBCC staff could be relied on for accuracy might only have been learned gradually; it was not enough for the CBCC to claim its own virtue of accuracy. The $\mathrm{CBCC}$ felt that its procedures for checking its coding provided accuracy to the greatest degree apt to be possible for information of such a complex nature as that in its files. It can not be predicted at what point confidence of the scientific community would have been placed on the accuracy of $\mathrm{CBCC}$ coding. Until that confidence had been won, the coded information files of the $C B C C$ would not have been used by every investigator to his greatest advantage.

The response to information received from the $\mathrm{CBCC}$ as a result of a search of its files was generally favorable. If, during the first years, the results of an information search in the CBCC files could not have the quality of completeness, the Center felt the retrieved information did have other qualities fully justifying the effort. Especially, if among the data retrieved from the files and applying to a given inquiry, there were some which would not have been included in published abstracts and indexes, it was felt that the Center's files had contributed valuable information to the requester. Secondly, what data was included in the CBCC files that was also indexed by published indexes could be approached in many ways other than by the two or three subject index criteria of published indexes and the possibility therefore existed that chemical-biological test data relevant to the specific information request would be retrieved from the CBCC files which could not have been found in the published index. Like many other possible studies, no comparative studies were made to determine the actual incidence of this.

\section{Aspirations of the Center:}

The Center was occasionally inspired to considerations of activities collateral with its principal goals, reflecting its broadest concept of the role such a center might play in its specialized scientific community. Three examples of these might be mentioned before summarizing the major aims. 
One Idea grew from the encountering of coding difficulties due, for example, to the frequent omission of details of test technique or to the obscurity of details needed for the CBCC code line (including adequate identification of chemicals and organisms used) or to the omission of test measurements leading to an author's evaluation. It seemed possible that the preparation and distribution of a set of recommendations for preparing chemical-biological data for publication might be eventually a logical undertaking of the Center. Possibly merely the general use of the Center would have demonstrated the necessity of including details of tests which might permit subsequent correlation with information from other tests of similar or diverse natures.

The CBCC might have served as a depository and reference center for methods of testing for, and evaluation of, chemical actions on biological systems and, further, might have been influential thereby in standardization of testing methods, for which a need is generally felt today. This activity could conceivably and logically have grown out of the CBCC experience with its own diversified Screening Program and from its general information collection.

It seems likely that an increasing number of specialized biological and chemical information collections will be established in the near future, many needing classification and coding schemes for categories of information not needed for chemical-biological test data. Uses, activities, geographical distributions and origins. diets, and requirements of organisms, as well as physical properties of chemicals and processes and reagents used in chemicals' syntheses are examples of such categories, any one of which might be needed for more than one information collection. The development, assistance in development, or the collection of these classification and coding schemes for information categories accessory to the categories needed specifically by the CBCC might reasonably have been a function of the Center and a function of considerable value, judging from inquiries recelved by the Center about schemes for these categories.

The major and more concretely defined aspirations of the Center were implicit in its name. It hoped to serve as a coordinator for development of methods for handling chemical-biological information-to be able, as a result of its pioneering efforts, to serve as a consultant to programs anywhere concerned with related information-handling problems. It also hoped to be coordinative of testing programs in the sense of making available chemical-biological information by collecting and exhaustively indexing unpublished as well as published data falling within that definition, the cjjective being to prevent, to the extent possible, duplication of effort and to suggest new directions of testing. Related to this, it asplred to studies of a correlative nature (chemical structure and biological response), using data from 1ts coded information collection. Its Screening Program's objective was coordinative in that the Program served as a clearing house for untested chemicals and biological testing facilities. Finally, it regarded as possible even coordination for, or assistance in, related activities of which the sponsoring of symposia and the collection of standard testing methods might be named as examples.

While these aspirations were never to be fully or, in some cases, even partially realized, it can now at least be hoped that the Biology Code and Key and the observations made here on the Center's functioning and use of the Codes will be found useful guides for future efforts in coding biological and chemical-biological information. The published Codes, both Chemical and Biology, may perhaps prove the distillate of, and only memorial to, the effort and ambitions of the CBCC. 



